\title{
Neutrophil endothelial cell interaction : investigations on TNF-[alpha] and E-selectin
}

Citation for published version (APA):

von Asmuth, E. J. U. (1995). Neutrophil endothelial cell interaction : investigations on TNF-[alpha] and Eselectin. [Doctoral Thesis, Maastricht University]. Rijksuniversiteit Limburg. https://doi.org/10.26481/dis.19950224ea

Document status and date:

Published: 01/01/1995

DOI:

10.26481/dis.19950224ea

Document Version:

Publisher's PDF, also known as Version of record

\section{Please check the document version of this publication:}

- A submitted manuscript is the version of the article upon submission and before peer-review. There can be important differences between the submitted version and the official published version of record.

People interested in the research are advised to contact the author for the final version of the publication, or visit the DOI to the publisher's website.

- The final author version and the galley proof are versions of the publication after peer review.

- The final published version features the final layout of the paper including the volume, issue and page numbers.

Link to publication

\footnotetext{
General rights rights.

- You may freely distribute the URL identifying the publication in the public portal. please follow below link for the End User Agreement:

www.umlib.nl/taverne-license

Take down policy

If you believe that this document breaches copyright please contact us at:

repository@maastrichtuniversity.nl

providing details and we will investigate your claim.
}

Copyright and moral rights for the publications made accessible in the public portal are retained by the authors and/or other copyright owners and it is a condition of accessing publications that users recognise and abide by the legal requirements associated with these

- Users may download and print one copy of any publication from the public portal for the purpose of private study or research.

- You may not further distribute the material or use it for any profit-making activity or commercial gain

If the publication is distributed under the terms of Article $25 \mathrm{fa}$ of the Dutch Copyright Act, indicated by the "Taverne" license above, 
NEUTROPHIL ENDOTHELIAL CELL INTERACTION INVESTIGATIONS ON TNF- $\alpha$ AND E-SELECTIN 



\title{
NEUTROPHIL ENDOTHELIAL CELL INTERACTION INVESTIGATIONS ON TNF- $\alpha$ AND E-SELECTIN
}

\section{PROEFSCHRIFT}

\author{
ter verkrijging van de graad van doctor \\ aan de Rijksuniversiteit Limburg te Maastricht, \\ op gezag van de Rector Magnificus,Prof. Mr. M.J. Cohen, \\ volgens het besluit van het College van Decunen, \\ in het openbaar te verdedigen \\ op vrijdag 24 februari 1995 om 16.00 uur
}

door

Eckhardt Jens Udo von Asmuth geboren te Haarlem, 11 september 1962 


\section{Promotores}

Prof. dr. G. Kootstra

Prof. dr. C.J. van der Linden (Katholicke Unniversiteit Nijmegen)

\section{C'o-promotor}

Dr. W.A. Buurman

\section{Beoordelingscommissie:}

Prof. dr. F.C.S. Ramaekers (voorzitter)

Prof. dr. D. Roos (Universiteit van Amsterdam)

Prof. dr. D.J. Ruiter (Katholieke Universiteit Nijmegen)

Prof. dr. G.J. Tangelder (Technische Universiteit Eindhoven)

Prof. dr. E.F.M. Wouters

Lay-out en produktie: Robin Reule, Den Haag

Druk: Progress, offset/xerografie, Zoetermeer 


\section{"A tree is best measured when it is down" (motto opera 'The civil wars', Robert Wilson and Philip Glass)}

Opgedragen aan Hetry Praagman en Jan van der Horst 


\section{CONTENTS}

blz.

Abbreviations

Chapter 1 Introduction:

General introduction

A Adhesion molecules and their role in neutrophil endothelial cell interaction

B Neutrophil chemotactic migration and neutrophil toxicity, and the involvement of adhesion molecules

C Differences between neutrophil agonists; a special role for TNF?

Chapter 2 Introduction to and discussion of the experiments

\section{Chapter 3 TNF- $\alpha$ :}

3.1 TNF- $\alpha$ and IL-6 in a zymosan-induced shock model 51

3.2 IL-6, IL-8 and TNF production by cytokine and lipopolysaccharide- 61 stimulated human renal cortic alepithelial cells in vitro

3.3 Antagonistic effects of lipopolysaccharide binding protein and bactericidal/ permeability-increasing protein on lipopolysaccharide induced cytokine release by mononuclear phagocytes. Competition for binding to lipopolysaccharide

Chapter 4 E-selectin:

4.1 Evidence for endocytosis of E-selectin in human endothelial cells

4.2 IFN- $\gamma$ regulates the expression of the adhesion molecule $F$ selectin and II -6 production by human endothelial cells in vitro

4.3 LPS and cytokine-induced endothelial cell IL-6 release and E- selectin expression; involvement of serum

4.4 Anti-CD14 antibodies reduce responses of cultured human endothelial cells to endotoxin

Chapter 5 Neutrophil endothelial cell interaction:

5.1 TNF- $\alpha$ induces neutrophil mediated injury of cultured human endothelial cells

$5.2 \mathrm{Fc} \gamma$ receptor mediated activation of neutrophil $\mathrm{H}_{2} \mathrm{O}_{2}$ release and of neutrophil mediated endothelial cell damage by a mAb against elastase

5.3 Involvement of the CD11b/CD18 integrin, but not of the endothelial cell adhesion molecules E-selectin and ICAM-1 in TNF- $\alpha$ induced neutrophil toxicity

5.4 Endothelial cell associated PAF, a co-stimulatory intermediate in TNF inuuced $\mathrm{H}_{2} \mathrm{O}_{2}$ release by adherent neutrophil leukocytes 
Intermezzo

Summary

Samenvatting

Dankwoord

Publicatielijst

Curriculum Vitae 


\section{ABBREVIATIONS USED}

\begin{tabular}{ll} 
Ab & antibody \\
Ag & antigen \\
BCS & bovine calf serum \\
BSA & bovine serum albumin \\
BPI & bactericidal/permeability increasing protein \\
CD & cluster of definition \\
ELAM-1 & endothelial leukocyte adhesion molecule-1 (also called E-selectin) \\
ELISA & enzyme-linked immunosorbent assay \\
EM & electron microscopy \\
FCS & fetal calf serum \\
FMLP & n-formyl Methionyl Leucyl Phenylalanine \\
GM-CSF & granulocyte macrophage colony stimulating factor \\
ICAM & inter-cellular adhesion molecule \\
IFN & interferon \\
Ig & immunoglobulin \\
IL & interleukin \\
h & human \\
HUVEC & human umbilical vein endothelial cell(s) \\
HI & heat inactivated \\
HS & human serum \\
LBP & LPS binding protein \\
LM & light microscopy \\
LPS & (bacterial) lipopolysaccharides \\
mAb & monoclonal antibody \\
PAF & platelet activating factor \\
PBS & phosphate buffered saline \\
PECAM-1 & platelet endothelial cell adhesion molecule \\
PHA & phyto haem agglutinin \\
PMA & phorbol myristate acetate \\
PMN & polymorphonuclear leukocytes \\
r & recombinant \\
RCEC & renal cortical eptithelial cell(s) \\
RPMI & named a specific tissue culture medium \\
RT & room temperature \\
SD & standert deviation \\
T/E & targetcell / effectorcell \\
TNF & tumor necrosis factor- $\alpha$ \\
\hline
\end{tabular}




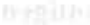

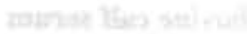


Chapter 1

\section{INTRODUCTION}

\section{General introduction}

As observed more than 100 years ago by Cohnheim using intravital microscopy (1), neutrophils begin to interact with the vessel wall by rolling along the endothelium, within minutes after injury to adjacent tissue. During this process, the velocity of rolling neutrophils is much lower than cells just tumbling in a shear flow near the vessel wall, suggesting increased adhesive interactions which partly resist the flow induced shear stress. On the basis of this observation, Cohnheim postulated molecular changes in vessel endothelium induced by inflammatory mediators leaking from the inflamed tissue.

During the last decade, three families of adhesion receptors participating in neutrophil interaction with endothelium have been defined: the integrin, immunoglobulin-related, and selectin molecules. During the same period of time, a series of novel soluble intlammatory mediators has been identified. These mediators, which are called cytokines, are produced locally, and have a mainly local function. The recent knowledge on adhesion molecules and cytokines has led to clear progress in understanding the regulation of neutrophil rolling along the ves. sel wall, and the subsequent steps of neutrophil behaviour during ongoing inflammation: neutrophil attachment to the vessel wall, neutrophil emigration into the tissue, chemotactic migration to the inflammatory site, and the activation of the toxic potential of neutrophils. Different aspects of the regulation of neutrophil behaviour during inflammation, and the identification of cytokines and adhesion molecules involved in it, are presented in this thesis. In this introduction an attempt is made to summarize and interpret the information now available on adhesion molecules and cytokines in terms of their specific relevance for neutrophil behaviour during inflammation.

Chapter A of this introduction focusses on adhesion molecules and their role in neutrophil rolling, neutrophil attachment to the vessel wall and neutrophil emigration into the tissue. Chapter $\mathbf{B}$ focusses on the two responses of neutrophils to activation by inflammatory agents, neutrophil chemotaxis and neutrophil toxicity, and on the role of adhesion molecules in these two functions. Chapter $\mathrm{C}$ focusses on differences between the cytokine tumor necrosis factor$\alpha$ (TNF) and other neutrophil activating agents, in their role in neutrophil behaviour. 


\section{ADHESION MOLECULES AND THEIR ROLE IN NEUTROPHIL ENDOTHELIAL CELL INTERACTION}

\section{A1. Integrins and immunoglobulin-related molecules}

Integrins (integral membrane glycoproteins) form a heterogenic group of dimer molecules, composed of an $\alpha$-chain and a B-chain, which are involved in many cell-cell and cell-substratum interactions (reviewed in 2). Three integrins, all sharing the same $\beta$-chain, are expressed on neutrophils: the $\alpha_{M} \beta_{2}$ integrin, known as CD1 la/CD18 or LFA-1, the $\alpha_{2} \beta_{2}$ integrin, known as $\mathrm{CD} 11 \mathrm{~b} / \mathrm{CD} 18$ or Mac-1 and the $\alpha_{x} \beta_{2}$ integrin, known as CD11c/CD18. The integrin $\mathrm{CD} 11 \mathrm{a} / \mathrm{CD} 18$ binds to the immunoglobulin-related molecules ICAM-1 or CD54, ICAM-2 or CD102, and ICAM-3 or CD50 on endothelium and leukocytes; CD1 l b/CD1 8 binds to ICAM1 but not to ICAM-2 (3-7), has affinity for Arg-Gly-Asp containing proteins such as C3bi and fibrinogen, for microbial surface components and for plastic $(8-10)$; CD11c/CD 18 is expressed in low amounts on neutrophils and has no clear function in neutrophil adhesion. The term $\beta_{2}$ integrin which is used in this introduction refers to CD11a/CDI8 and $\mathrm{CD} 11 \mathrm{~b} / \mathrm{CD} 18$ since little is known on the function of $\mathrm{CD} 1 \mathrm{c} / \mathrm{CD} 18$.

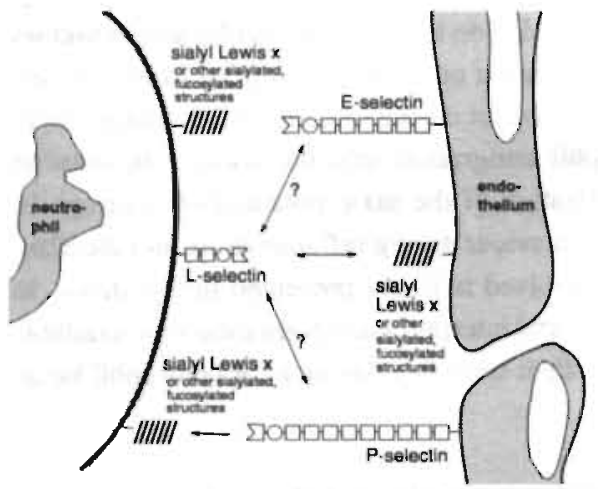

Integrins and inmunoglobulin-related molecules

The three ICAM's (InterCellular Adhesion Molecules) are more closely related to each other than these molecules are to other immunoglobulin super-family members $(5$, 11, 12). ICAM-1 and ICAM-2 are expressed on endothelium, on mononuclear leukocytes, but not on neutrophils, whilst ICAM-3 is absent on endothelium, but is highly expressed by resting leukocytes including neutrophils. The three ICAM's participate in adhesive reactions of multiple cell types ( 3 , $6,7,13)$.

PECAM-1 (Platelet Endothelial Cell Adhesion Molecule 1) or CD31 is another immunoglubilin superfamily member, expressed by platelets, T-cells, mononuclear cells and neutrophils, and is concentrated in the junctions of endothelial cells $(14,15)$. PECAM-1 has not been shown to bind to other adhesion molecules. PECAM-PECAM interactions might mediated both homotypic and heterotypic adhesive events (16-18). 


\section{A2. Selectins}

The selectins are the most recently recognized class of adhesion molecules (19). They have an $\mathrm{N}$-terminal lectin domain, one epidermal growth factor-like module, and from two to nine short consensus repeats, related to those found in complement-binding proteins. By contrast to integrins and immunoglobulin-related molecules, selectins have been found only on circulating cells and the endothelium, suggesting that they may be specialized for interactions within the vasculature.

P-selectin (CD62P, PADGEM or GMP-140) is expressed in $\alpha$-granules of platelets and in Weibel-Palade bodies of endothelial cells,

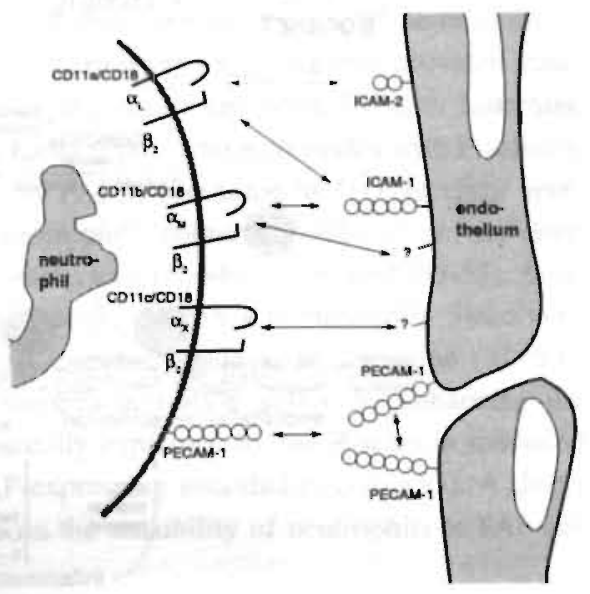
and is mobilized to the plasma membranes of

\section{Selectins}

these cells after activation by mediators of inflammation and hemostasis, allowing these cells to bind neutrophils and monocytes at the site of tissue injury (20-23). E-selectin (ELAM-1 or CD62E) is synthesized by endothelial cells in response to inflammatory mediators and promotes adhesion of neutrophils, monocytes, and a sub-population of lymphocytes (24-27). Lselectin (LAM-1, LECAM-1, or CD62L) is expressed on leukocytes, facilitates lymphocyte binding to endothelium during recirculation through peripheral lymph nodes, and mediates neutrophil emigration at inflammatory sites $(28,29)$. Specific partially overlapping carbohydrate ligands for selectins have been defined, such as sialyl Lewis $\mathrm{x}$ or CD15s on glycolipids and on the termini of $\mathrm{N}$ - and $\mathrm{O}$-linked oligosaccharides (30-32). Interestingly, L-selectin on neutrophils, but not on lymphocytes, carries sialyl Lewis $x$ carbohydrate groups (33), and plays a prominent role in neutrophil binding to E-selectin and P-selectin on endothelium (3334)

\section{A3. Selectin molecules mediate neutrophil rolling}

Binding of $\beta_{2}$ integrins to ICAM's, and selectin mediated binding facilitate different forms of neutrophil endothelial cell interactions. Neutrophil rolling on endothelium at venous shear stress can be induced solely by de novo expression of P-selectin and E-selectin on endothelial cells (35-38). In contrast to neutrophil adhesion at static conditions, neutrophil rolling can not be induced by neutrophil activation. Moreover, neutrophil activation decreases the efficiency of adhesion to P-selectin (37) and to E-selectin (34). Endothelial cell exposure to thrombin, $\mathrm{H}_{2} \mathrm{O}_{2}$, or histamine induces $P$-selectin mediated neutrophil rolling within minutes, whilst $\mathrm{E}$-selectin mediated neutrophil rolling peaks after 2 to 6 hours of endothelial cell activation with TNF, IL-1 $\beta$ or LPS $(36,37)$. In absence of additional neutrophil activation, rolling neutrophils remain round, and do not attach to the endothelium or emigrate (37). 


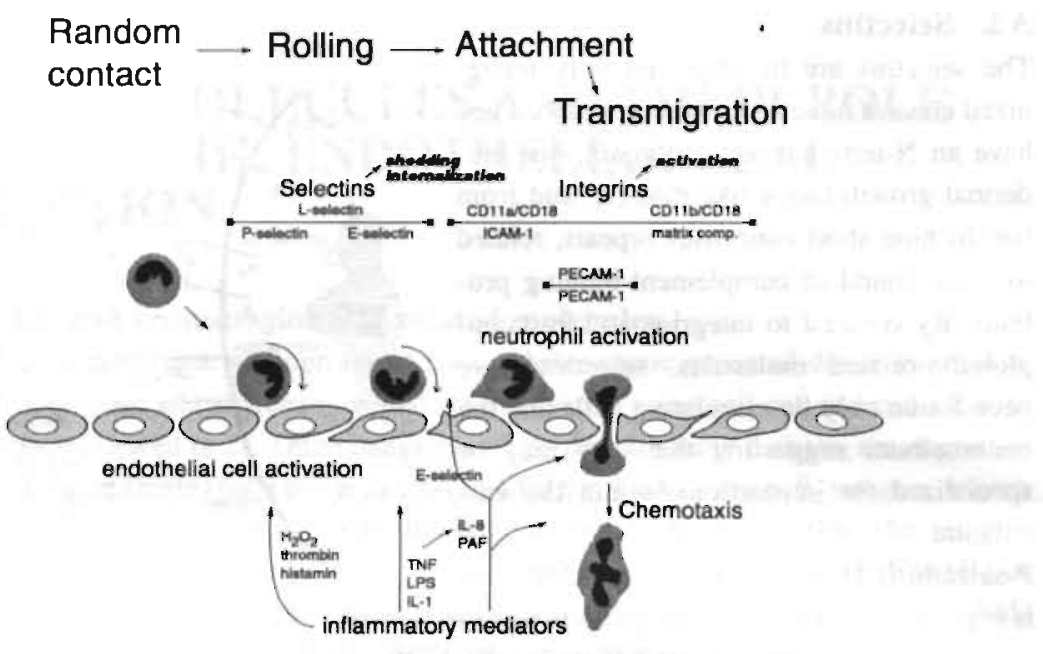

The regulation of neutrophil rolling and allachment

\section{A4. $\beta 2$ integrin molecules mediate neutrophil attachment in response to neutrophil activation}

As inflammatory reactions proceed, neutrophil rolling, as observed by intravital microscopy, decreases in velocity and is interrupted by halts until neutrophils come to a firm stop (1). When neutrophils are activated they first undergo a bipolar shape change which can even be induced when cells are held in suspension (37), and is also apparent in $\beta_{2}$ integrin deficientneutrophils (39). Rolling neutrophils, or neutrophils which contact a surface in the absence of shear stress subsequently become attached to the surface, and flatten slightly. Neutrophil attachment is mediated by an increase in the avidity of the neutrophil $\beta_{2}$ integrins $\mathrm{CD} 1 \mathrm{la} / \mathrm{CD} 18$ and $\mathrm{CD} 1 \mathrm{~b} / \mathrm{CD} 18$, which is initiated within minutes after neutrophil activation (40-43) and appears analogous to an increase in avidity described for CD11a/CD 18 in T lymphocytes in response to antigen receptor cross-linking $(44,45)$. Under venous shear stress, activation of neutrophils is insufficient to trigger neutrophil attachment, since initial $\beta_{2}$ integrin interaction with ICAM-1 or other ligands is not shear stress resistant $(36,46)$. In contrast to selectin mediated adhesion, $\beta_{2}$ mediated adhesion is dependent on temperature, ATP, and presence of $\mathrm{Mg}^{+*}(47,48)$. When activated neutrophils are allowed to attach and flatten via $\boldsymbol{\beta}_{2}$ integrin dependent mechanisms for several minutes, attachment can increase strongly and become resistant to extreme shear stresses $(37,49)$.

\section{A5. $\beta_{2}$ Integrin activation during neutrophil interaction with endothelium activated with $\mathbf{P}$-selectin inducing agents}

During the interaction of rolling neutrophils with endothelium, activated either with P-selec- 
tin or with E-selectin inducing agents, the neutrophil $\beta_{2}$ integrin CD11b/CD18 is'activated'; it acquires increased adhesive activity, which strengthens the attachment of neutrophils to activated endothelium. Different factors seem to coöperate in triggering this activated state. Activation of endothelium with the P-selectin inducing agents thrombin, $\mathrm{H}_{2} \mathrm{O}_{2}$, or histamine induces surface expression of platelet activating factor (PAF) which coincides with P-selectin expression (50-53). When neutrophil activation by PAF is prevented by PAF receptor antagonist or other means, $\beta_{2}$ integrin activation by neutrophils, contacting endothelium activated by $\mathrm{P}$-selectin inducing agents is prevented completely, and adhesion is reduced (53-55). Antibodies reactive with P-selectin, however, also reduce $\beta_{2}$ integrin activation (53). Since neutrophil binding to $P$-selectin alone is insufficient to induce $\beta_{2}$ integrin activation $(37,53)$, P-selectin is thought to effect neutrophil $\beta_{2}$ integrin activation solely by enhancing the response of neutrophils to PAF. This can be partially explained by the P-selectin mediated increased contact between neutrophils and PAF-expressing endothelial cells (53). A direct effect of P-selectin interaction with neutrophils on the sensibility of neutrophils to PAF has also been described (53).

\section{A6. $\beta_{2}$ Integrin activation during neutrophil interaction with endothelium activated with E-selectin inducing agents}

In parallel to endothelial cell activation with P-selectin inducing agents, activation of endothelium with the E-selectin inducing agents TNF, IL-1 $\beta$, and LPS triggers PAF surface expression, which peaks together with E-selectin expression, after 2 to 6 hours of activation $(56,56 \mathrm{~b}, 56 \mathrm{c})$. In contrast to neutrophil adherence to endothelium activated with P-selectin inducing agents. neutrophil adherence to E-selectin expressing endothelium is not reduced by addition of PAF-receptor antagonists $(48,56 \mathrm{~b})$. Additional involvement of other factors might make the role of PAF in $\beta_{2}$ integrin activation less essential. IL-8 and E-selectin itself could be such factors. In contrast to endothelial cells activated with P-selectin inducing agents, endothelial cells activated by E-selectin inducing agents will synthesize and release IL-8, a known neutrophil chemo-attractant (reviewed in 57). IL- 8 alone is sufficient to induce $\beta_{2}$ integrin activationand can therefore increase neutrophil adhesiveness $(58,59)$.

In addition to the effect of IL-8 on neutrophils, E-selectin-ligand interactions seem to have a more clear direct effect on neutrophils than P-selectin-ligand interactions. E-selectin can, even in a purified form, trigger activation of neutrophil $\beta_{2}$ integrins $(48,60)$. Three additional pathways, involving PAF, IL-8 and E-selectin itself, thus might cooperate in inducing activation of $\beta_{2}$ integrins of neutrophils contacting E-selectin expressing endothelium.

\section{A7. Modulation of neutrophil binding to E- and P-selectin as}

\section{a specialized function enabling neutrophil rolling and extravasation}

Neutrophil migration is thought to be based on variation in the number or the affinity of binding sites for neutrophils. Neutrophils migrate to the site with maximal binding capacity (61). Interestingly, the high affinity interactions between neutrophils and selectin molecules seem to result in a short-time contact, followed either by rolling downstream or by neutrophi] 
extravasation (chapter A8). A decrease in affinity of selectin-ligand binding rapidly upon attachment, could be an explanation for such behaviour, which would overcome the requirement of stronger binding sites at the leading front of cell motility. A decrease in affinity of neutrophil binding to E-selectin (34) and P-selectin (37) has been described to occur directly after neutrophil activation. This might be explained by shedding of the E-selectin and P-selectin ligand $L$-selectin from the neutrophil surface within minutes after activation $(34,62-65)$ and by the reduction in the amount of the neutrophil selectin ligand sialyl Lewis- $x$ on other surface structures than L-selectin after neutrophil activation (33).

These observations are consistent with a model of neutrophil extravasation in which initial selectin mediated shear stress resistent attachment will bring neutrophils in closer contact to, and prolong their interaction with inflammatory mediators such as PAF and IL-8 originating from activated endothelium and the surrounding tissue. In addition, selectin-ligand binding can activate neutrophils directly $(48,53,60)$. In response to this activation, selectin mediated adhesion is reduced and a more delicately regulated, $\beta_{2}$ integrin mediated adhesion pathway is activated, enabling directed (trans)migration. Whether the reduction in L-selectin and sialyl Lewis- $x$ can occur focally within seconds at the site of neutrophil-endothelial cell contact, resulting in local disconnection if simultaneous activation of $\beta_{2}$-integrin avidity has been insufficient, and thus leading to the characteristic rolling behaviour, remains to be elucidated.

In situations of severe systemic inflammation, presence of circulating neutrophil activating factors could induce L-selectin shedding of circulating neutrophils and therefore down-regulate selectin mediated neutrophil endothelial cell interaction. This mechanism might limit neutrophil extravasation in situations where circulating E-selectin inducing agents such as LPS and TNF cause systemic E-selectin expression.

\section{A8. Neutrophil emigration from the vasculature}

Neutrophils appear to reach the point at which they emigrate by rolling; no active migration along the vessel wall is evident by intravital microscopy. While the cell is flattening, a pseudopod is extended through the vessel at a junction between the endothelial cells. Transmigration continues as the pseudopod grows in ramifications and size until the entire cell body has emerged through a narrow gap between the endothelial cells $(1,66)$, a process which is clearly distinct from trans-cellular passage of mature blood cells from bone marrow tissue into marrow sinuses (67).

These observations have been made long before the relation between neutrophil rolling and E-selectin or P-selectin expression became apparent. Although the capacity of E-selectin and $\mathrm{P}$-selectin to mediate neutrophil rolling appears identical, their is a clear difference of E-selectin and $\mathrm{P}$-selectin expressing endothelium in triggering neutrophil emigration. Endothelium activated with E-selectin inducing agents acquires polar characteristics. Efficient vectorial neutrophil migration from the luminal to the basal side of E-selectin expressing endothelial cell monolayers monolayer is evident $(35,36,68,69)$. Migration of neutrophils through $E$ selectin expressing endothelium requires interaction between $\beta_{2}$ integrins and ICAM-1(36, 


\section{Random contact}

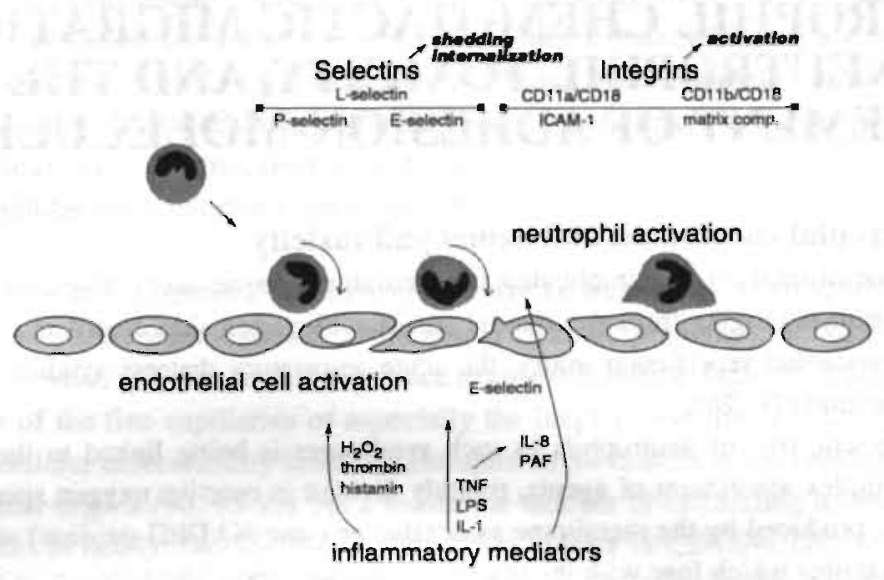

The regulation of neutrophil rolling, attachment, and trans migration

68,70 ). Although E-selectin plays a role in initial contact of neutrophils to such activated endothelium, neutrophil migration occurs independently from E-selectin $(36,68,70,71)$. After rapid activation of endothelial cell adhesiveness for neutrophils by $P$-selectin inducing agents, neutrophil migration through the endothelial cell monolayer is relatively low in comparison to E-selectin expressing endothelium $(35,72,73)$. A difference between E-selectin expressing endothelium and P-selectin expressing endothelium is, that P-selectin expressing endothelium does not release the neutrophil chemotaxin IL-8 (57). IL-8 was indeed found to be responsible for neutrophil migration through endothelium activated with E-selectin inducing agents by forming a chemotactic gradient across endothelial cell monolayer which guides neutrophil migration to the basal side of the monolayer at which the highest IL-8 concentration exists $(56,62)$. Additional roles in mediating neutrophil transmigration have been claimed for endothelial cell associated PAF (56), and for the immunoglobulin related adhesion molecule PECAM-1 (17) which is concentrated at junctions between endothelial cells, but is also present on neutrophils. Besides inducing $\beta_{2}$ integrin activation $(16,17)$, involvement of direct adhesive PECAM-PECAM interactions has also been hypothesized (17).

Neutrophil transmigration through activated endothelium is not associated with endothelial cell damage or increased vascular permeability $(35,69,74)$. Neutrophil degranulation and respiratory burst requires additional neutrophil activation $(35,74-76)$.

The regulation of the switch from neutrophil (trans)migration to neutrophil toxicity is discussed in part B of this introduction. 


\section{NEUTROPHIL CHEMOTACTIC MIGRATION AND NEUTROPHIL TOXICITY, AND THE IN- VOLVEMENT OF ADHESION-MOLECULES}

\section{B1. Neutrophil chemotaxis and neutrophil toxicity}

The human neutrophil is being implicated as a mediator of tissue destructive events in inflammatory syndromes ranging from rheumatoid arthritis, blistering skin disorders and ulcerative colitis to myocardial reperfusion injury, the acute respiratory distress syndrome and acute allograft rejection $(77,78)$.

The pathogenetic role of neutrophils in such syndromes is being linked to their ability to release a complex assortment of agents, roughly divided in reactive oxygen species (metabolites of $\mathrm{O}_{2}$, produced by the membrane associated enzyme NADPH-oxidase) and proteases (stored in granules which fuse with the plasma-membrane upon adequate activation). Reactive oxygen species and proteases are generally released in parallel, and cooperate in destroying cells and dissolving connective tissues (reviewed in 79).

Although these toxins normally defend the host against invading microbes, the neutrophil has little intrinsic ability to differentiate between foreign and host antigens and relies on other arms of the immune-system to select its targets. Besides recognizing surface bound complement and antibody Fc-parts, neutrophil-toxicity can be specifically triggered by a number of pro-inflammatory signal-molecules. A large number of such neutrophil agonists have been described, including microbial products such as bacterial lipopolysaccharides (LPS), the nformylated oligopeptide FMLP (used as a model for physiologic, phlogistic peptides released from bacteria ( 80 ) and damaged mitochondria ( 81 ). and zymosan (baker's yeast ghost cells); lipid mediators such as PAF, leukorriene $\mathrm{B}_{4}$ and monohydroxy-icosatetraenoic acids; cytokines such as TNF, GM-CSF, IL-1, and IL-8; and other inflammatory products such as complement factor C5a and immune complexes (reviewed in 82).

Agonist activation of neutrophils regulates two neutrophil functions: directing the neutrophil to the inflammatory scene, and activating neutrophil toxicity. Most soluble neutrophil agonists are chemotactically active, whilst others (TNF, LPS, GM-CSF) lack this capacity, and specifically activate neutrophil toxicity (chapter $\mathbf{C}$ ). Neutrophil chemotaxis and neutrophil toxicity will be discussed and related to a number of more specific phenomena, seen as a response of neutrophils to agonist activation: changes in the neutrophil cytoskeleton, neutrophil sequestration in the fine capillary bed, $\beta_{2}$ integrin activation and rapid temporal respiratory burst activity. Neutrophil respiratory burst activity (resulting the production of reactive oxygen species) is used as a representative of neutrophil toxicity. 


\section{B2. Rapid neutrophil responses to agonist activation; \\ Actin reorganization and neutrophil sequestration}

Resting neutrophils are round and actin, one of the main cytoskeletal proteins, is distributed diffusely throughout the cell in its globular form. Within one minute after chemotaxin addition, the neutrophil surface begins to ruffle, and actin is cross-linked and converted to subcortical filamentous actin (F-actin), forming a cytoskeletal network (83-88). As a result of F-actin formation, cellular deformability is decreased $(89,90)$.

This rapid neutrophil responses can have impressive consequences in vivo, which are seen when chemotaxins are administrated intravenously in healthy animals, or when neutrophils are activated ex vivo, and then re-infused. Since neutrophils have a diameter of about $7 \mu \mathrm{m}$ and the diameter of the fine capillaries of especially the lungs is less than $6,5 \mu \mathrm{m}(91,92)$, the decrease in cellular deformability leads to neutrophil-sequestration in the capillary bed of the lungs and other organs $(90,93-95)$. As a result, the number of circulating neutrophils drops within minutes to nearly $0 \%(95-100)$. Although the affinity of CD11b/CD18 is increased in parallel to the F-actin mediated decrease in neutrophil deformability (40-43), CD1 lb/CD18 mediated adhesion does not have a clear role in neutrophil sequestration (90, J.M. Harlan, unpublished observation). Neutrophil emigration from the vasculature or induction of tissueinjury remains largely absent $(97,99)$ and within 15 to 30 minutes the number of circulating neutrophils returns to (supra) normal levels $(95,97-100)$.

Whether neutrophil sequestration has any physiological relevance is doubtful. During most inflammatory diseases, appearance of circulating neutrophil activating factors will be gradual, allowing adaptation of the sensitivity of neutrophils to agonist-stimulation (chapter B4 and B6). Neutrophil sequestration might be an over-reaction caused by the absence of sufficient time to allow such an adaptation.

\section{B3. Rapid neutrophil responses to agonist activation; respiratory burst activity}

Neutrophils exposed to high amounts of chemotaxins show nearly immediate respiratory burst activity. Depending on the type and the magnitude of agonist stimulation, reactive oxygen production can be measured which decreases after 3 to 30 minutes $(87,101-106)$. The direct respiratory burst in response to chemotaxins occurs independent from adherence; neutrophils in contact with a substrate for adherence and suspended neutrophils show similar initial responses $(106,107)$. Although transient $C D 11 \mathrm{~b} / \mathrm{CD} 18$ upregulation (103) and transiently increased adherence $(108,109)$ mediated by CDI1b/CD18 (108) can be measured during this phase, CD1]b/CD18 mediated substrate interaction is not essential for the toxic response of neutrophils in this phase $(104,110)$.

\section{B4. Slow neutrophil responses to agonist activation; neutrophil chemotaxis}

$\beta_{2}$ Integrin dependent neutrophil spreading in absence of shear stress, general membrane ruf- 
fling, subcortical F-actin distribution and respiratory burst, seen within one minute after neutrophil-activation, are generally transient. Depending on the magnitude, and on the type (chapter $\mathrm{Cl}$ ) of the agonist to which the neutrophil is exposed, these response can last from a few minutes to approximately half an hour. After this time, the cells withdraw most ruffles, change from a stretched to a more rounded polarized morphology with ruffles only at the leading edge of the cell, and begin to migrate (84-86). In parallel, F-actin is redistributed to the leading edge of the cell $(85,111)$. Seizing of respiratory burst if neutrophils start migrating is not well documented. If neutrophils are subsequently exposed to higher agonist concentrations, neutrophils again stop migrating, round up and stretch temporarily (84). When agonist-concentrations are decreased, neutrophils also stop migrating and round up, but do not stretch (84).

Random migration changes to chemotaxis when neutrophils are placed in a gradient. Adhering neutrophils can orient and migrate in a gradient of FMLP, if a concentration-difference of $1 \%$ or more over their $10 \mu \mathrm{m}$ diameter exists $(112,113)$. Highest accuracy is reached at concentrations close to the dissociation constant, $\mathrm{K}_{\mathrm{d}}$, of FMLP from the cell receptor; at lower but also at higher concentrations the effectiveness of orientation and chemotactic migration decreases $(112,114)$. Cells observed in a visual chemotaxis assay system spread and flatten after the addition of the agonist, but begin to migrate after a few minutes, and soon about $80 \%$ of them has oriented and moves toward the highest concentration of the agonist (112). As they move up the gradient, they maintain a migrating polarized morphology, and ruffle only at their front $(112,84)$.

Chemotaxin-sensitivity, c.q. the dissociation constant of chemotaxin-binding, is adapted during agonist stimulation. Low amounts of chemotaxins increase the sensitivity to this agonist (115). Chemotaxin-concentrations which are high enough to elicit neutrophil activation decrease the sensibility to this agonist $(46,114-116)$, which might ensure ongoing detection of, and responsiveness to further increases in chemotaxin concentration on their path of migration (84).

In parallel, sensibility for most other chemotaxins increases $(101,115,116)$ which might optimize neutrophil chemotaxis in presence of gradients of low amounts of other agonists. The latter adaptation has been referred to as neutrophil-priming $(115,117)$. Seen from this viewpoint, observations of specific desensibilisation for IL-8 and C5a of neutrophils isolated from pustules from patients suffering from relapsing bullous staphyloderma (118) are congruent with an in vivo role for C5a and IL-8 in chemotaxis.

\section{B5. Neutrophil chemotaxis; roles of $\beta_{2}$ integrins}

Additionally to the increase in avidity of the neutrophil $\beta_{2}$ integrins CDIla/CD18 and CD11b/CD18 (40-43), neutrophil agonist exposure leads to translocation of CD11b/CD18 from an intracellular pool to the cell surface $(41,119)$. During chemotaxis CD11b/CD18 is preferentially inserted at the leading edge of cell-motility (120).

Initial activation induced adhesion strengthening occurs, however, mainly by an activation of 
pre-expressed CD11b/CD18 (40, 46), and lasts only a few minutes; only after a further increase in the stimulus the newly expressed $\mathrm{CD} 11 \mathrm{~b} / \mathrm{CD} 18$ acquires an active form and mediates migration (46). Whilst in vitro migration of neutrophils adherent to protein coated glass or plastic as well as in vivo neutrophil accumulation at inflammatory sites can be blocked effectively by CD11b/CD18 specific antibodies $(8,46,120 \mathrm{~b}, 121,122)$, transendothelial migration is reduced by both $\mathrm{CD} 11 \mathrm{a} / \mathrm{CD} 18$ and $\mathrm{CD} 1 \mathrm{lb} / \mathrm{CD} 18$ specific antibodies $(3,123,124)$.

The latter findings support the conclusion that $\mathrm{CD} 1 \mathrm{la} / \mathrm{CD} 18$ functions in locomotion of neutrophils, once its ICAM-ligands are available. Since there is no known rapidly mobilizable intra-cellular pool of CD1 $1 \mathrm{a} / \mathrm{CD} 18$ and neutrophil activation causes no increase in the amount of this integrin on the cell surface $(41,119)$, a role for CD11a/CD18 in mediating migration could be explained by temporally limited focal increases in avidity of CD11a/CD18. Spatially controlled avidity of CD11 a/CD 18 and probably also CD $11 \mathrm{~b} / \mathrm{CD} 18$ could cooperate with spatial distribution of newly expressed CD11b/CD18, in converting local neutrophil agonist activation in locally increased binding strength, and thus into locomotion to the site with high est agonist-presence. Evidence for continuous activation and deactivation of CD11b/CD18 during adhesive interactions (125) and the finding that freezing of adhesion molecules in a state of high-avidity blocks eosinophil migration (126) supports such a hypothesis.

\section{B6. Neutrophil chemotaxis; conclusions}

Neutrophil chemotaxis as described above, can be interpreted as a balanced way of agonist stimulation, in which the neutrophil carefully regulates a setpoint beyond which agonists stimulation leads to increased expression of $\mathrm{CD} 1 \mathrm{Ib} / \mathrm{CD} 18$ and activation of $\mathrm{CD} 1 \mathrm{la} / \mathrm{CD} 18$ and $\mathrm{CD} 1 \mathrm{lb} / \mathrm{CD} 18$. This setpoint is continuously adapted in a way that an chemotaxin-concentration exceeding the previous concentration leads to renewed activation. This principle has been described as temporal gradient sensing, and is thought to guide not only chemotaxis of neutrophils $(127,128)$ but also chemotaxis of bacteria (129). In neutrophils, but not in bacteria, temporal gradient sensing cooperates with a spatial gradient sensing mechanism $(84,127)$. The polar shape of migrating neutrophils seems to be correlated with focal expression and activation of $\mathrm{CD} 11 \mathrm{~b} / \mathrm{CD} 18(46,120)$, and therefore with focal adhesion-strengthening and directed migration. Seen from this view, the initial stretching-response seen rapidly after sudden massive agonist stimulation could result from 'over-stimulation' of this sensing mechanism of neutrophils, leading to generalized in stead of focally increased $\beta_{2}$ integrin avidity. The time needed to adapt the set point of this sensory mechanism could correlate with the duration of the initial stretching response during which locomotion is inhibited.

Rapid neutrophil respiratory burst is linked in time to the initial stretching response which precedes migration after sudden agonist exposure. Whether a causal principle exists which links respiratory burst activity to neutrophil stretching or to either subcortical F-actin distribution or generalized $\beta_{2}$ integrin activation, two phenomena which seem to be associated with neutrophil stretching, remains uncertain. The existence of such a link implicates a functional antagonism between neutrophil migration and neutrophil respiratory burst activity. Experi- 
mental evidence is congruent with this antagonism. Cytochalacin B, a fungal metabolite which interferes with F-actin formation, interferes with migration (130) and highly increases and prolongs respiratory burst activity of activated neutrophils $(87,109,115,131,132)$. The antagonism between neutrophil migration and neutrophil respiratory burst activity, c.q. the association between neutrophil respiratory burst activity, generalized $\beta_{2}$ integrin activation, and generalized subcortical F-actin distribution, is further emphasized in the following chapters on prolonged respiratory burst activity.

\section{B7. Neutrophil respiratory burst activity}

Since 1961 it has been observed that during phagocytosis of bacteria, zymosan, and particles such as latex beads, neutrophil oxygen consumption is increased, and oxygen radical release in phagosomes can be measured (133-135). About 15 years later, the potency of chemotaxins such as FML.P and C5a to induce a phagocytosis independent respiratory burst became evident (109, 136-138). Chemotaxin induced respiratory burst activity needed relatively high concentrations of chemotaxins (109), was lower $(109,136,138)$ and lasted shorter $(109,136)$ than phagocytosis induced oxygen radical production.

The last ten years, growing attention for neutrophil respiratory burst activity induced by a mechanism which seems to be a combination of phagocytosis induced respiratory burst activity and respiratory burst activity induced by chemotaxins and other soluble neutrophil agonists has risen. In a series of publications, Nathan et al. (139-143), Fehr et al. (106, 114, 144146), and Kownatzki and Kapp et al. (147-152) showed that neutrophils adherent to artificial surfaces ('frustrated phagocytosis' model) respond different to addition of high amounts of chemotaxins and other agonists in comparison to non-adherent neutrophils. Adherent neutrophils show a highly prolonged and increased respiratory burst, starting after a 'lag time' of 15 to 60 minutes, incited not only by chemotaxins, but also by a group of other agonists which lack chemotactic activity and fail to induce any respiratory burst activity by suspended neutrophils. The following chapters and part $\mathrm{C}$ further specificate the latter form of respiratory burst induction, and present evidence for its (patho)physiological relevance.

\section{B8. Slow neutrophil responses; substrate induced neutrophil spreading and prolonged respiratory burst activity}

In the previous chapters, the response on activation of neutrophils in contact with a substrate for adherence, has been described as a transient stretching response followed by a polar shape and migration. Substrate contacting neutrophils can, however, also show another response, during whitch initial stretching continues, resulting in highly flattened neutrophils which do not migrate. This response can be induced in vitro by placing resting neutrophils on uncoated polystyrene or glass surfaces as a substrate for adherence $(139,153)$. In parallel to extensive neutrophil spreading and flattening, F-actin localizes in small foci on the adherent surface (154). Even in absence of soluble agonists, neutrophil spreading on uncoated polystyrenetriggers strong and ongoing respiratory burst activity $(104,139,141,153)$. The 
increase in F-actin content (154), and initiation of respiratory burst (104, 139) start rapidly, but develop more slowly than during the rapid responses on stimulation with chemotaxins, and persist much longer. Polystyrene induced neutrophil respiratory burst can be easily reduced by altering its surface characteristics. Lowering the negative surface charge (141), surface-coating with serum $(141,139)$, with specific proteins $(104,139-141)$, or with a monolayer of cells (139) suppresses respiratory burst activity completely, or delays the time of onset.

Activation of such substrate contacting neutrophils with very high amounts of FMLP or C5a induces increased and highly prolonged respiratory burst in comparison to activation of suspended neutrophils $(104,106,139,143,147)$. Moreover, the neutrophil agonists TNF, GMCSF and LPS, which fail to induce rapid respiratory burst activity by suspended neutrophils, induce prolonged massive oxygen radical release when added neutrophils in contact with adequate surfaces $(75,106,139,140,141,148,149,151,155,156)$.

Rapid neutrophil respiratory burst activity, as defined previously, begins within 1 minute and lasts up to 30 minutes. Prolonged respiratory burst activity by neutrophils in contact with uncoated polystyrene or glass also begins rapidly, but lasts for hours $(104,139,141,153)$. Prolonged respiratory burst activity by neutrophils in contact with coated polystyrene or glass in response to adequate agonists activation (for details chapter $\mathrm{C} 1$ ) is characterized by a lag period of 15 to 60 minutes after which ongoing respiratory burst can be measured $(75,104$, 139,140 ). These different manifestations of neutrophil respiratory burst activity can be linked to actin-organization and adhesion molecules.

\section{B9. Neutrophil spreading and prolonged respiratory burst; role of F-actin}

Both neutrophil flattening $(154,157)$ and prolonged respiratory burst $(139,142,153,155)$ can be prevented by addition of cytochalasin B. Cytochalasin B, which interferes with F-actin formation, prevents the switch from initial adherence to migration (158) and prolongs rapid respiratory burst activity correlated with initial adhesion $(87,109,115,131,132)$.

Cytochalasin B also interferes with cell spreading $(154,158)$, and inhibits initiation of prolonged massive respiratory burst activity correlating with cell spreading $(139,142,153,155)$. This double action of cytochalasin B, increasing rapid respiratory burst activity and inhibiting prolonged respiratory burst activity, has not been explained so far. A direct relation between the cytoskeleton and the enzymes responsible for respiratory burst activity (159) might be responsible for these influences of cytochalasin B.

Another attractive idea is that cytochalasin B acts on respiratory burst activity indirectly, by inhibiting alterations in the shape and behaviour of neutrophils. Both the inhibition of migration and the inhibition of ongoing flattening might interfere with substrate-interaction dependent CDIIb/CDI8 functions linked to respectively stopping and beginning of respiratory burst activity. This option would implicate a role of $\mathrm{F}$-actin in facilitating specific CD1 lb/CD18 mediated adhesive interactions. 


\section{Introduction}

\section{B10. Neutrophil spreading and prolonged respiratory burst; role of $\beta_{2}$ integrins}

Extensive neutrophil spreading and flattening is linked to prolonged respiratory burst activity. Both neutrophil flattening and prolonged respiratory burst activity are dependent on CD 11 b/CD 18 function (75, 104, 140, 142, 160). In specilic in vitro conditions, CD1 lb/CD 18 function can be inhibited whilst neutrophil attachment or flattening can be facilitated by CD1 la/CD18-ICAM-1 interactions, selectin interactions, or lectin-mediated binding. These conditions however, do not allow prolonged respiratory burst activity in response to the neutrophil agonist TNF (75, see chapter $\mathrm{C} 1$ ), indicating that CD1 1b/CD18 does not just facilitate neutrophil flattening, but has a more direct role in prolonged neutrophil respiratory burst activity. Moreover, a number of polystyrene coatings, such as stearic acid, collagen, albumin inhibit prolonged respiratory burst activity without (completely) inhibiting CD/1b/CD 18 mediated attachment $(104,107,139,140)$.

$\beta_{2}$ integrins seem to have signal transducing capacities, since changes in cytosolic free $\mathrm{Ca}^{\prime \prime}$ and c-CAMP, and changes in cellular behaviour can be initiated by $\beta_{2}$ integrin substrate contact and by crosslinking of $\alpha$ and $\beta$ chains by specific antibodies (142, 161-165). A CD11b/CD18 submitted activation signal, depending on a specific state of CD11b/CD18, might thus be a prerequisite for prolonged neutrophil respiratory burst activity.

Whilst neutrophil chemotaxis seems to be linked to focal increases in CD1 lb/CD18 avidity, a generalized increase in CDI1b/CDI8 avidity seems to be correlated with both rapid and prolonged neutrophil respiratory burst activity. Direct evidence for a generalized highly avid state of surface CD11b/CD18 (and probably also CD11a/CD18) during ongoing respiratory burst activity is lacking until now.

The observation that initial CD11b/CD18 mediated neutrophil attachment to coated polystyrene requires static conditions, whilst after a short period of time, neutrophils become highly flattened and neutrophil attachment acquires resistance to extreme shear stresses $(37,49,142)$ clearly reflects a switch to generalized highly avid CD 1 1b/CD 18 mediated substrate interactions. Part of the mechanism by which this switch is regulated has recently been demonstrated by Nathan and all. and is presented in the next chapter.

\section{B11. Neutrophil spreading and prolonged respiratory burst; role of CD43}

Neutrophil adhesion is the result of a complex interaction of adhesive and anti-adhesive factors. Besides specific receptor-ligand interactions, hydrodynamic forces, and the arrangement of the cytoskeleton, specifically regulated electrostatic forces participate in determining neutrophil adhesion. Abrahamson suggested more than 60 years ago that a decrease in negative surface charge might facilitate the adhesion of neutrophils to the negatively charged endothelial cell surface during the inflammatory response (166). Resting neutrophils and other leukocytes express a long rigid sialoprotein with marked negative charge, known as CD43 (sialophorin, leukosialin). Parallel to neutrophil activation, and probably resulting from the release of proteases such as elastase and sialidase from activated neutrophils, adherent neutrophils can shed CD43 from their surface $(142,167-169)$. CD43 prevents neutrophil flattening. whilst 
leaving initial adherence unaffected (143). The mechanism for this effect appears to be linked to specific characteristics of CD43. The extended extracellular domain of CD43, which protrudes $45 \mathrm{~nm}$ from the plasma membrane on rat T-cells (170), farther than expected for any molecule on the surface of these cells, the rigidity, and the high negative charge ( $\mathrm{Pi}=4.1$ ) (171), make it plausible that for integrins or other adhesion molecules to mediate flattening of neutrophils, neutrophils must first shed, desialylate, and/or redistribute CD43 away from points of contact (143). CD43 thus acts as an 'anti-adhesive' molecule, which appears to prevent prolonged neutrophil respiratory burst activity and favor (chemotactical) migration for as long as its normal expression has not been affected.

\section{B12. Neutrophil spreading and prolonged respiratory burst; role of albumin}

Human serum albumin binds to surface CD43, and suppresses both agonist and protease induced CD43 shedding (143). This mechanism is likely to explain previous observations of the capacity of human serum albumin to prevent agonist induced prolonged respiratory burst activity $(140,143)$, to reduce F-actin formation correlated with neutrophil flattening (154), and to increase neutrophil chemotaxis (172-174). Thus, the impact of albumin on neutrophils is likely to be biphasic during the evolution of an inflammatory response. In healthy organisms, the high intravascular albumin concentrations may favor neutrophil-extravasation, and the low extravascular albumin concentrations may facilitate neutrophil retention in the extravascular tissues, where they may be relatively free to spread, degranulate, and undergo a respiratory burst. Reduction of the trans-vascular gradient of albumin in later stages of inflammation may have the opposite effects (143).

\section{B13. Slow neutrophil responses; conclusions}

Agonist activation of resting neutrophils induces a rapid initial phase, characterized by generalized subcortical F-actin deposition, generalized CD11b/CD18 activation, and, after adequate agonist exposure, a transient respiratory burst and protease-release. This initial adherence-independent phase probably occurs in response to any neutrophil agonist of sufficient strength. Neutrophils adapt rapidly by decreasing their sensibility to the initial agonist, and a switch to a polar shape with focal CD1/b/CD18 activation and F-actin deposition can be observed. This switch can, however, be prevented by extensive neutrophil spreading mediated by $\mathrm{CD} 11 \mathrm{~b} / \mathrm{CD} 18$ and by $\mathrm{CD} 43$ shedding. Both $\mathrm{CD} 11 \mathrm{~b} / \mathrm{CD} 18$ mediated binding and $C D 43$ shedding are highly regulated. Extreme conditions, such as neutrophil activation by the croton oil derived protein kinase $\mathrm{C}$ activating carcinogen PMA, triggers a prolonged respiratory burst independent from CD11b/CD18 mediated substrate contact $(107,142,147)$ and independent from albumin presence (143). Also, uncoated polystyrene surfaces trigger a prolonged respiratory burst independent from agonist presence $(104,139,141,153)$. In more physiological circumstances agonist conditions, substrate conditions and other environmental conditions such as albumin presence cooperate in determining whether the initial neutrophil response is followed either by a polar shape and migration or by increased flattening and prolonged neutrophil respiratory burst activity. 


\section{Chapter C}

\section{DIFFERENCES BETWEEN NEUTROPHIL AGONISTS; A SPECIFIC ROLE FOR TNF?}

\section{C1. Chemotaxis-inducing and respiratory burst-inducing agonists; in vitro evidence}

The response of neutrophils to agonists can be divided in a general initial response, and in specific prolonged responses. Reorganization of the neutrophil surface receptor make up seems a central feature in the initial response of neutrophils to agonist activation. This is indicated by the increase in CD11b/CD18 expression and by neutrophil priming, the latter being partly related to altered receptor expression $(175,176)$, found as common responses to the presence of the agonists indicated in Table 1.

However, the sensitivity of neutrophils to low molecular weight agonists such as C5a, FMLP, PAF, leukotriene $B_{4}$ and LPS tends to be lower in comparison to protein-agonists TNF- $\alpha$, TNF- $\beta$ and GM-CSF. Shedding of L-selectin from the neutrophil surface is another common response, showing similar kinetics as $\mathrm{CD} 1 \mathrm{lb} / \mathrm{CD} 18$ upregulation (65).

A clear divergence between different agonists is seen in their capacity to induce chemotaxis, and in the concentration required to induce respiratory burst activity (rable 1). On the basis of this divergence, neutrophil agonists can be divided into two groups. The first group, to which TNF- $\alpha$, TNF- $\beta$, GM-CSF and LPS belong, elicit a substrate-dependent prolonged respiratory burst as a slow response to concentrations which also elicit CD11b/CD18 upregulation and priming. TNF, GM-CSF and LPS are not chemotactically active, but inhibit migration towards chemotaxins $(144,148,177-181)$.

The second group, to which IL-8, FMLP, C5a, PAF and leukotriene $\mathrm{B}_{4}$ belong, elicit chemotaxis as a slow response to concentrations which also elicit $\mathrm{CD} 11 \mathrm{~b} / \mathrm{CD} 18$ upregulation and priming. Only at higher concentrations, these agents elicit a rapid respiratory burst (mainly in presence of cytochalasins) or a prolonged respiratory burst (in contact with appropriate surfaces). Respiratory burst activity occurs at 10 to 100 times the concentrations required for chemotaxis or CD11b/CD18 upregulation for IL-8, C5a and FMLP, and at more than 100 times higher concentrations of PAF and leukotriene $\mathrm{B}_{4}$ (lable I).

It seems legitimate to conclude that the role of IL-8, C5a, and FMLP in neutrophil behaviour in vivo is limited to chemotaxis, and that term 'chemotaxins' applies very well to these agonists. In vivo situations in which the exposure of neutrophils to the latter agonists is abrupt enough to avoid adaptation, and high enough to trigger a respiratory burst, will not easily occur. In parallel, neutrophil priming by IL-8, C.5a and FMLP can have a function in chemotaxis, in which priming optimizes migration towards low amounts of other chemotaxins. Neu- 
trophil priming by these chemotaxins is unlikely to cooperate in neutrophil respiratory burst activity. Priming does increases the rate of oxygen radical production but hardly decreases the threshold concentration needed to induce a respiratory burst by chemotaxins $(87,117,182)$. Also, neutrophil priming by IL-8, C5a and FMLP seems to fail in increasing respiratory burst in response to the first group of agonists. TNF-induced respiratory burst activity is not increased by either endothelial cell released or added IL-8 (76), by C5a (own unpublished observation) or by FMLP (148). Moreover, previous activation by such agonists decreases the sensitivity of neutrophils for TNF, by inducing rapid shedding of the TNF-receptor (156, 183). Clear priming effects of FMLP, C5a or IL- 8 on neutrophil toxicity elicited by GM-CSF or LPS have not been described.

\section{Table I.}

Comparison of neutrophil activation by some potential physiological soluble agonists.

\begin{tabular}{|c|c|c|c|c|c|c|}
\hline Agent & $\mathrm{EC}_{s}(M)$ & & & & & References \\
\hline & chemotaxis & $\begin{array}{l}\text { CD11b/CD18 } \\
\text { upregulation }\end{array}$ & priming & $\begin{array}{l}\text { rapid respir- } \\
\text { atory burst }\end{array}$ & $\begin{array}{l}\text { prolonged res- } \\
\text { piratory burst }\end{array}$ & \\
\hline TNF- $\alpha$ & absent & $10^{31-10^{3}}$ & $10^{11}-10^{-10}$ & absent & $10^{i i}-10^{i 0}$ & 75, 139, 148, 151, 172, 179, 180, 14, Iss \\
\hline $\mathrm{TNF}-\mathrm{B}$ & absent & not specified & not specified & absent & $2-7 \times 10^{-10}$ & $138,148,151,186$ \\
\hline GM-CSF & absent & $5 \times 10^{-12}-10^{10}$ & $10^{-11-} 10^{: 0}$ & atsent & $4 \times 10^{11}-10^{-10}$ & 198. 14L, $149,187.191$ \\
\hline LPS & absent & $1 \sim 10 \mathrm{ng} / \mathrm{ml}$ & $2-50 \mathrm{ng} / \mathrm{ml}$ & absent & $10-50 \mathrm{ng} / \mathrm{ml}$ & 110, 139, 144, 145, 192,195 \\
\hline Ll-8 & $5 \times 10^{-11-} 10^{9}$ & $10^{9}$ & $10^{9}$ & $10^{-9}-2 \times 10^{5}$ & $10^{-3}$ & $59,65,116,182,196.201$ \\
\hline FMLP & $10^{-1 i-10^{6}}$ & $1-7 \times 10^{0}$ & $4 \times 10^{3}$ & $4 \times 10^{-5}-4 \times 10^{-5}$ & $10^{3}-3 \times 10^{9}$ & $39,65,104,106,109,152,188,202,204$ \\
\hline $\mathrm{CSa}$ & $2 \times 10^{-10}$ & $4 \times 10^{30}-10^{9}$ & $10^{\circ}$ & $10^{5}$ & $1-3 \times 10^{-5}$ & 65. 106.152, 175, 197, 203, 205. 206 \\
\hline PAF & $10^{10}-10^{*}$ & $10^{11}-10^{5}$ & $10^{-12}-10^{3}$ & $10^{-5}-5 \times 10^{5}$ & $10^{5}-10^{5}$ & $65.206-215$ \\
\hline
\end{tabular}

$\begin{array}{llllll}\text { Leukotriene } B_{4} 10^{-9}-10^{-8} & 10^{-10}-10^{-9} & 10^{-8} & 10^{-6} & \text { unknown } & 85,204,206,214,216-221\end{array}$

\section{C2. Chemotaxis-inducing and respiratory burst-inducing agonists; in vivo evidence}

Evidence for a role of FMLP, C5a and IL-8 in chemotaxis, and for a role of TNF, GM-CSF, and LPS in neutrophil toxicity also arises from in vivo experiments. Systemic agonist administration leads to rapid neutropenia, resulting from neutrophil sequestration in the lungs and other organs. FMLP $(95,100,222)$, C5a $(95,99,100,223)$ and IL-8 $(97,98)$ induced neutropenia is restored within less than one hour, without resulting in clear tissue or organ damage. In contrast, TNF $(181,224-226), \operatorname{GM}-\operatorname{CSF}(190,227)$ and LPS $(95,96,222,224,226)$ induced neutropenia holds on for at least two hours, and can result in organ injury $(222,225$, 
226, 228). Whilst chemotaxin-induced neutropenia results solely from an F-actin dependent increase in neutrophil stiffness $(89,90,93)$, for LPS-induced neutropenia and involvement of CD11b/CD18 dependent anchoring of neutrophils in neutropenia at later time-points, has been demonstrated (94).

\section{C3. A specific role for the lipid agonists PAF and leukotriene $B_{4}$ ?}

In comparison to the other neutrophil agonists, PAF and leukotriene $B_{4}$ are weak inducers of neutrophil respiratory burstactivity; only after addition of relatively high concentrations of PAF $(208,210,211)$ or leukotriene $B_{4}(204,216,218,229,230)$ a low and short-lived respiratory burst can be measured. In sharp contrast with the $\mu \mathrm{M}$ concentrations of PAF needed to elicit respiratory burst activity of resting neutrophils, $10^{12} \mathrm{M}$ of PAFwas shown to increase TNF induced neutrophil respiratory burst effectively (209).

Co-production of PAF and leukotriene $\mathrm{B}_{4}$, by neutrophils itself or by surrounding cells, occurs in many instances during neutrophil mediated inflammatory processes $(56,56 \mathrm{~b}, 56 \mathrm{c}, 213$, 231-234). Evidence for involvement of endogenous $\operatorname{PAF}(209,232,235)$ and leukotriene $\mathbf{B}_{4}$ (204) in neutrophil respiratory burst activity, and for amplification of the respiratory burst by endothelial cell associated $\operatorname{PAF}(76,233,236)$ suggest that these lipid-mediators might have a regulatory role in many, if not all, pathophysiological situations associated with activation of the neutrophils respiratory burst.

\section{C4. Neutrophil-agonists; conclusions}

Focussing on prolonged neutrophil responses, a hypothetical devision of common soluble neutrophil agonists into three groups is made.

TNF, GM-CSF and LPS induce prolonged respiratory burst activity but not chemolaxis. IL-8, FMLP and C5a induce chemotaxis at low, and prolonged respiratory burst activity at high concentrations. PAF and leukotriene $\mathrm{B}_{4}$ induce chemotaxis and prime neutrophils for a prolonged respiratory burst in response to other agonist, but are relatively incapable of triggering a respiratory burst by resting neutrophils. The kinetics of the F-actin responses to the agonists support this division.

The first group of agents induce an increase in $\mathrm{F}$-actin content which remains high for a long period of time $(87,94,237)$. The second group of agents induce only a temporal increase in $\mathrm{F}$-actin content, although the decline in $\mathrm{F}$-actin content can be counteracted by increasing the agonist-concentration $(83,85,88,229)$. After F-actin formation induced by the third group of agents, a sharp decline, followed by ongoing oscillations in the F-actin content is found ( 88 , 229. 238).

A hypothetical functional characterization of the different agonist-groups can be postulated from these data. IL-8, bacterial formylated peptides (represented by FMLP), and C5a could have a main role in directing neutrophils to the inflammatory site. This function involves focally increased F-actin content.

Once neutrophils arrive in a zone with sufficient TNF, LPS or GM-CSF (or chemotaxin-concentrations too high to adapt to), the focal F-actin concentration is replaced by a general 


\section{Chapter 1}

increase in F-actin, migration is reduced, and facilitated by CD43 shedding and highly avid $\mathrm{CD} 11 \mathrm{~b} / \mathrm{CD} 18$ mediated substrate contact, the neutrophil flattens and becomes functionally active by releasing high amounts of proteases and reactive oxygen metabolites. Locally produced leukotriene $\mathrm{B}_{4}$ but especially PAF could have a co-regulatory role, enhancing both chemotaxis and prolonged respiratory burst activity.

\section{C5. TNF as a specialized regulator of neutrophil toxicity}

There is presumably no other cytokine, which has such a wide range of activities on so many cell types as TNF (239). TNF is released by hemopoietic cells, renal epithelial cells (240, $241)$, and by some tumor cells $(242,243)$. Two forms of TNF, TNF- $\alpha$ (cachectin) released mainly by mononuclear phagocytes, and TNF- $\beta$ (lymphotoxin) released by lymphocytes, have been identified, which show about $35 \%$ sequence similarity $(244,245)$, and act via the same receptors (reviewed in 246). Although circulating free TNF can be found temporarily after acute and severe inflammatory assaults, and a number of systemic inflammatory responses are mediated by TNF, TNF is thought to function in host defence mainly according to a paracrine model in which TNF is produced and acts locally (reviewed in 247). TNF has a number of characteristics which fit very well with a key role in regulating neutrophil toxicity:

1. TNF elicits endothelial cell mediated neutrophil rolling. Together with $\mathrm{LL}-1$, which lacks the capacity to induce prolonged neutrophil respiratory burst activity (139), TNF is the most powerful known physiological inducer of E-selectin expression by the endothelial cell vessel lining $(24,248,249)$. An in vivo role for TNF in mediating E-selectin expression in situations of LPS induces septic shock has been demonstrated (250).

2. TNF induces endothelial cell mediated neutrophil attachment and transmigration. Parallel to E-selectin expression, TNF induces endothelial cell associated PAF $(56,56 \mathrm{c})$, endothelial cell IL- 8 release $(57,241)$ and increased expression of endothelial cell ICAM-1 expression $(249,251)$. PAF, IL-8 and ICAM-1 mediate neutrophil attachment and transmigration $(3,56,62,123)$.

3. TNF directly induces prolonged neutrophil respiratory burst activity and can be indirectly responsible for neutrophil chemotaxis. TNF has a direct effect on neutrophils, leading to inhibition of chemotactic migration $(148,178,186,179,180)$, neutrophil spreading (142), a prolonged respiratory burst $(75,139,140,148,151,155,156)$ and protease release $(102$, $156,252,253)$. This response is incited at TNF-concentrations of $10^{-11} \mathrm{M}$ and more.

Indirectly, via induction of IL-8 release by other tissue cells such as fibroblasts $(254,255)$, renal epithelial cells $(241,256)$ and hepatocytes $(257)$, a TNF gradient can induce an IL-8 gradient, which has strong chemotactic properties.

In vitro medium concentrations of $10^{-10} \mathrm{M}$ IL- 8 are measured within hours after incubation of renal epithelial cells with only $6 \times 10^{-13} \mathrm{M}$ TNF (241). TNF concentrations which are 10 to 100 times belowconcentration required to induce inhibition of chemotaxis thus might induce neutrophil chemotaxis indirectly by enhancing IL- 8 release. Only once neutrophils have migrated to a region with local TNF-concentrations higher than $10^{-11} \mathrm{M}$, accumulation of neutrophils, 
and subsequent triggering of neutrophil toxicity might occur. In vivo evidence on these statements is limited, since adequate and selective inhibition of local TNF-production or TNF-bioactivity remains difficult. After local TNF-administration, however, clear neutrophil accumulation and local tissue damage are found (258-260).

4. Activation of neutrophil elastase release limits TNF-presence. TNF induces the release of neutrophil secondary granule constituents $(102,156,252,253)$. Elastase and catchepsin G, two major proteases stored in secondary granules, can inactivate TNF by proteolytic cleavage $(261,262,263)$. Furthermore, proteolitic cleavage by elastase induces shedding of the neutrophil TNF-receptor, and therefore decreases the sensitivity of neutrophils to TNF (264). Thus, a feed-back mechanism can be postulated, which limits TNF-induced neutrophil accumulation and neutrophil toxicity, via inactivation of TNF and neutrophil TNF-receptors once a certain concentration of elastase (and a breakdown of the anti-protease shield by reactive oxygen species) is achieved.

5. Systemic neutrophil activation limits the bioactivity of systemic TNF as well as neutrophil sensitivity to TNF. Neutrophil activation leads to shedding of the TNF-receptor of neutrophils $(156,183)$. Shedded TNF-receptors are capable of inactivating TNF $(265,266)$, whilst neutrophils which have shed their TNF-receptors show decreased responses to TNF $(156,267)$. Tissue injury as a result of neutrophil sequestration in the lungs and liver following severe trauma will, for example, be counteracted by this decrease in sensibility for local TNF. Additionally, systemic presence of neutrophil agonists will result in high concentrations of circulating TNF receptors, which can buffer TNF leaking into the circulation, and therefore reduce the potentially lethal responses to systemic TNF (183).

6. TNF specifically cooperates in neutrophil mediated inactivation of foreign structures. Neutrophilic granulocytes are specialized in digesting foreign material. Respiratory burst activity and degranulation are essential in this process, and are activated either during phagocytosis or after intense spreading (see chapter B7 and B8). Both phagocytosis and intense spreading are thought to result directly from increased adhesive interactions; the only principle difference is the size of the particle to which the neutrophils attaches (268).

Regulation of binding, phagocytosis and respiratory burst activity are closely linked processes. Direct binding of foreign structures can occur via CD1 lb/CD18, which has affinity for the capsule-components of gram negative bacteria and yeast, specific parasite-components, and plastic surfaces $(9,10,269,270)$.

$\mathrm{CD} 1 \mathrm{lb} / \mathrm{CD} 18$ mediated interactions with yeast particles directly incite a process of progressive attachment, phagocytosis, and prolonged respiratory burst activity $(104,153,269,271)$. TNF can cooperate in this cascade by strongly enhancing phagocytosis of particles and by increasing respiratory burst activity (272-275).

The induction-profile of TNF-release matches very well with a role for TNF in supporting particle-digestion by neutrophils. Attachment of mononuclear phagocytes to plastic (276) or phagocytosis of yeast particles $(277,278)$ specifically induces TNF gene transcription or release. Furthermore, surface-bound immuno-globulins $(279,280)$ and surface-bound complement (277) are strong and specific triggers for TNF release by mononuclear phagocytes. 
Thus, the specific production of TNF in response to foreign structures, and the capacity of TNF to enhance of their digestion by neutrophils, might imply a crucial role for 'TNF in coping with foreign substances by the immune-system.

\section{C6. GM-CSF, a potential regulator of neutrophil toxicity?}

GM-CSF is a hemopoietic growth factor with substantial effects on the proliferation of myeloid leukocytes. Its in vitro effects are, however, not confined to myelopoieses, but identify GM-CSF as a powerful regulator of myeloid leukocyte functions (reviewed in $28 \mathrm{l}$ and 282). GM-CSF lacks, however, most effects of TNF on non-myeloid cells. Induction of endothelial E-selectin, ICAM-1, PAF and IL-8, for example, has not been reported. T-cells, macrophages, mast-cells, endothelial cells and fibroblasts can be triggered to release GM-CSF, and GMCSF has pleiotropic connections within the cytokine-network. Close connections with TNF exist: TNF enhances transcription of GM-CSF (283-285) and enhances GM-CSF induced effects (286) whilst GM-CSF also induces production of TNF (286-289). GM-CSF is thought to be produced and act locally, since detectable levels of GM-CSF in the circulation have not been found $(281,282)$. In vivo evidence, demonstrating local presence or involvement of GMCSF in (patho)physiological processes, has, however, been very limited $(290,291)$. Whether GM-CSF plays an actual role in homeostatic maintenance of myelopoiesis and in host defence thus remains to be answered.

\section{C7. LPS, a potential regulator of neutrophil toxicity?}

Bacterial lipopolysaccharides (LPS or endotoxin), the principal lipid component of the outer leaflet of the envelope of gram-negative bacteria, is recognized by, and elicits strong responses in essentially all multicellular organisms. Recognition of LPS in humans depends on complexation of LPS with specific serum proteins and subsequent binding to CD14 (292-295). Mononuclear phagocytes express high amounts of CD14 (about 50.000 molecules/cell) (296) and respond to low LPS-concentrations $\left(\mathrm{EC}_{30} 10 \sim 100 \mathrm{pg} / \mathrm{ml}\right)(292,295,297)$. Neutrophils express smaller amounts of CD14 $(195,298)$ and respond to higher LPS-concentrations $\left(\mathrm{EC}_{50} \mathrm{l}-50 \mathrm{ng} / \mathrm{ml}\right.$ ) (Table 1). Tissue cells such as endothelial cells do not clearly express CD14 $(299,300)$, and respond only to very high LPS-concentrations ( $\mathrm{EC}_{50}$ up to $1 \mu \mathrm{g} / \mathrm{ml}$ ). However, we could show that this response is mediated by CD14 (251), which might originate from mononuclear phagocytes (299-303). Mononuclear phagocytes thus seem to be specialized in detecting small amounts of LPS, and in responding in an earlier stage during LPS-challenge. TNF release by these cells starts within one hour after LPS-exposure, and TNF mediates many of the effects seen after experimental LPS-administration (250, 304-306). The direct effects of LPS on neutrophils (inhibition of chemotaxis, prolonged F-actin formation, stretching, degranulation and induction of a prolonged respiratory burst $(144,94,139,145)$, as well as the indirect effects (induction E-selectin, ICAM-1, and IL-8 $(24,248,251)$ which mediate respectively neutrophil rolling, neutrophil attachment, neutrophil transmigration and chemo(axis), are similar to the effects of TNF. The LPS concentrations needed to induce these effects are, however, $10^{2}$ to $10^{4}$ times higher than concentrations of LPS needed to induce INF: 
release by monocytes, and even at sufficient concentrations, the effects of LPS on neutrophils (139) and on endothelial cells $(24,251)$ generally remains lower than the effects of TNF. The direct response to LPS thus seems to be delegated to a selective cell population, whilst other cells use a signal of thisspecialized cell to respond indirectly to LPS (303). Furthermore, the effectiveness of experimental administration of TNF-specific antibodies in counteracting systemic LPS-responses $(304,305)$, in vivo endothelial cell responses $(250)$ and neutrophil responses (306) to LPS or bacteremia, argues for the importance of a TNF-mediated indirect effect of LPS. Whether the direct pathway, activation of cells such as neutrophils and endothelial cells by LPS, has still physiological relevance, remains to be determined. Specific situations might exist during which the indirect pathway is nonfunctional. In a disease such as paroxysmal nocturnal hemoglobinuria in which cell-associated CD14 is lacking, in the extravascular space, or after LPS-desensitization of myeloid cells by prolonged contact with LPS, the direct pathway of endothelial cell activation might be crucial for an inflammatory response to LPS (303).

\section{C8. TNF as a specialized regulator of neutrophil toxicity; conclusions}

The control of neutrophil toxicity is a major challenge in host defense. TNF has unique characteristics in regulating this neutrophil function. Specific local release by mononuclear phagocytes, several levels of control of bioactivity of and sensibility for TNF, and the potential to induce, partly indirect, neutrophil rolling, attachment, transendothelial migration, chemotaxis, and activation of neutrophil toxicity, give TNF a potential key-position in the control of neutrophil toxicity. Whether the role of TNF is indeed crucial in the regulation of neutrophil toxicity, remains a major question.

Evolution might have favored the appearance of a redundancy of inflammatory mediators with overlapping effects, thus minimizing the risk for perturbation of intercellular communication during crucial immune-responses. In vivo models in which TNF-mediated communication-signals are selectively and completely eliminated should provide part of the answer to this question. Recent techniques of raising TNF-receptor gene knock-out mice (307) might achieve this goal. In mice lacking the $55 \mathrm{kD}$ TNF receptor only a increased sensitivity to infection with intracellular-living bacteria such as Listeria was observed (307). This finding could implicate that most functions of TNF are indeed relatively easily by-passed by other, maybe as yet undiscovered, mediators. Whatever the answer is, investigations on TNF have a unique place in the history of unraveling the answers host defence has developed in dealing with microbial challenge. 


\section{References}

1. Cohnheim, J. 1889. Lectures on general pathology: a handbook for practitioners and students. London. The New Sydenham Society.

2. Ruoslahti, E.. 1991. Integrins. J. Clin. Invest. 87:1.

3. Smith. C. W., S. D. Marlin, R. Rothlein, C. Toman, and D. C. Anderson. 1989. Cooperative intactions of LFA-1 and Mac-1 with intercellular adbesion molecule-1 in facilitating adherence and transendothelial migration of human neutrophils in vitro. J. Clin. Invest. 83:2008.

4. Diamond, M. S., D. E. Staunton, A. R. de Fougerolles, S. A. Stacker, J. Garcia-Aguilar, M. L. Hibbs, and T. A. Springer. 1990. ICAM-1 (CD54)-a counter-receptor for Mac-1 (CD11b/CD18). J. Cell BioL 111:3129.

5. Staunton, D. E., M. L. Dustin, and T. A. Springer. 1989. Functional cloning of ICAM-2, a cell adhesion ligand homologous to ICAM-1. Nature 339:6I.

6. de Fougerolles, A. R., S. A. Stacker, R. Schwarting. and T. A. Springer. 1991. Characterization of ICAM2 and evidence for a third counter-receptor for L.FA1. J. Exp. Med. 174:253.

7. De Fougerolles, A. R., and T. A. Springer. 1992. Intercellular adhesion molecule 3 , a third adhesion counter-receptor for lymphocyte function-associated molecule 1 on resting lymphocytes. J. Exp. Med. 175:185.

8. Dana, N., B. Styrt, J. D. Griffin, R. F. Todd III, M. S. Klempner, and M. A. Amaout. 1986. Two functional domains in the phagocyte membrane glycoprotein Mol identified with monoclonal antibodies. J. ImmunoL 137:3259.

9. Wright, S. D., S. M. Levin, M. T. C. Jong. Z. Chad, and L. G. Kabbash. 1989. CR3 (CDIllb/CD18) expresses one binding site for Arg-Gly-Asp-containing peptides and a second site for bacterial lipopolysaccharides. J. Exp. Med. 169:175.

10. Relman, D., E. Tuomanen, S. Faikow, D. T. Golenbock, K. Saukkonen, and S. D. Wright. 1990. Recognition of bacterial adhesin by an integrin: macrophage CD3 $\left(\alpha_{2} \beta_{2}\right.$, CD11b/CD18) binds filamentous hemagglutin of Bordetella pertussis. Cell 61:1375.

11. De Fougerolles, A. R., L. B. Klickstein, and T. A. Springer. 1993. Cloning and expression of intercellular adhesion molecule 3 reveals strong hornology to other immunoglobulin family counterreceptors for lymphocyte function-associated antigen I. J. Exp. Med. 177:1187.

12. Faweet, J., C. L. Holness, L. A. Needham, H. Turley, K. C. Gatter, D. Y. Mason, and D. L. Simmons. 1992. Molecular cloning of ICAM-3, a third ligand for LFA-1, constitutively expressed on resting leukocytes. Narure 360:481.

13. Dustin. M. L., R. Rothlein, A. K. Bhan, C. A. Dinarel-lo. and T. A. Springer. 1986. Induction by IL 1 and interferon- $\gamma$. tissue distribution. biochemistry, and function of a natural adherence molecule (ICAM-1). J. ImmunoL 137:245.

14. Newman. P. J., M. C. Berndt, J. Gorski, G. C. White II. S. Lyman, C. Paddock, and W. A. Muller. 1990.
PECAM-I (CD31) eloning and relation to adhesion molecules of the immunoglobulin gene superfamily. Science 247:1219.

15. Stockinger, H., S. J. Gadd et al. 1990. Molecular characterizationand functional analysis of the leako cyte surface protein CD31. J. Immunol 145:3889.

16. Tanaka, Y., S. M. Albeda et al. 1992. CD31 expressed on distinctive $\mathrm{T}$ cell subsets is a preferential amplifier of $\beta 1$ integrin-mediated adhesion. J. Exp. Med. 176:245.

17. Muller, W. A., S. A. Weigl, X. Deng, and D. M. Phil. lips. 1993. PECAM-1 is required for transendothelial migration of leukocytes. J. Exp. Med. 178:449.

18. Muller, W. A., M. E. Berman, P. J. Newman, H. M. Delisser, and S. M. Albeda. 1992. A heterophilic adhesion mechanism for platelet/endothelial cell adhesion molecule 1 (CD31). J. Exp. Med. 175:1401.

19. Bevilacqua, M. E. Butcher, B. Furie, B. Furie, M. Gallatin, M. Gimbrone, J. Harlan, K. Kishimoto, L. Lasky, R. McEver, J. Paulson, S. Rosan. B. Seed, M. Siegelman, T. Springer, L. Stoolman, T. Tedder, A. Varki, D. Wagner, I. Weissman, and G. Zimmerman. 1991. Selectins, a family of adhesion receptors. Cell 67:233.

20. Larsen, E. A. Celi, G. E. Gilbert, B. C. Furic, J. K. Erban, R. Bonfanti, D. D. Wagner, and B. Furie. 1989. PADGEM protein: a receptor that mediates the interaction of activated platelets with neutrophils and monocytes. Cell 59:305.

21. Geng, J. G. M. P. Bevilacqua, K. L. Moore, T. M. Mclntyre, S. M. Prescott, J. M. Kim, G. A. Bliss, G. A. Zimmerman, and R. P. MeEver. 1990. Rapid neutrophil adhesion to activated endothelium mediated by GMP-140. Nature 343:757.

22. Hattori, R, K. K. Hamilton, R. D. Fugates, R. P. McEver, and P. J. Sims. 1989. Stimulated secreton of cndothelial von Willebrand factor is accornpanied by rapid redistribution to the cell surface of the intracellular granule membrane protein GMP-140. J. Biol Chem. 264:7768.

23. Patel, K. D., G. A. Zimmerman, S. M. Prescott, R. P. McEver, and T. M. McIntyre. 1991. Oxygen radicals induce human endothelial eells to express GMP-140 and bind neutrophils. J. Cell. Biol. 112:749.

24. Bevilacqua, M. P., J. S. Pober, D. L. Mendrick, R. S. Cotran, and M. A. Gimbrone. 1987. Identification of an inducible endothelial-Ieukocyte adhesion molecule. Proc. Nail. Acad. Sci. USA 8d:9238.

25. Lecuwenberg. J. F. M., G. M. A. A. Jeunhomme, and W. A. Buurman. 1990. Adhesion of polymorphonuclear cells to human endothelial cells. Adhesionmolecule-dependent and Fe-receptor-mediated adhesion-molecule-independent mechanisms. Clin. Exp. Immunol. 81:496.

26. Lecuwenberg. J. F. M., T. M. A. A. Jeunhomme, and W. A. Buurman. 1992. Role of ELAM-1 in adhesion of monocytes to activated humin endothelial cells. Scand. J. ImmunoL 35:335. 
27. Shimizu, Y., S. Shaw, N. Graber, T. Venkat Gopal, K. J. Horgan, G. A. van Seventer, and W. Newman. 1991. Activation-independent binding of human memory T cells to adhesion molecule ELAM-1. Nature 349:799.

28. Jutila, M. A.. L. Rott, E. L. Berg, and E. C. Butcher. 1989. Function and regulation of the neutrophil MEL-14 antigen in vivo: comparison with LFA-1 and

MAC-1.

J. Immunol. 149:3.318.

29. Lasky, L. A., M. S. Springer, T. A. Yednock, D. Dowbenko, C. Fennie, H. Rodriguez, T. Nguyen, S. Stachel, and S. D. Rosen. 1989. Cloning of a lymphocyte homing receptor reveals a lectin domain. Cell 56:1045.

30. Brandley, B. K., S. J. Swiedler, and P. W. Robbins. 1991. Carbohydrate ligands of the LEC Cell Adhesion Molecules. Cell 63:681.

31. Larsen, G. R., D. Sako, T. J. Ahern, M. Shaffer, 1. Er-ban, S. A. Sajer, R. M. Gibson, D. D. Wagner, B. C. Furie, and B. Furic. 1992. P-selectin and E-selectin. Distinct but overlapping ligand specificities. J.BiolChem. 267:11104.

32. Foxall, C., S. R. Watson, D. Dowbenko, C. Fennie, L. A. Lasky, M. Kismo, A. Hasegawa, D. Asa, and B. K. Brandley. 1992. The three members of the selectin receptor fumily recognize a common carbohydrate epitope, the sialy! Lewis(x) oligosaccharide. J. Cell BioL 117:895.

33. Picker, L. J., R. Aaron Warnock, A. R. Burns, C. M. Doerschuk. E. L. Berg, and E. C. Butcher. 1991. The neutrophil selectin LECAM-1 presents carbohydrate ligands to the vaseular selectins ELAM1 and GMP-140. Cell 66:921.

34. Kishimoto, T. K., R. A. Wamock, M. A. Jutila, E.C. Butcher, C. Laune, D. C. Anderson, and C. W. Smith. 1991. Antibodies against human neutrophil LECAM-1 (L.AM-1/Leu-8/DREG-56 antigen) and endothelial cell ELAM-1 inhibit a common CD18-independent adhesion pathway in vitro. Blood 78:805. 35. Moser, R., B. Schleiffenbaum, P. Groscurth, and J. Fehr. 1989. Interleukin 1 and tumor necrosis factor stimulate human vascular endothelial cells to promote transendothelial neutrophil passage. J. Clin. Invest. 83:444.

36. Lawrenee, M. B., C. W. Simith, S. G. Eskin, and L. V. Mclntire 1990. Effect of venuus shear stress on CD/8̈-mediated neutrophil athesion to eultured endothelium. Blood 75:227.

37. Lawrence, M. B., and T. A. Springer. 1991. Leukocytes roll on a solectin at physiologic flow rates: distinction from and prenequisit for adhesion through integrins. $C+1 / 65: 859$.

38. Arfors, K. - E., C. Lundberg, L. Lindborn, K. Lundberg. P. G. Bcatty, and J. M. Harlan. 1987. A monoclonal ancibody to the mumbrane glycoprotein complex CD18 inhibits polymorphonuclear leukosyte accumulation and plasma leakege in vivo. Blood 69:738.

39. Smith, C. W., R. Rothlein, B. J. Hughes, M. M. Mariscalco, H. E. Rudloff, F. C. Schmalsticg, and D. C. Anderson. 1988. Recognition of an endo- thelial cell determinant for CD18-dependent human neutrophil adherence and transendotbelial migration. J. Clin. Invest. 82:1746.

40. Vedder, N. B., and J. M. Harlan. 1988. Increased surface expression of CDIlb/CDI8 (Mac-1) is not required for stimulated neutrophil adherence to cul. tured endothelium. J. Clin. Invest. 81:676.

41. Todd, R. F., III, M. A. Amaout, R. E. Rosin, C. A. Crowly, W. A. Peters, and B. M. Babior. 1984. Subcellular localization of the large subunit of Mol (Mol alpha; formerly gp 110), a surface glycoprotein associated with neutrophi! adhesion. J. Clin. Invest. 74:1280.

42. Forsyth, K. D., and R. J. Levinsky. 1989. Role of LFA- 1 adhesion glycoprotein in neutrophil adhesion to endothelium and plastic surfaces. Clin. Exp. Imm. 75:265.

43. Lo, S. K., G. A. van Seventer, S. M. Levin, and S. D. Wright. 1989. Two leukocyte receptors (CD11a/ CD18 and CD1 lb/CD18) mediate transient adhesion to endothelium by binding to different ligands. J. Immunol 143:3325.

44. Dustin, M. L., and T. A. Springer. 1988. Lymphocyte function associated antigen-1 (L.FA-1) interaction with intercellular adhesion molecule-1 (ICAM-1) is one of at least three mechanisms for lymphocyte adhesion to cultured endothelial cells. J. Cell BioL 107:321.

45. Hibbs, M. L., H. Xu, S. A. Stacker, T. A. Springer. 1991. Regulation of adhesion to ICAM-1 by the cytoplasmic domain of LFA-1 integrin $\beta$ subunit. Science 251:1611.

46. Hughes, B. J., J. C. Hollers, E. Crockett-Torabi, and C. W. Smith. 1992. Recruitment of CDI1b/CD18 to the neutrophil surface and adherence-dependent locomotion. J. Clin. Invest 90:1687.

47. Dobrina, A., B. R. Schwarz, T. M. Carlos, H. D. Ochs, P. G. Beatty, and J. M. Harlan. 1989. CD11/CD18-independent neutrophil adherence to inducible cndothelial-leucocyte adhesion molecules (E-LAM) in vitro. Immunology 67:502.

48. Kuijpers, T. W. B. C. Hakken, M. Hoogerwerf, J. F. M. Leeuwenberg, and D. Roos. 1991. Role of endothelial leukocyte adhesion molecule- 1 and platelet-activating factor in neutrophil adherence to IL-1prestimulated endothelial cells. J. ImmunoL 147:1369.

49. Worthen, G. S, L. A. Smedly, M. G. Tonnessen, D. Ellis, N. F. Veelkel, J. T. Reeves, and P. M. Henson. 1987. Effect of shear stress on adhesive interaction between neutrophils and cultured endothelial cells. J. AppL Physiol 63:2031.

50. Mcintyre, T. M., G, A. Zimmerman, K. Satoh, and S. M. Prescont. 1985. Culured buman endothelial cells synthesize both platelet-activating factor and prostacyclin in response to histamine, bradykinin, and ATP. J. Clin. Imvest. 76:271.

51. Prescolt, S. M., G. A. Zimmerman, and T. M. McIntyre. 1984. Humatn endothelial cells in culture pro duce platelet-activating factor (1-alkyl-2-acetyl-snglycero-3-phosphocholine) when stimulated with thrombin. Prac. Nall Acad Sci USA 81:3534. 
52. Lewis, M.S., R.E. Whatley, P.C. Cain, T.M. MeIntyre. S. M. Prescott, and G. A. Zimmerman. 1988. Hydrogen peroxide stimulates synthesis of plateletactivating factor by endothelium and induces endothelial cell dependent neutrophil adhesion. J. Clin. Invest. 82:2045.

53. Lorant, D.E., K.D. Patel, T.M. Melntyre, R.P. McEver, S. M. Prescoth, and G. A. Zimmerman. 1991. Coexpression of GMP-140 and PAF by endothelium stimulated by histamine or thrombin: a juxtacrine system for adhesion and activation of neutrophils. $J$. Cell Biol 115:223.

54 Toothill, V. J., J. A. van Mourik, H. K. Nieuwenhuis, M. J. Metzelaar, and J. D. Pearson. 1990. Characterization of the enhanced adhesion of neutrophil leukocytes to thrombin-stimulated endothelial cells. J. Immunol 145:283.

55 Zimmerman, G. A., T. M. McIntyre, M. Mehra. and S. M. Prescolt. 1990. Endothelial cell-associated platelet-activating factor, a novel mechanism for signalling intercellular adhesion. J. Cell Biol 110:529.

56. Kuijpers, T. W., B. C. Hakker, M. H. L. Hart, and D. Roos. 1992. Neutrophil migration across monolayers of eytokine-prestimulated endothelial cells: a role for platelet-activating factor and for IL-8. J. Cell BioL 117:565.

56b. Bussolino, F, F. Brevario, C. Tetta, M. Anglieta, M. Mantovani, and E. Dejana. 1986. Interleukin 1 stimulates platelet activating factor production in cultured human endothelial cells. J. Clin. Invest. 77:2027.

S6c. Bussolino, F. G. Camussi, C. Tetta, G. Garbarino, A. Bosia, and C. Baglioni. 1990. Selected cytokines promote the synthesis of platelet-activating factor in vascular endothelial cells: comparison between tumor necrosis factor alpha and beta and interleukin-1. J. Lipid. Mediat 2Suppl:S15.

57. Baggiolini, M., A. Walz, and S. L. Kunkel. 1989. Neutrophil-activating peptide-1/interleukin 8, a novel cytokine that activates neutrophils. J. Clin. Invest. 84:1045.

58. Carveth, H. J., J. F. Bohnsack, T. M. Mclntyre, M. Baggiolini, S. M. Prescott and G. A. Zimmerman. 1989. Neutrophil activating factor (NAF) induces polymorphonuclear leukocyte adherence to endothelial cells and to subendothelial matrix proteins. Biochem. Biophys. Res. Comm. 162:387.

59. Detmers, P. A., S. K. Lo. E. Olsen-Egber, A. Walz, M. Baggiolini, and Z. A. Cohn. 1990. Neutrophilactivating protein 1 /interleukin 8 stimulates the binding activity of the leukocyte adhesion receptor CD11b'CD18 on human neutrophils. J. Exp. Med. 171:1155.

60. Lo, S. K., S. Lee, R. A. Ramos, R. Lobb, M. Rosa, G. Chi-Rosso, and S. D. Wright. 1991. Endothelialleukocyte adhesion molecule 1 stimulates the adhesive activity of leukocyte integrin CR3 (CD1 1b/CD18, Mac-1, $\alpha_{4} \beta_{2}$ ) on humanneutrophils. J. Exp. Med. 173:1493.

61. Carter, S. B.. 1965. Principles of cell motility: The direction of cell movement and cancer invasion. Nature, 208:1183.
62. Huber, A. R., S. L. Kunkel, R. F. Todd, III, and S. J. Weiss. 1991. Regulation of transendothelial migration by endogenous interleukin-8. Science 254:99.

63. Smith, C. W., T. K. Kishimoto, O. Abbass, B. Hug hes, R. Rothlein, L. V. Mclntire, E. Butcher, and D. C. Anderson. 1991. Chemotactic factors regulate lectin adhesion molecule I (L.ECAM-1)-dependen? neutrophil adhesion to cytokine-stimulated endothelial celts in vitro. J. Clin. Imvest. 87:609.

64. Kishimoto, T. K., M. A. Jutila, E. L. Berg, and E. C. Butcher. 1989. Neutrophil Mac-1 and MEL-14 athesion proteins inversily regulated by chemotacticfactors. Science 245:1238.

65. Luscinskas, F, J-M Kiely, H. Ding, M. S. Obin, C. Heber, J. B. Baker, and M. A. Gimbrone. 1992. In vitro inhibitory effect of IL-8 and other chemoatractants on neutrophil-endothelial adhesive interactions. J. Immanol 149:2163.

66. Marchesi, V. T. 1961. The site of leucocyte emigration during inflammation. J. Exp. Physiol. 46:115.

67. Tavassoli, M. 1979. The narrow-bloxd barrier. Br. J. Haematol. 41:297.

68. Srnith, C. W., R. Rothlein, B. J. Hughes, M. M. Mariscalco, H. E. Rudloff, F. C. Schmalstieg. and D. C. Anderson. Recognition of an endothelia] cell determinant for CD 18-dependent human neutrophil adherence and transendothelial migration. J. Clin. Invest. 82:1746.

69. Furic, M. B., and D. D. McHugh. 1989. Migration of neutrophils across endothelial monolayers is stimu lated by treatment of the monoayers with interleukin. lor tumor necrosis factor. J. ImmunoL 143:3309.

70. Hakkert, B. C., T. W. Kuijpers, J. F. M. Leeuwenberg, J. A. van Mourik, and D. Roos. 1991. Neutrophil and monocyte adherence to and migration across monolayers of cytokine-activated endothelial cells: the contribution of CD18, ELAM-1, and VLA-4. Blood 78:2721.

71. Furie, M. B., M. J. Burns, M. C. Tancinco, C. D. Benjamin and R. R. Lobb. 1992. E-selectin (endothelialIcukocyte athesion molecule-i) is not required for the migration of neutrophils across $\Pi$ - - l-stimulated endothelium in vitro. J. ImmunoL 148:2395.

72. Drake, W. T., N. N. Lopes. J. W. Fenton II, and A. C. Issekuth. 1992. Thrombin enhancenent of interleukin- 1 and tumor necrosis factor- $\alpha$ induced polymorphonuclear leukocyte migration. Lab. Invest. 67:617.

73. Moser, R., P. Groscurt, and J, Fehr. 1990. Promotion of transendothelial neutrophil passage by thrombin. J. Cell Sci. 96:737.

74. Gibbs, L. S., L. Lai and A. B. Malik. 1990. Tumor necrosis factor enhances the neutrophil-dependent increase in endothelial permeability. J. Cell. PhysioL 145:496.

75. von Asmuth, E. J. U., C. J. van der Linden, J. F. M. Leeuwenberg and W. A. Buurman. 1991. Involvement of the CDIIbCD18 integrin, but not of the endothelial cell adhesion molecules ELAM- 1 and ICAM-I in tumor necrosis factor- $\alpha$ induced neutrophil toxicity. J. Immanol. 147:3869. 
76. vori Asmuth, E. J. U, and W. A. Butrman. Endothelial cell associated platelet-activating factor (PAF), a costimulatory intermediate in turnor necrosis factor- $\alpha$ (TNF- $\alpha$ ) induced $\mathrm{H}_{2} \mathrm{O}_{2}$, release by adherent neutrophil leukocytes J.Immunoh in press.

77. Malech, H. L., and J. I. Gallin. 1987. Neutrophils in human diseases. New Engl. J. Med. 317:687.

78. Henson, M. P., and R. B. Johnston Jr. 1987. Tissue injury in inflammation: oxidants, proteinases, and cationic proteins. J. Clin. Invest. 79:669.

79. Weiss, S. J.. 1989. Tissue destruction by neutrophils. New EngL J. Med. 320:365.

80. Maraseo, W. A., S. H. Phan, H. Knutzch, H. J. Showell, D. E. Fletner, R. Naim, E. L. Becker, and P. A. Ward. 1984. Purification and identification of formyl-methionyl-leucyl-phenylalanine as the major peptide neutrophil chemotactic factor produced by Escherichia coli. J. Biol Chem. 259:5430.

81. Carp, H. 1982. Mitochondrial N-formylmethionyl proteins as chemoattractants for neutrophils. J. Exp. Med. 155:264.

82. Becker. E. L.. 1990. The short and happy life of neutrophil activation. J. Leuk. BioL 47:378.

83. Wallace, P. J., R. P. Wersto, C. H. Packman, and M.A. Lichtman. 1984.Chemotactic peptide-induced chan-ges in neutrophil actin conformation. J. Cell Biol 99:1060.

84. Zigmond, S. H., and S. J. Sullivan. 1979. Sensory adaptation of leukocytes to chemotactic peptides. J. Cell Biol. 82:517.

85. Howard, T. H., and C. O. Oresajo. 1985. The kinetics of chemotactic peptide-induced change in $\mathrm{F}$-actin content, F-actin distribution, and the shape of neutrophils. J. Cell BioL 101:1078.

86. Howard, T. H. D. Wang, and R. L. Berkow. 1990. Lipopolysaccharide modulates chemotactic peptideinduced actin polymerization in neutrophils. J. Leuk. Biol. 47:13.

87. Berkow, R. L., D. Wang, J. W. Larrick, R. W. Dodson, and T. H. Howard. 1987. Enhancement of neutrophil superoxide production by preincubation with recombinant human tumor necrosis factor. J. I $\mathbf{m m u}$ noL 139:3783.

88. Westlin, W. F., J-M. Kiely, and M. A. Gimbrone. 1992. Interleukin-8 induced changes in human neutrophil actin conformation and distribution: relationship to inhibition of adhesion to cytokine-activated endothelium. J. Leuk. BioL 52:43.

89. Downey, G. P., E. L. Elson, B. Schwab III, S. C. Erzurum, S. K. Young, and G. S. Worthen. 1991. Biophy. sical properties and microfilament assernbly in neutrophils: modulation by cyclic A.MP. J. Cell Biol. 114:1179.

90. Worthen, S. C., B. Schwab III, E. L. Elson, and G. P. Downey. 1989. Mechanics of stimulated neutrophils: cell stiffening induces retention in capillaries. Science 245:183.

91. Glazier, J. B., J. M. Hughes, J. E. Maloncy, and J. B. West. 1969. Measurements of capillary dimensions and blood volume in rapidly frozen lungs. J. Apph Physiol. 26:65.

92. Beyers, N. C. M. Doerschuk, H. Coxson, and
J. C. Hogg. 1989. Neutrophil volume and capillary segment diameter in the rabbit, the dog. and the human (Abstract), Am. Rev. Resp. Dis. 139:A297.

93. Selby, C., E. Drost, P. K. Wraith, and W. MacNee. 1991. In vivo neutrophil sequestration within the lungs of humans is deternined by in vitro "filterability". J. AppL Physiol 71:1996.

94. Erzurum, S. C., G. P. Downey, D. E. Doherty, B. Schwab III, E. L. Elson, and G. S. Worthen. 1992. Mechanisms of lipopolysaccharide-induced neutrophil retention; relative contributions of adhesive and cellular mechanical properties. J. ImmunoL 149:154.

95. Kajita, T., and T. E. Hugli. 1990. C5a-induced neutrophilia; a primary humoral mechansim for requitment of neutrophils. Am. J. Nephrol. 137:467.

96. Haslen, C, G. S. Worthen, P. C. Giclas, D. C. Morrison, J. E. Henson, and P. M. Henson. 1987. The pulmonary vascular sequestration of neutrophils in endotoxemia is initiated by an effect of endotoxin on the neutrophil in rabbits. Am. Rev. Resp. Dis. 136:9.

97. Van Zee, K. J., E. Fischer, A. S. Hawes, C. A. Hebert, T. G. Terrell, J. B. Baker, S. F. Lowry, and L. L. Moldawer. 1992. Effects of intravenous IL-8 administration in nonhuman primates. J. ImmunoL 148:1746.

98. Hechtman, D. H., M. I. Cybulsky, H. J. Fuchs, J. B. Baker, and M. A. Gimbrone, Jr. 1991. Intravascular IL-8; inhibitor of polymorphonuclear leukocyte accurnulation at sites of acute inflammation. $J$. Immunol 147:883.

99. Webster, R. O., G. L. Larsen, B. C. Mitchel, A. J. Goins, and P. M. Henson. 1982. Absence of inflammatory lung injury in rabbits challenged intravascular with complement derived chemotactic factors. Am. Rev. Respir. Dis. 125:335.

100. O'Flaherty, J. T., H. J. Showell, and P. A. Ward. 1977. Neutrophenia induced by systemic infusion of chemotactic factors. J. Immunol. 118:1586.

101. Van Epps, D. E., and M. L. Garcia. 1980. Enhancement of neutrophil function as a result of prior exposure to chemotactic factor. J. Clin. Invest. 66:167.

102. Sample, A. K. C. J. Czuprynski. 1991. Priming and stimulation of bovine neutrophils by recombinant human interleukin-1 alpha and tumor necrosis factor alpha. J. Leuk, Biol 49:107.

103. Yuo, A, S. Kitagawa, A. Ohsaka, M. Saito, and F. Takaku. 1990. Stimulation and priming of human neutrophils by granulocyte colony-stimulating factor and granulocyte-maerophage colony-stimulating factor: qualitative and quantitative differences. Biochem. Biophys. Res. Commun. 171:491.

104. Shappell, S. B., C. Toman, D. C. Anderson, A. A. Taylor, M. L. Entman and C. W. Smith. 1990. Mac-1 (CDIlb/CDI8) mediates adherence-dependent hydrogen peroxide production by human and canine neutrophils. J. Immunol. 144:2702.

105. Cohen, H. J., and M. E. Chovaniec. 1978. Superoxide generation by digitonin-stimulated guinea pig granulocytes. J. Clin. Invest. 61:1081.

106. Dahinden, C. A., J. Fehr, and T. E. Hugli. 1983. Role of cell surface contact in the kinetics of superoxide production by granulocytes. J. Clin. Invest. 72:113. 
107. Dri, P., R. Cramer, M. Romano, P. Spessotto, and P. Patriaca. 1991. Effect of biological surfaces on neutrophil $\mathrm{O}^{2}$ production and its releationship to the CD $11 \mathrm{~b} / \mathrm{CD} 18$ integrin-dependent adherence. Imt. J. Tissue React. 13:193.

108. Lo, S. K., P. A. Detmers, S. M. Levin, and S. D. Wright. 1989. Transient adhesion of neutrophils to endothclium. J. Exp. Med. 169:1779.

109. Boxer, L. A., M. Yoder, S. Bonsib, M. Schmidt, P. Ho, R. Jersild, and R. L. Bachner. 1979. Effects of a chemotactic factor, N-formylmethionyl peptide, on adherence, superoxide anion generation, phagocytosis, and microtubule assembly of human polymorphonuclear leukocytes. J. Lab. Clin. Med. 93:905.

110. Wright, S. D., P. A. Detmers, Y. Aida, R. Adamowski, D. C. Anderson, 2. Chad, L. G. Kabbash, and M. J. Pabst. 1990. CD18-deficient cells respond to lipopolysaccharide in vitro. J. ImmunoL 144:2566.

111. Oliver, J., R. Lalchandani, and E. Becker. 1977. Actín redistribution during conconavalin $A$ cap formation in rabbit neutrophils. J. Reticuloendothel Soc. 21:359.

112. Zigmond, S. H. 1977. Ability of polymorphonuclear leukocytes to orient in gradients of chemotactic fuctors. J. Cell. BioL 75:606.

113. Grimes, G. J., and F. S. Bames. 1973. A technique for studying chemotaxis in well defined chemotactic ficlds. Exp. Cell Res. 29:375.

114. Fehr, J., and C. Dahinden. 1979. Modulating influence of chemotactic factor-induced cell adhesiveness on granulocyte function. J. Clin. Invest. 64:8.

115. McPail, L. C., C. C. Clayton, and R. Snyderman. 1984. The NADPH oxidase of human polymorphonuclear leukocytes. J. Biol Chem. 259:5768.

116. Schroeder, J. M., U. Mrowietz, E. Morita, and E. Christophers. 1987. Purification and partial biochemical characterization of a human monocytederived, neutrophil-activating peptide that lacks interleukin 1 activity. J. ImmunoL 139:3474.

117. Bender, J. G., L. C. McPail, and D. E. van Epps. 1983. Exposure of human neutrophils to chemotactic factors potentiates activation of the respiratory burst enzyme. J. Immunol 130:2316.

118. Mrowietz, U., J-M. Schröder, J. Brasch, and E. Christophers. 1992. Infiltrating neutrophils differ from circulating neutrophils when stimulated with C5a, NAP1/LL-8, LTB, anf FML.P. Scand. J. Immunol, 35:7I.

119. Bainton, D. F., L. J. Miller, T. K. Kishimoto, and T. A. Springer. 1987. Leukocytc adhesion receptors are stored in peroxidase-negative granules of human neutrophils. J. Exp. Med. 166:I64I.

120. Francis, J. W., R. F. Todd, L. A. Boxer, and H. R. Petty. 1989. Sequential expression of cell surface C3bi receptors during neutrophil locomotion. J. Cell Physiol 140:519.

$120 \mathrm{bJutila}$, M. A., L. Rott, E. L. Berg, and E. C. Butcher. 1989. Function and regulation of the neutrophil MEL-14 antigen in vivo: comparison with LFA-1 and MAC-1.J. Immunol 143:3318.

121. Rosen, H, and S. Gordon. 1987. Monoclonal antibody to the murine type 3 complement receptor inhibits adhesion of myelomonocytic cells in vitro and inflammatory recruitment in vivo. J. Exp. Med. 166:1685.

122. Rosen, H.. 1990. Role of CR3 in induced myelomonocytic recruitment: insights from in vivo monoclonal antibody sndies in the mouse. J. Leukocyle BioL 48: 465 .

123. Furie, M. B., M. C. A. Tancinco, C. W. Smith. 1991. Monoclonal antibodics to leukocyte integrins CDI $I$ / CD18 and CD11b/CD18 or intercellular adhesion molecule-1 (ICAM-1) inhibit chemoattractant-stimulated neutrophil transendothelial migration in vitro. Blood 78:2089.

124. Anderson, D. C., R. Rothlein, S. D. Marlin, S. S. Krater, and C. W. Smith. 1990. Impaired transendothelial migration by neonatal neutrophils: abnormalities of Mac-1 (CD1lb/CD18)-dependent adherence reactions. Blood 78:2613.

125. Kuijpers, T. W., L. Koendeman, R. S. Weening. A. J. Verbocven, and D. Roos. 1990. Continuous cell activation is necessary for stable interaction of complement receptor type 3 with its counter-stricture in the aggregation response of human neutrophils. Eur. J. ImmunoL 20:501.

126. Kuijpers, T. W., E. P. J. Mul, M. Blom, N. L. Kovach, F. C. A. Gaeta, V. Tollefion, M. J. Elices, and J. M. Harlan. 1993. Freezing adhesion molecules in a state of high-avidity binding blocks cosinophil migration. J. Exp. Med. 178:279.

127. Zigmond, S. H., H. I. Levirsky, and B. J. Kreel. 1981 Cell polarity: an examination of its behavioural expression and its concequences for polymorphonaclear leukocyte chemotaxis. J. Cell Biol. 89:585.

128. Alt, W. 1980. Biased random walk models for chemotaxis and related diffusion approximations. $\mathbf{J}$. Math. Biol. 9:147.

129. NacNab. R. M., and D. E. Koshland, Jr. 1972. Gradient-sensing machanisms in bacterial chemotaxis. Proc. Nall Acad. Sci. USA 69:2509.

130. Zigmond. S. H., and J. G. Hirsch. 1972. Effects of cytochalasin B on polymorphonuclear leukocyte locomotion, phagocytosis and glycolysis. Exp. Cell Res. 73:383.

131. Slowell, H, J, R. J. Freer, S. H. Zigmond, E. Schiffrnann, S. Aswanikumar, B. Corcoran, E. L. Becker. 1976. The structure relations of synthetic peptides as chemotactic factors and inducers of lysosomal enzyme secretion for neutrophils, J. Exp. Med. 143:1154.

132. Lehmeyer, J. E., R. Snydernoan, and R. B. Johnston Jr. 1979. Stimulation of neutrophil oxidative metab olism by chemotactic peptides: influence of calcium ion concentration and cytochalasin $B$ and comparison with stimulation by phorbol myristate acetate. Blood 54:35.

133. Iyer, G. Y. N., D. M. F. Islam, and J. H. Quastel. 196! Biochemical aspects of phagocytosis. Nature 192:535.

134. Karnovsky, M. L.. 1968. The metaholism of leukocytes. Semin. Hematol 5:156.

135. DeChatelet. L. R.. 1978. Initiation of the respiratory burst in human polymorphonuclear leukocytes: a critical revicw. J. Reticolendothel Soc. 24:73. 
136. Hatch, G. E. D. E. Gardner, and D. B. Menzel. 1978. Chemiluminescence of phagocytic cells caused by $n$ fornnylmethionyl peptides. J. Exp. Med. 147:182.

137. Curnutte, J. T., and B. M. Babior. 1974. Biological defence mechanisms. The effect of bacteria and serum on superoxide production by granulocytes. J. Clin. Invest. 53:1662.

138. Goldstein, I.M., D. Roos, H.B. Kaplan, and G. Weissmann. 1975. Complementand immunoglobulins stimulate superoxide production by human leukocytes independently of phagocytosis. J. Clin. Invest. 56:1155.

139. Nathan, C. F. 1987. Neutrophil activation on biological surfuces. J. Clin. Invest. 80:1550.

140. Nathan, C., S. Srimal, C. Farber, E. Sanchez, L. Kabbash, A. Asch, J. Gailit, and S. D. Wright. 1989. Cytokine-induced respiratory burst of human neutrophils: dependence on extracellular matrix protcins and CD11/CD18 integrins. J. Cell BioL 109:1341.

141. Nathan, C. F.. 1989. Respiratory burst in adherent human neutrophils: triggering by colony-stimulating factors CSF-GM and CSF-G. Blood 73:301.

142. Nathan, C., and E. Sanchez. 1990. Tumor Necrosis Factor and $C D I / / C D 18\left(\beta_{2}\right)$ integrins act synergistcally to lower eAMP in human neutrophils. $J$. Cell Biol. 111:2171.

143. Nathan, C., Q. Xic, L. Halbwachs-Mecarelli, and W. W. Jin. 1993. Albumin inhibits neutrophil spreading and hydrogen peroxide release by blocking the shedàing of CD43 (sialophorin, leukosialin). J. Cell Biol. 122:243.

144. Dahinden, C. C. Galanos, and J. Fehr. 1983. Granulocyte activation by endotoxin. I. Correlation between adherence and other gramulocyte functions, and role of endotoxin structure and biologic activity. J. I mmunoL 130:857.

145. Dahinden, C., and J. Fehr, 1983. Granulocyte activation by endotoxin. II. Role of granulocyte adherence, aggregation, and effect of cytochalasin B, and comparison with chemotactic peptide-induced stimulation. J. ImmunoL 130:863.

146. Fehr, J., R. Moser, D. Leppert, and P. Groscurth. 1985. Antiadhesive properties of biological surfaces are protective against stimulated granulocytes. J. Clin. Invest. 76:535.

147. Kownatzki, E., and S. Uhrich. 1987. Differential effects of nylon fibre adherenee on the production of superoxide anion by human polymorphonuclear neu= trophilic granulocytes stimulated with chemountractants, ionophore A23187 and phorbol myristate acetate. Clin. Exp. ImmunoL 69:213.

148. Kownatzki, E., A. Kapp, and S. Uhrich. 1988. Mudulation of human neutrophilic granulocyte functions by recombinam human tumor nccrosis factor and recombirant human lymphotoxin. Promotion of adherence, inhibition of chemotactic migration and superoxide anion release from adherent cells. Clin. Exp. Immunol. 74:143.

149. Kapp, A., G. Zeck-Kapp, M. Danner, and T. A. Luger. 1988. Human granulocyle-macrophage colony stimulating factor: an effective direct activator of human polymorphonuclear neutrophilic granulocytes. J. Invest Dermatol. $91: 49$.
150. Neumann, M., and E. Kownatzki. 1989. The effect of adherence on the generation of reactive oxygen species by human neutrophilic granulocytes. Agents and Actions 26:183.

151. Kapp, A., G. Zeck-Kapp, and D. Blohm. 1989. Human tumor necrosis factor is a potent activator of the oxidative metabolism in buman polymorphonuclear neutrophilic granulocytes: comparison with human lymphotoxin. J. Invest. Dermatol. 92:348.

152. Kownatzki, E, and S. Uhrich. 1990 . Production of superoxide anion and hydrogen peroxide by human neutrophilic granulocytes during ehemotactic migration towards f-Met-Leu-Phe, C5a, leukotriene $\mathrm{B}_{3}$. monocyte derivedchemotaxin/IL-8 and platelet activating factor. Int. Arch. Allergy AppL Immunol 93:344.

153. Johnston, R. B., Jr., and J. E. Lehmeyer. 1976. Elaboration of toxic oxygen by-products by neutrophils in a model of immune complex disease. J. Clin. Invest. $57: 836$.

154. Soutbwick, F. S., G. A. Dabiri, M. Paschetto, and S. H. Zigmond. 1989. Polymorphonuclear leukocyte adherence induces actin polymerization by a transduction pathway which differs from that used by chemoattractants. J. Cell Biol. 109:1561.

155. Laudanna, C., S. Miron, G. Berton, and F. Rossi. 1990. Tumor necrosis factor- $\alpha /$ cachectin activates the $\mathrm{O}_{2}$ gencrating system of human neutrophils independently of the hydrolysis of phosphoinositides and the release of arachidonic acid. Biochem. Biophys. Res. Commun. 166:308.

156. Schleiffenbaum, B., and J. Fehr. 1990. The tumor necrosis factor receptor and neutrophil function. J. Clin. Invest. 86:184.

157. Brown, A. F.. 1984. Neutrophil and monocyte behaviour in three-dimensional matrices. Scanning Electron Microscopy II:747.

158. Zigmond, S. H., and J. G. Hirsch. 1972. Effects of cytochalasin B on polymorphonuclear leukocyte locomotion, phagocytosis and glycolysis. Exp. Cell Res. 73:383.

159. Woodman, R.C.. J.M. Ruedi, A.J. Jesaitis, N. Okamura, M.T. Quinn, R.M. Smith, J.T. Cumutte, and B.M. Babior. 1991. Respiratory burst oxidase and three of four oxidase-related polypeptides are associated with the cyto skeleton of human neutrophils. J. Clin. Inversh. 87:1345.

160. Entmin, MI.L., K. Youker, S. B. Shappell, C. Siegel, R. Rothlein, W. J. Dreycr, F. C. Schmalstieg, and C. W. Sinith. 1990. Neutrophil adberence to isolated canine myocytes. Evidence for a CDI8-dependent mechanism. J. Clin. Invest. 85:1497.

161. Noesel, C. van, F. Micuemi, M. Brouwer, M. A. de Rje. L. A. Aarden, and R. A. W. van Lier. 1988. Regulatory properties of LFA-1 alpha and beta chains in human T-lymphocytc acivation. Noture 33.3:850.

162. Wacholtz, M. C., S. S. Patel, and P. E. Lipsky. 1989. Leukocyte function-associated antigen 1 is an activation molecule for human T cells. J. Exp. Med. I70:431.

163. Pardi, R., J. R. Bender, C. Dettori, E. Giannazza, and E. G. Engleman. 1989. Heterogenous distribution and 
transmembrane signalling properties of lymphocyte function-associated antigen (LFA-1) in human lymphocyte subsets. J. Immunol 143:3157.

164. Richter, J., J. Ng-Sikorski, I. Olsson, and T. Andersson. 1990. Tumor necrosis factor-induced degranulation in adherent human neutrophils is dependent on CD11b/CD18-integrin-triggered oscillations of cytosolic free $\mathrm{Ca}^{2+}$. Proc.Nall. Acad. Sci. USA 87:9472.

165. Berton, G., C. Laudanna, C. Sorio, and F. Rossi. 1992. Generation of signals activating neutrophil functions by leukocyte integrins: LFA-1 and gp 150/ 95, but not CR3, are able to stimulate the respiratory burst of buman neutrophils. J. Cell BioL 116:1007.

166. Abrahamson, H. A.. 1927. The mechanism of the inflammatory process. 1. The electrophoresis of the blood cells of the horse and its releation to leukocyte emigration. J. Exp. Med. 46:987.

167. Carnpanero, M. R., R. Pulido, J. L. Alonso, J. P. Pivel, F. X. Pimental-Muiños, M. Fresno, and F. SánchezMadrid. 1991. Down-regulation by tumor necrosis factor- $\alpha$ of neutrophil surface expression of the sialophorin CD43 and the hyaluronate receptor CD44 through a proteolytic mechanism. Eur. J. ImmunoL. 21:3045.

168. Rieu, P., F. Porteu, G. Bessou, P. Lesavre, and L. Halbwachs-Mecarelli. 1992. Human ncutrophils release their major membrane sialoprotein, leukosialin (CD43). during cell activation. Eur. J. Immunol. 22:302I.

169. Kuijpers, T. W. M. Hoogerwerf. K. C. Kuijpers, B. R. Schwartz, and J. M. Harlan. 1992. Cross-linking of sialophorin (CD43) induces neutrophil aggre. gation in a CD18-dependent and a CD18-independent way. J. ImmunoL 149:998.

170. Cyster, J. G., D. M. Shotton, and A. F. Williams. 1991. The dimension of the T lymphocyte glycoprotein leukosialin and identification of linear epitopes that can be modified by glycosylation. $E M B O J$. 10:893.

171. Remold-O'Donnell, E., and F. S. Rosen. 1990. Sialophorin (CD43) and the Wiskott-Aldrich syndrome. Immunodefic. Rev. 2:151.

172. Keller, H. U.. 1966. Studies on chemotaxis. III Modification of Boyden's technique for the evaluation of chemotactic agents. Immunology 10:225.

173. Keller, H. U., S. Barandun, P. Kistler, and J. S. Ploem. 1979. Locomotion and adhesion of neutrophil granulocytes. Effects of albumin. fibrinogen and gamma globulin studied by reflection contrast microscopy. Exp. Cell Res. 122:351.

174. Valerius, N. H. 1983. Chemotaxis, spreading and oxidative metabolism of neutrophils: influence of albumin in vitro. Acta Pathol Microbiol Scand. Sect. C Immunol 91:-43.

175. Zimmerli, W., A-M. Reber, and C. A. Dahinden. 1990. The role of formylpeptide receptors, C5a receptors, and cytosolic-free calcium in neutrophil priming. J. Infect. Dis. 161:242.

176. van Epps, D. E., S. Simpson, J. G. Bender, and D. E. Chenoweth. 1990. Regulation of C5a and formyl peptide receptor expression on human polymorphonuclear leukocytes. J. Immunol 144:1062.
177. Gasson, J. C., R. H. Weisbart, S. E. Kaufman, S. C. Clark, R. M. Hewick, G. G. Wong, and D. W. Golde. 1984. Purified human granulocyte-macrophage colony-stimulating factor: direct action on neutrophils. Science 226:1339.

178. Salycr, J. L., J. F, Bohnsack, W. A. Knape, A. O. Shigeoka, E. R. Ashwood, and H. R. Hill. 1990. Mechanims of tumor necrosis factor- $\alpha$ alteration of PMN adhesion and migration. Am. J. Pathol 136:831.

179. Shalaby, M. R., M. A. Palladino, Jr, S. E. Hirabayashi, T. E. Eesalu, G. D. Lewis, H. M. Shepard, and B. B. Aggarwal. 1987. Receptor binding and activation of polymorphonuclear neutrophils by tumor necrosis factor-alpha. J. Leuk. BioL 41:196.

180. Ferrante, A. M. Nandoskar, A. Walz, D. H. B. Goh, I. C. Kowanko. 1988. Effects of tumor necrosis factor ajpha and interleukin- 1 alpha and beta on human neutrophil migration, respiratory burst and degranula tion. Int. Arch. Allengy appl Immun. 86:82.

181. Schell-Frederick, E., T. Tepass, G. Lorscheidt, M. Pfreundschuh, M. Schaadt, and V. Diehl. 1989. Effect of recombinant tumor necrosis factor (rHuTN. Fa)on human sicutrophils and monocytes: in vitro, ex. vivo and in vivo. Eur. J. HaematoL 43:286.

182. Daniels, R.H., M.J. Finnen, M.E. Hill, and J.M. Lackie. 1992. Recombinant human monoxyte IL-8 primes NADPH-oxidase and phospholipase $\mathrm{A}_{2}$ activa tion in human neutrophils. Immunology 75:I57.

183. Porteu, F., and C. Nathan. 1990. Shedding of tumor necrosis factor receptors by activated human neutrophils. J. Exp. Med. 172:599.

184. Yonemaru, M., K. E. Stephens, A. Ishizaka, H. Zheng, R. S. Hogue, J. J. Crowley, J. R. Hatherill, and T. A. Raffin. 1989. Effects of tumor necrosis factor on PMN chemotaxis, chemiluminescence, and elastase activity. J. Lab. Clin. Med. 114:674.

185. Steadman, R., Petersen, M. M., N. Topiey, D. Williams, N. Matthews, B. Spur, and J. D. Williams. 1990. Differential augmentation by recombinant buman tumor necrosis factor- $\alpha$ of neutrophil respons. es to particulate zymosan and glycan. J. Immunol. 144:2712.

186. Figari, I. S., N. A. Mori. and M. A. Palladino, Jr. 1987. Regulation of neutrophil migration and superoxide production by recombinant tumor necrosis fac. tors- $\alpha$ and $-\beta$ : comparison to recombinant interferon$\gamma$ and interleukin-1 $\alpha$ Blood 70:979.

187. Weisbar, R.H., L. Kwan, D.W. Golde, and J.C. Gasson. 1987. Human GM-CSF primes neutrophils for enhanced oxidative metabolism in response to the major physiological chemoattractants. Blood 87:18.

188. Arnaout, M. A., E. A. Wang. S. C. Clark, and C. A. Cieff. 1986. Human recombinant granulocyiemacrophage colony-stimulating factor increases cellto-cell adhesion and surface expression of adhesion. promoting surface glycoproteins on mature granulocytes. J. Clin. Invest. 78:597.

189. Lopez, A. F., D. J. Williamson, J. R. Gamble, C.G. Begley, J.M. Harlan, S.J. Klebanoff, A. Waltersdorph, G. Wong, S. C. Clark, and M. A. Vadas. 1986. Recombinant human granulocyte-macrophage colony -stimulating factor stimulates in vitro mature human 
neutrophil and eosinophil function, surface receptor expression, and survival. J. Clin. Invest. 78:1220.

190. Yong, K. L., and D. C. Linch. 1992. Differential effects of granulocyte- and granulocyte-macrophage colony-stimulating factors (G- and GM-CSF) on neutrophil adhesion in vitro and in vivo. Eur. J. Haemafol 49:251.

191. Kownatzki, E., E. Liehl, H. Aschauer, and S. Uhrich. 1990. Inhibition of chemotactic migration of human neutrophilic granulocytes by recombinant human granulocyte-macrophage colony-stimulating factor. Immunopharm. 19:139.

192. Aida, Y., and M. J. Pabst. 1990. Priming of neutrophils by lipopolysaccharide for enhanced release of superoxide. J. Immunol. 145:3017.

193. Guthrie, L. A., L. C. McPail, P. M. Henson, and R. B. Johnston, Jr. 1984. Priming of neutrophils for enhanced release of oxygen metabolites by bacterial lipopolysaccharide. J. Exp. Med. 160:1656.

194. Lynn, W.A., C. R.H. Raetz, N. Qureshi, and D.T. Golenbock: 1991. Lipopolysaccharide-induced stimulation of CDIlb/C.D18 expression on neutrophils. J. Immunol. 147:3072.

195. Wright, S. D., R. A. Ramos, A. Hermanowski-Vosatka, P. Rockwell, and P. A. Detmers. 1991. Activation of the adhesive capacity of CR3 on neutrophis by endotoxin: dependence on lipopolysaccharide binding protein and CD14.J. Exp. Med. 173:1281.

196. Yoshirnura, T., K. Matsushima, S. Tanaka, E. A. Robinson, E. Appella, J. J. Oppenheim, and E. J. Leonard. 1987. Purification of a human monocytederived neutrophil chemotactic factor that bas peptide sequence similarity to other host defense cytokines. Proc. Nall Acad Sci. USA 84:9233.

197. Walz, A., B. Dewald, V. von Tseharner, and M. Baggiolini. 1989. Effects of the neutrophil-activating peptide NAP-2, platelet basic protein, connective tis. sue-activating peptide II, and platelet factor 4 on human neutrophils. J. Exp. Med 170:1745.

198. Thelen, M., P. Peveri, P. Kernen, V. von Tschamer, A. Walz, and M. Baggiolini. 1988. Mechanism of neutrophil activation by NAF, a novel monocytederived peptide agonist. $F A S E B$ J. 2:2701.

199. Wolpe, S. D., G. Davatelis, B. Sherry, B. Beutler, D.G. Hesse, H.T. Nguyen, I. L. Moldawer, C.F. Nathan, S. F. Lowry. and A. Cerami. 1988. Macrophages secrete a novel heparin binding protein with intlam. matony and neutrophil chemokinetic properties. J. Exp. Med. 167:570.

200. Walz., A., F. Meloni, I. Clark-Lewis, V. von Tschamer, and $\mathrm{M}$. Baggiolini. 1991. $\left[\mathrm{Ca}^{2 *}\right]_{1}$ changes and respiratory burst in human neutrophits and monocytesinJuced by NAP-1/interleukin-8, NAP-2, and gra/MGSA. J. Leuk. Biol. 50:279.

201. Moser, B., 1. Clark-Lewis, R. Zwahien, and M. Baggiolini. 1990. Neutrophil-activating properties of the melanoma growth-stimulatory activity. $J$. Exp. Med. 171:1797.

202. Simchowitz, L, and I. Spilberg. 1979. Chernotactic factor-induced generation of superoxide radicals by human neutrophils: evidence forl a role of sodium. J. Immunol 123:2428.
203 McPail, L. C., and R. Snydernan. 1983. Acrivation of the respiratory burst enzyme in human polymorphonuclear leukocytes by chemoattractants and other soluble stimuli. J. Clin. Inrest. 72:192.

204. Palmblad, J., H. Gyllenhammer, J. A. Lindgren, and C. L. Malmsten. 1984. Effects of leukotrienes and fMet-Leu-Phe on oxidative metabolism of neutrophils and eosinophils. J. Immunol 132:3041.

205. Webster, R. O., S. R. Hong, R. B. Johnston. Jr., and P. M. Henson. 1980. Biological effects of the human complement fragments $\mathrm{CSa}$ and $\mathrm{CSa}_{3 \mathrm{am}}$ on neutrophil function. Immunopharmacology 2:201.

206. Tonnesen, M. G., D. C. Anderson, T. A. Springer, A. Knedler, N. Avdi, and P. M. Henson. 1989. Adherence of ncutrophils to cultured human microvascular endothelial cells. Stimulation by chemotactic peptides and lipid mediators and dependence upon the Mac-1, LFA-1, gp150,95 glycoprotein fanily. J. Clin. Invest 83:637.

207. Varani, J., S. E. G. Fligiel, G. O. Till, R. G. Kunkel, U. S. Ryan, and P. A. Ward. 1985. Pulmonary endothelial cell killing by human neutrophils. Possible involvement of the hydroxy! radical. Lab. Invest. 53:656.

208. Vercelloti, G. M., H. Q. Yin, K. S. Gustavson, R. D. Nelson, and H. S. Jacob. 1988. Platelet-actiyatting factor primes neutrophil responses to agonists: role in promoting neutrophil-mediated endothelial cell damage. Blood 71:1100.

209. Braquet, P., D. Hosford, P. Kolk, J. Guilbaud, and M. Paubert-Braquet. 1991. Effect of platelet activating factor on tumor necrosis factor-induced superoxide generation from human neutrophils. Lipids 26:1071.

210. Ingraham, L. M., T. D. Coates, J. M. Allen, C. P. Higgins, R. L. Bachner, and L. A. Boxer. 1982. Metabolic membrane, and functional responses of human polymorphonuclear leukocytes to platelet-activating factor. Blood 59:1259.

211. Lad, P. M., C. V. Olson, and I. S. Grewal. 1985. Platelet-activating factor mediated effects on human neutrophil functions are inhibited by pertussis toxin. Biochem. Biophys. REs. Commun. 129:632.

212. Shaw, J. O., R. N. Pinckard, K. S. Ferrigni, L. M. MeManus, and D. J. Hanahan. 1981. Activation of human neutrophils with 1- $O$-hexadecyloctadecyl2-acetyl-sn-glyceryl-3-phosphorylcholine (platelet activating fictor), J. ImmunoL I27:1250.

213. Steward, A. G. T. Harris, M. De Nechilo, and A. F. Lopez. 1991. Involvement of leukotriene $B_{4}$ and platelet-activating factor in cytokine primingof human polymorphonuclear leucocytes. Immunology 72:206.

214. Baggiolini, M. and B. Dewald. 1986. Stimulus amplification by $\mathrm{PAF}$ and $\mathrm{LTB}$, in human neutrophils. Pharmacol Res. Comm. 18:51.

215. Shaw, J. O., R. N. Pinckard, K. S. Fenigni, L. M. McManus, and D. J. Hanahan. 1981. Activation of human neutrophils with 1-O-hexadecy Voctadecyl2-wcetyl-sn-glyceryl-3-phosphorylcholine (platelet activating fuctor). J. ImmunoL 127:1250.

216. Sumimoto, H., K. Takeshige, and S. Minakami. 1984. 
Superoxide production of human polymorphonuclear leukocytes stimulated by leukotriene $B_{4}$. Biochim.Biophys. Acta 803:271.

217. Goetzl, E. J., and W. C. Pickett. 1981. Novel structural detcrminants of the human neutrophil chemotactic activity of leukotriene B4. J. Exp. Med. 154:1243.

218. Serhan, C. N., A. Radin, J. E. Smolen, and H. Korchak. 1982. Leukotriene B4 is a complete secretagogue in human neutrophils: a kinetic analysis. Biochym. Biophys. Res. Commun. 107:1006.

219. Sumimoto, H. K. Takeshige, and S. Minakami. 1984. Superoxide production of human polymorphonuclear leukocytes stimulated by leukotriene $\mathrm{B}_{4}$. Biochim. Biophys. Acta 803:271.

220. L.ewis, R. A., E. J. Goetzl. J. M. Drazen, N. A. Soter, K. F. Austen, and E. J. Corey. 1981. Functional characterization of synthetic leukotriene $B$ and its stereochemical propertics. J. Exp. Med. 154:1243.

221. Ford-Hutchinson, A.W., M. A. Bray, M. V. Doig, M. E. Shipley, and M. J. H. Smith. 1980. Leukotriene $B$, a potent chemokinetic and aggregating substancercleased from polymorphonuclear leukocytes. Nature 286:264.

222. Worthen, G. S., C. Haslett, A. J. Rees, R. S. Gumbay, J. E. Henson, and P. M. Henson, 1987. Neutrophilmediated pulmonary vascular injury. An. Rev. Respir. Dis. 136:19.

2.23. Lundberg, C., F. Marceau, and T. E. Hugli. 1987. C5a-induced hemodynamic and hematologic changes in the rabbit. Am. J. Pathol. 128:471.

224. Michie, H. R., D. R. Spriggs et al. 1988. Tumor necrosis factor and endotoxin induce similar metabolic responses in human beings. Surgery 104:280.

225. Bertani, T., M. Abbate, C. Zoja, D. Corna, N. Perico, P. Ghezzi, and G. Remuzzi. 1989. Tumor necrosis factor induces glomerular damage in the rabbit. $A m$. J. Pathol 134:4I9.

226. Stephens, K. E., A. Ishizaka, J. W. Larrick, and T. A. Raffin. 1988. Tumor necrosis factor causes increased pulmonary permeability and edema. Comparison to septic acute lung injury. Am. Rev. Resp. Dis. 137:1364.

227. Hovgaard, D., S. Schifter, A. Rabol, B. T. Mortensen, and N. I. NisseNissen. 1992. In wivo kinetics of "Indium-labelled autologous granulocytes following iv. administration of granulocytc-macrophage colony-stimulating factor (GM-CSF), Eur. $J$. HaematoL 48:202.

228. Traccy, K. J.. B. Beutler, et al. 1986. Shock and tissue injury induced by recombinant human cachectin. Science 234:470.

229. Omann, G. M. A. E. Traynor, A. L. Harris, and L. A. Sklar. 1987. LTB $_{\mathrm{a}}$-induced activation signals and responses in neutrophils are short-lived compared to formylpeptide. J. Immunol 138:2626.

230. Palmblad. J., C. L. Malmsten, A-M. Udén, O. Rắdmark. L. Engstedt, and B. Samuclsson. 1981. Leukotriene $\mathbf{B}_{4}$ is a potent and stereospecific stimulator ofneutrophil chemotaxis and adherence. Blood 58.658.

231. Cluzel, M., B. J. Undem, and F. H. Chilton. 1989. Release of platelet activating factor and the meta- bolism of leukotriene $\mathrm{B}_{4}$ by the human neutrophilwhen studied in a cell superfusion model. J. I $\mathbf{m m u}$ nol 143:3659.

232. Steward, A. G., P. N. Dubbin, T. Harris, G. J. Dusting. 1990. Platelet-activating factor may act as a second messenger in the release of icosanoids and superoxide anions from leukocytes and endothelial cells. Proc. NatL Acad. Sci. USA 87:3215.

233. Vercelloti, G. M., N. W. R. Wickham, K. S. Gustafson, H. Q. Yin, M. Hebert, and H. S. Jacob. 1989. Thrombin-treated endothelium primes neutrophil functions: Inhibition by Platelet-activating factor receptor agonists. J. Leuk. Biol. 45:483.

234. McColl, S. R., E. Krump, P. H. Nacchache, P. E. Poubelle, P. Braquet, M. Braquet, and P. Borgeat. 1991. Granulocyte-macrophage colony-stimulating factor increases the synthesis of leukotriene $\mathrm{B}_{4}$ by human neutrophils in response to platelet-activating factor. J. Immunol 146:1204.

235. Bates, E. J., D. P. Harvey, and A. Ferrante. 1992. Inhibition of neutrophil respiratory burst and degranulation responses to platelet-activating factor by antagonists WEB 2086, CV6209 and CV3988. Int. Arch. Allergy ImmunoL 97:50.

236. Verceloti, G. M., C. F. Moldow, N. W. Wickam, and H. S. Jacobs. 1990 . Endothelial; cell platelet-activating fuctor primes neutrophíl responses: amplification of endothelial activation by neutrophil products. J. Lipid Mediat. 2:\$23.

237. Krishna, K. M. D. L. Kilby, M. S. Currie, H. J. Cohen, and W. P. Pelers. 1992. Changes; in actin state and chemotactic peptide receptor expression in granulocytes during cytokine administration after autologous bone marrow transplantation. Lymphokine Cytokine Res. 11:15.

238. Omann, G. M., M. M. Porasilk, and L. A. Sklar. 1989. Oscillating actin polymerization/depolymerization responses in human polymorphonuclear leukocytes. J. Biol Chem. 264:I6355.

239. Fiers, W. 1991. Tumor necrosis factor, characterization at the molecular, cellular and in vivo level. FEBS Letters 285:199.

240. Yard, B.A., M. R. Daha, M. Kooymans-Couthino, J. A. Bruijn, M. E. Paape, E. Schrama, L. A. van Es, and F. J. van der Woude. 1992. IL-I $\alpha$ stimulated TNF $\alpha$ production by cultured human proximal tubular epithelial cells. Kidney Internat. 12:383.

241. von Asmuth, E. J. U., M. A. Dentener, M. Ceska, and W. A. Buuman. IL-6, II. 8 and TNF production by cytokine and lipopolysaccharide-stimulated human renal cortical epithelial cells in vitro. 1994 Eur. Cyrokine Net. 5:301.

242. Spriggs, D.R., K. Imamura, C. Rodriguez, E. Sariban, and D. W. Kufe. 1988. Tumor necrosis factor expression in human epithelial tumor eell lines. $\mathrm{J}$. Chin Invest. 81:455.

243. Rubin, B.Y., S. L. Anderson, S. A. Sullivan, B. D. Williamson, E. A. Carswell, L. J. Old. 1986. Nonhematcpoietic cells selected for resistence to tumor necrosis factor produce turnor necrosis factor. J. Exp. Med 164:1350.

244. Gray. P. W., B. B. Aggarwal of al. 1984. Cloning and 
expression of cDNA for human lymphotoxin, a lymphokine with tumor necrosis factor activity. Nature 312:721.

245. Fiers, W. 1991. Tumor necrosis factor, characterization at the molecular, cellular, and in vivo level. FEBS lett. 285:199.

246. Tartaglia, T. A., and D. V. Goeddel. Two TNF receptors. Immunol Today 13:151.

247. Engelberts, 1. 1994. Tumor necrosis factor during sepsis. Thesis. University of Limburg. The Netherlands.

248. Leeuwenberg, J. F. M., T. M. A. A. Jeunhomme, and W. A. Buuman. 1989. Induction of an activation antigen on human endothelial cells in vitro. Eur. J. Immunol. 19:715.

249. Pober, J. S., M. A. Gimbrone Jr, L. A. Lapierre, D. L. Mendrick, W. Fiers, R. Rothlein, and T. A. Springer. 1986. Overlapping patterns of activation of human endothelial cells by interleukin 1, tumor necrosis factor, and immune interferon. J. Immunol 137:1893.

250. Schlag, G., and H. Redl. 1993. Pathophysiology of shock, sepsis, and organ failure. Berlin. Springer Verlag. pp 556.

251. von Asmuth, E.J.U., J.F.M. Leeuwenberg, M. Ceska, W. A. Buuman. 1991. L.PS and cytokine-induced endothelial cell IL 6 release and ELAM-1 expression; involvement of serum. Eur. Cytokine Net. 2:291.

252. Richter, J., T. Andersson, and 1. Olsson. 1989. Effect of tumor necrosis factor and granulocyle macrophage colony stimulating factor on neutrophil degranulation. J. Immunol. 142:3199.

253. Renesto, P., and M. Chignard. 1991. Tumor neerosis factor- $\alpha$ enhances platelet activation via catchepsin G released from neutrophils. J. Immunol. 146:2305.

254. Larsen, C. G., A. O. Anderson, J. J. Oppenheim, and K. Matsushima. 1989. Production of interleukin- 8 by human dermal fibroblases and keratinocytes inresponse to interleukin-1 or tumour necrosis factor. Immunol 68:3I.

255. Mielke, V., J. G. J. Bauman et al. 1990. Detection of neutrophil-activating peptide NAP/L- 8 and NAP/IL8 mRNA in human recombinant $I L-1 \beta$ - and human recombinant tumor necrosis factor-a-stimulated human dermal fibroblast. J. ImmunoL 144:153.

256. Schmouder. R.I., R. M. Strieter, R. C. Wiggins, S. W. Chensuc, and S. L. Kunkel. 1992. In vitro and in vivo interleukin-8 production in human renal cortical epithelia. Kidney Int. 41:191.

257. Thornton, A.J. R. M. Strieter, 1. Lindley, M. Baggiolioni, and S. L. Kunkel. 1990. Cytokine induced gene expression of a neutrophil chernotactic factor/LL-8 in human hepatocytes. J. ImmunoL I44:2609.

258. Share, R. J., R. J. Margolis, M. Askari, E. P. Amento and R. D. Granstein. 1988. Induction of dermal and subcutaneous inflammation by recombinant cachectin/tumor necrosis factor (TNFot) in the mouse. J. Invest DermatoL 91:353.

259. Piguet. P. F., G. E. Grau, and P. Vassalli. 1990. Subeutaneous perfusion of rumor necrosis factor induces local proliferation of fibroblases, capillaries, and epidermal cells, or massive tissue necrosis, Am. J. Pathol 136:103.
260. Mason, M. J., and D. E. Van Epps. 1989. In vivo neutrophil emigration in response to interleukin- 1 and tumor necrosis factor-alpha. J. Leuk. BioL 45:62.

261. Scuderi, P., P. A. Nez, M. L. Duerr, B. J. Wong, and C. M. Valdez. 1991. Catchepsin-G and leukocyte elastase inactivate human tumor necrosis factor and lymphotoxin. Cell Immunol. 135:2.

262. Nortier, J., P. van den Abeele, E. Noel, Y. Bosseloir, and M. Goldman. 1991. Enzymatic degradation of tumor necrosis factor by activated human neutrophils: role of elastase. Lje Sci 49:1879.

263. Kessel, K. P. M. van, J. A. G. van Strijp, and J. Verhoef. 1991. Inactivation of recombinant human tumor necrosis factor- $\alpha$ by proteolitic enzymes released from stimulated human neutrophils. J. Immunol 147:3862.

264. Porteu, F., M. Brockhaus, D. Wallach, H. Engelinann, and C. F. Nathan. 1991. Human neutrophil elastase releases a ligand-binding fragment from the $75 \mathrm{kDa}$ tumor necrosis factor (TNF) receptor. Comparison with the proteolitic activity responsible for shedding of TNF receptors form stimulated neutrophils. J. Biol Chem. 266:18846.

265. Loetscher, H., R. Gentz, M. Zulauf, A Lustig, H. Tabuchi, J. Schlaeger, M. Brockhaus, H. Gallati, M. Manneberg, and W. Lesslauer. 1991. Recombinant $55-\mathrm{kDa}$ tumor necrosis factor (TNF) receptor. Stoichiometry of binding to TNF $\alpha$ and TNF $\beta$ and inhibition of TNF activity. J. Biol Chem. $266: 18324$.

266. Engelberts, I., S. Stephens, G. J. M. Francot, C. J. van der Linden, and W. A. Buurman. 1991. Evidence of different effects of soluble TNF-receptors on various TNF measurements in human biological fluids. Lancet 338:515.

267. Asmuth, E.J.U. von, J.F.M. Leeuwenberg, C.J. van der Linden, and W.A. Buurman.1991. Tumour necrosis factor- $\alpha$ induces neutrophil mediated injury of cultured human endothelial cells. Scand J. Immunol 34:197.

268. Bell, G. 1. M. Dembo, and P. Bongrand. 1984. Cell adhesion. Competition between nonspecific repulsion and specific binding. Biophys. J. 45:105I.

269. Ross, G. D., J. A. Cain, and P. J. Lachman. 1985. Membrane receptor type three (CR3) has lectin-like properties homologous to bovine conglutinin and functions as a receptor for zymosan and rabbit erythrocytes as well as for $\mathrm{iC} 3 \mathrm{~b}$. J. Immunol 134:3307.

270. Talamás-Rohana, P., S. D. Wright, M. R. Iennartz, and D. G. Russell. 1990. Lipophosphoglycan from Leishmania mexicana promastigotes binds to members of the CR3, pl 50,95 and LFA-1 family of leukocyte integrins. J. Immunol 144:4817.

271. Huu, T. P., S. Chollet-Martin, A. Perianin, C. Marquetty, P. Sourbier, C. Babin-Chevaye, D. Olive, M. A. Gougerot-Pocidalo, P. Debre, and J. Hakim. 1987. Comparison of blocking effects of monoclonal antibodies anti-MO1- $\alpha$ and anti-L.FA-1- $\alpha$ on human neutrophil functions. Immunology 62:61.

272. Steadman, R., M. M. Petersen, N. Topley, D. Willians, N. Matthews, B. Spur, and J. D. Willians. 1990. Differential augmentation by recombinant hu- 
man tumor necrosis factor- $\alpha$ of neutrophil responses to particulate zymosan and glucan. J. Immunol. I44:2712.

273. Klebanoff, S. J., M. A. Vadas, J. M. Harlan, L. H. Sparks, J. R. Gamble. J. M. Agosti, and A. M. Waltersdorph. 1986. Stimulation of neutrophils by tumor necrosis factor. J. Immunol 136:4220.

274. She, Z-W., M. D. Wewers, D. J. Herzyk, A. L. Sagone, and W. B. Davis. 1989. Tumor necrosis factor primes neutrophils for hypochlorous acid production. Am. J. Phys. 257:L338.

275. Shalaby, M. R., B. B. Aggarwal, E. Rinderknecht, L. P. Svedersky, B. S. Finkle, and M. A. Palladino, Jr. 1985. Activation of human polymorphonuclear neutrophil functions by interferon- $\gamma$ and tumor necrosis factor. J. ImmunoL 135:2069.

276. Eierman, D. F., C. E. Johnson, and J. S. Haskill, 1989. Human monocyte inflammatory mediater gene expression is selectively regulated by adherence substrates. J. Immunol 142:1970.

277. von Asmutb, E. J. U., J. G. Maessen, C. J. van der Linden, and W. A. Buurman. 1990. Tumour necrosis factor alpha (TNF- $\alpha$ ) and interleukin 6 in a zymosaninduced shock model. Scand. J. ImmunoL 32:313.

278. Zuckerman, S. H., G. F. Evans, Y. M. Snyder, and W. D. Roeder. 1989. Endotoxin-macrophage interaction: post-translational regulation of tumor necrosis factor expression. J. Immunol. 143:1223.

279. Debets, J. M. H., C. J. van der Linden, I. E. M. Dicteren, J. F. M. Leeuwenberg, and W. A. Buurman. 1988. Fc-receptor cross-linking induces rapid secretion of tumor necrosis factor (cachectin) by human peripheral blood monocytes. J. ImmunoL 141:1197.

280. Debets, J. M. H., J. G. J, van de Winkel, J. L. Ceuppens, I. E. M. Dieteren, and W. A. Buurman. 1990 Cross-linking of both FcyRI and FcrRII induces secretion of tumor necrosis factor by human monocytes, requiring high affinity $\mathrm{Fc}-\mathrm{F} c \gamma R$ interactions. $\boldsymbol{J}$. Immunol. 144:1304.

281. Freund, M., and H.-D. Kleine. 1992. The role of GMCSF in infection. Infection 20.S2:S84.

282. Gasson, J. C.. 1991. Molecular physiology of granulocyte-macrophage colony-stimulating factor. Blood 77:1131.

283. Seclentag, W. K., J. J. Mermod, R. Montesano, and P. Vassali. 1987. Additive effects of interleukin $I$ and tumciur necrosis factor on the accumulation of the three granulocyte and macrophage colony-stimulating factor mRNAs in human endothelial cells. EMBO J. $6: 2261$

284. Sluannon, M. F., J. R. Gamble, and M. A. Vadas. 1988. A novel tumor necrosis factor-responsive transcription factor which recognizes a regulatory element in hemopoietic growth factor genes. MoL Cell. Biol 10:2950.

285. Munker, R. J. Gasson, M. Ogawa and H. P. Koeffler. 1986. Recombinant human TTF induces production of granulocyte-monocyte colony-stimulating factor. Nature 323:79.

286. Caux, C. S. Saeland, C. Fuvre, V. Duver, P. Mannoni, and J. Banchereau. 1990. Tumor necrosis factoralpha strongly potentiates interleukin-3 and granulo- cyte-macrophage colony-stimulating factor-induced proliferation of human CD34+ hematopoietic progenitor cells. Blood 75:2292.

287. Heidenreich, S., J-H. Gong. A. Schmidt, M. Nain. and D. Gemsa. 1989. Macrophage activation by granulocyte/macrophage colony-stimulating factor. Priming for enhanced release of tumor necrosis factor- $\alpha$ and prostaglandin $\mathrm{E}_{2}$. J. Immunol 143:1198.

288. Warren, M. K., and P. Ralph. 1986. Macrophage growth factor CSF-1 stimulates human monocyte production of interferon, tumor necrosis factor and colony stimulating activity. J. Immunol. 137:2281.

289. Cannistra, S. A., A. Rambaldi, D. R. Spriggs, F. Hermann, D. Kufe, and J. D. Griffin. 1987. Human granulocyte-macrophnge colony-stimulating factor induces expression of the tumor necrosis factor gene by the $\mathrm{U} 937$ cell line and by normal human monocytes. J. Clin. Invest 79:1720.

290. Williamson, D. J., C. G. Begley, M. A. Vadas, and D. Metealf. 1988. The detection and initial characterization of colony-stimulating factors in synovial fluid. Clin. Exp. Immunol 72:67.

291. Xu, W. D., G. S. Firestein, R. Taetle, K. Kaushansky, and N. J. Zvaifler. 1989. Cytokines in chronic inflammatory arthritis. II. Granulocyte-macrophage colonystimulating factor in rheumatoid synovial effusions. J. Clin. Invest. 83:876.

292. Wright, S.D., R. A. Ramos, P. S. Tobias, R. J, Ulevitch, and J. C. Mathison. 1990. CD14, a receptor for complexes of lipopolysaccharide (LPS) and LPS binding protein. Science 249:1431.

293. Heumann, D., P. Gallay, C. Barma, P. Zaech, R. J. Ulevitch, P. S. Tobias, M.P. Glauser, and J. D. Baumgartner. 1991. Control of lipopolysaccharide (L.PS) binding and LPS-induced turnor necrosis factor secretion in human peripheral blood monocytes. J. Immunol. 148:3505.

294. Wright, S.D., R. A. Ramos, M. Patel, and D. S. Miller. 1992. Septin: a factor in plasma that opsonizes lipopolysaccharide-bearing particles. for recognition by CD14 on phagocytes. J. Exp. Med. 176:719.

295. Dentener, M. A., V. Bazil, E. J. U. von Asmuth, M. Ceska M., and W. A.Buurman. Involvement of CD14 in lipopolysaccharide induced tumor necrosis factor- $\alpha$ interleukin- 6 and interleukin- 8 release by human monocytes and alveolar macrophages. J. Immunal in press.

296. VanVoorhis, W. C., R. M. Steinman, L. S. Hair, J. Lubar, M. D. Witmer, S. Koide, and Z. A. Cohn. 1983. Specific antimononuclear phagocyte monoclonal antibodies. Application to the purification of dendritic cells and the tissue localization of macrophag. es. J. Exp. Med. 158:126.

297. Dentener, M. A., E. J. U. von Asmuth, G. J. M. Francol. M. N. Marra, and W. A. Buurnan. 1993. Antagonistic effects of lipopolysaccharide binding protein and bactericidal/permeability-increasing protein on lipopolysaccharide-induced cytokine release by mononuclear phagocyres. Competition for binding to lipopolysaccharide. J. Immunol. 151:4258.

298. McMichacl, A. 1987. Leucocyte Typing III. White 
cell differentiation antigens. p. 572. Oxford University Press, Oxford.

299. von Asmuth. E. J. U., M. A. Dentener, V. Baril, M. G. Bouma, J. F. M.Lecuwenberg, and W. A. Buurman. 1993. Anti-CD14 antibodies reduce responses of cultured human endothelial cells to endotoxin. Immunol. 80:78.

300. Frey, E. A., D. S. Miller, T. Gullstein Jahr, A. Sundan, V. Bazil. T. Espevik, B. B. Finlay, S. D. Wright. 1992. Soluble CD14 participates in the response of cells to lipopolysaccharide. J. Exp. Med. 176:1665.

301. Pugin, J., C-C. Schrürer-Maly, D. Leturcq, A. Moriarty, R. J. Ulevitch, and P. S. Tobias. 1993. Lipopolysaccharide activation of human endothelial and epithelial cells is mediated by lipopolysaccharide-binding protein and soluble CD14. Proc. Nath Acad. Sci. USA 90:2744.

302. Huziot, A., G-W. Rong. J. Silver, and S. M. Goyert. 1993. Recombinantsoluble CD14 mediates the activation of endothelial cells by lipopolysaccharide. J. Immunol. 151:1500.

303. Pugin, J., R. J. Ulevitch, and P. S. Tobias. 1993. A critical role for monocytes and CDI 4 in endotoxininduced endothelial cell activation. J. Exp. Med. 178.2193.

304. Beutler, B., I. W. Milsark, and A. C. Cerami. 1985. Passive immunization against cachectin/tumor necrosis factor protects mice from lechal effects of endotoxin, Science 229:869.

305. Fong. Y., Tracey, K. J., et al. 1989. Antibodies to cachectin/tumor necrosis factor reduce interleukin $1 \beta$ and interleukin 6 appearance during lethal bacteremis. J. Exp. Med. 170:1627.

306. Windsor. A. C. J., C. J. Walsh, et al. 1993. Tumor necrosis factor $-\alpha$ blockade prevents neutrophil CD 18 receptor upregulation and attenuates acute lung inju$r y$ in porcine sepsis without inhibition of neutrophil oxygen radical generation. J. CLin. Invest. 91:1459.

307. Pfeffer, K., T. Matsuyami, et al, 1993. Mice deficient for the $55 \mathrm{kd}$ tumor necrosis factor receptor are resistent to endotoxin shock, yet succumb to L. monocytogenes infection. Cell 73:457. 


\section{INTRODUCTION TO AND DISCUSSION OF THE EXPERIMENTS}

The studies presented in this thesis are part of the rapidly evoluating fieids in immunology of adhesion-molecules and cytokines. During the realization of the experimental work presented in this thesis, both knowledge and technical possibilities increased rapidly, and the questions which were asked and answered in the individual manuscripts represent the status quo of the moment at which they were written. The central theme of this thesis is the regulation of neutrophil-endothelial cell interaction during inflammation.

The experimental work presented in this thesis can be divided into three parts. Chapter 3 focusses on TNF. Chapter 4 focusses on E-selectin. In chapter 5 , the involvement TNF and E-selectin in neutrophil endothelial cell interaction is investigated.

\section{Chapter 3}

In chapter 3 the conditions which lead to the release of TNF and related cytokines such as IL-6 and IL-8 were investigated. TNF is known to be a main mediator of the pathophysiological changes during gram negative sepsis, released mainly by mononuclear phagocytes (reviewed in 1). Lipopolysaccharide (LPS) from the outer leaflet of the envelope gram-negative bacteria, also called endotoxin, is the 'classical' agent responsible for TNF-release by mononuclear phagocytes.

Since TNF can be held responsible for mortality associated with experimental endotoxin induced sepsis syndrome (1), it seemed important to identify the mechanisms which determine whether TNF-release contributes to a controlled host-protective inflammatory response, or leads to a toxic overshoot-reaction with potentially lethal outcome.

In the first paper of this chapter, it was shown that TNF is not only associated with gram negative sepsis, but can also be partly responsible for the sepsis syndrome induced by zymosan (purified ghost cells of bakers yeast). In our model, the trigger for massive TNF-release appeared not to be restricted to one specific agent, such as endotoxin, but was the result of a combination of triggers: the zymosan-particles themselves, particle bound serum components and activated soluble serum components.

Further evidence that TNF-release is rather a highly regulated multifactorial event than an isolated response of a single cell-population to one toxic agent, is presented in chapter 3.2 and 3.3.

Renal epithelial cells share some properties such as phagocytosis and oxygen radical release with mononuclear phagocytes. In chapter 3.2 we demonstrated that cultured explanted human renal epithelial cells responded to cytokines and endotoxin by releasing TNF, IL-6 and IL-8. 
These findings emphasize that renal epithelial cells are not just target cells during inflammatory challenge, but can participate directly in the regulation of ongoing inflammation.

As indicated by the name 'endotoxin', lipopolysaccharides have long been considered as host threatening microbial poisons. Serum components were thought to play an host-protecting role by 'detoxificating' LPS $(2,3)$. More recent investigations pointed out that the immunogenicity of LPS is influenced by two homologous proteins: LBP, an acute phase reactant released by the liver, which highly increases LPS binding to CD14, and BPI, which is produced by activated neutrophils and is capable of inactivating LPS.

Experiments on the interactions of these proteins, performed in close collaboration withMieke Dentener in our laboratory, demonstrated that BPI can prevent association of LPS with LBP and thus prevent LPS-induced cytokine-release by mononuclear phagocytes (paper 3.3). BPI thus represents a physiological regulator of LPS-toxicity, which could be important in preventing LPS-induced septic shock-like syndromes. Thus, the recognition of endotoxin by cells of the immune-system represents another level at which the TNF-response is rather balanced by specific other host mediators, than an isolated reaction to a 'toxic' microbial agent.

\section{Chapter 4}

E-selectin is an endothelial cell adhesion molecule for neutrophils and other cells which is temporarily expressed after endothelial cell activation with TNF and other pro-inflammatory agents, and has a main role in the recruitment of neutrophils at sites of inflammation. Several aspects of this novel adhesion molecule were investigated in close collaboration with Jet Leeuwenberg, using two monoclonal antibodies produced at our laboratory.

We were interested in possible functional effects of E-selectin interaction with its ligand on neutrophils. Whilst our investigations on the effects of E-selectin-ligand binding on the behavior of neutrophils and endothelial cells were negative;, we observed that E-selectin is not stably expressed by endothelial cells but is internalized after a short stay on the cell surface. E-selectin binds soluble L-selectin, which is released from the neutrophil surface after activation $(4,5)$ and other soluble sialyl Lewis $X$ moieties containing proteins, which are found in the circulation of some adenocarcinoma-patients $(6,7)$ and of patients with an acute generalized inflammation (8). Both such proteins can reduce neutrophil adherence to activated endothelium $(8,9)$. Furthermore, E-selectin contains six repetitive regions with sequence homology to known complement regulatory proteins (10). As suggested by Johnston et al. (11), these regions might bind $\mathrm{C} 3 \mathrm{~b}$ or $\mathrm{C} 4 \mathrm{~b}$ to facilitate clearance of circulating immune-complexes. E-selectin internalization, as described in paper 4.1, could have a function in decontaminating the circulation during severe immunological challenge. Furthermore E-selectin internalization could be involved in the downregulating of E-selectin expression, which

\footnotetext{
- Neutrophil interaction with E-selectin fails to trigger respiratory burst activity (chapter 2.2), but induces chemotasinlike neutrophil activation as, was demonstrated later in a study of S. K. Lo et al. (4).
} 
occurs some 4 to 8 hours after the initiation of E-selectin expression. The mechanism of the induction and downregulation of E-selectin expression was further investigated in the chapters 4.2, 4.3 and 4.4. Three mechanisms are described in these chapters, which co-regulate E-selectin expression. IFN- $\gamma$, which fails to induce E-selectin expression by itself, increases E-selectin and other endothelial cell responses to TNF, IL-1B and LPS (chapter 4.2), as was conlirmed by parallel investigations of Doukas and Pober (12). Presence of so far unidentified heat labile serum-components during endothelial cell activation appeared to be essential in facilitating full E-selectin expression (chapter 4.3).

The kinetics of E-selectin expression were, however, not affected by presence of IFN- $\gamma$ or serum. Serum-presence appeared particularly important for full endothelial cell responses to LPS. Involvement of serum-components and of the cell surface protein CD14 in monocyteactivation by LPS had just been elucidated by S. D. Wright et al $(13,14)$.

Data which show that CD14 molecules are crucially involved in LPS-activation of endothelial cells are presented in chapter 4.4 , and are supported by simultaneous reports by other groups (15-17).

\section{Chapter 5}

As depicted in chapter 3 and 4, TNF is part of a highly regulated network of mediators which modify both the release and the effects of TNF. Part of the influence of TNF on neutrophilendothelial cell interaction is induced indirectly, by the induction of E-selectin on endothelial cells, by effects on other adhesion molecules involved in endothelial-neutrophil interaction such as ICAM-1 and CD11b/CD18, by effects on other inflammatory mediators such as IL8, which are released by endothelial cells in response to TNF, and by PAF expressed by endothelium in response to TNF-activated neutrophils (chapter 1).

In chapter 5, the involvement of TNF, and of TNF-regulated adhesion-molecules and inflammatory mediators in neutrophil endothelial cell interaction is investigated, focussing on neutrophil mediated endothelial cell damage. Additionally, TNF-induced neutrophil activation was compared with neutrophil activation by an neutrophil binding elastase reactive monoclonal antibody, used as a model for the influence on neutrophils of anti-neutrophil cytoplasmic antibodies which are commonly found in systemic vasculitides such as Wegener's granulomatosis (chapter 5.2).

E-selectin appeared not to be involved directly in neutrophil mediated endothelial cell damage, but to have a specific role in neutrophil adhesion (chapter 5.3). This in contrast to the neutrophil adhesion molecule CD11b/CD18 which, besides mediating adhesion, has an essential role in facilitating neutrophil respiratory burst activity and neutrophil mediated endothelial cell damage (chapter 5.3). A clearly defined and generally accepted function of E-selectin as a mediator of neutrophil rolling behavior, being the first phase of neutrophil endothelial cell interaction during inflammation, has been worked out during the last years (18-20), and is described in chapter 1.

Specification of the role of TNF in neutrophil endothelial cell interaction, in relation to other inflammatory mediators. appeared to be more complex. TNF was more powerful in inducing 
neutrophil respiratory burst activity and neutrophil mediated endothelial cell injury than other physiological neutrophil agonists such as IL-1, IL-8, and endotoxin (chapter 5.1 and 5.3). TNF-induced neutrophil activation depended on a direct effect of TNF on surface contacting neutrophils (chapter 5.1), without involvement of endothelial cell responses to TNF, such as endothelial IL-8 release (chapter 5.1, 5.3 and 5.4), but with involvement of endothelial cell PAF-expression in response to products of TNF-activated neutrophils (chapter 5.4). Based on these and other studies, such as a number of recent publications of Nathan et al. on the mechanism of prolonged neutrophil respiratory burst activity (21-24), and attempt can be made to specify the role of TNF in regulating neutrophil behavior during inflammation.

A characterization of the different phases in neutrophil behavior during inflammation, and arguments for a specific function for TNF as a 'secretagogue', a neutrophil agonist which triggers a highly adherent status and induces degranulation and strong respiratory burst activity, are depicted in chapter 1. Many details of this model still need to be clarified. The response of neutrophils to TNF-activation is regulated by the adhesive interaction with the environmentof the neutrophil. How actions of cytokines are integrated with information from adhesion-receptors remains a major question. Although the action of TNF on neutrophils offers one of clearest examples of the significance of the influence of matrix-proteins and adhesionmolecules in the response to cytokines, this influence is certainly not limited to neutrophils (reviewed in 25).

Intercellular communication seems to rely more principally on two arms: soluble, cytokine mediated, signals and the fibrous skeleton, composed of intracellular actin filaments, which are, via adhesion molecules, connected to filaments in neighbor-cells or to the extracellular connective tissue in which most cells are normally embedded. By this fibrous 'backbone' structure, cells are part of a larger organization. The composition and tightness of this structure might be a way by which responses of individual cells are coordinated. 


\section{References}

1. Debets, J. M. H. 1989. Endogenous mediators of sepsis and cachexia. Siudies on tumor necrosis factor. Thesis. University of Limburg. The Netherlands.

2. Ulevitch, R. J., and A. R. Johnston. 1978. The modification of biophysical and endotoxic properties of bacterial lipopolysaccharides by serum. J. Clin. Invest. 62:1313.

3. Skarnes, R. C. 1970 . Host defence against bacterial endotoxemia: Mechanism in normal animals. J. Exp. Med, 132:300.

4. Lo, S. K., S. Lee, R. A. Ramos, R. Lobb, M. Rosa, G. Chi-Rosso. and S. D. Wright. 1991. Endothelialleukocyte adhesion molecule 1 stimulates the adhesive activity of leukocyte integrin CR3 (CD11b/CD18, Mac-1, $\alpha_{\mathrm{Al}_{1}} \mathrm{~B}_{2}$ ) on human neutrophils. J. Exp. Med. 173:1493.

5. Kishimoto, T. K., M. A. Jutila, E. L. Berg, and E. C. Butcher. 1989. Neutrophil Mac-1 and MEL-14 adhesion proteins inversely regulated by chemotactic factors. Science 245:1238.

6. Kannagi, R., Y. Fukushi, T. Tachikawa, A. Noda, S. Shin, K. Shigeta, N. Hiraiwa, Y. Fukuda, T. Inamoto, S-I. Hakomori, and H. Imura. 1986. Quantitative and qualitative characterization of human cancer associated serum glycoprotein antigens expressing fucosyl or sialyl-fucosyl type 2 chain polylactosamine. Cancer Res 46:2619.

7. Fukushima, K., M. Hirota, P. 1. Terasaki, A. Wakisaka, H. Togashi, D. Chia, N. Suyama, Y. Fukushi, E. Nudelman, and S-I. Hakomori. 1984. Characterization of sialosylated Lewis ${ }^{x}$ as a new tumor-associated antigen. Cancer Res 44:5279.

8. De Graaf, T. W., M. E. van der Stelt, M. G. Anbergen, and W. van Dijk.1993. Inflammation-induced expression of sialyl Lewis $\mathrm{x}$-containing glycan structures on $\alpha_{1}$-acid glycoprotein (orosomucoid) in human sera. J. Exp. Med. 177:657.

9. Walz. G., A. Aruffo, W. Kolanus, M. Bevilacqua, and B. Seed. 1990. Recognition by E-selectin of the sialyl-Le determinant on myeloid andtumor cells. Science 250:1132.

10. Bevilacqua, M. P., S. Stengelin, M. A. Gimbrone Jr., and B. Seed. 1989. Endothelial leukocyte adhesion molecule 1: an inducible receptor for neutrophils related to complement regulatory proteins and lectins. Science 243: 1160.

11. Johnston, G.I., R. G. Cook, and R. P. McEver. 1989. Cloning of GMP-140, a granule membranc protein of platelets and endothelium: sequence similarity to protcins involved in cell adhesion and inflammation. Cell 56: 1033.

12. Doukas, J., and J. S. Pober. 1990. IFN-Y enhances endothelial cellactivation induced by tumor necrosis factor but not IL-1. J. ImmunoL 145:1727.

13. Schumann, R. R., S. R. Leong, G. W. Flaggs, P. W. Gray, S. M. Wright. J. C. Mathison, P. S. Tobias, and R. J. Ulevitch, 1990. Structure and function of lipopolysaccharide binding protein. Science 249:1429.

14. Wright, S.D., R. A. Rumos, P. S. Tobias. R. J. Ulevitch, and J. C. Mathison. 1990. CD14, a receptor for complexes of lipopolysaccharide (L.PS) and LPS binding protein. Science 249:1431.

15. Frey, E. A., D. S. Miller, T. Gullstein Jahr, A. Sundan, V. Bazil, T. Espevik, B. B. Finlay, S. D. Wright. 1992. Soluble CD14 perticipates in the response of cells to lipopolysaccharide. J. Exp. Med. 176:1665.

16. Pugin, J., C-C. Schrürer-Maly, D. Leturcq, A. Moriarty, R. J. Ulevitch,and P. S. Tobias. 1993. Lipopolysaccharide activation of buman endothelial and epithelial cells is mediated by lipopolysaccharide-binding protein and soluble CD|4. Proc. Nall. Acad. Sel. USA 90:2744.

17. Haziot, A., G-W. Rong. J. Silver, and S. M. Goyert. 1993. Recombinant soluble CD14 mediates the activation of endothelial cells by lipopolysaccharide. J. Immunol 151:1500.

18. Moser, R., B. Schleiffenbaum, P. Groscurth, and J. Fehr. 1989. Interleukin 1 and tumor necrosis factor stimulate human vascular endothelial cells to promote transendothelial neutrophil passage. J. Clin. Invest. 83:444.

19. Lawrence, M. B., C. W. Smith, S. G. Eskin, and L. V. Melntire. 1990. Effect of venous shear stress on CD18-mediated neutrophil adhesion to cultured endothelium. Blood 75:227.

20. Lawrence, M. B., and T. A. Springer. 1991. Leukocytes roll on a selectin at physiologic flow rates: distinction from and prerequisit for adhesion through integrins. Cell 65:859.

21. Nathan, C. F. 1987. Neutrophil activation on biological surfaces. J. Clin. Invest. 80:1550.

22. Nathan, C., S. Srimal, C. Farber, E. Sanchez, L. Kabbash, A. Asch, J. Gailit, and S. D. Wright. 1989. Cytokine-induced respiratory burst of human neutrophils: dependence on extracellular matrix proteins and CD11/CD18 integrins. J. Cell Biol. 109:134I.

23. Nathan, C., and E. Sanchez. 1990. Tumor Necrosis Factor and CD11/CD18 $\left(B_{2}\right)$ integrins act synergistically to lower cAMP in humanneutrophils, $J$, Cell Biol. 111:2171.

24. Nathan, C., Q. Xic, L. Halbwachs-Mecarelli, and W. W. Jin. 1993. Albumin inhibits neutrophil spreadiug and hydrogen peroxide release byblocking the: shedding of CD43 (sialophorir, leukosialin). J. Cell Biol 122:243.

25. Nathan, C., and M. Sporn. 1991. Cytokines in context. J. Cell BioL 113:98I. 


\title{
TUMOR NECROSIS FACTOR- $\alpha$ (TNF) AND INTERLEUKIN 6 IN A ZYMOSAN INDUCED SHOCK MODEL
}

\author{
ECKHARDT J.U. VON ASMUTH, JOS G. MAESSEN, \\ CEES J. VAN DER LINDEN, WIM A. BUURMAN
}

Scand. J. Immunol. 1990, 32: 313-319

\section{Summary}

7 NF plays a central role in endotoxin or gram negative bacteria induced septic shock. Zymosan can elicit a 'septic shock' syndrome in rodents, in absence of endotoxin.

1 TNF and IL-6 release in mice treated with zymosan was investigated. One hour after intra-peritoneal zymosan injection, maximal TNF-levels were measured in serum, followed by IL-6 peak-levels one hour later. Treatment with a monoclonal antibody against TNF lowered zymosan-induced mortality from $63 \%$ to $11.6 \%$, while maximal IL-6 levels were lowered by $41 \%$.

Mechanisms triggering zymosan induced cytokine-release in murine macrophages were analyzed in vitro. Cytokine-release was only slightly triggered by uncoated zymosan particles. $39 \%$ of TNF-release by macrophages appeared to be triggered by zymosan-bound activated complement. Maximal TNF release also required presence of natural antibodies against zymosan and zymosan activated serum. In contrast, maximal IL-6 release was reached upon stimulation with zymosan activated serum only, whilst presence of zymosan particles lowered this response.

We conclude that TNF is a crucial mediator in zymosan provoked 'septic shock'. TNF relcase can be incited by different immunological pathways, without a need for direct presence of endotoxins. Although IL-6 release during septic shock is partly dependent of TNF, in vitro trigger mechanisms for IL-6 and TNF differ remarkably. 


\section{TNF and IL- 6 in zymosan induced shock}

\section{Introduction}

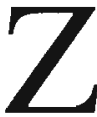

ymosan, a product consisting of purified bakers yeast ghost-cells, can delicit a 'septic shock' syndrome in germ-free rats(15). This finding gave a new impulse to the discussion whether septic shock and multiple organ failure are linked obligatory to bacterial endotoxin, or represent a general overshoot in the activation cascade of the immune-system.

Recent investigations demonstrated a pivotal role for the monokine Tumor Necrosis Factor (TNF) or Cachectin in mediating these mechanisms. A single dose of recombinant TNF given to rats provokes hypothermia, hypotension, metabolic acidosis and lethargy, finally followed by death(33). Histological changes such as hemorrhagic lungs, interstitial edema, margination of neutrophils in several organs, intestinal necrosis and necrosis of renal tubuli are found in this model(20). Comparable results have been achieved in dogs and mice $(4,35,24,21)$. These symptoms show great overlap with the phenomena seen after administration of bacterial endotoxin. Symptoms of endotoxin provoked septic shock could in turn be blocked effectively with antibodies directed against $\operatorname{TNF}(5,34)$.

TNF affects almost all cell types, inducing inflammatory as well as non-inflammatory responses. The pathways by which these responses are elicited are partly indirect, by provoking a release of other cytokines including IL-1, IL-6 and factors such as Platelet Activating Factor and prostaglandin E2 $(7,39,9,12)$. Both IL-1 and TNF have been shown to stimulate neutrophil adhesion to endothelium(26), the first step in the pro- cess of tissue infiltration by neutrophils. The importance of this facet was demonstrated by preventing MOF and mortality in a rabbit hemorrhagic shock model with adhesion blocking antibodies(36).

Recent investigations have shown that part of the effects for which IL-1 was held responsible, were in fact provoked by IL-6(18). The exact effects of IL-6 in vivo are still Jargely unresolved. IL-6, also called hybridoma growth factor, B2 interferon or B-cell stimulatory factor 2 , is a $26 \mathrm{kD}$ protein that has been shown to be related to acute inflammatory processes $(19,1)$. IL-6 production is demonstrated for macrophages, fibroblasts, and a variety of other cell types $(1,17,31)$.

IL-6 has shown to have hepatocyte stimulating activity, thereby regulating the major acute phase protein response(13). Furthermore it acts as an activator of T-cell proliferation and is considered to induce synthesis of immunoglobulins by B-cells(19).

The putative involvement of TNF and IL- 6 in zymosan provoked "septic shock" in mice was investigated. Serum levels of both cytokines were measured after a single intraperitoneal dose of zymosan. The effect of administration of an antibody directed against TNF, on survival and cytokine levels in mice treated with zymosan, was studied. Using an in vitro model, an attempt was made to reveal the pathways that contribute to the zymosanelicited TNF and IL- 6 production by murine macrophages. 


\section{Materials and Methods}

\section{Animals}

Female Swiss-mice of an age of 10 weeks, weighing 24-29 grams, were obtained from Charles River Breeding laboratories (Heidelberg, FRG). They were maintained on standard laboratory chow and were allowed free access to food and water.

\section{Reagents}

Zymosan A (Sigma, St Louis, MO) for in vivo use, was suspended in highly liquid paraffine (Merck, Darmstad, FRG) $25 \mathrm{~g}$ in $100 \mathrm{ml}$. To obtain a homogeneous suspension, zymosan was thoroughly mixed with a small amount of paraffine in a mortar. Paraffine was used rather than saline to permit slower contact with the zymosan(15). For the in vitro use, zymosan was suspended in distilled water, heated at $100^{\circ} \mathrm{C}$ for 60 minutes and washed twice in saline. A stock solution of $500 \mathrm{mg}$ in $10 \mathrm{ml}$ of phosphate buffered saline (PBS) was stored at $4^{\circ} \mathrm{C}$. TN3, a hamster monoclonal antibody specific for murine TNF and lymphotoxin, which inhibits the biological activity of these agents(32), was kindly provided by Drs Sheehan and Schreiber via Celltech, Slough, UK.

\section{In vivo study}

Mice were randomized in three groups on the day of the experiment. Group I $(n=46)$ was given zymosan, $25 \mathrm{mg}$ in $1.0 \mathrm{ml}$ of paraffine. Group $\Pi(n=28)$ was given TN3, 500 $\mu \mathrm{g}$ in $500 \mu l$ PBS, four hours prior to the administration of zymosan. A third group of 10 mice served as a control group and was given only $1.0 \mathrm{ml}$ paraffine. All substances were administered by intra-peritoneal injection. Visual signs of illness, body-weight and mortality were registered twice daily.

\section{In vitro study}

Macrophages were obtained by peritoneal rinsing of ether anaesthetized mice with $10 \mathrm{ml}$ RPMI 1640. The peritoneal macrophages were counted and concentrated to $5 \times 10^{5}$ cells/ml in RPMI. Experiments were performed in quadruplicate, using 96 well cluster plates (Costar, Cambridge, MA). Each well received $100 \mu \mathrm{l}$ macrophage-suspension, $50 \mu \mathrm{l}$ zymosan-suspension $(10 \mathrm{mg} / \mathrm{ml}$ in RPMI) or RPMI, $50 \mu 150 \%$ murine serum in RPMI or RPMI. Serum was obtained freshly by cardiac puncture of mice anaesthetized with ether, and kept at $4^{\circ} \mathrm{C}$. Zymosan-antibody free serum was made by adding an equal part zymosan suspension $(20 \mathrm{mg} / \mathrm{ml}$ in RPMI 1640) to the serum, followed by 30 minutes incubation on melting ice. Subsequently the serum was spun three times, in order to remove zymosan particles. Complement inactivation was performed by heating serum at $56^{\circ} \mathrm{C}$ for 30 minutes. Opsonized zymosan was prepared freshly by incubating zymosan with a $50 \%$ serum, 50\% RPMI 1640 mixture (5mg in $1 \mathrm{ml}$ ) for 30 minutes on melting ice, followed by three wash-steps to remove serum. Zymosan activated serum was prepared by performing the same procedure at $37^{\circ} \mathrm{C}$.

\section{TNF elisa}

96-Well immuno assay plates (Nunc, Roskilde, Denmark) were coated overnight at $4^{\circ} \mathrm{C}$ with TN3 $(5 \mu \mathrm{g} / \mathrm{ml})$. Plates were blocked with $1 \%$ (wt/vol) bovine serum albumin (BSA)(Sigma, St Louis, MO) in PBS for one hour at room temperature.

After four washings with wash-buffer (consisting of PBS, $0.1 \%$ BSA, $0.1 \%$ Tween 20 ) test samples were added to the plate for one hour at room temperature. A standard titra- 
tion curve was obtained by making serial dilutions of a known sample of recombinant murine TNF (Genzyme, Cambridge, MA) in medium identical to the test sample. Next. plates were washed four times with washbuffer and incubated with rabbit anti-mouse TNF immune serum (Genzyme) and peroxidase conjugated goat anti-rabbit IgG (Jackson, WestGrove, PA).

After adding the substrate (o-Phenylene-diamine, $0.43 \mathrm{mg} / \mathrm{ml}$, Sigma) to the plates for 10 minutes, the color-reaction was stopped with $1.0 \mathrm{M} \mathrm{H}_{2} \mathrm{SO}_{4}$ and photospectrometry (492 nm) was performed using a micro ELISA autoreader (Flow, Irvine, UK).

The ELISA has a lower detection limit of $150 \mathrm{pg} / \mathrm{ml}$.

\section{IL-6 bioassay}

The IL-6 dependent B9 cell-line(1), kindly provided by Dr L. van Aarden (CLB, Amsterdam, The Netherlands) was used to determine IL- 6 levels. Calculations were performed as described by S. Gillis et al(14).

In short: cells were cultured in $10 \%$ bovine calf serum (BCS) (Hyclone, Logan, Utah), 100 units $/ \mathrm{ml}$ Penicillin $\mathrm{G}$ and $100 \mu \mathrm{g} / \mathrm{ml}$ streptomycin in RPMI 1640 medium, containing 5 units IL-6/ml and grown in 96-well serocluster plates (Costar).

Cells were washed twice to remove IL 6 at the beginning of the assay, then brought to $5 \times 10^{4}$ cells/ml and transferred to RPMI 1640 containing $10 \% \mathrm{BCS}$ and gentamicin.

Serial dilutions of the test samples were added to the wells. A standard titration curve was made with recombinant human IL-6 sample kindly provided by $\mathrm{Dr} L$. van Aarden. After 68 hours of culture at $37^{\circ} \mathrm{C}$, cells were incubated for four hours with $0.25 \mu \mathrm{Ci}$ ${ }^{3} \mathrm{HTdR}$ (specific activity $5.0 \mathrm{Ci} / \mathrm{mM}$ ).
Cell-proliferation was defined by measuring ${ }^{3} \mathrm{HTdR}$ uptake in a liquid scintillation counter.

\section{Statistics}

Statistical significance was determined using the Students $t$ test and the chi square test. A p-value less than 0.05 was considered to be significant.

\section{Results}

In vivo study

Shortly after intra-peritoncal injection of $25 \mathrm{mg}$ zymosan, mice becane lethargic and stopped eating. Within hours they developed symptoms like rugged fleece, tachypnoea, swollen mucous membranes and diarrhoea. In a group of 20 animals, IL- 6 and TNF serum concentrations were measured (Fig. I). Both cytokines appeared rapidly after zymosan injection in the serum. Peak levels were reached at one hour tor TNF, at two hours for IL- 6 , followed by a steep decline.

Treatment with monoclonal antibodies against TNF, four hours before administration of zymosan, resulted in lowering the peak-level of IL- 6 serum-concentration from 1160 units $/ \mathrm{ml}$ to 690 units $/ \mathrm{ml}$, whilst $500 \mu \mathrm{g}$ of TN3 showed adequate to prevent measurable TNF serum-concentrations. Serum samples of mice in the paraffine treated control group, showed elevation of neither IL-6 nor TNF level.

Investigations about the influence of monoclonal antibodies against TNF on zymosaninduced mortality were performed by comparing three groups of mice; group A (10 mice) who received $1.0 \mathrm{ml}$ paralfine. group B (46 mice) who received $25 \mathrm{mg}$ zymosan suspended in $1.0 \mathrm{ml}$ paraffine, and group $\mathrm{C}$ 

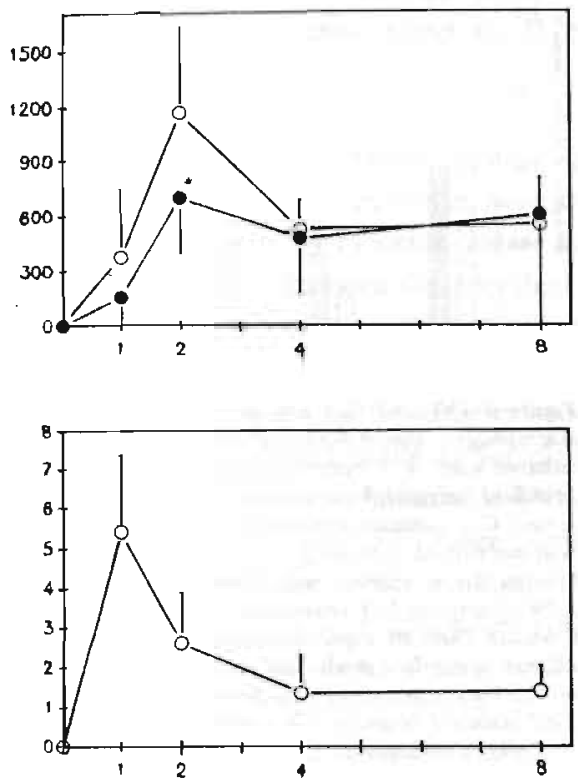

Figure 1. $I L-6(A)$ and TNF (B) serumconcentrations during first 8 hours after intra-peritoneal administration of $25 \mathrm{mg}$ zymosan. Open circles represent cytokine-levels in zymosan-treated mice, filled circles represent cytokinelevels in zymosan plus TN3 treated mice. During the first eight hours TNF serumlevels in TN3 treated mice were below defection limit. Data are expressed as means ( $n=4)$ $\pm S D$.

* $P=0.137$ compared with zymosan only $T=2 h$.

(26 mice) who received $500 \mu \mathrm{g}$ antiserum against TNF, four hours before zymosanadministration.

After two days of severe illness in group B and $\mathrm{C}$ (in both groups a weight-loss of about 4.5 grams was recorded), $63.0 \%$ of the mice in group $\mathrm{B}$ died. Mortality in group $\mathrm{C}$ was reduced to $11.6 \%$, which implicates that treatment with TN3 prevents more than $80 \%$ of zymosan induced mortality in this situation (Fig. 2). Weight recovery began three days after zymosan-injection. appearing

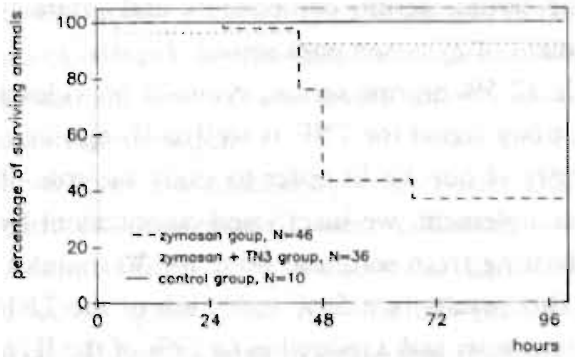

Figure 2 Influence of administration of antibodies directed against TNF on mortality in $25 \mathrm{mg}$ zymosan treated mice. In the period between 4 days and the end of the observation period at 13 days after zymosan administration, no mortality was recorded.

* Difference in mortality between zymosan treated mice with and without TN3 pretreatment is highly significant, $(p<0.001)$.

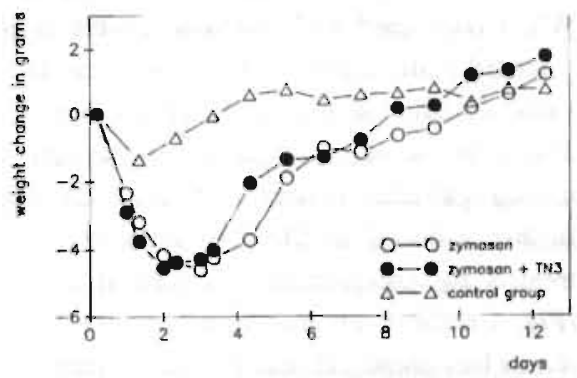

Figure 3 Change body-weight during first 12 days after treatment with zymosan, intervention with TN3, or paraf. fine only (control group). Data are expressed as means of the mice shown in Figure 2. The zymosan/paraffine administration directly before the first measurement resulted in a rise in body-weight of 0.9 grams.

slightly faster in group $\mathrm{C}$ as in the survivors of group B, and was complete after 11 days (Fig. 3).

\section{In vitro study}

Production of both cytokines by freshly isolated peritoneal macrophages was measured after 6 hours of exposure to zymosan at 
$37^{\circ} \mathrm{C}$. In this model we studied the influence of serum, serum components and pretreatment of zymosan with serum (Fig.4).

In $12.5 \%$ murine serum, zymosan provides a strong signal for TNF as well as $\Pi$ L- 6 release (Fig. 4 bar A). In order to study the role of complement, we inactivated complement by heating fresh serum to $56^{\circ} \mathrm{C}$ for 30 minutes. This results in a $56 \%$ reduction of the TNF response, and a reduction to $19 \%$ of the IL- 6 response (Fig. 4 bar B) on zymosan stimulation in presence of normal serum (standard stimulation).

The role of zymosan activated serum and serum opsonized zymosan particles was tested by separating serum and zymosan particles after an incubation period of 30 minutes. When compared with cytokine levels after standard stimulation, TNF response on activated serum was only $20 \%$ (Fig. 4 bar C). The response of macrophages to the serum treated particles reached $70 \%$, which was further reduced to $20 \%$ if particles were treated by complement inactivated serum (Fig. 5 respectively bar $A$ and bar $B$ ). Thus, it can be concluded that the major stimulus for TNF-production is formed by zymosan particles opsonized by complement.

The IL- 6 response on complement opsonized zymosan particles does hardly exceed spontaneous release (Fig. 5 respectively bar $A$ and bar $D$ ). Activated serum without zymosan particles however appeared to trigger IL6 levels nearly twice as high $(196 \%)$ as in the same medium with zymosan particles still present (Fig. 4 respectively bar $C$ and bar A). This value showed the highest variation in a series of experiments, which appeared to be dependent on low contamination with zymo-

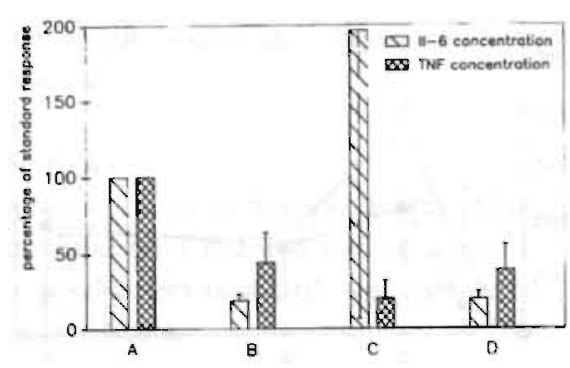

Figure 4 TNF and $I L-6$ release by murine peritoneal macrophages, after 6 hours culture. Macrophages were cultured with: $A=$ zymosan in unireated fresh serum (standard release) $\boldsymbol{B}=$ zymosan in heat inactivated serwn; $C=$ zymosan activated serum; $D=$ zymosan in heat inactivased, antibody free serum. Spontaneous cytokine release in cultures with untreated serum reached $3.7 \%$ of standard TNF relcase and $19.4 \%$ of standard $I L$ 6 release. Data are expressed as means $(n=4) \pm S . D$. in relation to cytokine production in cultures with zymosan in $12.5 \%$ untreated serum (standard response). This standard response (expressed as $100 \%$ ) reaches $18 \mathrm{ng} / \mathrm{ml}$ TNF and 9,600 units/ml IL-6.

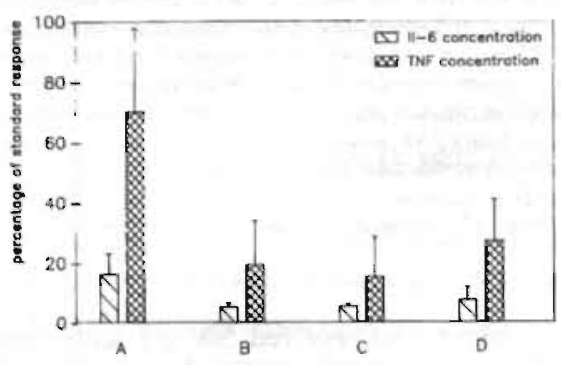

Figure 5 TNF and $I L-6$ release by macrophages afier exposure to zymosan, in serumfree medium. Macrophages were cultured 6 hours at $37{ }^{\circ} \mathrm{C}$ with: $\mathrm{A}=$ zymosan opsonized with normal serum: $B=$ zymosan opsonized with heat inactivated serum; $C=$ unopsonized zmosan: $D=$ medium without zymosin. Data are expressed as means $(n=4) \pm S . D$. in relation to the standard response (see Fig. 4).

san particles caused by insufficient spinningout of these particles. Therefore we conclude that in this model IL-6 release is mainly induced by zymosan activated serum. 
Even small amounts of zymosan particles appear to have a negative effect on IL-6 release.

To investigate whether natural occurring antibodies directed against zymosan, have an important function in the cytokine release as measured above, we removed these antibodies from heat inactivated serum (removing antibodies from normal serum would also diminish complement activity) as described. Zymosan particles in such antibody depleted and heat inactivated serum induced a TNFresponse which was only 5\% lower compared to TNF-responses upon zymosan in heat inactivated serum with antibodies still present (Fig. 4 respectively bar $D$ and bar $B$ ). IL-6 release upon zymosan in heat inactivated serum was not influenced by antibodyremoval.

\section{Discussion}

In this study, we show that one hour after intra peritoneal zymosan administration in mice, a peak-concentration of TNF can be measured in serum. Furthermore, circulating TNF can be reduced for almost $100 \%$ by injecting a monoclonal antibody directed against TNF.

This inhibition of biologically active TNF is shown to be associated with a reduced severeness of the zymosan provoked illness as reflected by significantly lower mortality rates. Therefore we conclude that TNF can be considered to be a pivotal mediator in zymosan provoked shock, a role which TNF also is thought to play in $\operatorname{sepsis}(5,34,10,3)$. IL- 6 has been measured in serum from patients with meningococcal septic shock (37), in serum of renal transplant recipients(23) and in synovial fluids of patients with rheumatoid arthritis(16). IL-6 serum levels might be a good grade-indicator of the shock-syndrome provoked by zymosan. We measured IL-6 serum levels shortly after zymosan injection.

Peak levels were reached one hour after TNF: had its maximal serum concentration. Administration of a monoclonal antibody directed against TNF reduced this peak by $41 \%$. These findings indicate that IL-6 may in part be provoked by TNF or by TNF relat ed events.

Similar data were obtained after administration of bacterial endotoxin in mice (manuscript submitted for publication).

However, the data also indicate that other important lL-6 triggering mechanisms exist. Furthermore, it appeared that animals receiving TNF-neutralizing antibodies developed severe symptoms of illness, indicating that besides TNF other factors are involved in the pathogenesis of zymosan induced shock.

The mechanisms which mediate the release of TNF and IL- 6 after exposure to zymosan were investigated in vitro experiments.

Zymosan consists of ghost cells derived from bakers yeast and contains primarily polysaccharides without detectable protein(25). So far three mechanisms are known, by which zymosan can trigger an immune response. Firstly, normal serum contains natural IgG immunoglobulins which bind to zymo$\operatorname{san}(30)$. Complexes formed this way activate the classical pathway of the complement system, and may elicit TNF-release by crosslinking macrophage $\mathrm{Fc}$-receptors(11).

Secondly, receptor mediated binding and ingestion of the zymosan particle can occur. Complement receptor 3 , which is present on macrophages as well as granulocytes, has 
two binding-sites: a lectin-like region, with direct binding-potential to zymosan, bacterial endotoxin etc., and an iC $3 b$ specific binding site(38). The latter function results, in synergistic cooperation with CRI, in increased binding and ingestion of complement-opsonized particles(28). Thirdly, the binding of $\mathrm{C} 3 \mathrm{~b}$ to the zymosan-surface results in increased conversion of $\mathrm{C} 5$ to C5a(29), which has been shown to trigger monocyte TNF-release(22).

Figure 6 summarizes the different pathways by which zymosan triggers macrophage TNF and $\mathrm{IL}-6$ release in medium containing $12.5 \%$ serum, as they can be deduced from our in vitro experiments.

TNF release appeared to be dependent on all three groups of mechanisms cited above, although the effects that can be contributed to macrophage Fc-receptor crosslinking seems to be small and is therefore not significant in this series of experiments. Surprisingly, serumfree culture of macrophages in presence of bare zymosan particles does not trigger more TNF release than control cultures do.

An explanation for this finding might be that the very same meehanism that underlies TNF release induced by bare zymosan particles, is also triggered by plastic surfaces not coated with serum proteins.

The relevance of this specification of trigger mechanisms for macrophage TNF release might be, that the connection between bacterial endotoxin and TNF release is not as direct and unique as is often thought.

Parallel to this, also the septic shock syndrome might, for as far as it is related more to systemic TNF levels than systemic endo-

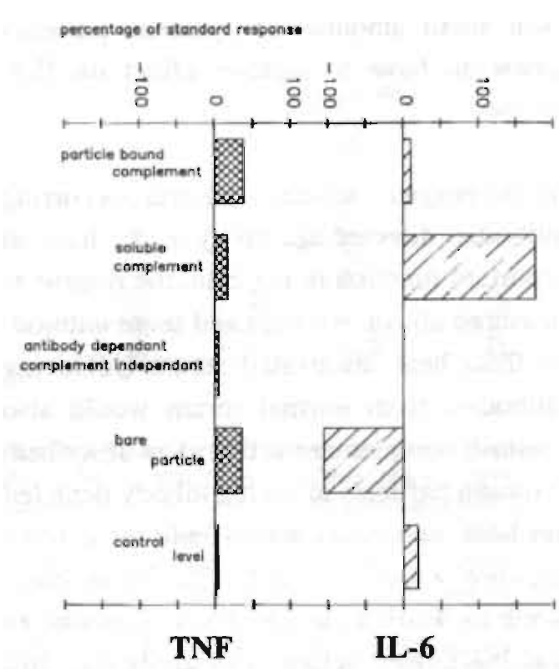

Figure 6 Contributions of particle bound complemens, soluble complement, antibody dependent and comple. ment independent activation, bare zymosan particles and spontaneous release in the standard macrophage II. 6 and TNF response (sce Fig. 4). Data shown here are interpretations which can be dedured directly from the data as shown in Fig.4

toxin challenge, be due to a general activation of immunological systems, more than to bacterial infections directly.

The IL- 6 triggering capacity of the different mechanisms investigated here, showed a completely different pattern (see Fig. 6 for summarized data). Whereas several pathways add synergistically to incite macrophage TNF release, highest IL- 6 levels are reached upon culturing macrophages in zymosan activated serum.

The induction of IL-6 release by particle bound complement is very low compared to serum containing activated complement.

Fc-receptor mediated triggering of macrophages fails to induce extra IL- 6 release in this model. The linkage between IL -6 release and soluble activated complement is stressed 
by the finding that presence of zymosan particles even lowers IL-6 release. Moreover, serumfree culture of macrophages with zymosan particles opsonized with unheated serum results in a lower IL-6 release than the spontaneous release measured in $12.5 \%$ serum. TNF levels, in contrast, reached up to $51 \mathrm{ng} / \mathrm{ml}$ in the same cultures (unheated serum opsonized zymosan particles in serumfree medium), whilst spontaneous release in serum was $0.9 \mathrm{ng} / \mathrm{ml}$.

Thus, although there are several reports of IL- 6 release induced by TNF exposure in vivo and in vitro $(39,8,31,6)$, the relationship between these two cytokines might be much more complex than a simple causal system. TNF and IL- 6 but also TNF and IL-1(27) can be induced separately.

It appears that these cytokines, which have closely linked biological effects, each have their own pattern of triggers or conditions which regulate their release. Compared to other mainly quantitative humoral systems, like the clotting cascade or the complement system, relations in the network of cytokines might have much more distinguished qualitative aspects.

\section{References}

1. Aarden, L.A., dc Grool, E.R., Schaap, E.L. \& Lansdorp, P.M. Production of hybridoma growth factor by burnan monocytes. Eur. J. Immunol. 17, 1411, 1987.

2. Bakenhof, J.P.J., de Groot, E.R., Evers, R.F., Pannekcek. H. \& Aarden, L. Molecular Cloning and expression of hybridoma growth factor in Escherichia Coli. J. Immunol. 139, 4116, 1987.

3. Beutler, B. \& Cerami, A. The endogenous mediator of endotoxin sbock. Clin. Res. 34, 192, 1986.

4. Beutler, B.A., Milsark, I.W. \& Cerami, A. Cachectin tumor necrasis factor: production, distribution, and metabolic fate in vivo. J. Immunol. 135, 3972, 1985.

5. Beutler, B., Milsar, I.W. \& Cerami, A.C. Passive immunisation against cachectin/tumor necrosis factor protects mice from lethal effect of endotoxin. Science 229, 869, 1985.
6. Brouckaert, P., Spriggs, D.R., Demetri, G, Kufe, D.W. \& Fiers, W. Circulating Interleukin 6 during a continuous infusion of Tumor Necrosis Factor and Interferon gamma. J. Exp. Med. 169, 2257, 1989.

7. Camussi, G., Bussolino, F., Salvidio, G. \& Baglioni, C Tumor Necrosis Factor/Cachectin stimulates Peritoneal Macrophages. Polymorphonuclear Neutrophils, and Vascular Endothelial Cells to synthesize and release Platclet-Activatin Factor. J. Exp. Med. 166, $1390,1987$.

8. Van Damme, J., Opdenakker, G., Simpson, R.J., Rubira, M.R., Cayphas, S. Vink, A., Billiau, A \& van Snick, J. Indentification of the $26 \mathrm{kD}$ protein, interferon B2 (IFN-B2) as a B-cell hybridoma/plasmocyloma growth factor induced by interleukin 1 und tumor necrosis factor. J. Exp. Med. 165, 914, 1987.

9. Dayer, J.M., Beutler, B. \& Cerami, A. Cachectin/ tumor necrosis factor stimulates collagenase and prostaglandin $\mathrm{E} 2$ production by human synovial cells and dermal fibroblasts. J. Exp. Med. 162, 2163, 1985.

11. Debets, J.M.H., van der Linden, C.J., Dicteren, I.E.M., Leeuwenberg, J.F.M. \& Buurman, W.A. FE-recptor cross-linking induces rapid secretion of tumor necrosis factor (cachectin) by human peripheral blood monocytes. J. Immunol. 141, 1197-1201, 1988.

10. Debets, J.H.M.. Kampmeijer, R., van der Linden, M.P. M.H., Buurman, W.A. \& van der Linden, C.J. Plasma tumor necrosis factor and mortality in critically ill septic paticnts. Crit. Care. Med. 17, 489, 1989.

12. Dinarello, C.A., Cannon, J.G., Wolf, S.M. Bernheim, H.A., Beutler, B., Figari, I.S., Palladino, M.A. \& O'Connor, J.V., Tumor necrosis Factor (cachectin) is an endogenous pyrogen and induces production of interleukin-1. J. Exp. Med. 163, 1433, 1986.

13. Gauldie, J., Richards, C., Harnish, D., Lansdorp, P. \& Bauman. H. Interferon B2/B cell stimulatory factor type-2 shares identity with monocyte-derived hepatocyte-stimulating factor and regulates the major acute phase protein response in liver cells. Proc. NatL. Acad. Sci. USA. 84, 7251, 1987.

14. Gillis, S., Fern, M.M., Ou, W. \& Smith, K.A. T cell growth factor: parameters of production and a quantitative microassay for activity. J. ImmunoL 120, $2027,1978$.

15. Goris. R.J.A., Boekholiz, W.K.F, van Bebber, I.P.T., Nuytink, J.K.S. \& Schillings, P.H.M. Multiple organ failure and sepsis without bacteria. Arch. Surg. 121, 897, 1986.

16. Guerne, P.A., Zuraw, B.L., Vaughan, J.H., Carson, D.A. \& Lotz, M. Synovium as a source of II. 6 in. vitro. J. Clin. Invest. 83, 585, 1989.

17. Haegeman, G., Content, J., Volekaer, G., Derynck, R., Tavernier, J. \& Fiers, W. Structural analysis of the secquence coding for an inducable $26-\mathrm{kDa}$ protein in human fibroblasts. Ear. J. Biochem. 159, 625, 1986.

18. Helle. M., Brakeshoff, J.P.J., de Groot, E.R. \& Aarden. L. Interleukin 6 is involved in Interleukin 1induced activities. Eur. J. Immunol. 18, 957, 1988.

19. Hirano, T., Yusukawa, K., Harada, H., Taga, T., Waunnabe, Y., Matsuda, T., Kashiwaunura, S.. Iwamatsu, A, 


\section{TNF and IL-6 in zymosan induced shock}

Tsunasawa, S., Sakjyama, F., Matsui, H., Takahara, Y., Taniguchi, T. \& Kishimoto, T., Complementary DNA for a novel Interleukin (BSF-2) that induces B lymphocytes to produce immunolglobulin. Nature 324, 73,1986 .

20. Kettelhut, I.C., Fiers, W. \& Goldberg, A.L. The toxic effects of tumor necrosis factor in vivo and their prevention by cyclooxygenease inhibitors. Proc. Nall Acad. Sci. USA 4273, 1984.

21. Natanson, C., Eichenholz, P.W., Danner, R.L. Eichacker, P.Q., Hoffman, W.D., Kuo, G.C., Banks, S.M., MacVittie, T.J. \& Parrillo, J.E., Endotoxin and tumor necrosis factor challenges in dogs simulate the cardiovascular profile of human septic shock. J. Exp. Med. 169, 823, 1989.

22. Okusawa, S., Yancey, K.B., van der Meer, J.W.M., Endres, S., Lonneman, G.. Hefter. K., Frank, M.M., Burke, J.F., Dinarello, C.A. \& Gelfand, J.A. C5a stimulates secretion of tumor necrosis factor from human mononuclear cells in vitro. J. Exp. Med. 168, 443, 1988.

23. van Oers, M.H.J., van der Heyden, A.A.P.A.M. \& van Aarden, L. Interleukin-6 (II-6) in serum and urine of renal transplant recipients. Clin. Exp. ImmunoL 7I, 314, 1988.

24. Oliff, A., Defeo-Jones, D., Boyer, M., Martinez, D., Kiefer, D., Vuocolo, G., Wolfe, A. \& Socher, S.A. Tumors secreting human TNF/Cachectin induce cachexia in Mice. Cell 50, 555, 1987.

25. Pillemer, L. \& Ecker, E.E. Anticomplementary factor in fresh yeast. J. Biol. Chem. 137, 13, 1941.

26. Pohlman, T.H., Stanness, K.A., Beatty, P.G., Ochs, H.D. \& Harlan, J.M., An Endothelial Cell Surface Factor(s) Induce in Vitro by Lipopolysaccharide. Interleukin 1, and Tumor Necrosis Factor-alpha, Increases Neutrophil Adherence by a C.Dw18-dependent Mechanism. J. ImmunoL 136, 4548, 1986.

27. Riesenfeld-Orn, I., Wolpe, S., Garcia-Bustos, J.F. Hoffinann. M.K. \& Tuomanen. E. Production of Interleukin 1 but not Tumor Necrosis Factor by human monocytes stimulated with pneumococcal cell surface components. Infect. Imm. 57, 1890, 1989.

28. Ross, G.D., Cain, J.A. \& Lachmann, PJ. Membrane complement receptor type three (CR3) has lectin-like properties analogous to bovine conglutinin and func. tions as a receptor for zymosan and rabbit erythrecytes as well as a receptor for iC3b. J. Immunol. 134, 3.307, 1985.

29. Schenkein. H.A. \& Ruddy. S. The role of Immunoglobulins in alternative pathway activation by zymosan. II. The effect of IgG on the kineties of the alternative pathway. J. Immunol. $126,11,1981$.

30. Schenkein, H.A. \& Ruddy, S. The role of immunoglobulins in alternative pathway activation by zymo. san.l. Human IgG with specificity for Zymosan enhances alternative pathway activation by Zymosan. J. Immunol. 126, 7, 1981 .

31. Shalaby, M.R., Waage, A. \& Espevik, T. Cytokine regulation of Interelukin 6 production by human endothelial cells. Cell ImmunoL 121, 372, 1989.

32. Sheehan, K.C.F., Ruddle, N.H. \& Schreiber. R.D. Generation and characterisation of hamster monoclo- nal antibodies that neutralizes Murine Tumor Necrosis Factors. J. Immunol. 142, 3884, 1989.

33. Tracey, K.J.B., Beutler, B., Lowry, S.F, Merryweath. er, J., Wolpe, S. \& Milsark. I.W. ct al Shock and Tissue Injury Induced by Recombinant Human Cachec. tin. Science 234, 470, 1984.

34. Tracey, K.J., Fong, Y., Hesse, D.G., Manogue, K.J., Lee, A.T. Kuo, G.C., Lowry, S.F. \& Cerami, A. Anti Cachectin TNF monoclonal antibodies prevent septic shock during Lethal bacteraemia. Nature 330, $662,1987$.

35. Tracey, K.J., Lowry, S.F, Fahey III, T.J., Albert, J.D., Fong, Y., Hesse, D., Beutler, B., Manogue, K.R., Calavano, S., Wei, H., Cerami, A. \& Shires, G.T. CachectirfTNF induces lethal shock and stress hormone in dog. Surg. Gynaecol. Obstet. 164, 415, 1987.

36. Vedder, N.B., Winn, R.K., Rice, C.L., Chi, E.Y., Arfors, K.E. \& Harlan, J.M. A Monoclonal Antibody to the Adherence-promoting Leukocyte Glycoprotein CD18, Reduces Organ injury and Improves Survival from Hemorrhagic Shock and Resuscitation in Rabbits. J. Clin. Invest. 81,939, 1988.

37. Waage, A., Brandtzaeg, P., Halstensen, A., Kierulf, P. \& Espevik, T. The complex pattern of cytokines in serum from patients with menigococcal septic shock. J. Exp. Med. 169, 333, 1989.

38. Wright, S.D., Levin, S.M., Jong. M.T.C., Chad, Z \& Kabbash, L.G. CR3 (CD11b/CD18) expresses one binding site for Arg-Gly-Asp containing peptides and a second site for bacterial lipopoly saccharide. $\boldsymbol{J}$. Exp. Med. 169, 175, 1989.

39. Zhang, Y, Lin, J X. \& Vilcek, J. Synthesis of Interleukin 6 (Interferon-B2/ B cell stimulatory factor 2) in human fibroblasts is uriggered by an increase of intracellular cyclic AMP*. J. BioL Chem. 263, 6177, 1988. 


\section{IL-6, IL-8 AND TNF PRODUCTION BY \\ CYTOKINE AND LIPOPOLYSACCHARIDE- STIMULATED HUMAN RENAL CORTICAL EPITHELIAL CELLS IN VITRO}

ECKHARDT J. U. VON ASMUTH, MIEKE A. DENTENER, MIROSLAW CESKA ${ }^{1}$ AND WIM A.BUURMAN

'Sandoz Forschungsinstitut, Wien, Austria

Eur. Cytokine Netw., 1994 5:301-310

\section{Abstract}

7 he capacity of renal epithelial cells to produce IL-6, IL-8 and TNF was investigated. Cultures of explanted human renal cortical epithelial cells (RCEC) were established,

1 and cytokine-release and mRNA expression by these cells were measured. IL-6, IL-8 and TNF release were measured after stimulation with IL-1 $\beta$, TNF- $\alpha$, LPS and the phorbol esther PMA. All these agents were found to induce increased release of all three cytokines. Whilst no spontaneous TNF-release occurred, IL-6 and IL- 8 were continuously released by non-stimulated RCEC cultures. IL-1 $\beta$ was the most potent trigger enhancing both RCEC cytokine release and expression of IL-6, IL- 8 and TNF mRNA. Indomethacin, budesonide, cyclosporin and FK 506 were tested for their influence on RCEC cytokine release. Only the steroid budesonide appeared to reduce both spontaneous and IL-1 $\beta$ induced cytokine release.

Our data demonstrate stimulus specific release of IL-6, IL- 8 and TNF by RCEC, and suggest that cytokine cell-to-cell communication may be important in regulating inflammatory processes in the kidney. 


\section{Cylokine production by renal epithelial cells}

\section{Introduction}

$\mathrm{R}$ enal allograft rejection, and a number of auto-immune syndromes can Cytokines are generally considered to be mediators responsible for immune-injury leading to progressive cell-death and organ disfunction. Several lines of evidence support such a role for TNF in renal injury.

In vitro studies demonstrated that TNF triggers toxicity of neutrophils $(1,2)$ and eosinophils (3), functions as a co-stimulatory factor for T-cells $(4,5)$, but can also induce pro-inflammatory changes in endothelial cells $(6,7)$, renal mesangial cells $(8,9)$ and other non hematopoietic cells.

In vivo, infusion of TNF was shown to induce glomerular damage in rabbits (10), to potentiate renal damage caused by ischemia in rats (11), to accelerate renal disease and mortality in a murine model for lupus nephritis (12) and to cause exacerbation of antibody-mediated glomerular injury in rats (13). Furthermore, a positive correlation of renal expression of TNF mRNA with disease activity in mice with lupus nephritis (12) and rats with immune-complex glomerulonephritis has been described (14).

In a rat model for nephrotoxic serum nephritis, inhibition of renal injury by administration of anti-TNF antibodies was demonstrated (15). In humans, presence of TNF and IL-6 in serum (16-20) and increased renal TNF and IL-6 mRNA expression $(21,22)$ has been demonstrated during renal allograft-rejection. Besides suggesting involvement of TNF in inflammatory renal injury, the presence of mRNA also raised the possibility that renal cells would produce and secrete TNF and IL-6. TNF-production, both in vitro by monocytes or in vivo, is accompanied by production of IL- 6 and IL- 8 .

Although IL-6 and IL-8 have not been described to be directly responsible for tissue-injury, these cytokines act in concert with TNF to modulate inflammatory processes. IL- 6 and IL- 8 are released by hemopoietic as well as non-hemopoietic cells such as endothelial cells and fibroblasts in response to bacterial LPS, cytokines and other stimuli $(7,23-26)$.

IL-6 is a multi-potential inflammatory cytokine which induces acute phase protein synthesis by the liver (27), maturation of B-cells (28) and activation of T-cells (29). IL-6 has, however, also an anti-inflammatory role by down-regulating TNF-release upon LPSchallenge (23). IL-8 mainly acts on neutrophils; IL-8 regulates transendothelial migration (26, 30), and induces neutrophil activation (31).

In this study, we investigated whether cultured human RCEC can be triggered to release $\mathrm{IL}-6, \mathrm{lL}-8$ and TNF. Furthermore, we studied the regulation of the release of thesc cytokines.

\section{Material and methods \\ Reagents}

rh TNF- $\alpha$ was kindly provided by BASF/ Knoll AG. (Ludwigshafen, FRG). miL-1 $\beta$ was a kind gift of Dr. S. Gillis (Immunex, Seattle, WA). LPS (phenol extract of E. Coli 055:B5) and PMA were purchased from Sigma (St. Louis, MO).

\section{RCEC culture}

RCEC explant cultures were obtained using previously described techniques (32). Briefly, small biopsies from the human renal cor- 
tex were obtained from kidneys not suitable for transplantation for technical reasons. The capsula was removed and the cortex-tissue was cut into small pieces, which were incubated in $0.25 \%$ trypsin for 25 minutes at $37^{\circ} \mathrm{C}$. The mixture was then filtered through one layer of sterile gauze to remove glomeruli, the filtrate was centrifuged, and the pellet was resuspended in RPMI-1640 (Gibco Europe, Paisley, Scotland) supplemented with $10 \%$ heat-inactivated bovine calf serum (BCS) (Hyclone, Logan, UT) and antibiotics.

The mixture was placed in fibronectin coated (fibronectin kindly provided by Dr. J. van Mourik, CLB, Amsterdam, The Netherlands) tissue culture flasks (Costar, Cambridge, MA). When confluent, the monolayers were subcultured by harvesting the cells by addition of trypsin-EDTA $\left(0.05 \%, 0.02 \%\right.$ in $\mathrm{Ca}^{++}$ $\mathrm{Mg}$ " free PBS), and redistributed to new flasks at a 1:3 subculture ratio. Cells were redistributed 3 times before use in the experiments.

\section{RCEC characterization}

The cultured renal cortical cells showed a pavement-like monolayer morphology which remained stable for 5 to 6 redistribution cycles. Functional characteristics of subcultures gained by above described procedures have been extensively studied, showing that these cells retain a number of functional characteristics typical of the proximal tubule (32). The cultured RCEC were characterized by immunofluorescence examination.

No cells showed positive staining after incubating TNF-activated monolayers with an anti E-selectin mAb, excluding endothelial cell contamination. Also, no cells showing positive staining after incubation with an
anti-CD14 mAb, excluding contamination with mononuclear phagocytes. Bright fluorescence, consistent with intermediate filaments, was seen for all cells using an anticytokeratin monoclonal antibody.

This monoclonal antibody staining pattern is consistent with a homogenous primary culture of cells of epithelial origin.

\section{Culture of human umbilical vein endothelial cells (HUVEC) and human dermal fibroblasts.}

HUVEC were obtained by collagenase treatment of the human umbilical vein. The cells were cultured in fibronectin-coated tissue culture flasks in RPMI-1640, supplemented with $10 \%$ heat-inactivated human serum, $10 \% \mathrm{BCS}, 50 \mu \mathrm{g} / \mathrm{ml}$ heparin (Sigma), 30 $\mu \mathrm{g} / \mathrm{ml}$ endothelial growth supplement (Collaborative Research Incorporated, Bedford, MA) and antibiotics.

Endothelial cells were characterized by their pavement-like monolayer morphology and by positive staining with an anti E-selectin $\mathrm{mAb}$ after $4 \mathrm{~h}$ incubation with TNF. Cells of passage 3 to 4 were used for the experiments.

Human dermal fibroblasts (kindly provided by the department of Human Genetics, University of Limburg, The Netherlands) were propagated in RPMI-1640 supplemented with $10 \% \mathrm{BCS}$ and antibiotics in fibronectin coated tissue culture flasks and characterized by their spindle-like morphology. Endothelial cell contamination was absent, as concluded from negative staining with an anti E-selectin $\mathrm{mAb}$ after $4 \mathrm{~h}$ incubation with TNF. Cells of passage 6 to 10 were used for the experiments. 


\section{Induction of cytokine release}

HUVEC, RCEC, and human fibroblasts were sceded at $10^{\circ}$ cells/well in fibronectin-coated 96-well flat-bottom tissue culture plates (Costar) in culture medium, one day prior to stimulation.

The cells were rinsed twice with RPMI- 1640 and the medium was replaced by the appropriate agents in RPMI- 1640 supplemented with $10 \%$ BCS and antibiotics. Media and preparations of TNF, IL-1 $\beta$ and PMA were tested for endotoxin contamination by the chromogenic limulus amoebocyle lysate assay (Coatest, Kabi Diagnostica, Nyköping, Sweden), and were found to contain less than $5 \mathrm{pg} / \mathrm{ml}$ LPS in final solutions. Supernatants were harvested and kept at $-20^{\circ} \mathrm{C}$ until use in the IL-6, IL. 8 and TNF ELLISA.

\section{$I L-6, I L-8$ and TNF ELISA}

The culture supernatant IL-6, IL-8 and TNF concentrations were determined using previously described sandwich-ELISA for IL-6 (33), IL-8 (34) and TNF (35). In short, 96-well immuno maxisorp plates (Nunc, Roskilde, Denmark) were coated with cytokine-specific murine mAb; for IL-6 a newly developed IL-6 specific mAb 5E1 was used. rhIL 6, a generous gift from Prof. Dr. W. Sebald (Physiologisch-Chemisches Institut der Universität, Würzberg. FRG), rhIL-8 and rhTNF $-\alpha$ were used for standard titration curves. Test samples were added.

Next polyclonal rabbit anti-human IL-6 antiserum and polyclonal rabbit anti-human TNF- $\alpha$ were added, followed by peroxidase conjugated goat anti-rabbit IgG (Jackson, Westgrove, PA) for the IL-6 and TNF-ELISA respectively. Phosphatase conjugated polyclonal goat anti-human IL-8 was used for the IL-8 ELISA. O-Phenylene-diamine (Sigma) was added as a substrate for peroxidase and p-nitrophenyl phosphate (Sigma) as a substrate for phosphatase. Photospectometry was performed at $492 \mathrm{~nm}$ (IL-6 and TNF ELISA) and $405 \mathrm{~nm}$ (IL-8 ELISA). The ELISA lower detection limits were $10 \mathrm{pg} / \mathrm{ml}$ IL- $6,100 \mathrm{pg} / \mathrm{ml} \mathrm{IL-} 8$ and $10 \mathrm{pg} / \mathrm{ml}$ TNF- $\alpha$.

\section{Preparation and analysis of RNA}

RCEC were grown and stimulated as described in $150 \mathrm{~cm}^{2}$ tissue culture flasks (Costar). Total cellular RNA was isolated as described (36). RNA samples were treated as recommended by Amersham and applied onto a $\mathrm{N}^{+}$Membrane (Amersham, Buckinghamshire, UK), using a Biodot apparatus (Biorad, Richmond, CA). cDNA probes were labeled with ${ }^{3} \mathrm{P}$ dCTP using the random primer labeling kit of Boehringer Mannheim (Boehringer Mannheim, Mannheim, FRG) and hybridized to the blot $\left(10^{6} \mathrm{cpm} / \mathrm{ml}\right)$ as described (37).

The IL-6 probe (1.3 kb HILI-EcoRI fragment) was kindly provided by Dr. Aarden (CLB, Amsterdam, Netherlands), the IL-8 probe $(0.35 \mathrm{~kb}$ EcoR 1 fragment) was kindly provided by Dr. I. Lindley (Sandoz, Wien, Austria) and the actin probe (1.3 Pst fragment) was kindly provided by Dr. Berkvens (University of Leiden, Leiden, The Netherlands). Labeled bands were visualized by autoradiography.

\section{RESULTS}

\section{RCEC produce IL-6, IL-8 and TNF} in response to cytokines, $L P S$ and PMA IL-6, IL-8 and TNF release by cultured explanted RCEC from four different donors were measured after $18 \mathrm{~h}$ of stimulation with different agents. In absence of stimulus, nanograms per milliliter of both IL- 6 and IL- 
Chapter 3.2

Table $1: I L-6, I L-8$ and $T N F$ release by $R C E C$

unstimulated $100 \mathrm{ng} / \mathrm{ml} \mathrm{TNF} \quad 1 \mu \mathrm{g} / \mathrm{ml} \mathrm{LPS}$

$100 \mathrm{U} / \mathrm{ml}$ IL-1

$100 \mathrm{ng} / \mathrm{ml}$ PMA

Donor:

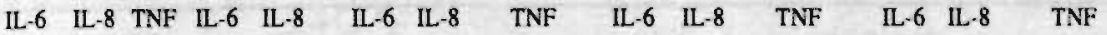

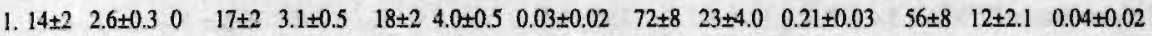

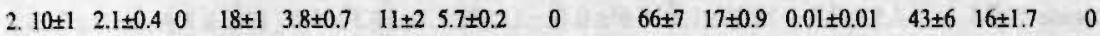

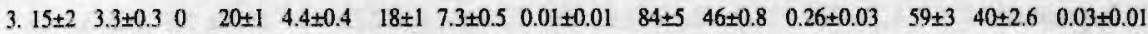

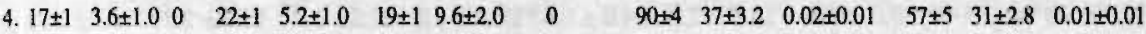

RCEC from four different donors were cultured to a density of $2 \times 10^{4}$ cells/well, ans stimulated with the indicated agents in one experiment. Supernatant-samples were collected after 18 hours of culture, and $I L-6, I L-8$ and TNF were measured in identical samples. Dala are expressed in $n g / m l$ as mean $\pm S D$ from four measurements.

8 were present in the supernatant medium, implicating a release of more than $1 \mathrm{ng}$ of IL6 and IL- 8 per $10^{6}$ cells per hour (Table 1 ). Ongoing spontaneous IL- 6 and IL- 8 release was found in the primary in vitro culture, and remained stable up to six redistribution cycles. Presence of IL-1 $\beta$, and to a lesser extend presence of TNF and PMA during the $18 \mathrm{~h}$ incubation period induced clear increases in IL-6 and IL-8 levels (Table 1).

In contrast to IL-6 and IL-8, no spontaneous TNF release was measured. In part of the cultures, stimulation with IL-1 $\beta$ and PMA induced TNF release. TNF release was, in comparison to IL-6 and IL-8 release, lower and showed strong variation between cells from different donors (Table 1).

IL-6, IL-8 and TNF supernatant concentrations showed a near-linear increase during the first $24 \mathrm{~h}$ of stimulation, with a lag-peri-

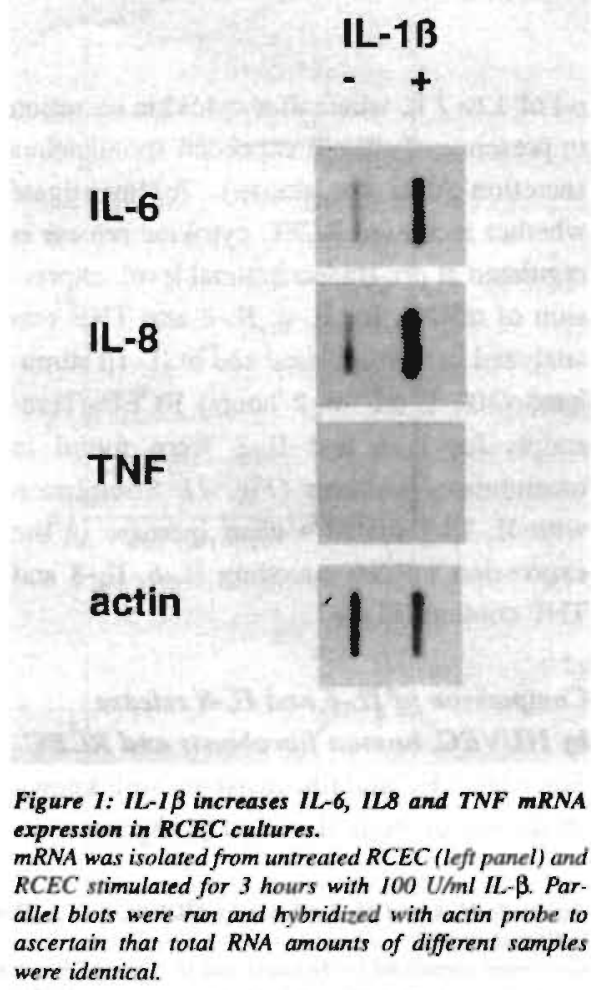

ascertain that total RNA amounts of different samples were identical. 
Table 2: The influence of immuno-suppressive agents on $I L-1$ induced cylokine release.

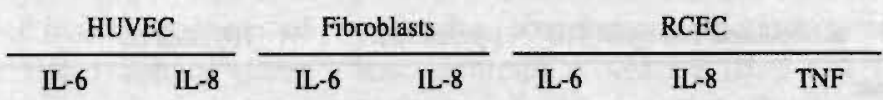

No agent

$5.4 \pm 0.9 \quad 15.0 \pm 1.1 \quad 25.0 \pm 3.7 \quad 20.2 \pm 2.0 \quad 25.5 \pm 4.7 \quad 11.0 \pm 1.3 \quad 0.27 \pm 0.04$

Indomethacin $10^{-6} \mathrm{M}$

$5.4 \pm 0.6$

$14.4 \pm 15$

$17.9^{t} \pm 1.5$

$21.0+5.9$

$26.0 \pm 1.0$

$10.6 \pm 1.6 \quad 0.32 \pm 0.06$

Budesonide $10^{7} \mathrm{M}$

$4.5 \pm 0.7$

$12.8^{t} \pm 1.6 \quad 5.6^{t} \pm 0.4$

$11.9^{t} \pm 2.1$

$19.3^{\ddagger} \pm 3.6 \quad 10.3 \pm 1.8 \quad 0.13^{\ddagger} \pm 0.03$

Cyclosporin $10^{\circ} \mathrm{M}$

$4.3^{t} \pm 0.1$

$14.2 \pm 2$

$21.8 \pm 0.9$

$21.0 \pm 4.4$

$22.7 \pm 4.2$

$10.4 \pm 1.8 \quad 0.24 \pm 0.06$

FK $50610^{\circ} \mathrm{M}$

$5.0 \pm 0.5$

$14.5 \pm 2.3 \quad 24.0 \pm 0.5 \quad 20.5 \pm 5.2$

$24.2 \pm 2.7$

$10.4 \pm 2.7 \quad 0.27 \pm 0.03$

Cells were stimulated with $100 \mathrm{U} / \mathrm{ml} / L-\beta$ for 18 hours. Immuno-suppressive agents were added together with $I L-I$. IL-6, IL-8 and TNF release were measured in identical samples. Data are given in ng/ml as mean and SD of quadruplicares.

'p<0.05 and $p<0.01$, as compared to cytokine release under identical circumstances but in absence of the immunosuppressive agent (determined by the unpaired, rwo-tailed Student's t-test).

od of 1 to $2 \mathrm{~h}$, whereafter cytokine secretion in presence of stimuli exceeded spontaneous secretion (data not shown). To investigate whether increased RCEC cytokine release is regulated at pre-transcriptional level, expression of mRNA for IL- $6, \mathrm{IL}-8$ and TNF was analyzed in unstimulated and in IL- $1 \beta$ stimulated (100 U/ml for 2 hours) RCEC. Transcripts for IL-6 and IL-8 were found in unstimulated cultures (Fig. 1). Stimulation with $\mathrm{IL}-1 \beta$ induced a clear increase in the expression mRNA encoding IL-6, IL-8 and TNF content (Fig. 1).

\section{Comparison of $I L-6$ and $I L-8$ release} by HUVEC, human fibroblasts and RCEC Since HUVEC and fibroblast are well known producers of both IL- 6 and IL-8, we com- pared the induction profile of IL- 6 and IL-8 release by these cells and by RCEC. The influence of $18 \mathrm{~h}$ stimulation with different concentrations of TNF, LPS, IL- $1 \beta$ and PMA on IL-6 and IL-8 release was measured (Fig. 2 ). Without stimulation, RCEC secreted both IL-6 and IL-8, HUVEC secreted IL-8 only, whereas fibroblast secreted majorly IL-6.

The three cell-types showed an increased IL6 and IL-8 release in response to all 4 stimuli (Fig. 2). The highest amounts of IL-6 and IL-8 release were seen after stimulation with 100 to $1000 \mathrm{U} / \mathrm{ml} \mathrm{IL-1 \beta}$. RCEC and fibroblasts responded, in contrast to HUVEC, very poorly to stimulation with LPS. A small increase in both RCEC IL- 6 and IL-8 release was, however, found throughout all experi-

Figure 2: $I L-6$ and $I L-8$ release by HUVEC ( $O$ ), fibroblasts ( $)$ ) and RCEC ( $\triangle$ ) after stimulation with the indicated agents.

Cells were stimulated for 18 hours and $I L-6$ and $I L-8$ concentrations were derernined in supermatant-samples. Data are expressed as mean $\pm S D$ from four measurements. If SD bars are not shown, they fall within the symbol. 
Chapter 3.2

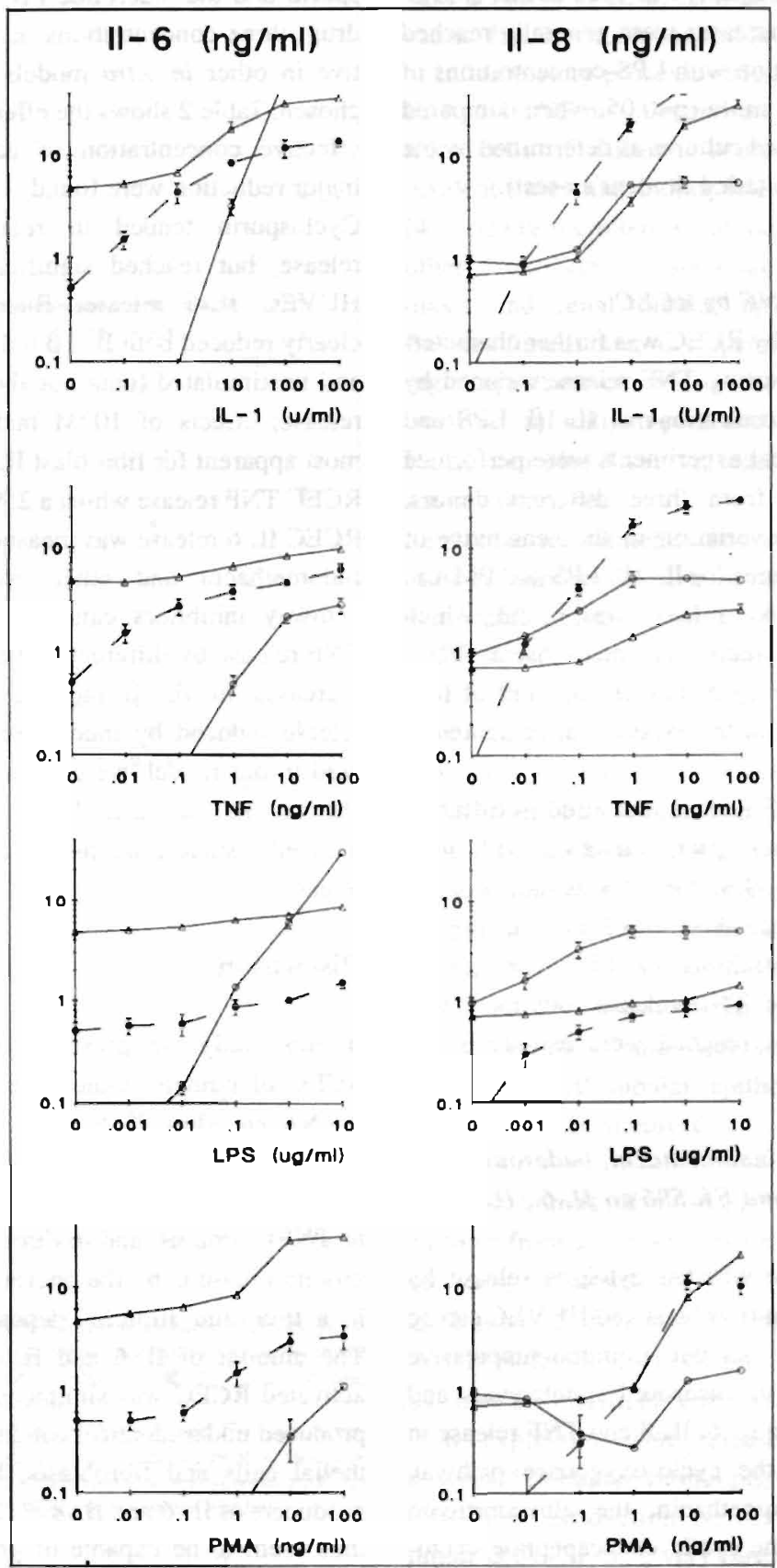


ments in which LPS was used in this study. Significant increases were generally reached after stimulation with LPS-concentrations of $100 \mathrm{ng} / \mathrm{ml}$ or more $(\mathrm{p}<0.05$, when compared to unstimulated cultures as determined by the unpaired two-tailed Student's $t$-test).

\section{Release of TNF by RCEC}

TNF release by RCEC was further characterized by measuring TNF release induced by different concentrations of IL-1 $\beta$, LPS and PMA. Identical experiments were performed with RCEC from three different donors. Considerable variation in the sensitivity of different cultures for IL- $1 \beta$, LPS and PMA in respect to TNF release was found, which probably explains the near-absent TNFrelease found by cells from two out of four donors tested in the experiment presented in table 1.

Maximal TNF release measured in different RCEC cultures after activation with high amounts of IL-1 and PMA was more consistent and reached about 1 to $1.5 \mathrm{ng} / \mathrm{ml}$ (Fig. 3). High concentrations of LPS consistently induced some TNF release, but the TNFconcentrations reached were usually below $100 \mathrm{pg} / \mathrm{ml}$.

\section{Influence of indomethacin, budesonide,} cyclosporin and FK 506 on $I L-6, I L-8$ and TNF release

To investigate whether cytokine release by RCEC, human fibroblast and HUVEC can be regulated by known immuno-suppressive compounds, we measured spontaneous and IL $1 \beta$ induced IL- $6, I L-8$ and TNF release in presence of the cyclo-oxygenase pathway inhibitor indomethacin, the glucocorticoid budesonide, the cyclic endecapeptide cyclo- sporin and the macrolide FK 506. For each drug, three concentrations in a range effective in other in vitro models (38-41) were chosen. Table 2 shows the effects of the most effective concentration of each drug. No major reduction were found.

Cyclosporin tended to reduce cytokinerelease, but reached significance only for HUVEC IL- 6 release. Budesonide more clearly reduced both IL- $1 \beta$ induced (Table 2 ) and unstimulated (data not shown) cytokine release; effects of $10^{-7} \mathrm{M}$ budesonide were most apparent for fibroblast IL-6 release and RCEC TNF release whilst a $25 \%$ reduction in RCEC IL-6 release was measured (Table 2). Indomethacin and other cyclo-oxygenase pathway inhibitors can increase IL- 1 and TNF release by different cell-types $(40,42)$. Increases in IL-1 $\beta$ induced RCEC TNFrelease induced by indomethacin, as measured in our model, were to small to be conclusive. In contrast, $10^{-6} \mathrm{M}$ indomethacin induced a small reduction in fibroblast IL- 6 release.

\section{Discussion}

In this study we presented evidence that RCEC of human tubule origin can express mRNA encoding IL-6, IL-8 and TNF, and secrete these proteins. RCEC were able to respond to primary (LPS), secondary (IL-1 $\beta$ or TNF) stimulus, and to direct activation of protein kinase $\mathrm{C}$ by the phorbol esther PMA in a time and stimulus dependent fashion. The amount of IL- 6 and IL- 8 released by activated RCEC was similar to the amounts produced under identical conditions by endothelial cells and fibroblasts, known strong producers of IL-6 and IL-8 (7, 24-26). RCEC thus seem to be capable of producing rele- 

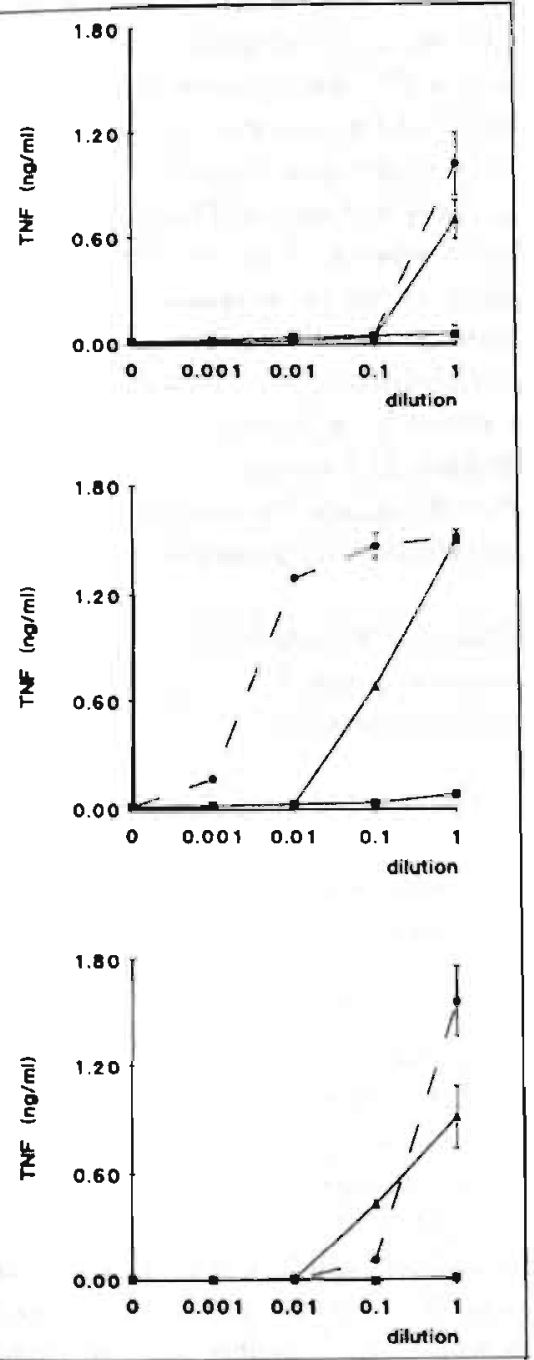

Figure 3: TNF release by three cultures of RCEC from different donors after stimulation with serial dilutions of $I L-I \beta(C, I=1000 \mathrm{U} / \mathrm{ml}), L P S(\mathrm{Q}, I=I \mu \mathrm{g} / \mathrm{ml})$ and PMA (A, $l=100 \mathrm{ng} / \mathrm{ml}$ ).

Cells were stimulated for 18 hours and TNF concentrations were determined in supermatant-samples. Data are expressed as mean $\pm S D$ from four measurements. If $S D$ bars are not shown, they fall within the symbol. vant amounts of IL-6, IL-8 and 'INF, implicating that, in the human kidney, the 'tuning" of inflammatory processes triggered by IL-6, IL-8 and TNF may depend on contributions from cells of different sources, including resident interstitial mononuclear phagocytes (43), newly recruited mononuclear cells and other leukocyles, endothelial cells, fibroblasts and renal tubular epithelial cells. Besides functioning as a specific target during allograft rejection $(44,45)$, which can be involved in antigen-presentation $(46,47)$, RCEC can play a role in regulating inflammatory processes.

Leukocyte-recruitment, mediated by TNFinduced expression of adhesion molecules, neutrophil migration, mediated by an IL-8 gradient, and activation of lymphocytes, monocytes and neutrophils, mediated by local presence of IL-6, IL-8 and TNF, are processes in which direct participation of RCEC could be relevant. These contributions of RCEC may have particular importance in renal allograft rejection, where these cells are the primary stimulus for leukocyte activation. However, also in other types of tubulo-interstitial disease including pyelonephritis, vasculitis and allergic interstitial nephritis, renal tubular epithelial cytokine release could be involved.

Documentations of primary epithelial cell cultures from a human organ expressing and secreting cytokines like $\mathrm{L}-6, \mathrm{IL}-8$ or TNF are limited. IL- 6 release has been shown by freshly isolated human dermal cells (48) and by human intestinal epithelial cells (49). IL- 8 expression and release have been described in human retinal pigment epithelia (50). TNF production is, besides in some tumor cells $(51,52)$, very rare in non-hemo- 
poietic cells. Our data, and recent data on RCEC secretion and expression of IL-8 (53) and TNF (22), thus extend the range of cell populations capable of IL-8 and TNF release. Additional evidence for a role for renal epithelial cells in producers of IL-6 comes from data on IL-6 release by rat mesangial cells (54-56) and by human renal cell carcinoma $(57,58)$.

The signal-transduction pathways which are involved in eliciting IL-6, IL-8 and TNF production are still unclear. For fibroblasts two independent pathways of IL- 6 gene activation have been described; a protein kinase C-dependent and a cAMP-dependent signal transduction pathway (25). It seems clear that cytokine-release signal transduction pathways may vary depending on: A) the stimulus eliciting cytokine release $(24,59)$, B) the phenotype of the cell involved (59), and $C)$ the cytokine which is released $(60$, 61). The latter finding is stressed by the clearly different induction profiles of IL- 6 and TNF release by mononuclear phagocytes $(23,59,62)$.

In parallel, we found that RCEC TNF-release differs from RCEC IL- 6 and IL- 8 release and from TNF-release by human mononuclear cells: Unstimulated RCEC show no TNFrelease, but constitutively release high amounts of IL- 6 and IL.-8.

The concentrations of IL- $1 \beta$ and PMA needed for RCEC TNF-release were much higher than concentrations needed for RCEC IL-6 and IL- 8 release, and for monocyte TNF release $(23,59,63)$. TNF-release was, in contrast to IL-6 and IL-8, very heterogenous among RCEC from different donors: a finding which has also been described by Yard et al. (22). As for monocyte TNF-release, this inter-individual variation was linked to stimulus-sensitivity rather then to the potential to release TNF after maximal activation (64). Finally, LPS was, even at high concentrations, a very weak stimulus for RCEC TNF, IL- 6 and IL-8 release. This might be related to the absence of surface-CD14 on RCEC, which is known to mediate activation of monocytes by low amounts of LPS $(63,65)$. In endothelial cells, which also lack CD14 expression, serum-derived soluble CD14 mediates LPS-activation $(66,67)$.

Why RCEC are less sensitive to LPS than endothelial cells, remains to be elucidated.

Since IL-1 induced RCEC TNF release, and stimulation with TNF triggers RCEC IL-6 and IL- 8 release, TNF could be a second mediator for IL- 1 induced IL- 6 and IL- 8 release. Addition of an excess of an inhibitory anti-TNF mAb did, however, not decrease IL-1 induced RCEC IL- 6 and IL- 8 release (data not shown), arguing against an important role for endogenous TNF release as a mediator for IL-1 induced RCEC IL-6 and IL-8 release. Furthermore, we investigated whether IL-6, which acts as an inhibitor of TNF-release in monocytes (23), has such a role in our model. Neither (pre)incubation

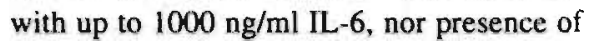
an inhibitory anti IL- $6 \mathrm{mAb}$, however, influenced IL-1 induced TNF release (data not shown). $\mathrm{PGE}_{2}$ is another potential inhibitor of RCEC TNF release. $\mathrm{PGE}_{2}$ is released by LPS and cytokine stimulated rat mesangial cells $(68,69)$, and reduces LPS induced TNF release by the same cells (69).

We measured, however, no clear influcnce of the cyclo-oxygenase pathway inhibitor indomethacin on unstimulated or IL-1 induced RCEC cytokine-release, suggesting no major 
role for $\mathrm{PGE}_{2}$ and other cyclo-oxygenase pathway products in our model. Further, we investigated whether budesonide, cyclosporin and FK 506, drugs which are used to prevent allograft rejection, reduce renal cytokine-release. Only the steroid budesonide inhibited cytokine release by RCEC and other cells. Budesonide induced reductions did, however, not exceed $50 \%$, which is in contrast with the nearly complete steroid induced abrogation of TNF release by mononuclear phagocytes stimulated with endotoxin $(41,70)$. Incomplete inhibition of the release of neutrophil chemotactic activity by IL-1 stimulated renal epithelial cell cultures by corticosteroids has been reported previously (71). Whether these findings implicate principle differences between mononuclear phagocytes and renal epithelial cells in regard to their sensitivity to corticosteroids remains to be illucidated.

\section{IL-6, IL-8 and TNF are multi-functional} cytokines and important mediators of inflammatory processes. The capacity of RCEC to release these cytokines, as demonstrated in this study, argues for a model in which renal tubular epithelial cells are actively engaged in regulating inflammation. Which steps in the interaction between renal tubular cells and neighboring cells during inflammation finally lead to progressive tissue-damage and loss of renal function, appears to be a problem with increasing complexity.

\section{References}

1. Nathan CF, 1987. Neutrophil activation on biological surfaces. J. Clin. Invest. 80:1550.

2. von Asmuth EJU, Leeuwenberg JFM, van der Linden CJ, Buurman WA. 1991. Tumour necrosis factor $\alpha$ induces neutrophil mediated injury of culcured human endothelial cells. Scand. J. ImmunoL. 34:197.

3. Slungaard A, Vercellotti GM, Walker G, Nelson RD, Jacob HS. 1990. Tumor necrosis factor $\alpha /$ cacbectin stimulates eosinophil oxidant production and toxicity towards endothelium. J. Exp. Med. 171:2025.

4. Hurme M. 1988. Both interleukin 1 and tumor necrosis factor enhance thymocyte proliferation. Eur. J. Immunol. 18:1303.

5. Ranges GE, Bombara MP, Ajyer RA, Rice GG, Palladino MAJr. 1989. Tumor necrosis factor $\alpha$ as a proliferative signal for an IL-2 dependent $T$ cell line: Strict species specificity of action. J. Immunol. 142:1203.

6. Pohlman TH, Stanness KA, Beatty PG. Ochs HD, Harlan JM. 1986. An endothelial cell surface factor(s) induced in vitro by lipopolysaccharide, interleukin 1 , and tumor necrosis factor- $\alpha$ increases neutrophil adherence by a CDw18-dependent mechanism. $J$. Immunol. 136:4548.

7. Shalaby MR, Waage A, Espevik T. 1989. Cytokine regulation of interlevkin 6 production by human endothelial cells. Cellular Immunol. 121:372

8. Pfeilschifter J, Pignat W, Vosbeck K, Mürki F. 1989. Interleukin 1 and tumor necrosis factor synergistically suimulate prostaglandin synthesis and phospholipase A2 release from rat renal mesangial cells. Biochem. Biophys. Res. Commun. 159:385.

9. Pirotzki E, Delattre RM, Hellegouarch A, Lonchampt MO, Aarden L, Braquet P, Galanaud P. 1990. Interleukin- 6 production by tumor necrosis factor and lipopolysaccharide-stimulated ral renal cells. Clin. Immunol. Immunopathol 56:271.

10. Bertani T, Abbate M, et al. 1989. Tumor necrosis factor induces glomerular damage in the rabbit. Am. J. Pathol. 134:419.

11. Maessen JG, Greve J-W, Buurrnan WA, Kootstra G. 1989. Sensitivity of ischemically damaged kidneys to inflammatory reactions. Transplant. Proc. 21:1261.

12. Brennan DC, Yui MA, Wuthrich RP, Kelley VE. 1989. Tumor necrosis factor and $\mathbb{L}-1$ in new zealand black/white mice ; Enbanced gene expression and acceleration of renal injury. J. ImmunoL 143: 3470.

13. Tomosugi NI, Cashman SJ et al. 1989. Modulation of antibody-mediated glomerular injury in vivo by bacterial lipopolysaccharide, tumor necrosis factor, and IL-1. J. ImmunoL 142:3083.

14. Werber HI, Emancipator SN, Tykocinski ML, Sedor JR. 1987. The interleukin 1 gene is expressed by rat glomerular mesangial cells and is augmented in immune complex glomerulonephrits. J. Immunol 138:3207.

15. Hruby ZW, Shirota K, Jothy S, Lowry RP. 1991 . Antiserum against tumor necrosis factor-alpha and a pro- 


\section{Cytokine production by renal epithelial cells}

tease inhibitor reduce immune glomerular injury. Kidney Inn. 40:43.

16. Maury CPJ, Teppo A-M. 1987. Raised serum levels of cachectintumor necrosis factor $\alpha$ in renal allograft rejection.

J. Exp. Med. 166:1132.

17. Mclaughlin PJ, Aikawa AA, Davies HM, Bakran A, Sells RA, Johnson PM. 1991. Tumour Necrosis factor in renal transplantation. Transplant Proc. 23:1289.

18. Tsuchida A, Salem H, Thomson N, Hancock WW. 1992. Tumor neerosis factor production during kuman renal allogaft rejection is associated with depression of plasma protein $C$ and free protein $S$ levels and decreased intragraft thrombomodulin expression. J. Exp. Med. 175:81.

19. Yoshimura N. Oka T, Kahan BD. 1991. Sequential determinations of serum interleukin 6 levels as an immunodiagnostic tool to differentiate rejection from ncphrotoxicity in renal allograft recipients. Transplantation $51: 172$.

20. Noronha IL, Daniel V, Rambuusek: $M$, Waldberr $R$, Opelz G. 1990. Soluble Interleukin-2 receptor (sM-2R) and tumor necrosis factor plasma levels in senal allograft rejection. Transplant. Proc. 22:1859.

21. Caillat-Zucman S, Vanden Broecke C. Legendre C, Noel L-H, Kreis H, Bach J.F, Tovey MG. 1991. Differential in situ expression of cytokine genes in human renal rejection. Transplant. Proc. 23:229.

22. Yard BA, Daha MR et al. 1992. IL- $1 \alpha$ stimulated TNF $\alpha$ production by culured human proximal tubular epithelial cells. Kidney Inft. 42:383.

23. Aderka D, Le J, Vileek J. 1989. IL-6 inhibits lipopolysaccharide-induced tumor necrosis factor production in cultured human monocytes, 4937 cells, and in mice. J. Immunol. 143:3517.

24. yon Asmuth EJU, Leeuwenberg JFM, Ceska M, Bumrnan WA 1991. LPS and cytokine-induced endothelial cell IL-6 release and ELAM-1 expression; involvement of serum. Eur. Cytokine Net 2:291.

25. Zhang Y, Lin J-X, Vilcek J. 1988. Synthesis of Interleukin 6 (Interferon- $\beta / 3$ cell stimulatory factor 2 ) in human fibroblasts is triggered by an increase in intracellular cyclic AMP. J. Biol. Chem. 262:6177.

26. van Damme J, Decock B, Conings R, Lenaerts J-P. Opienakker G, Billiau A. 1989. Tbe chemotactic activity for gramulocytes produced by virally infected fibroblasts is identical to monocyte derived interleukin 8. Eur. J. Immunol. 19:1189.

27. Castell JV, Gomez-Lechon MJ, David M. Hirano T, Kishimoto T, Heinrich PC. 1988. Recombinant human interleukin-6 (IL-6/BSF-2/HSF) regulated the synthesis of acute phase proteins in human hepatocy. tes. FEBS Lell. 232:347.

28. Hirano T, Yasukawa K, et al. 1986. Complementary DNA for a novel buman interleukin (BSF-2) that induces B lymphocytes to produce immunoglobulin. Narure 324:73.

29. Garman RD, Jacobs KA, Clark SC, Raulet DH. 1987. B-cell-stimulatory factor $2(\beta 2$ interferon) functions as a second signal for interleukin 2 production by mature murine T eells. Proc. Nath Acad Sci USA 84: 7629 .

31. Huber AR, Kunkel SL, Todd RF, Weiss SJ. 1991. Regulation of transendothelial neutrophil migration by endogenous IL-8. Science 254:99.

31. Baggiolini $M$, Walz A, Kunkel SI. 1989. Neutrophilactivating peptide-1/interleukin 8, a novel cytokine that activates neutrophils. J. Clin. Invest. 84:1045.

32. Kempson SA, McAteer JA, Al-Mahrouq HA, Dousa TP, Doughery GS, Evan AP. 1989. Proximal ubule characteristics of cultured human renal cortex epithelium. J. Lab. Clin. Med. 113:285.

33. Lecuwenberg JFM, von Asmuth EJU, Jeunhomme TMAA, Buurman WA. 1990. IFN-y regulates the expression of the adhesion molecule ELAM-1 and IL. 6 production by human endothelis! cells in vitro. J. Immunol. 145:2110.

34. Ceska M, Effenberger F, Peichl P. Pursch E. 1989. Purification and charactcrization of monoclonal and polyclonal antibodies to neutrophil activating peptide (NAP-1). The development of a sensitive EL.ISA for the determination of NAP-1 and anti-NAP-1 antbodics. Cytokine 1:136 (abstract).

35. Engelberts 1., Möler A, Schoen GJM, van der Linden. CJ, Buurman WA. 1991. Evaluation of measurement of human TNF in plasma by ELISA. Lymfokine: Cytokine Res. 10:133.

36. Sambroook J, Fritsch EF, Maniatis T. eds. 1989. Molecular Cloning. New York: Cold Spring Harbor Laboratory Press, 7.10.

37. Sambrocok J, Fritsch EF, Maniatis T. eds. 1989. Molecular Cloning. New York: Cold Spring Harbor Laboratory Press, 7.52.

38. Walliser P, Benzie CR, Kay JE. 1989. Inhibition of murine B-lymphocyze proliferation by the novel immunosuppressive drug FK-506. Immunology $68: 434$.

39. Blocmena E, van Oers RHJ, Weinreich S, StilmuMeinesz AP, Schellekens PTA, van Lier RAW. 1989. The influence of cyclosporin $A$ on the altemative pathways of human T cell activation in viro. Eur. J. Immunol 19:943.

40. Kunkel SL, Wiggins RC, Chensue SW, Larrick J. 1986. Regulation of mecrophage tumor necrosis factor production by prostaglandin $E_{2}$. Biochem. Biophys. Res. Commun. 137:404.

41. Debets JMH, Ruers TJM, Van der Linden MPMH, Vun der Linden CJ, Buurman WA. 1989. Inhibitory effect of corticosteroids on the secretion of tumour nexrosis factor (TNF) by monocytes is dependent on the stimulus inducing TNF synthesis. Clin. Exp. Immunal 78:224.

42. Matsumolo K. Hatano M. 1991. Soluble immunc complexes stimulate production of interleukin- 1 by cultured rat glomerular mesangial cells. Am. $J$. Nephrol 11:138.

43. Schreiner GF, Kieley JM, Cotran RS, Unanue ER. 1981. Characterization of resident glomentar cells in the rat expressing "Ia" deteminants and manifesting genetically restricted interactions with lymphocytes. J. Clin. InvesL 68:920.

44. Miltenburg AMM, Meyer-Paape ME, Daha MR, Paul 
1.C. 1988. Lymphokinte activated killer cells lyse human rewal cancer cell lines and cultured nomal kidney cells. Immunol. 63:729.

45. vatn der Woude FJ, Daha MR, Milienburg AMM, Paape ME, Bruijn JA, van Bockel HJ, van Es LA. 1990. Renal allograft infiltrated celis: Further analysis of donor-specific lysis. Human Immunol 28:186.

46. Wuthrich RP, Glimcher LH. Yui MA, Jevnikar AM, Dumas SE. Kelley VE. 1990. MHC class II, antigen presentation and tumor necrosis factor in renal tubular cells. Kidney Im. 37:783.

47. Vegt PA, van der Linden CJ, Daemen AJJM, Jeekel J. Butman WA. 1982. Lymphocyte stimulation by canine kidncy cells. Transplantation 34:134.

48. Kimbauer R, Köck A, et al. 1989. IFN- $\beta 2$, B cell differentiation factor 2, or hybridoma growth factor (11.6) is expressed and released by human epidermal cells and epidermoid carcinoma cell lines. J. Immunol. 142:1922.

49. Shirota K, LeDuy L, Yuan S, Jothy S. 1990. Interleukin-6 and its receptor are expressed in buman intestinal cells. Virchows Arch [B] 58:303.

50. Elner VM, Surieter RM, Elner SG, Baggiolini $M$, Lindley I, Kunkel SL. 1990. Neutrophil chemotactic factor (IL-8) gene expression by cytokine-treated retinal pigment epithelial cells. Am. J. Pathol 136:745.

51. Spriggs DR. Imamura K, Rodriguez C, Sariban E, Kufe DW. 1988. Tumor necrosis factor expression in human epithelial tumor cell lines. J. Cin. Invest. $81: 455$.

52. Rubin BY, Anderson SL, Sullivan SA, Williamson BD. Carswell EA, Old LJ. 1986. Nonhematopoietic cells selected for resistence to tumor necrosis factor produce turnor necrosis factor. J. Exp. Med. 164:1350.

53. Schmouder RL, Strieter RM, Wiggins RC, Chensue SW, Kunkel SL. 1992. In vitro and in vivo interleukin-8 production in human renal cortical epithelia. Kidney Int. 41:191.

54. Pirotzky A, Delattre RM, Hellegouarch A. Lonchampt MO, Aarden L, Braquet P, Galanaud P. 1990. Interleukin-6 production by tumor necrosis factor and lipopolysaccharide-stimulated rat renal cells. Clin. Immunol. Immunopathol 56:27I.

55. Horii Y, Muraguchi A. et al. 1989. Involvement of IL 6 in mesangial proliferative glomerulonephritis. J. ImmunoL 143:3949.

56. Rucf C. Budde K. ct al. 1990. Interleukin 6 is an autocrine growth factor for mesangial cells. Kidney Int. 38:249.

57. Gruss H-J, Brach MA, Mertelsmann RH, Herrmann F. 1991. Intcrferon-gamma interrupts autocrine growth mediated by endogenous interleukin- 6 in tenal-cell carcinoma. Int. J. Cancer 49:770.

58. Sakai A, Kawano M, Kuramoto A. 1991. Interleukin6 produced by renal-cell carcinoma cells and progression of multiple myeloma. New Engl J. Med. 324:1893.

59. Aarden L, Helle M, Bocije L, Pascaul-Salcedo D, de Groot E. 1991. Differential induction of interleukin-6 production in monocytes, endothelial cells and smooth muscle cells. Eur. Cytokine Net. 2:115.
60. Mengozzi M. Sironi M. Gadina M. Ghezzi P. 1991. Reversal of defoctive 11.6 production in lipopolysac. charide-tolerant mice by phorbol myristatc acetate. J. ImmunoL 147:899.

61. Burchen SK, Weaver WM, Westall JA, Larsen A, Kronheim S, Wilson CB. 1989. Regulation of tumor necrosis factor/cachectin and L-1 secretion in human mononuclear phagocytes. J. Immunol. 140:3473.

62. von Asmuth EJU, Maessen JG, wan der Linden CJ, Buurman WA. 1990. Tumour necrosis factor alpha $(\mathrm{TNF}-\alpha)$ and interleukin 6 in a zymosan-induced shock model. Scand. J. Immunol 32:313.

63. Dentener MA, Bazil V, von Asmuth EJU, Ceska M, Buurman WA. Involvement of CD14 in lipopolysaccharide induced tumor necrosis factor- $\alpha$, interleukin6 and interleukin-8 release by human monoxytes and alveolar J. Immunol in press.

macrophages.

64. Engelberts I, Sundrarn R et al. The effect of replacement of dietary fat by paim oil in in vitro cylokine release. British $J$. Nutrition in press.

65. Wright SD, Ramos RA, Tobias PS, Ulevitch RJ, Mathison JC. 1990. CDI4, a receptor for complexes of lipopolysaccharide (LPS) and LPS binding protein. Science 249:1431.

66. Frey EA, Miller DS, Gullstein Jalur T, Sundan A, Bazil V. Espevik T. Finlay BB, Wright SD. 1990. Soluble CD14 participates in the response of cells to lipopolysatcharide. J. Exp. Med. 176:1665.

67. von Asmuth EJU. Dentener MA. Bazil V, Bouma MG, Leeuwenberg JFM, Buurman WA. 1993. AntiCD14 antibodies reduce responses of cultured human endothelial cells to endotoxin. Immunol $80: 78$.

68. Pfeilschifter J. Miihl H. 1990. Interleukin I and tumor necrosis factor potentiate angiotensin II- and calcium ionophore-stimulated prostaglandin E2 synthesis in rat nesangial cells. Biochem. Blophys. Res. Commun. 169:585.

69. Baud L, Oudinet J.P et al. 1989. Production of tumor necrosis factor by rat mesangial cells in response to bacterial lipopolysaccharide. Kidney Int. 35:IIII.

70. Luedke El, Cerami A. 1990. Interferon $\gamma$ overcomes glucoconticoid suppression of cachectiv/umor necrosis factor biosynthesis by murine macrophages. J. Clin. Invest. 86:1234.

71. Wantanabe K, Nakagawa H. 1990 . Cytokines enhance the production of a chemotactic factor for polymorphonuclear leukocytes by rat renal! glomerular epithelicid cells. Nephron 54:169. 


\section{ANTAGONISTIC EFFECTS OF LIPOPOLY- SACCHARIDE (LPS) BINDING PROTEIN AND BACTERICIDAL/PERMEABILITY-INCREASING PROTEIN ON LPS-INDUCED CYTOKINE RELEASE BY MONONUCLEAR PHAGOCYTES}

\section{COMPETITION FOR BINDING TO LPS}

MIEKE A. DENTENER*, ECKHARDT J.U. VON ASMUTH, GABY J.M. FRANCOT, MARIAN N. MARRA“ AND WIM A. BUURMAN

'Department of Pulmonary Diseases, University Hospital Maastricht, the Netherlands "IncytePharmaceuticals Inc., Palo Alto, CA, USA

Journal of Immunology 1993, 151: 4258-4265

\section{Abstract}

erum proteins play an important role in lipopolysaccharide (LPS)-induced cell activation. The LPS binding protein (LBP) enhances cellular responses to LPS whereas the polymorphonuclear leucocyte product bactericidal/permeability-increasing protein (BPI) inhibits LPS-induced cell activation. In this study the influences of LBP and BPI, two proteins with opposite effects, but with considerable sequence homology, on LPS-induced mononuclear phagocytic cell cytokine release was studied. LBP was shown to enhance LPSinduced tumor necrosis factor (TNF)-a, interleukin (IL)- 6 and IL-8 release by mononuclear phagocytic cells, whereas BPI inhibited the release of these cytokines. Furthermore, the effects of LBP and BPI on LPS-induced cytokine release by mononuclear phagocytic cells were shown to be counteractive. BPI interfered with the enhancing effect of LBP on the LPSinduced cytokine release. At high LBP to BPI ratios, BPI could no longer inhibit LBP induced enhancement. In accordance, increasing concentrations of BPI abrogated the LBP effect. Next it was shown that LBP and BPI compete for binding to LPS, by using an assay system that detects binding of free BPI to an anti-BPI monoclonal antibody (mAb). LPS prevented binding of BPI to anti BPI mAb, whereas preincubation of LPS with LBP prevented the LPSinduced inhibition. Also it was observed that both BPI and LBP inhibited LPS activity in the chromogenic LAL assay. We conclude from this study that LBP and BPI have counteractive effects upon LPS-induced mononuclear phagocytic cell cytokine release, by competing for binding to LPS. 


\section{Introduction}

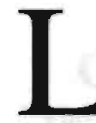

PS is known to activate a number of cell types such as PMN, mononuclear phagocytes and endothelial cells. Serum proteins have been found to play an important role in LPS-mediated cell activation. Among these proteins is LPS binding protein (LBP), a $60 \mathrm{kDa}$ acute phase reactant, which is also present in normal plasma $(1,2)$. This glycoprotein facilitates binding of LPS to CD14, a newly described receptor for LPS (3).

The presence of LBP increases the capacity of LPS 1) to prime PMN (4-6), 2) to induce cytokine release by mononuclear phagocytes $(3,7-9)$, and 3$)$ to induce lgM expression by a CD14 transfected pre-B cell line $70^{\circ} Z / 3$ (10). In addition to LBP, a new group of serum proteins with LPS opsonizing activity for binding to CDI4, called 'septin', has been described (11).

Also LPS inhibiting proteins have been reported. PMN produce the very potent bactericidal/permeability-increasing protein (BPI) which is stored in the azurophilic granule (12), but is also expressed on the cell surface $(13,14)$. This protein was shown to bind to LPS with high affinity (15-17), to induce bacterial killing (18, 19), and to inhibit effects of LPS in several in vitro settings. BPI inhibits LPS-induced PMN priming, TNF- $\alpha$ production in whole blood and activation of procoagulant proteases in Limulus amebocyte lysates $(13,20-22)$. BPI and LBP, two proteins with opposite effects upon LPS activation, have considerable sequence homology $(1,2,23-25)$.

Furthermore, both bind to the lipid A part of $\operatorname{LPS}(7,13,20,26,27)$.
In this study, we investigated whether LBP and BPI affect, besides the LPS-induced TNF- $\alpha$ release, also the LPS-induced IL- 6 and IL-8 release by mononuclear phagocytes. Furthermore we investigated the functional relationship between LBP and BPI on LPS-induced cytokine release. Our data indicate that the properties of LBP and BPI are counteractive.

These data prompted us to investigate whether these counteractive effects could be explained by competition for binding to LPS.

\section{Materials and Methods}

\section{Reagents}

Human rTNF- $\alpha$ was kindly provided by BASF/Knoll Ag (Ludwigshafen, FRG); human rIL-6 by Prof. W. Sebald, (Physiologisch-Chemisches Institut der Universität, Würzburg, FRG); human rIL-8 by Dr. I. Lindley (Sandoz Forschungsinstitut, Vienna); and human rIL-1 $\beta$ by Dr. S. Gillis (Immunex, Seattle, WA). LPS (from Escherichia coli, serotype 055:B5), the phorbol ester PMA and polymyxin B sulfate were purchased from Sigma (St. Louis, MO).

Macrophage serum-free medium (M $\varnothing-S F M)$ was obtained from GIBCO Europe (Paisley, Scotland). Human serum (HS) obtained from the local blood bank, was pooled, sterilized by a $0.2 \mu \mathrm{m}$ filter, heated to $56^{\circ} \mathrm{C}$ for $30 \mathrm{~min}$ utes and stored at $4^{\circ} \mathrm{C}$. HS contained $<5$ $\mathrm{pg} / \mathrm{ml}$ endotoxin, as determined in the chromogenic LAL assay (Kabi Pharmacia, Mölndal, Sweden). Human rBPI was produced by transfected chinese hamster ovary cells and was purified sequentially by ion exchange column and by size exclusion column. Human rLBP was produced by the transfected human embryonic kidncy cell line 293 EBNA provided by Invitrogen (San 
Diego, $C A)$. The conditioned medium contained $\pm 2.5 \mu \mathrm{g} / \mathrm{ml}$ human rLBP. A BPI neutralizing $\mathrm{mAb} 4 \mathrm{E} 3$ was obtained by injecting mice with human rBPI followed by classical procedures. The selection and properties of the $\mathrm{mAb}$ will be discussed in detail elsewhere. In short, the antibody was selected on basis of the following properties 1) reactivity with human $r B P I, 2$ ) inhibition of the biological property of BPI to reduce the LPSinduced cell activation, as measured by mononuclear phagocytic cell TNF- $\alpha$, release, and 3) inhibition by LPS of mAb reactivity to BPI. An antiserum to BPI was obtained by immunizing rabbits with human rBPI. This anti-BPI antiserum did not cross-react with human rLBP as tested in ELISA assay.

\section{Endotoxin determination}

Endotoxin was measured using Chromogenic Limulus Amebocyte Lysate assay, performing the assay as described by the manufacturer (Kabi Pharmacia), For measurement of endotoxin content in serum, the serum was heated to $75^{\circ} \mathrm{C}$ for 5 minutes, to inactivate all serum proteins.

\section{Cells}

The monocytic cell line Mono Mac 6 was obtained from DSM (Braunschweig, FRG) (28). Human peripheral blood mononuclear phagocytes, obtained from buffy coats of healthy volunteers, kindly provided by the local blood bank, were isolated as described (29). In short, mononuclear cell suspensions obtained after Lymphoprep (Nycomed, Oslo, Norway) centrifugation were allowed to clump by low speed centrifugation at $4^{\circ} \mathrm{C}$. Cell clumps, consisting for 80 to $95 \%$ of mononuclear phagocytes, were separated from the rest of the cells by sedimentation through ice cold HS. PMN contumination of the cell suspension was less than $5 \%$.

\section{Induction of cytokine-release}

LPS, LBP and BPI were resuspended in M $\varnothing$ SFM or in medium consisting of RPMI 1640 (GIBCO) and $10 \%$ HS. These reagents, alone or in combination were added in 96 . well flat bottom tissue culture plates (Costar, Cambridge, MA) reaching an end volume of $150 \mu \mathrm{l} /$ well, and incubated for 30 minutes at $37^{\circ} \mathrm{C}$. Mononuclear phagocytic cells or Mono Mac 6 cells were washed five times to remove all serum-components, resuspended in the required medium and subsequently added to the plates $\left(10^{6} \mathrm{cells} / \mathrm{ml}\right.$ mononucle ar phagocytes or $4: 10^{\prime \prime}$ cells $/ \mathrm{ml}$ Mono Mac $6,50 \mu \mathrm{L}$ well). Indicated concentrations of the reagents in the experiments refer to the concentrations at the beginning of the cell incubation. which were $75 \%$ of the pre-incubation concentrations. After $18 \mathrm{~h}$ incubation at $37^{\circ} \mathrm{C}$, supernatants were harvested and kept at $-20^{\circ} \mathrm{C}$ until use in the cytokine specific ELISA.

\section{Competitive assay for $L P S$ binding of LBP and $B P I$}

Competition of LBP and BPI for binding to LPS was assayed with BPI specific mAb 4E3. This $m A b$ recognizes only free BPI and does not interact with BPI that has formed a complex with LPS. The assay measures the influence of LBP on LPS-induced inhibition of binding of BPI to anti BPI mAb 4E3.

96-well immuno maxisorp plates (Nunc, Roskilde, Denmark) were coated overnight at $4^{\circ} \mathrm{C}$ with $4 \mathrm{E} 3$. A concentration range of LPS was preincubated 30 minutes at $37^{\circ} \mathrm{C}$, with different concentrations of LBP. Next, human rBPI $(40 \mathrm{pg} / \mathrm{ml})$ was added and the 

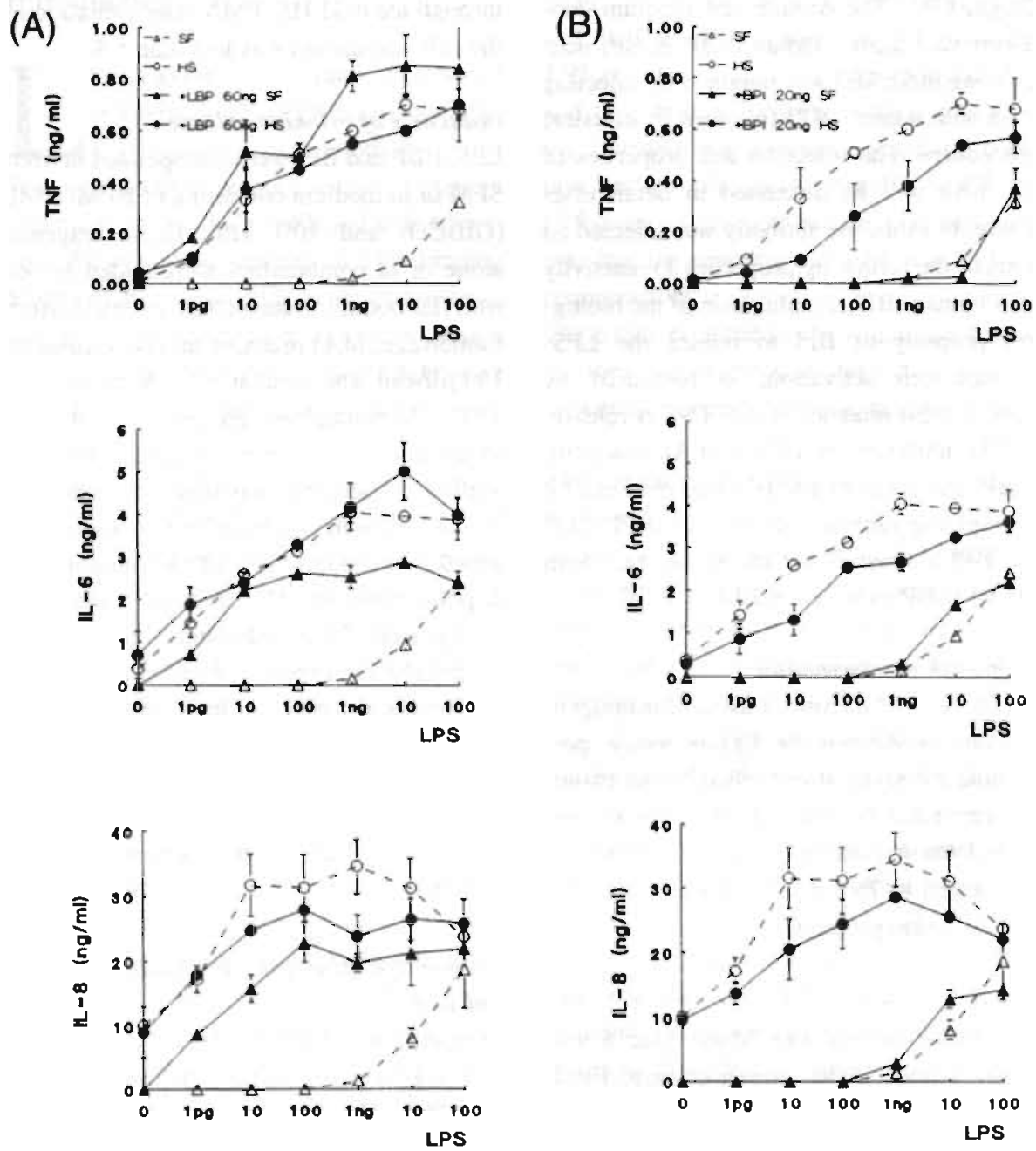

Figure 1. Influences of $\angle B P(A)$, and $B P I(B)$ on $L P S$-induced mononuclear phagocyfic cell cytokine relcase. A concenIration range of LPS was preincubated 30 minutes $37^{\circ} \mathrm{C}$ with no other reagent, with $60 \mathrm{ng} / \mathrm{ml} \mathrm{LBP}$ or with $20 \mathrm{ng} / \mathrm{ml}$ BPI, under serum free condirions $(S F)$ or in the presence of $10 \%$ HS. Mononuclear phagocytes were stimulated for 18 h and $T N F-\alpha, I L-6$ and $I L-8$ release were determined in specific ELISA. Dafa are expressed as mean and SD of four measuremens. SD bars are ominted if they fall within the symbol.

mixture was further incubated 30 minutes at $37^{\circ} \mathrm{C}$. Subsequently the mixture of reagents was added to the plates and incubated $1 \mathrm{~h}$ at room temperature. Washing and dilution of reagents were performed in assay buffer, consisting of $50 \mathrm{mM}$ Tris, $\mathrm{pH} 7.4,150 \mathrm{mM}$ $\mathrm{NaCl}, 0.05 \%$ tween $20,1 \mu \mathrm{g} / \mathrm{ml}$ polymyxin B sulfate. Assay buffer contained $\pm 10 \mathrm{ng} / \mathrm{ml}$ 


\section{Chapter 3.3}

endotoxin. Plates were developed with polyclonal anti-BPI and peroxidase conjugated goat anti-rabbit IgG (Jackson ImmunoResearch, Westgrove, PA). TMB (KPL, Gaithersburg MD) was used as a substrate for peroxidase. Photospectometry was performed at $450 \mathrm{~nm}$.

\section{TNF- $\alpha, I L-6$ and IL-8 ELISA}

Cytokine concentrations in the culture supernatants were determined using sandwichELISA for TNF- $\alpha$ (30), IL-6 (31) and IL-8 (32). In short, 96-well immuno maxisorp plates (Nunc) were coated overnight at $4^{\circ} \mathrm{C}$ with cytokine specific murine mAb. Human rTNF- $\alpha$, human rIL- 6 and human rIL- 8 were used for standard titration curves. Test samples were added and incubated for 2 to $3 \mathrm{~h}$ at room temperature. Polyclonal rabbit antihuman TNF- $\alpha$, anti-human IL- 6 and antihuman IL- 8 antiserum were followed by peroxidase conjugated goat anti-rabbit IgG (Jackson). TMB (KPL) was used as a substrate for peroxidase. Photospectometry was performed at $450 \mathrm{~nm}$. The lower detection level of ELISA was $20 \mathrm{pg} / \mathrm{ml}$ for TNF- $\alpha, 10$ $\mathrm{pg} / \mathrm{ml}$ for IL-6 and $10 \mathrm{pg} / \mathrm{ml}$ for IL-8.

\section{Results}

Influences of LBP and BPI on LPS-induced mononuclear phagocytic cell cytokine release.

The influences of LBP and BPI on LPSinduced TNF- $\alpha$, IL- 6 and IL- 8 release by mononuclear phagocytes were studied. To this end a concentration range of LPS was preincubated for 30 minutes at $37^{\circ} \mathrm{C}$ with $60 \mathrm{ng} / \mathrm{ml} \mathrm{LBP}$ or $20 \mathrm{ng} / \mathrm{ml} \mathrm{BPI}$ and added to mononuclear phagocytic cells either under serum-free conditions or in presence of $10 \%$
HS. Cytokine release by mononuclear phagocytic cells was shown to be strongly dependent upon presence of serum (Fig. I).

The enhancing effect of serum was less pronounced at higher LPS concentrations (10$100 \mathrm{ng} / \mathrm{ml}$ ). Addition of LBP to different concentrations of LPS, in absence of serum, strongly enhanced mononuclear phagocytic cell TNF- $\alpha$, IL- 6 and IL-8 release, resulting in cytokine release comparable to that observed in presence of $10 \%$ HS (Fig. IA). In presence of serum, LBP did not influence LPS-induced cytokine release.

BPI inhibited mononuclear phagocytic cell TNF- $\alpha$, IL- 6 and IL- 8 release partially in the LPS range from 1 pg to $10-100 \mathrm{ng} / \mathrm{ml}$, depending on the cytokine studied, in presence of $10 \%$ HS (Fig. 1B). Using higher BPI concentrations, up to $3 \mu \mathrm{g} / \mathrm{ml}$, the inhibitory effect of BPI was enhanced, although never a complete inhibition was observed (data not shown).

Under serum-free conditions no inhibitory effect of BPI was observed. BPI did not reduce mononuclear phagocytic cell TNF- $\alpha$ release in response to $\mathrm{IL}-1 \beta$ and PMA in presence of serum (data not shown), indicating that BPI selectively reduced LPS-induced mononuclear phagocytic cell responses. Neither LBP nor BPI induced detectable amounts of mononuclear phagocyles cytokine release in absence of LPS (Fig. I).

A minor contamination of mononuclear phagocytic cell preparation with PMN could lead to PMN produced BPI, which may obscure the effect of exogenous BPI in the described serum-free experiments. Therefore the effect of BPI under serum-free conditions on the LPS-induced cytokine release by the 


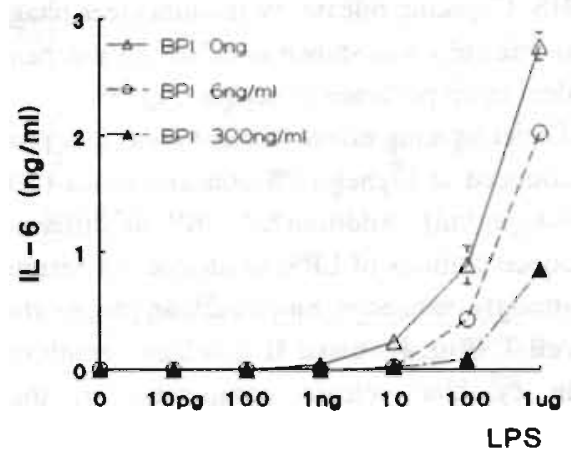

Figure 2. Influence of $B P I$ on $L P S$-induced $I L-6$ release by Mono Mac 6. A concentration range of LPS was pre. incubated 30 minutes $37^{\circ} \mathrm{C}$ with different concentrations of BPI under serum-free conditions. Cells were stimulat ed for $18 \mathrm{~h}$ and $I L-6$ release was determined in an ELISA. Data are expressed as mean and SD of four measurements. SD bars are omitred, if they fall within the symbol.

monocytic cell line Mono Mac 6 was investigated. This cell line responds to relative high LPS concentrations by releasing cytokines (33). In these experiments, BPI substantially reduced LPS-induced IL-6 release (Fig. 2). These data showed that BPI can, also in the absence of serum, inhibit LPS-mediated cell activation.

\section{Counteractive effects of LBP and BPI on LPS activity}

The observation that BPI and LBP have opposite effects upon LPS-induced cytokine release by mononuclear phagocytic cells and the reports that LBP and BPI, proteins with considerable sequence homology (25), both bind to lipid A part of LPS $(26,27)$ prompted us to investigate whether the effects of BPI and LBP are counteractive.

The influence of BPI on LBP-enhanced mononuclear phagocytic cell cytokine release by LPS was studied by pre-incuba- tion ( 30 minutes at $\left.37^{\prime \prime} \mathrm{C}\right)$ a concentration range of LBP and LPS $(1 \mathrm{ng} / \mathrm{ml})$ in the presence or absence of BPI $(3 \mathrm{ng} / \mathrm{ml})$.

Fig. 3A shows that LBP, in a concentration dependent manner, enhanced LPS-induced TNF- $\alpha$, IL- 6 and IL- 8 release. The presence of $B P I$ reduced the enhancement of the response induced by LBP. BPI could no longer reduce $L B P$ induced enhancement at a LBP concentration of $600 \mathrm{ng} / \mathrm{ml}$.

Next, the influence of increasing concentrations of BPI on the enhancement by LBP $(60 \mathrm{ng} / \mathrm{ml})$ of the cellular responses to LPS $(5 \mathrm{ng} / \mathrm{ml})$ was studied.

In accordance with above mentioned data, BPI, even at higher concentrations. did not inhibit L.PS-induced cytokine release by mononuclear phagocytic cells (Fig. 3B).

However, BPI reduced the LBP enhanced cytokine release in a concentration dependent manner. At a BPI concentration of $3 \mu \mathrm{g} / \mathrm{ml}$, therc was no difference between LPS-induced cytokine release in the absence or presence of LBP. These results show that LBP and BPI have counteractive properties upon LPS-induced cell activation.

\section{$L B P$ and BPI compete for binding to LPS.}

Next, it was investigated if the described counteractive effects of LBP and BPI upon LPS-induced cell activation were caused by competition for binding to LPS. To this end an assay was developed; competition of LBP and BPI for LPS binding was assayed by means of BPI specific mAb 4E3. This mAb, coated on the bottom of a 96-well plate, can only recognize free BPI and does not interact with BPI that has formed a complex with LPS. Binding of BPI to 4E3 was detected with polyclonal anti-BPI and peroxidase 

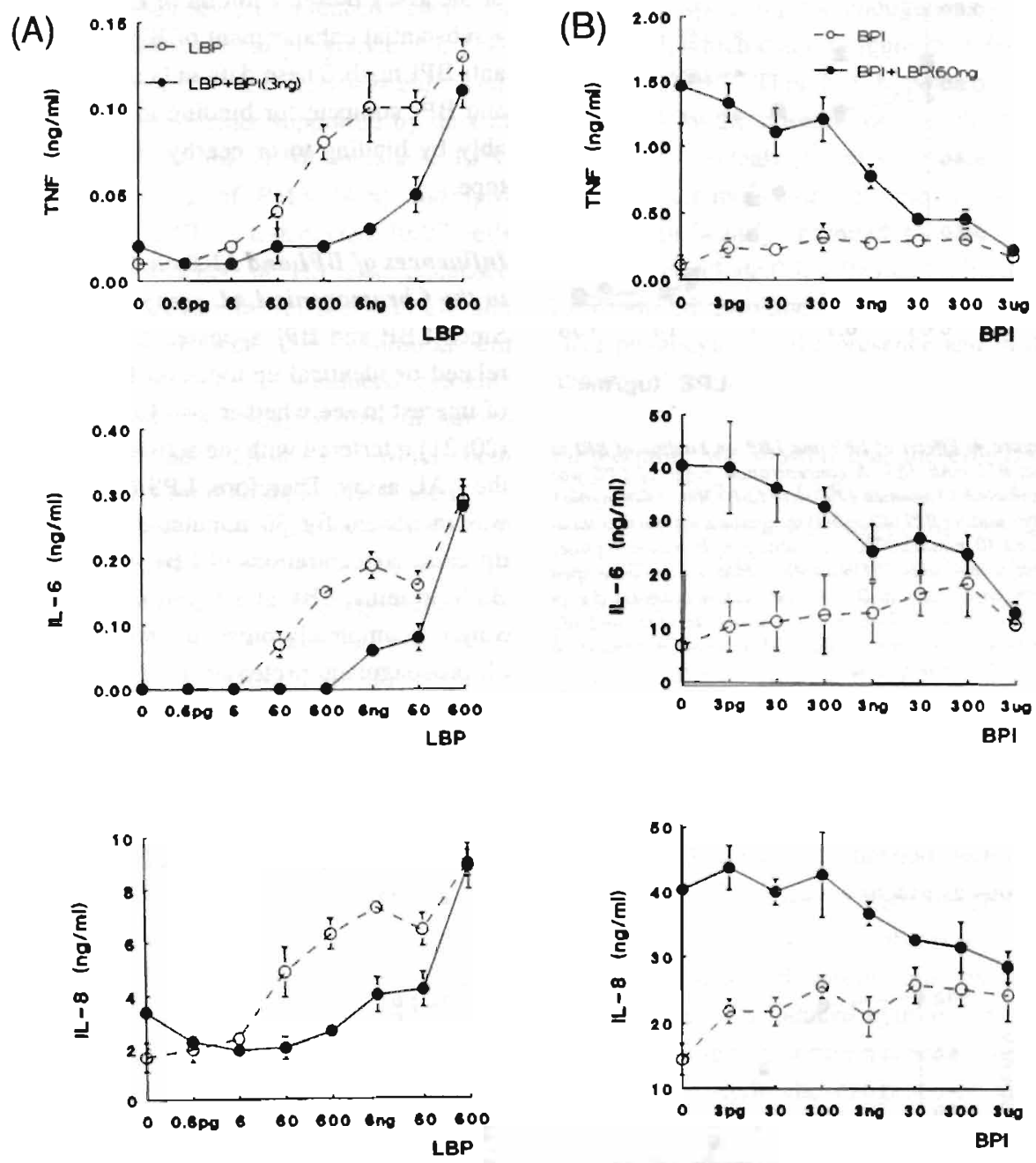

Figure 3. Antagonistic effects of LBP and BPI on LPS-induced mononuclear phagocytic cell cytokine release. Different concentrations of LBP were preincubated 30 minutes $37^{\circ} \mathrm{C}$ with I ng/ml LPS in presence or absence of $3 \mathrm{ng} / \mathrm{ml} \mathrm{BPI}(\mathrm{A})$ or different concentrations of $B P I$ were preincubated 30 minutes $37^{\circ} \mathrm{C}$ with $5 \mathrm{ng} / \mathrm{ml}$ LPS in presence or absence of 60 $n g / m l ~ L B P(B)$ under serum-free conditions. Cells were stimulated for $18 \mathrm{~h}$ and TNF- $\alpha, I L-6$ and $I L-8$ release were determined in specific ELISA. Data are expressed as mean and SD of four measurements. SD bars are not shown, if they fall within the symbol.

conjugated goat anti-rabbit IgG.

The influence of LPS on BPI binding to the anti-BPI $\mathrm{mAb} 4 \mathrm{E} 3$ was measured in the pres- ence or absence of LBP. The data showed that LPS prevented binding of BPI to 4E3 (Fig. 4). Addition of LBP abrogated the LPS- 


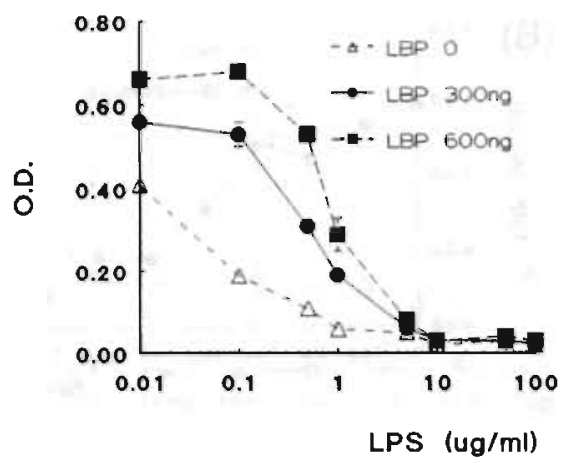

Figure 4. Effects of LPS and LBP on binding of BPI to anti-BPI $m A B$ 4E3. A concentration range of LPS was incubated 30 minutes $37^{\circ} \mathrm{C}$ with LBP ( 300 or $600 \mathrm{ng} / \mathrm{ml}$ ). After adding $B P I(40 \mathrm{pg} / \mathrm{ml})$ the mixture was further incubated 30 minutes $37^{\circ} \mathrm{C}$ and subsequently added to plates coated with anti-BPI mAb 4E3. Plates were developed with polyclonal anti-BPI and peroxidase conjugated goat anti-rabbit IgG. Data are expressed as O.D. and are mean and SD of three values. SD bars are not shown, if they fall within the symbol. of the assay buffer, addition of LBP induced a substantial enhancement of BPI binding to anti-BPI $\mathrm{mAb}$. These data indicate that LBP and BPI compete for binding to LPS, probably by binding to or nearby the same epitope.

\section{Influences of BPI and LBP on LPS activity in the Chromogenic LAL assay}

Since LBP and BPI appeared to react with related or identical epitopes on LPS, it was of interest to see whether also LBP, like BPI $(20,21)$ interfered with the activity of LPS in the LAL assay. Therefore, LPS (100 pg/ml) was incubated for 30 minutes at $37^{\circ} \mathrm{C}$ with different concentrations of LBP or BPI.

Both proteins, LBP at $1.5 \mu \mathrm{g} / \mathrm{ml}$ and BPI at $3 \mathrm{ng} / \mathrm{ml}$ completely prevented the activation of procoagulant proteases in the Limulusamebocyte lysates by LPS (Fig. 5).

\section{Discussion}

In this study we showed that L.BP functions as a general enhancer of LPS-induced cell

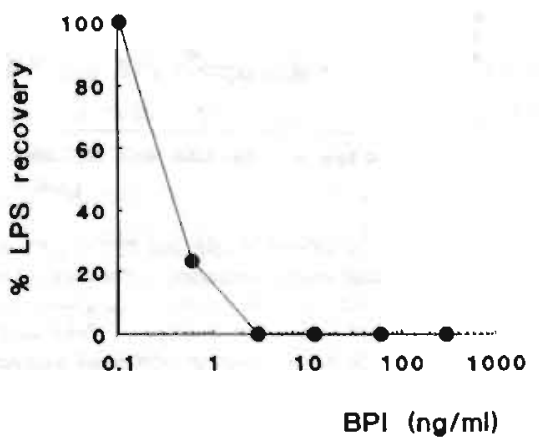

Figure 5. Influences of LAP and BPI on the activity of LPS in the chromogenic LAL-assay. LPS (100 pg/ml) was preincubated for 30 minutes at $37^{\circ} \mathrm{C}$ with different concentrations of IBP (A) or BPI (B). LPS-activity was ihen derermined in the LAL assay. The effects of LBP and BPI are expressed as percentage of recoveny of $L P S$ activity in the $L A L$ assay One representative experiment out of a serie of three is shown. 
activation. Besides LPS-induced release of TNF-a by mononuclear phagocytes $(3,7-9)$, also release of IL- 6 and IL- 8 was enhanced. These data are further supported by data of others showing that LBP enhances LPSinduced priming of PMN (4-6) and IgM expression by CD14 transfected 70Z/3 cells (10). The presence of HS also enhanced LPS-induced cytokine release strongly and addition of LBP under these conditions did not further enhance LPS-induced cytokine release. These data suggest that in human serum, LBP and septin (11), which both opsonize LPS for binding to CD14, are available in adequate amounts to opsonize all exogenous LPS. In serum a balance will exist between several LPS activity regulating proteins, among which soluble CD 14 described to inhibit LPS activation $(34,35)$. Presence of these proteins could be the explanation for the observation that cytokine release in presence of serum-free medium supplemented with LBP is not exactly equal to cytokine release in presence of $10 \%$ HS.

BPI was shown to partially block, not only the LPS-induced release of TNF- $\alpha(13,21$, 22), but also the release of IL- 6 and IL- 8 by mononuclear phagocytic cells in presence of serum. In contrast, under serum-free conditions no effect of BPI was detected. The relatively high concentrations of LPS that are required to induce cytokine release under serum-free conditions might trigger a mechanism of LPS induced activation of mononuclear phagocytes, that is independent of CD14, LBP and BPI (31).

Another explanation for the lack of effect of BPI under serum-free conditions could be that a minor contamination with PMN of the mononuclear phagocytic cell suspension might be responsible for endogenously produced BPI. which could obscure the effect of exogenous BPI. This last hypothesis was confirmed by the observation that the LPSinduced IL- 6 release, under serum-free conditions, of the monocytic cell line Mono Mac 6 was significantly inhibited by BPI. It is therefore concluded that BPI can inhibit the LPS-induced cytokine release by mononuclear phagocytes, in the presence and in the absence of serum.

Furthermore we showed that the effects of LBP and BPI on LPS-induced cytokine release by mononuclear phagocylic cells are counteractive. BI'I, concentration dependent . ly, interfered with the enhancing effect of LBP on the LPS-induced cytokine release. At high LBP to BPI ratios, BPI could no longer block the LBP-induced enhancement. In accordance, it was shown that increasing concentrations of BPI abrogated the LBP effect.

The antagonistic effects of LBP and BPI can explain the above discussed observation that $\mathrm{BPI}$, in presence of serum, only partially inhibited the LPS-induced cytokine release. The LBP present in serum has an antagonistic influence upon the exogenously added BPI. Furthermore this phenomenon could explain the observations of Aida et al. that PMN are not able to inactivate LPS in presence of plasma (36). In line with the suggestion of the authors we hypothesize that LBP protects LPS against inactivation by BPI, produced by activated PMN.

Since both LBP and BPI are known to bind to the lipid A part of LPS $(7,13,20,26,27)$, we investigated whether the antagonistic 
effect was based on a competitive binding of LBP and BPI to LPS. Using an assay system that consisted of a detection system for free BPI, we are the first to show that BPI and LBP compete for binding to LPS. Moreover, the fact that both BPI $(20,21)$ and LBP inhibit LPS activity in the LAL assay provide further evidence for the theory that these two proteins bind to the same or near the same region on the LPS molecule. We therefore conclude that the observed antagonistic effects of LBP and BPI on LPS induced cytokine release by mononuclear phagocytic cells, can be explained by competition of LBP and BPI for binding to LPS.

Responses of cells to relatively low concentrations of LPS is mediated via the glycosylphosphatidylinositol anchored membrane protein CD14, which is strongly expressed on mononuclear phagocytes (37) and weakly on PMN (4). Interaction of LPS with CD 14 is facilitated by LBP and by septin.

Here we showed that BPI may interfere in this signal transduction pathway by competing with LBP for binding to LPS and thus interfering with the LPS-LBP complex interaction with CD14. Both LBP and BPI were shown to be involved not only in LPSinduced TNF- $\alpha$ release $(3,7-9,13,21,22)$, but also in LPS-induced IL-6 and IL-8 release, as was also recently described for CD14 (31). The fact that CD14 mediates LPS effects primarily at low LPS concentrations explains the observation that the effects of LBP and BPI upon LPS-induced cytokine release were absent at high LPS concentrations.

Since the observation that LBP and BPI have antagonistic effects upon LPS-induced cell activation we expect that the balance between these two proteins determines LPS activity under physiological conditions. The role of septin in this process needs to be elucidated. The nature of these proteins influencing LPS activity is quite different. BPI is rapidly produced by $P M N$ in response to LPS and other stimuli, although only a small part is reported to be released $(12,13)$. LBP on the other hand is an acute phase reactant, which is continuously present in plasma, that increases with slower kinetics (2). Septin is also reported to be constitutively present in plasma (11).

Summarizing, in this study we investigated the functional relationship between LBP and $B P I$, two proteins involved in the response to gram-negative bacteria with considerable sequence homology, but with opposite effects. LBP and BPI were shown to have antagonistic effects upon the LPS-induced TNF- $\alpha$, IL- 6 and IL- 8 release by mononuclear phagocytic cells, by competition for bind ing to LPS.

\section{References}

1. Tobias P. S., K. Soldmu, and R. J. Ulevitch. 1986. Isolation of a lipopolysaccharide-binding acute phase reactant from rabbit serum. J. Exp. Med. 164:777.

2. Schuman, R. R., S. R. Leong, G. W. Flaggs, P. W. Gray, S. D. Wright, J. C. Mathison, P. S. Tobias, and R. J. Uleviteb. 1990. Structure and function of lipopolysaccharide binding protein. Science 249:1429.

3. Wright, S. D., R. A. Ramos, P. S. Tobias, R. J. Ulevitch, and J. C. Mathison. 1990. CDI4, a receptor for complexes of lipopolysaccharide (LPS) and LPS binding protein. Science 249:1431.

4. Wright, S. D., R. A. Ramos, A. Hermanowski-Vosatka, P. Rockwell, and P. A. Detmers. 1991. Activation of the adhesive capacity of CR3 on neutrophils by endotoxin: dependence on lipopolysaccharide binding protein and CD14. J. Exp. Med. I73:1281.

5. Vosbeck, K., P. Tobias, H. Mueller, R. A. Allen, K.-E. Arfors, R. J. Ulevitch, and L. A. Sklar. 1990. Priming of polymorphonuclear granulocytes by lipopolysaccharide and its complexes with lipopolysaccharide 
binding protein and high density lipoprotein. $J$. Leucocyte Biol. 47:97.

6. Worthen, G. S., N. Avdi, S. Vukajlovich, and P. S. Tobias. 1992. Neutrophil adherence induced by lipopolysaccharide in vitro; rolc of plasma component interaction with lipopolysaccharide. J. Clin. Invest. 90:2526.

7. Mathison J. C., P. S. Tobias, E. Wolfson, and R. J. Ulevitch. 1992. Plasma lipopolysaccharide (L.PS)binding protein, a key component in macrophage recognition of gram-negative LPS. J. ImmunoL 149:200.

8. Heumann, D., P. Gallay, C. Barras, P. Zaech, R. J. Ulevitch, P. S. Tobias, M. Glauser, and J. D. Baumgartner. 1992. Control of lipopolysaccharide (LPS) binding and LPS-induced tumor necrosis factor secretion in human peripheral blood monocytes. $J$. Immunol 148:3505.

9. Martin, T. R., J. C. Mathison, P. S. Tobias, D. J. Letureq, A. M. Moriarty, R. J. Maunder, and R. J. Ulevitch. 1992. Lipopolysaccharide binding protein enhances the responsiveness of alveolar macrophages to bacterial lipopolysaccharide. J. Clin. Imvest. 90:2209.

10. Lee, J.-D., K. Kato, P. S. Tobias, T. N. Kirkland, and R. J. Ulevitch. 1992. Transfection of CD14 into $702 / 3$ cells dramatically enhances the sensitivity to complexes of lipopolysaccharide (LPS) and LPS binding protein. J. Exp. Med. I75:1697.

11. Wright, S. D., R. A. Ramos, M. Patel, and D. S. Miller. 1992. Septin: a factor in plasma that opsonizes lipopolysaccharide-bearing particles for recognition by CD14 on phagocytes. J. Exp. Med. 176:719.

12. Weiss, J., and 1. Olsson. 1987. Cellular and subcellular localization of the bactericidal/permeabilityincreasing protein of neutrophils. Blood 69:652.

13. Marra, M. N., C. G. Wilde, M. S. Collins, J. L. Snable, M. B. Thornton, and R. W. Scott. 1992. The role of bactericidal/permeability-increasing protein as a narural inhibitor of bacterial endotoxin. J. ImmunoL 148:532.

14. Weersink, A. J. L., K. P. M. van Kessel, M. E. van den Tol, J. A. G, van Strijp, R. Torensma, J. Verhoef, P. Elsbach, and J. Weiss. 1993. Human granulocytes express a 55-kDa lipopolysaccharide-binding protein on the cell surface that is identical to the bactericidal/permeability-increasing protein. J. Immunol. 150:253.

15. Weiss, J., S. Beckerdite-Quagliata, and P. Elsbach. 1980. Resistance of gram-negative bacteria to purified bactericidal leucocyte proteins. J. Clin. Invest. 65:619.

16. Weiss, J., K. Muello, M. Victor, and P. Elsbach. 1984. The role of lipopolysaccharides in the action of the bactericidal/permeability-increasing neutrophil protein on the bacterial envelope. J. Immunol. 132:3109.

17. Mannion, B. A., E. S. Kalatzis, J. Weiss, and P. Elsbach. 1989. Preferential binding of the neutrophil cytoplasmic granule-derived bactericidal/permeability increasing protein to target bacteria. J. Immunol. 142:2807.
18. Weiss, J., P. Elsbach, 1. Olsson, and H. Odeberg. 1978. Purification and characterization of a potent bactericidal and membrane active protein from the granules of human polymorphonuclear leucocytes. $J$. Biol. Chem. 253:2664.

19. Elsbach, P., J. Weiss, R. C. Franson, S. BeckerditeQuagliata, A. Schneider, and L. Harris. 1979. Separation and purification of a potent bactericidal/permeability-increasing protein and a closely associated phospholipase $A_{2}$ from rabbit polymorphonuclear leucocytes; observations on their relationship. J. Biol. Chem. 254:11000.

20. Marra, M. N., C. G. Wilde, J. E. Grifthth, J. L. Snable, and R. W. Scott. 1990. Bactericidal/permeabilityincreasing protein has endotoxin-ncutralizing activity. J. ImmunoL 144:662.

21. Ooi, C. E., J. Weiss, M. E. Doerfler, and P. Elsbach. 1991. Endotoxin-neutralizing properties of the $25 \mathrm{kD}$ $\mathrm{N}$-terminal fragment and a newly isolated $30 \mathrm{kD} \mathrm{C}$. terminal fragment of the $55-60 \mathrm{kD}$ bactericidal/perneability-increasing protein of human neutrophils. J. Exp, Med. 174:649.

22. Weiss, J., P. Elsbach, C. Shu, J. Castillo, L. Grinna, A. Horwitz, and G. Theofan. 1992. Human bactericidal/permeability-increasing protein and a recombinant $\mathrm{NH}_{2}$-terminal fragnent cause killing of serumresistant gram-negative bacteria in whole blood and inhibit tumor necrosis factor release induced by the bacteria. J. Clin. Invest. 90:1122.

23. Ooi, C. E., J. Weiss, P. Elsbach, B. Frangione, and B. Mannion. 1987. A 25-kDa $\mathrm{NH}_{2}$-terminal fragment carries all the antibacterial activities of the human neutrophil $60-\mathrm{kDa}$ bactericidal/permeability-increasing protein. J. Biol Chem. 262:14891.

24. Gray, P. W., G. Flaggs, S. R. Leong, R. J. Gumina, J. Weiss, C. E. Ooi, and P. Elsbach. 1989. Cloning of the cDNA of a human neutrophil bactericidal protein, structural and functional correlations. J. Biol. Chem. 264:9505.

25. Tobias, P. S., J. C. Mathison, and R. J. Ulevitch. 1988. A family of lipopolysaccharide binding proteins involved in responses to gram-negative sepsis. $J$. Biol. Chem. 263:13479.

26. Tobias, P. S., K. Soldau, and R. J. Ulevitch. 1989. Identification of a lipid A binding site in the acute phase reactant lipopolysaccharide binding protein. $J$. Biol. Chem. 264:10867.

27. Gazzano-Santoro, H., J. B. Parent, L. Grinna, A. Horwitz, T. Parsons, G. Theofan, P. Elsbach, J. Weiss, and P. J. Conlon. 1992. High-affinity binding of the bactericidal/permeability-increasing protein and at recombinant amino-terminal fragment to the lipid A region of lipopolysaceharide. Infect. Immun. 60:4754.

28. Ziegler-Heitbrock, H. W. L., E. Thiel, A. Fütterer, V. Herzog, A. Wirtz, and G. Riethmüller. 1988. Establishment of a human cell line (Mono Mac 6) with characteristics of mature monocytes. Int. J. Cancer 41:456.

29. Graziano, R. F., and M. W. Fanger. 1987. FcyRI and FcyRII on monocytes and granulocytes, are cytotoxic trigger molecules for tumor cells. J. ImmunoL 
$139: 35,36$.

30. Engelberts, 1., A. Moller, G. J. M. Schoen, C. J. Van der L.inden, and W. A. Buurman. 1991. Evaluation of measurement of human TNF in plasma by ELISA. Lymfokine Cytokine Res. 10:69.

31. Dentener, M. A., V. Bazil, E. J. U. von Asmuth, M. Ceska, and W. A. Buurman. 1993. Involvement of $\mathrm{CDI} 4$ in lipopolysaccharide-induced tumor neerosis factor- $\alpha$, IL -6 and IL -8 release by buman monocytes and alveolar macrophages. J. ImmunoL 150:2885.

32. Ceska, M., F. Effenberger, P. Peichi, and E. Purscb. 1989. Purification and characterization of monoclonal and polyclonal antibodies to neutrophil activating peptide (NAP-1): the development of a sensitive ELISA for the determination of NAP-I and antiNAP-1 antibodies. Cyrokine 1:136 (Abstr.).

33. Rafferty, B., J. A. Mower, Y. S. Taktak, and S. Poole. 1991. Measurement of cytokine production by the monocytic cell line Mono Mac 6 using novel immunoradiometric assays for interleukin- $1 \beta$ and interleukin-6. J. Immunol Methods. I44:69.

34. Bazil, V., V. Horejsi, M. Baudys, H. Kristofová, J. L. Strominger, W. Kostka, and 1. Hilgert. 1986. Biochemical characterization of a soluble form of the 53kDa monocyte surface antigen. Eur. J. ImmunoL 16:1583.

35. Schïtt, C. T. Schilling, U., Grunwald, W. Schönfeld, and C. Krìger. 1992. Endotoxin-neutralizing capacity of soluble CD14. Res. Immunol. 143:71.

36. Aida, Y., and M. J. Pabst. 1990 . Priming of neutrophils by lipopolysaccharide for enhanced release of superoxide, requirement for plasma bat not for tumor necrosis factor- $\alpha$. J. ImmunoL 145:3017.

37. Knapp, W. 1989. Mycloid section report. In Leucocyte Typing IV. W. Knapp, B. Dörken, W. R. Gilks, E. P. Rieber, R. E. Schmidt, H. Stein, and A. E. G. Kr. Von dem Borne, eds. Oxford University Press, Oxford, New York and Tokyo, p. 747. 


\title{
EVIDENCE FOR ENDOCYTOSIS OF E-SELECTIN IN HUMAN ENDOTHELIAL CELLS
}

\author{
ECKHARDT J.U. VON ASMUTH, EDGAR F. SMEETS, LEO A. GINSEL: \\ JOS J.M.ONDERWATER *", JET F.M. LEEUWENBERG, WIM A. BUURMAN
}

'Department of Cell Biology and Histology, University of Nijmegen,

Nijmegen, The Netherlands.

"Laboratory for Electron Microscopy, University of Leiden, Leiden, TheNetherlands.

Eur. J. Immunol. 1992, 22: 2519-2526

\section{Summary}

1

-selectin is an inducible adhesion molecule on endothelial cells. The internalization of this glycoprotein was investigated on TNF-activated cultured human umbilical vein endothelial cells (HUVEC). Kinetics of inter cellular adhesion molecule-1 (ICAM-1) were studied in parallel-experiments. Internalization studies were performed with radioiodinated antibodies in an acid-elution endocytosis assay, and by immunohistology; both approaches gave equivalent results. [12'I]ENA1, a mAb specific for E-selectin, was internalized at a rate of approximately $1.7 \%$ of the membrane-bound [ $\left.{ }^{125} \mathrm{I}\right] \mathrm{mAb}$ per minute. In contrast. less than $0.1 \%$ of membrane bound [ ${ }^{125}$ I]RR $1 / 1$, a mAb specific for ICAM-1, was internalized per minute. TNF-activated HUVEC were immuno-stained and examined by light-microscopy (LM) and electron microscopy (EM). LM revealed presence of ENA1, but not RR1/1, after 30 minutes of incubation with these $\mathrm{mAb}$ 's in cytoplasmic vesicles, which were characterized as multivesicular bodies by EM. Without previous mAb-exposure of the endothelial cells, both high amounts of E-selectin and BSA complexed to colloidal gold, used as a marker for fluid phase internalization, were detected in the same organelles, thus arguing against $\mathrm{mAb}$ interaction induced E-selectin internalization. Furthermore, the amount of E-selectin surface expression was not influenced by ongoing mAb presence, also arguing against $\mathrm{mAb}$ interference with normal E-selectin kinetics.

Taken together, these results indicate that TNF-activated HUVEC constitutively internalize E-selectin. Physiological significance of E-selectin internalization in the regulation of E-selectin membrane-expression, and in clearing E-selectin ligands from the circulation, needs further investigation. 


\section{Introduction}

$\mathrm{E}$ -selectin (consensus term for ELAM$1 /$ LECAM2 (1)) is a $115 \mathrm{kD}$ membrane glycoprotein (2) which is transiently expressed on human endothelial cells after activation with TNF, IL-1 and bacterial LPS (2-5).

E-selectin is engaged in the adherence of neutrophil granulocytes $(2,6)$, a subpopulation of monocytes $(7,8)$ and skin homing T-cells $(9,10)$ to activated endothelium.

In contrast with $\mathrm{CD} 18$ mediated adhesion, E-selectin offers a venous shear stress resistent, temperature insensitive anchoring (11, 12), for which neutrophil L-selectin (13) (consensus term for MEL14/LECAM1 (1)), and glycolipids and glycoproteins containing sialylated Lewis $\mathrm{x}$ tetrasaccharide-moieties (14-16) might function as a ligand. Neutrophil interaction with E-selectin does not play a role in activating neutrophil oxidative burst activity $(17,18)$ or in mediating neutrophil transmigration (13), although neutrophil CD11b/CD18 membrane expression and adhesive capacities are increased after interaction with E-selectin (19).

E-selectin is, together with the largely homologous adhesion molecules L-selectin and $\mathrm{P}$-selectin, composed of an amino-terminal lectin-like domain followed by an epidermal growth factor-like domain and six repetitive motifs, related to those found in complement-binding proteins.

E-selectin has a trans-membrane domain and a short cytoplasmic tail (20). Biosynthetic labeling experiments performed by Bevilacqua et al. (20) and Smeets et al. [E.F. Smeets, submitted for publication] demonstrated that the E-selectin molecule has a short half-life, since labeled E-selectin molecules were largely lost 3 hours after labeling was terminated. Apparently, E-selectin molecules are not stably expressed on the cell-surface. Presence of a tyrosine residue in the intracellular tail of E-selectin has led to the hypothesis that E-selectin might be internalized via clathrin coated pits (20).

The present study was undertaken to investigate the kinetics of the E-selectin molecule. Using the E-selectin specific mAb ENA1 (6) as a marker, we demonstrated that E-selectin is constitutively internalized, and transferred to multivesicular bodies in the cytoplasm in TNF-stimulated HUVEC. ICAM-1 was investigated in parallel, and found not to be internalized.

\section{Materials and Methods}

Reagents and antibodies

Recombinant human TNF-a was kindly provided by BASF/Knoll AG. (Ludwigshafen FRG). mAb ENAl (IgGI), reactive with E-selectin (6), was prepared as described (21). mAb RR1/1 (IgGl), a kind gift of Dr. Rothlein (Boehringer Ingelheim, Ridgefield, CT) is reactive with ICAM-1 (22). mAb MOPC2I (IgG1), a non specific control antibody. was kindly provided by Celltech (. Slough, UK).

\section{Radioiodination of antibodies}

Antibodies were radiojodinated using Iodobeads (Pierce, Rockford, IL) according to the manifacturer's instructions. Three Iodobeads were pre-loaded with $250 \mathrm{mCi} \mathrm{Na}^{1: 35}$ (Amersham, Buckinghamshire, England) in $500 \mathrm{ml}$ PBS for 5 minutes at RT. About 250 $\mathrm{mg}$ of protein $\mathrm{G}$ purified RR1/1 and ENAl were added in a small volume and the incu- 
bations were continued for 10 minutes. Subsequently, the iodobeads were removed and labelled protein and free iodine were separated on a Sephadex G-50 column (Pharmacia, Upsala, Sweden), equilibrated with $0.5 \%$ BSA (Sigma) in PBS. The radiolabeled protein $(50-150 \mathrm{mCi} / \mathrm{mg})$ was stored at $-20^{\circ} \mathrm{C}$.

\section{Cells}

HUVEC were obtained by collagenase treatment of the human umbilical vein. The cells were cultured in fibronectin-coated (fibronectin kindly provided by Dr. J. van Mourik, CLB, Amsterdam, The Netherlands) tissue culture flasks (Costar, Cambridge, MA) in RPMI1640 (Gibco Europe, Paisley, Scotland), supplemented with $10 \%$ heat-inactivated human serum, $10 \%$ heat-inactivated bovine calf serum (BCS) (Hyclone, Logan, UT), $50 \mathrm{mg} / \mathrm{ml}$ heparin (Sigma), $30 \mathrm{mg} / \mathrm{ml}$ endothelial growth supplement (Collaborative Research Incorporated, Bedford, MA) and antibiotics. Endothelial cells were characterized by their pavement-like monolayer morphology and positive staining with $\mathrm{mAb}$ hec7 directed against PECAM-1 (23). generously provided by Dr. W.A. Muller, Rockefeller University, NY.

\section{Internalization assays}

Two days before the experiment, endothelial cells of passage three were seeded on fibronectin coated $25 \mathrm{~cm}^{2}$ tissue culture flasks. After activation with TNF (4-5 hours to study E-selectin, 12-18 hours to study ICAM-1), monolayers were rinsed twice with ice-cold PBS containing $\mathrm{Ca}^{2}, \mathrm{Mg}^{2+}$ and $0.1 \%$ BSA. Cell-surface antigens were labeled by 15 minutes of incubation with 10 $\mathrm{mg} / \mathrm{ml}\left[{ }^{125} \mathrm{I}\right] \mathrm{mAb}$ in PBS containing $\mathrm{Ca}^{2+}$. $\mathrm{Mg}^{2+}$ and $0.1 \%$ BSA at $4{ }^{\circ} \mathrm{C}$. Excess of $\left[{ }^{125} 1\right] \mathrm{mAb}$ was removed and monolayers were rinsed extensively. Incubation of unstimulated HUVEC monolayers with $10 \mathrm{mg} / \mathrm{ml}\left[{ }^{125}\right]$ ENAl bound less than $5 \%$ of the amount of ${ }^{12.5}$ bound to TNF-stimulated HUVEC. After labeling and washing, monolayers were incubated with pre-warmed $\left(37^{\circ} \mathrm{C}\right) \mathrm{RPMI} 164010 \% \mathrm{BCS}$ for various times. Subsequently, supernatant medium was collected and cells were rinsed two times with cold PBS containing $\mathrm{Ca}^{2+}, \mathrm{Mg}^{2+}$ and $0.1 \%$ BSA. Supernatant medium and the latter two wash fractions were pooled and the amount of ${ }^{125} \mathrm{I}$ in this sample was measured in a gamma-counter. Next, monolayers were incubated for 10 minutes with cold $0.1 \mathrm{M}$ citrate buffer of $\mathrm{pH} 3$ containing $\mathrm{Ca}^{2+}$ and $\mathrm{Mg}^{2+}$, rinsed once with the same buffer and twice with PBS containing $\mathrm{Ca}^{2+}, \mathrm{Mg}^{2+}$ and $0.1 \%$ BSA, to remove cell-surface bound $\left[{ }^{125} \mathrm{I}\right] \mathrm{mAb}$. Elution buffer fractions and wash fractions were pooled and the amount of ${ }^{125} \mathrm{I}$ in this sample was measured in a gamma-counter.

Cells were then solubilized by incubation with $1 \mathrm{M} \mathrm{NaOH}$ for 10 minutes at room tcmperature (RT). The amount of ${ }^{125} \mathrm{I}$ in the lysate was measured in a gamma-counter. The specific $\mathrm{pH} 3$ insensitive fraction was calculated by correcting lysate-fraction measurements for the background amount of pH 3 insensitive cell-associated ${ }^{125} \mathrm{I}$. Background $\mathrm{pH} 3$ insensitive ${ }^{125} \mathrm{I}$ ranged from $5 \%$ to $9 \%$ of the total amount of cell-associated ${ }^{125}$ I after labeling, and was defined as the amount of ${ }^{125}$ I which remained cell-associated when cells where treated with $\mathrm{pH} 3$ citrate buffer directly after labeling.

\section{Immuno-staining}

Two days before the experiment, endothelial cells of passage three were grown on micro- 
scope slides coated with gelatin (Difco, Detroit, MI) fixed with $0.5 \%$ glutaraldehyde (Merck, Darmstadt, FRG) and covered with flexiperm chambers (Heraeus, Amsterdam, The Netherlands). After activation with $10 \mathrm{ng} / \mathrm{ml}$ TNF (5 hours to investigate E-selectin kinetics, 18 hours to investigate ICAM-1 kinetics), endothelial cell monolayers were rinsed twice with cold PBS containing $\mathrm{Ca}^{2+}$ and $\mathrm{Mg}^{2+}$ and, for membrane immuno-staining, fixed by a 5 minute incubation with $3 \%$ formaldehyde and $2 \%$ sucrose in PBS containing $\mathrm{Ca}^{2+}$ and $\mathrm{Mg}^{2+}$, followed by extensive washing. For intracellular staining, permeabilization was performed by incubation with $96 \%$ methanol during 5 minutes at $\mathrm{RT}$, rinsing, and incubation with aqua bidest, $\mathrm{pH} 7.4$, containing $20 \mathrm{mM}$ HEPES, $300 \mathrm{mM}$ sucrose, $3 \mathrm{mM} \mathrm{MgCl}$, $50 \mathrm{mM} \mathrm{NaCl}$, and $0.5 \%$ Triton X-100 (Sigma), for 5 minutes at RT. Cells were then incubated with $5 \mathrm{mg} / \mathrm{ml}$ ENA1, RR $1 / 1$ or MOPC21 in RPMI 1640 $10 \%$ BCS at RT for 30 minutes, rinsed three times, incubated with horse radish peroxidase conjugated goat anti mouse antibodies in RPMI1640 $10 \%$ BCS for 30 minutes at $\mathrm{RT}$, and stained with 3-3'-Diaminobenzidine.4HCl (Sigma) plus $0.1 \% \quad \mathrm{H}_{2} \mathrm{O}_{2}$ and Meyer's Hematoxylin.

\section{Electron microscopy}

Two days before the experiment, endothelial cells of passage three were grown on fibronectin coated $75 \mathrm{~cm}^{2}$ tissue culture flasks. Monolayers were preincubated as described in section 2.5. BSA-gold was prepared by conjugating BSA to colloidal gold particles of about $5 \mathrm{~nm}$ as described by Slot et al. (25), and added to part of the HUVEC monolayers during the last 30 minutes at $37^{\circ} \mathrm{C}$. Monolayers were rinsed twice with ice-cold PBS con- taining $\mathrm{Ca}^{2-}$ and $\mathrm{Mg}^{2+}$, and fixed with $0.1 \%$ glutaraldehyde and $1 \%$ formaldehyde (freshly prepared from paraformaldehyde) in $0.1 \mathrm{M}$ phosphate buffer $\mathrm{pH} 7.4$ for 2 hours. After threc washings with PBS, cells were removed from the culture flask with a rubber policeman, spun down in $10 \%$ gelatin in PBS and stored overnight at $4^{\circ} \mathrm{C}$ in $1 \%$ formaldehyde in $0.1 \mathrm{M}$ phosphate buffer. Ultrathin cryosectioning was done as described previously (26). Cells, which were preincubated with ENA 1, were labeled on the cryosections with rabbit anti mouse $\mathrm{IgG}$ visualized with Protein A complexed to colloidal gold (25). Otherwise the cells were labeled on the cryosections with ENA1, rabbit anti mouse IgG and protein-A gold. The sections were examined in a Philips EM $201 \mathrm{C}$ electron microscope operating at $80 \mathrm{KV}$.

\section{Results}

Kinetics of surface E-selectin and ICAM-I using radioiodinated $m A b$ as a marker.

Radioiodinated E-selectin specific mAb ENAl, and ICAM-1 specific mAb RRl/1, were used as markers for E-selectin and ICAM-1 respectively.

TNF-activated HUVEC monolayers were labeled at $4^{\circ} \mathrm{C}$ with $\left[{ }^{125} \mathrm{I}\right] \mathrm{mAb}$, rinsed, and incubated at $37^{\circ} \mathrm{C}$ for various times to allow redistribution of E-selectin and ICAM-1. Supernatants were harvested to determine the amount of release of E-selectin and ICAM-1. Only small amounts of ${ }^{125}$ I were measured in the supernatant of [ ${ }^{25}$ I]ENA1 labeled HUVEC after incubation at $37^{\circ} \mathrm{C}$ for up to two hours (Fig. IA), indicating that E-selectin release and loss of surface-bound [ ${ }^{125}$ I]ENA1 does not play a substantial role during the first two hours at $37^{\circ} \mathrm{C}$ after labeling. Up to $40 \%$ of the ${ }^{125} \mathrm{I}$ label was, however, 
found in the supernatant of $\left[{ }^{125} I\right]$ RR $1 / 1$ labeled monolayers after 2 hours of incubation at $37^{\circ} \mathrm{C}$, which could represent release of ICAM-1 (Fig. 1B). Direct evidence for release of both E-selectin and ICAM-1 from the cells, was acquired using ELISA's for soluble E-selectin and ICAM-1, and immunoprecipitation. These results are presented elsewhere (J.F.M. Leeuwenberg, submitted for publication).

To distinguish between internalized molecules and cell surface molecules, cells were then treated with a $\mathrm{pH} 3$ elution-buffer. Cell lysates were prepared, and the relative distribution of $\left[{ }^{125} \mathrm{I}\right] \mathrm{mAb}$ in the elution buffer and in the cell lysate was determined.

After [ ${ }^{125}$ I] ENA 1 labeled cells were warmed to $37^{\circ} \mathrm{C}$, an increasing amount of [ $\left.\left.{ }^{125} \mathrm{I}\right] \mathrm{ENA}\right]$ remained cell associated after elution (Fig. I) and must therefore have been internalized into a compartment protected from the externally applied elution buffer (Fig. IA). From these data, an internalization rate of $1.7 \%$ of membrane E-selectin per minute was estimated by regression analysis (Fig. IA, inset), implicating a half-life of 40 minutes for a surface E-selectin molecule on 4 to 5 hours TNF-activated HUVEC. Similar experiments were performed in which 2 hour as well as 10 hour TNF-activated HUVEC were labelled with [ $\left.{ }^{125} I\right]$ ENA 1 . No clear surface E-selectin half-life differences were found between 2 hour, 4 hour and 10 hour
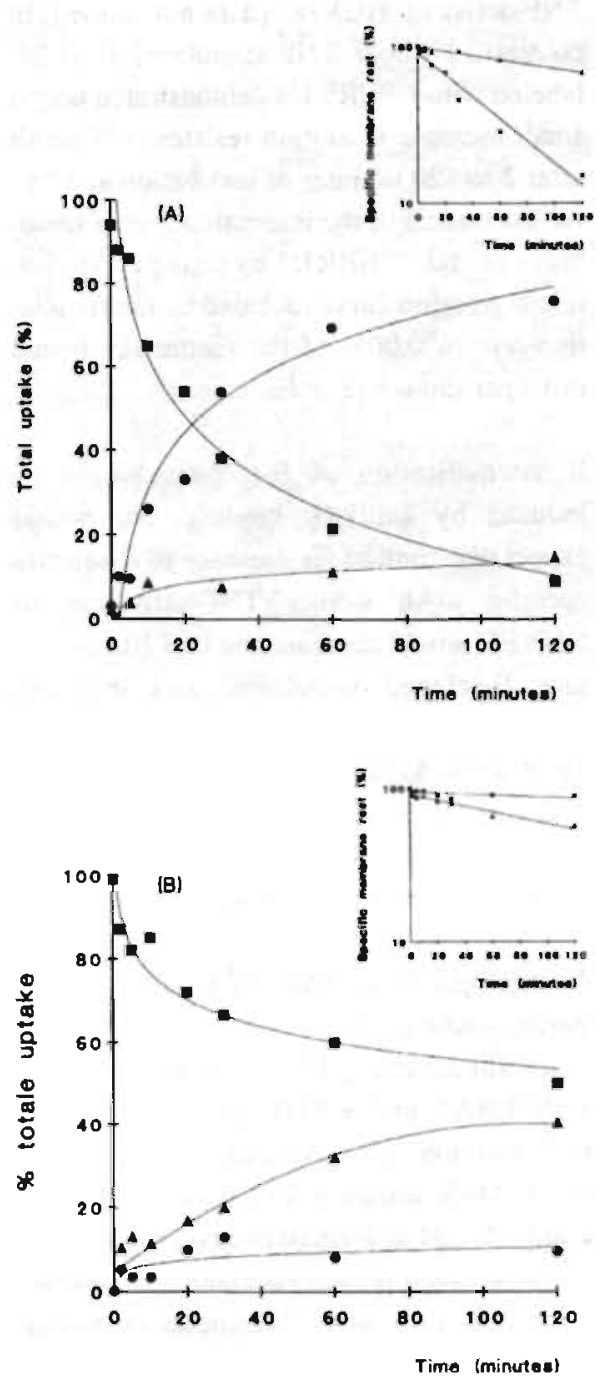

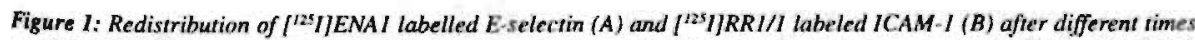
a $37^{\circ} \mathrm{C}$. HUVEC were acrivated with $10 \mathrm{ng} / \mathrm{ml}$ TNF (4 hours to study $E$-selectin, 12 hours to study ICAM-I) ghter which $10 \mu \mathrm{g} / \mathrm{ml} /{ }^{2 s} / \mathrm{mAb}$ was added for 15 minues at $4 \mathrm{C}$. Monolayers were exiensively rinsed, incubased for the incubatd time-interval at $37^{\circ} \mathrm{C}$ and samples were acquired as indicared in Materials and Methods: Supermatan fractions ( $\mathbf{\Delta}$ ), $\mathrm{pH}$ 3 sensitive membrane fractions (D) and the specific $\mathrm{pH} 3$ insensitive endocyotic fractions (O) (corrected for non-spe-

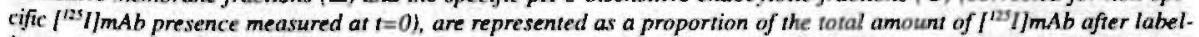
ing at $4^{\circ} \mathrm{C}$. Inset: The relative reduction of the amount of membrune bound $I^{125} \mathrm{I} / \mathrm{mAb}$ due to internalizuion only $(\Theta)$ and ${ }^{21} \mathrm{I}$ dissociation from the monolayer only $(\mathbf{\Delta})$ after different times at $37^{\circ} \mathrm{C}$, as culculated from the main figure data, and expressed in log scale. 
TNF-activated HUVEC (data not shown). In contrast, 12 hour TNF-stimulated HUVEC labeled with [ ${ }^{125}[] R R 1 / 1$ demonstrated only a small increase in elution resistent $\left[{ }^{125}\right] \mathrm{mAb}$ after 2 to 120 minutes of incubation at $37^{\circ} \mathrm{C}$. An estimation of the internalization of membrane bound [ $\left.{ }^{125} I\right] R R 1 / 1$ by fitting a logarithmic regression curve revealed an internalization-rate of $0.06 \%$ of the membrane-bound mAb per minute (Fig $I B$, inset).

If internalization of E-selectin would be induced by antibody binding, one would expect that continuous presence of E-selectin specific mAb during TNF-activation of HUVEC would decrease the half-life of surface E-selectin molecules, and therefore reduce the amount of E-selectin surface expression. As shown in Table 1, no significant reduction in $E$-selectin expression was seen after 4 hours of activation, induced by either ENA 1, RR 1/1 or control IgG1 mAb.

\section{Microscopic localization of $E$-selectin} during endocytosis.

TNF stimulated HUVEC were incubated with ENAl and RR1/1 at $37^{\circ} \mathrm{C}$ to allow redistribution of mAb-antigen complexes, and $\mathrm{mAb}$-localization was evaluated by $\mathrm{LM}$ and EM. LM examination revealed visually unaltered membrane-expression of E-selectin and ICAM-1 after 30 minutes of incubation with respectively ENAl and RRI/1 (not shown). After permeabilization of the cell

Figure 2: Peraxidase-staining of 30 minute ENAI (A) and RRIII (B) incubated HUVEC at $37^{\circ} \mathrm{C}$. HUVEC was acrivated with $10 \mathrm{ng} / \mathrm{ml}$ TNF for 5 hours (for E-selectin staining) and 18 hours (for ICAM-I staining). mAb were added during the last 30 minutes of TNF-incubation and immuno-staining of permeabilized cells was performed as mentioned in Materials and Methods. Heavily stained cytoplasmic vesicles are found in ENAI, but not in $R R I / I$ incubated monolayers.

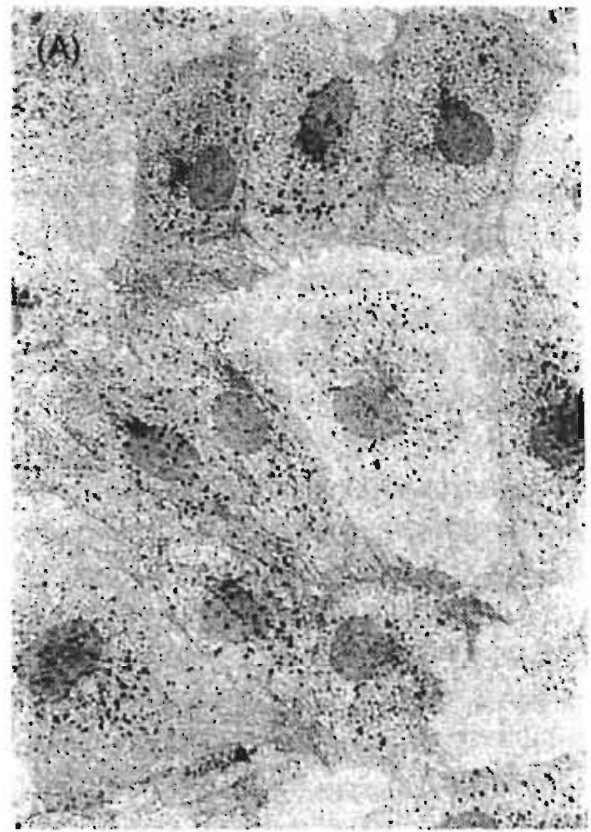

(B)
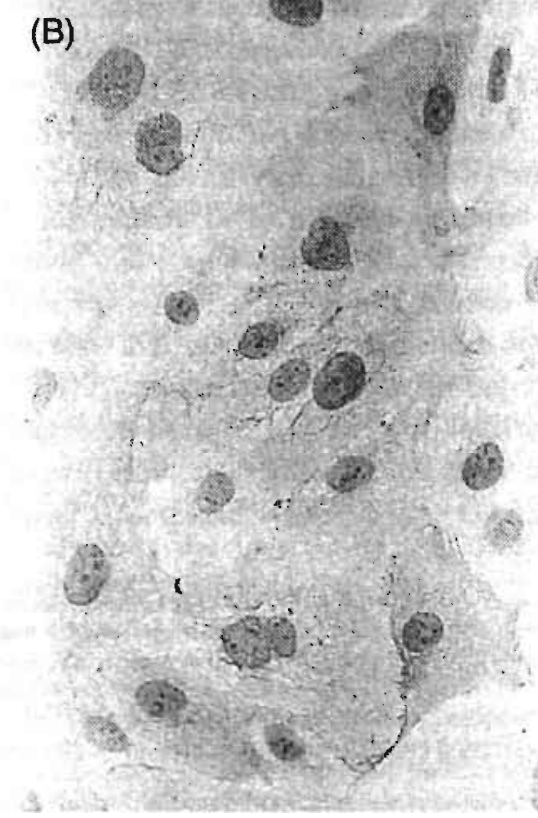


\begin{tabular}{ll} 
Preincubation & $\mathrm{A}_{492 \mathrm{~nm}}$ \\
\hline medium only & $0.04 \pm 0.01$ \\
TNF & $1.41 \pm 0.07$ \\
TNF + ENA1 & $1.31 \pm 0.06 *$ \\
TNF + RR $1 / 1$ & $1.45 \pm 0.06$ \\
NF + MOPC21 & $1.44 \pm 0.05$
\end{tabular}

Table I. Influence of $m A b$ presence on $E$-selectin membrane expression.

HUVEC in microtiter-plates were incubated for 4 hours at $37^{\circ} \mathrm{C}$ in $200 \mu /$ well RPMII640 $10 \%$ BCS and additives $(10 \mathrm{ng} / \mathrm{ml} \mathrm{TNF}$ and $10 \mu \mathrm{g} / \mathrm{ml} \mathrm{mAb}$ as indicated). Plates were then rinsed three times with cold $\mathrm{pH} 3$ citrate buffer, to remove cell surface antibodies. E-selectin expression was subsequently measured in ELISA using $M A b$ ENAI and peroxidase labeled goat anti mouse antibodies as described (2I). Results indicate mean $\pm S D$ of 4 measurements.

* $p=0.07$, when compared to E-selectin expression in absence of mAb, as determined by the unpaired, twotailed Student's t-test.

membranes clear vesicles were seen in ENAl incubated (Fig. 2A), but not in RR $1 / 1$ (Fig. $2 B$ ) or control mAb (MOPC21, data not shown) incubated cells. Such vesicles were also found, using the anti E-selectin mAb ENA2 (21), 1.2B6 (27), and H4/18 (2) (data not shown), indicating that internalization did not involve mAb binding to a specific epitope on the E-selectin molecule. Monolayers incubated with ENAl at $4^{\circ} \mathrm{C}$ did not show $\mathrm{mAb}$ containing vesicles (data not shown). EM examination of TNF-stimulated HUVEC, after incubation with ENAI for 30 minutes at $37^{\circ} \mathrm{C}$, revealed presence of this $\mathrm{mAb}$ in endo-lysosomal structures (Fig. 3).

Gold particles were found on the plasma membrane (Fig. $3 A$ ), in small vesicles close to the plasma-membrane (average diameter $0.15 \mathrm{~mm}$. Fig. $3 B$ ), and in multivesicular bodies of bout $0.8 \mathrm{~mm}$ diameter (Fig. 3 C).

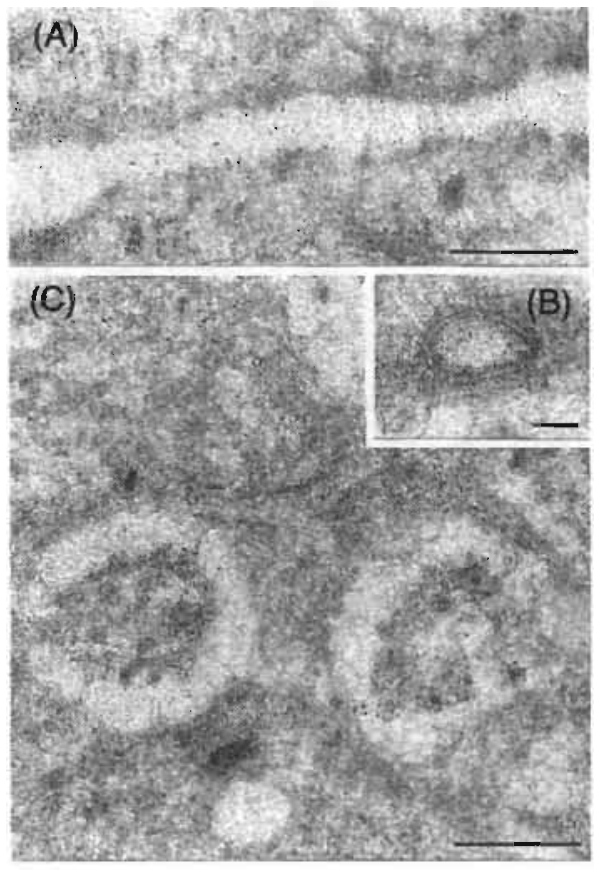

Figure 3: EM visualization of ENAl in endo-lysosomal structures of 5 hour TNF activated HUVEC. MAb were added during the last 30 minutes of TNF-incubation. Cryasections were labeled with rabbit anti mouse $\lg G$ and then with protein-A gold $(10 \mathrm{~nm})$. Gold particles were found on the plasma membrane $(A)$, in small vesicles close to the plasma-membrane $(B)$, and in multivesicular hodies $(C)$. Bars represent $0.5 \mu \mathrm{m}(A$ and $C)$ and $0.1 \mathrm{~mm}(\mathrm{~B})$.

Too few clathrin coated pits and clathrin coated vesicles were found in these sections, to allow conclusions on the involvement of the clathrin coated pit endocytotic pathway.

If E-selectin internalization occurred spontaneously, without being influenced by mAbbinding, internalized E-selectin should be present in the same endocytotic vesicles in TNF-activated endothelium without previous $\mathrm{mAb}$ incubation. Intra-cellular expression of E-selectin and ICAM-1 was therefore evalu- 

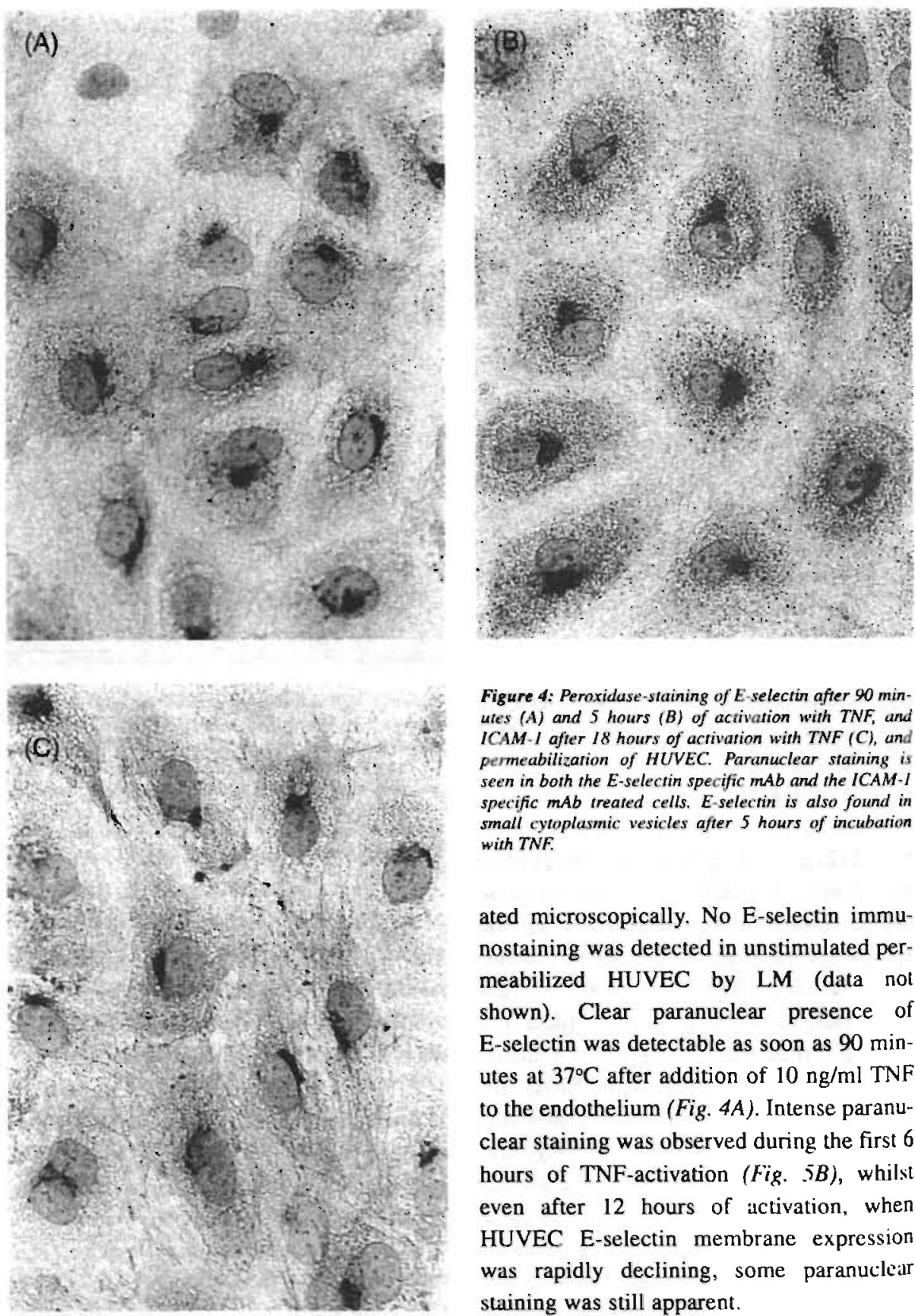

Figure 4: Peroxiduse-staining of E-selectin after $90 \mathrm{~min}$ utes (A) and 5 hours (B) of activation with TNF, and $I C A M-I$ after 18 hours of acrivation with $T N F(C)$, and permeabilization of HUVEC. Paranuclear staining is seen in both the E-selectin specific mAb and the ICAM-I specific mab treated cells. E-selectin is also found in small cyroplasmic vesicles after 5 hours of incubation with $T N F$.

ated microscopically. No E-selectin immunostaining was detected in unstimulated permeabilized HUVEC by LM (data not shown). Clear paranuclear presence of E-selectin was detectable as soon as $90 \mathrm{~min}$ utes at $37^{\circ} \mathrm{C}$ after addition of $10 \mathrm{ng} / \mathrm{ml} \mathrm{TNF}$ to the endothelium (Fig. 4A). Intense paranuclear staining was observed during the first 6 hours of TNF-activation (Fig. $5 B$ ), whilst even after 12 hours of activation, when HUVEC E-selectin membrane expression was rapidly declining, some paranucleir staining was still apparent. 
Five hours or more stimulated HUVEC showed a similar para-nuclear distribution pattern for ICAM-1 staining (Fig. 4C). Cryosections of TNF-stimulated HUVEC were stained with ENAl, rabbit anti mouse IgG and protein A-gold. EM examination of these sections revealed the Golgi-apparatus as the origin of this para-nuclear E-selectin spot (Fig. 5A). Besides in the Golgi-apparatus, LM also showed presence of E-selectin in cytoplasmic vesicles when HUVEC was stimulated with TNF for more than 3 hours (Fig. 4B). These vesicles were characterized as multivesicular bodies by electron microscopy (Fig. 5B), and showed the same characteristics as the previously described endolysosomal structures (Fig. 3C). No ICAM-1 was detected in such organelles by either LM (Fig. 4C) or EM (data not shown).

If the ENAl containing multivesicular bodies, stained after warming ENA1 labelled HUVEC to $37^{\circ} \mathrm{C}$ for 30 minutes would be identical to the spontaneously occurring E-selectin containing multivesicular bodies, E-selectin in the latter structures would originate from endocytosis of membrane E-selectin. To acquire direct evidence for the endocytotic content of these spontaneously occurring E-selectin containing multivesicular bodies, we added $5 \mathrm{~nm}$ BSA colloidal gold conjugates to HUVEC-medium during the last 30 minutes of a 5 hour TNF-activation interval, thus allowing internalization of these particles by fluid phase endocytosis. Cryosections were subsequently incubated with ENA1 and with rabbit anti mouse $\operatorname{IgG}$ and protein-A gold $(10 \mathrm{~nm})$. Endocytosed albumin-coated gold-particles were observed in multivesicular bodies, which were also labeled with anti E-selectin (Fig. 5C), demonstrating that these vesicles contain endocy-
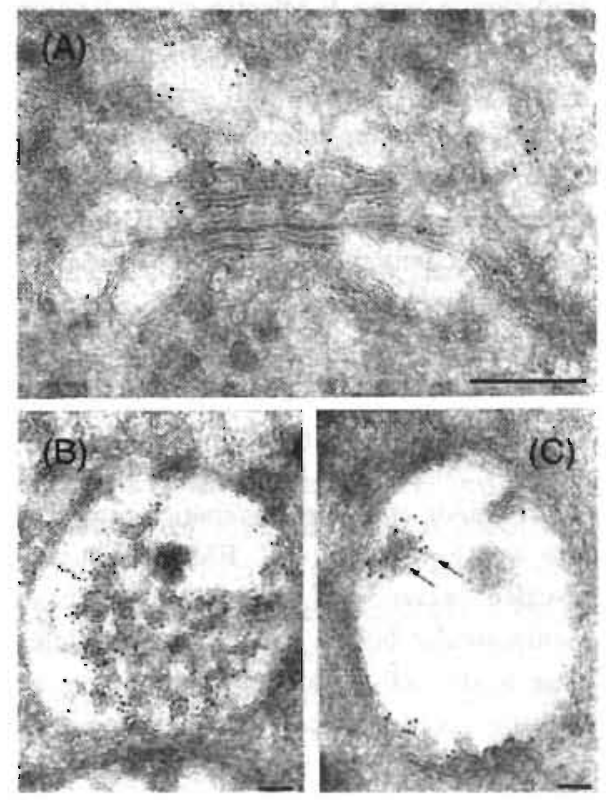

Figure 5: EM visualization of intra-cellular E-selectin antigen and co-localization of endocytosed BSA-gold conjugates in 5 hour TNF stimulated HUVEC. Cryosecrions were incubated first with anti E-selectin and then with rabbit anti mouse $\mathrm{Ig} G$ and protein $-A$ gold $(10 \mathrm{~nm})$. Gold particles were observed in the cisternae of the Golgi-apparatus, and most likely in the trans-Golgi network (A). Multivesicular bodies were heavily labeled $(B)$. Part of the HUVEC monolayers were co-incubated the last 30 minutes at $37^{\circ} \mathrm{C}$ with BSA-gold $(5 \mathrm{~nm})$. The endocyrosed albumin-coated gold-particles (arrows), were observed in multivesicular bodies, which were also labeled with anti E-selectin (large gold particles) (C). Bars indicale $0.5 \mu \mathrm{m}$ ( $A$ ) and $0.1 \mu \mathrm{m}$ ( $B$ and $C$ ).

tosed material, which argues for cell-surface origin of E-selectin found in these spontaneously occurring multivesicular bodies.

\section{Discussion}

We demonstrated in this study that surface E-selectin on TNF-activated HUVEC is rapidly internalized. Such internalization was demonstrated and quantified for $\mathrm{mAb}$ ENAl labeled membrane E-selectin in an 
acid-elution assay. E-selectin internalization was not caused by non-specific membrane internalization, since $\left[{ }^{125} \mathrm{I}\right] \mathrm{mAb}$ reactive with ICAM-1 were internalized at less then $0.1 \%$ per minute. Internalized $\mathrm{mAb}$ were stained and visualized by $\mathrm{LM}$ and EM. Intracellular accumulation of $\mathrm{mAb}$ was apparent after 5 minutes or more, when TNF-activated HUVEC cells were incubated with anti E-selectin mAb at $37^{\circ} \mathrm{C}$, but was absent when the incubation was performed with anti ICAM-1 mAb and with isotype-matched control $\mathrm{mAb}$, and when incubation-temperature was lowered to $4^{\circ} \mathrm{C}$. EM examination revealed presence of internalized $\mathrm{mAb}$ in multivesicular bodies and in small vesicles close to the cell-membrane. The number of clathrin-coated pits and clathrin coated vesicles, found in the EM-sections, was too small to allow conclusions on the involvement of these structures in the internalization-process.

Direct study of endocytosis of surface-molecules requires some kind of surface-limited labeling or modification of the molecule. Such methods potentially interfere with normal molecule-traffic.

Therefore, indirect evidence was acquired suggesting that internalization of E-selectin occurred spontaneously instead of being induced by antibody-binding. E-selectin presence was detected without previous mAb exposure in vesicles apparently identical to the vesicles in which we found internalized ENA1, thus indicating that the localization of E-selectin in these multivesicular bodies also occurs in absence of mAb. Direct proof that these multivesicular bodies contained endocytosed material was obtained by demonstrating that fluid phase BSA-gold particles were co-internalized in these organelles.
This argues strongly against other than endocytotic origin for E-selectin in these organelles. Additionally, no clear reduction in membrane-expression of E-selectin was induced by presence of an excess of ENA1, suggesting an unaltered half-life of surface E-selectin in presence of ENA1.

Furthermore, induction of internalization of E-selectin by antibody-binding would implicate some kind of signal transduction and cellular activation mechanism. We could, however, not detect any change in $\left[\mathrm{Ca}^{++}\right]_{\mathrm{i}}$. Taken together, the presented results indicate that E-selectin is constitutively internalized, and that E-selectin bound antibodies are passively co-internalized. Since the cytoplasmic portion of E-selectin contains a tyrosine residue (20), which can be recognized by adaptor proteins mediating the formation of clathrin baskets, thus facilitating internalization in clathrin coated pits (28), clathrin coated pit mediated internalization appears to be the most likely mechanism for E-selectin internalization. No re-expression of $\left[{ }^{125} \mathrm{I}\right] \mathrm{mAb}$ labelled E-selectin after internalization was found. Instead, we measured an ongoing intracellular accumulation of ${ }^{125} \mathrm{I}$ in continuous presence of an excess of [25I]ENAl (data not shown).

These results are in line with the reported short half-life of biosynthetically labelled E-selectin molecules (20), and the ongoing presence of E-selectin in the Golgi apparatus of HUVEC after having reached maximal membrane expression (as demonstrated in this study), indicating ongoing protein synthesis.

Although the purpose of E-selectin internalization remains speculative, two possible functions emerge. Internalization prevents static presence of E-selectin molecules on 
the cell surface, and thus enables endothelial cells to regulate the amount of surfaceexpression of E-selectin. E-selectin internalization might therefore be a crucial prerequisite for the rapid reduction in E-selectin membrane-expression, occurring after 4 to 6 hours of in vitro endothelial cell activation. The current identification the oligosaccharide moiety NeuNAca2-3GalB1-4(Fuca 1-3)GlcNAc, known generically as sialylated Lewis $x$ (14-16), and of L-selectin (13) as potential E-selectin ligands, gave rise to the hypothesis that removal of E-selectin ligands from the circulation could be a major function of E-selectin internalization.

Most human cells do not express sialylated Lewis $x$. During transformation to malignancy, however, many adenocarcinoma-lines acquire the capacity to synthesize this oligosaccharide, leading to circulating mucin-like molecules with sialyl Lewis $\mathrm{x}$ moieties in patients with such malignancies $(29,30)$.

In parallel, another potential ligand of E-selectin, L-selectin (14), might be present in circulation during generalized infectious states, since rapid shedding of this receptor by neutrophils after activation with IL-8, FMLP or PMA has been reported in vitro $(13,31)$.

Both shedded L-selectin and soluble sialyl Lewis $\mathrm{x}$ moieties containing proteins can reduce neutrophil adherence to activated endothelium (16), and could therefore interfere with neutrophil recruitment or other neutrophil functions. Internalization of E-selectin might result in co-internalization of circulating sialyl Lewis $\mathrm{x}$ and shedded L-selectin, thus clearing these molecules from circulation, and re-establishing normal neutrophil-adherence. Generalized E-selectin expression during septic shock like syn- dromes $(32,33)$, and local E-selectin expression, found in the vasculature of human adenocarcinoma of the breast (own unpublished observation), could thus have a double influence on leukocyte adhesion.

First E-selectin offers a binding site for part of the leukocyte population, and secondly, E-selectin could decrease the amount of circulating adhesion inhibiting factors.

Besides a lectin-like domain, and an epidermal growth factor-like domain, involved in adherence of myeloid cells to endothelial cells (16), E-selectin contains six repetitive regions with sequence homology to known complement regulatory proteins $(20)$. As suggested by Johnston et al. (34), these regions might bind $\mathrm{C} 3 \mathrm{~b}$ or $\mathrm{C} 4 \mathrm{~b}$ to facilitate clearance of circulating immune complexes. Seen from these viewpoints, endocytosis of E-selectin as described here. would be a mechanism critically linked to its function as a molecule involved in decontaminating the circulation in situations of severe immunological challenge.

In conclusion, this study demonstrates that E-selectin is internalized rapidly after having reached the cell-membrane. E-selectin internalization can occur together with an E-selectin bound antibody as a ligand, but is presumably not incited by this interaction. Further studies, to investigate the potential presence and function of co-internalization of physiological E-selectin ligands, might be of interest.

The auhors thank Dr W.A. Muller, Rockefeller University, $N Y$, and $\operatorname{Dr} R$. Rothlein, Boehringer Ingelheim, Ridgefield, CT, Dr J.S. Pober, Brighan and Women's Hospinal, Boston, MA and Dr. D. Haskard, Girys and St. Thomas Hospital, London, UK, for generously providing $m A b$ used in this work 


\section{Evidence for endocytosis of E-selectin in human endothelial cells}

\section{References.}

1. Bevilacqua, M.P, Butcher, E., Furic, B., Gallatin, M., Gimbrone, M., Harlan, J., Kishimoto, K., Lasky, L.. McEver, R., Paulson, J., Rosen, S., Seed, B., Siegelman. M., Springer, T., Stoolman, L., Tedder, T., Varki. A., Wagner, D., Weissman. I. and Zimmerman, G., Cell 1991. 67: 233.

2. Bevilacqua, M.P., Pober, J.S., Mendrick, D.L., Cotran, R.S. and Gimbrone, Jr., M.A., Proc. NatL Acad. Sci. USA. 1987. 84: 9238.

3. Leeuwenberg, J.F.M., Jeunhomme, T.M.A.A. and Buurman, W.A., Eur.J.ImmunoL 1989. 19: 715.

4. Munro, J.M., Pober, J.S. and Cotran, R.S., Lab. Invest. 1991. 64: 295.

5. Munro, J.M., Pober, J.S. and Cotran, R.S., Am. J. Pathol. 1989. 135: 121.

6. Leeuwenberg, J.F.M., Jeunhomme, G.M.A.A. and Buurman, W.A., Clin. Exp. ImmunoL 1990. 81: 486.

7. Leeuwenberg, J.F.M., Jeunhomme, T.M.A.A. and Buurman, W.A.Scand. J. Imm. 1992. 35: 335.

8. Curlos, T., Kovach, N. Schwarz, B., Rosa, M., Newman, B., Wayner, E., Benjamin, C., Osborn, L., Lobb, R. and Harlan, J., Blood 1991. 77: 2266.

9. Shimizu. Y.. Shaw, S., Graber, N., Gopal, T.V. et al., Nature 1991. 349: 799.

10. Picker, L.J., Kisihimoto, T.K., Smith, C.W., Warnock, R.A., and Butcher, C., Nature 1991. 349: 796.

11. Lawrence, M.B., Smith, C.W., Eskin, S.G. and Mclntire, L. V., Blood 1990. 75: 227.

12. Dobrina, A., Schwartz, B.R., Carlos, T.M., Ochs, H.D., Beatty, P.G. and Harlan, J.M., Immunology 1989. 67: 502 .

13. Smith, C.W., Kishimoto, T.K., Abbass, O., Hughes, B., Rothlein, R., McIntire, L.V., Butcher, E. and Anderson, D.C., J.Clin.Invest. 1991. 87; 609.

14. Lowe, J.B., Stoolman, L.M., Nair, R.P., Larsen, R.D., Bernhend, T.L. and Marks R.M., Cell 1990. 63: 475.

15. Phillips, M.L., Nudelman, E., Gaeta, A., Perez, M. Singhal, A., Hakomori, S. I. and Paulson, J.C., Science 1990. 250: 1130.

16. Walz, G., Aruffo, A., Kolanus, W., Bevilacqua, $M$. and Seed, B., Science 1990. 250: 1132.

17. Von Asmuth. E.J.U., van der Linden, C.J., Leeuwenberg. J.F.M. and Buurman, W.A., J. Immunol 1991. $147: 3869$.

18. Gibbs, L.S., L.ai, L. and Malik, A.B., J. Cell Phys. 1990. 145: 496.

19. Lo, S.K., Lee, S., Ramos, R.A.. Lobb, R., Rosa, M., Chi-Rosso, G. and Wright, S.D., J. Exp. Med. 1991. 173: 1493.

20. Bevilacqua, M.P. Stengelin, S., Gimbrone, Jr., M.A. and Seed, B., Science 1989. 243: 1160.

21. Leeuwenberg, J.F.M, Jeunhomme, G.M.A.A. and Buurman, W.A., Transplant Proc. 1990. 22: 1991.

22. Rothlein, R., Dustin, M.L., Marlin S.D. and Springer, T.A., J. Immunol. 1986. 137: 1270.

23. Muller, W.A.. Ratti, C.M., MCDonnell S.L. and Cohn. Z.A., J. Exp. Med. 1989. 170: 399.

24. Smeets, E.F., von Asmuth, E.J.U., van der Linden, C. J., Leeuwenberg, J.F.M. and Buurman, W.A., Bio- technic and Histochemistry in press.

25. Slot, J.W. and Geuze, H.J., Eur. J. Cell BioL 1985. 38: 87.

26. Fransen, J.A.M. Ginsel, L.A., Hauri, H.P., Sterchi, E. and Blok, J., Eur. J. Cell BioL 1985. 38: 6.

27. Wellicome, S.M., Thomhill, M.11., Pitzalis, C., Thomas, D.S., Lanchburry, J.S.S., Panayi, G.S. and Haskard, D.O., J. Immunol. 1990. 144: 2558.

28. Picret, B.M.F., EMBO J. 1988. 7: 3.336 .31 [CTI2ref]

Watkins, W.M., Adv. Hum. Genet. 1980. 10: I.

29. Kannagi, R., Fukushi, Y., Tachikawa, T., Noda, A, Shin. S.. Shigeta, K., Hiraika, N., Fukuda, Y., Intmoto, T., Hukomori, S.-1. and Imura, H., Cancer Res. 1986. $46: 2619$.

30. Fukushima, K., Hirota, M., Terasahi. PI., Wakisaka. A., Togashi, H., Chia, D., Suyama, N., Fukushi, Y., Nudelman, E. and Hakomori, S.-1., Cancer Res. 1984. 44: 5279.

31. Kishimoto, T.K., Jutila, M.A., Berg, E.L.. and Butcher, E.C., Science 1989. 245: 1238.

32. Redl, H., Dinges, H.P., Buurman, W.A., Van der Linden, C.J., Pobe1, J.S., Cotran, R.S. and Schag. G., Am. J. Pathol 1991. 139: 461.

33. Engelberts, I., Samyo, S.K., Leeuwenberg, J.F.M., van der Linden, C.J. and Buurman, W.A., J. Surg. Res. in press.

34. Johnston, G.I., Cook, R.G. and McEver, R.P., Cell 1989. $56: 1033$. 


\section{IFN- $\gamma$ REGULATES THE EXPRESSION OF THE ADHESION MOLECULE ELAM-1 AND IL-6 PRODUCTION BY HUMAN ENDOTHELIAL CELLS IN VITRO}

JET F. M. LEEUWENBERG, ECKHARDT J. U. VON ASMUTH.

TRUDI M. A. A. JEUNHOMME AND WIM A. BUURMAN

J. Immunol. 1990, 145:2110-2114

\section{Summary}

Tn this study two new in vitro effects of IFN- $\gamma$ on human umbilical vein endothelial (HUVE) cells were described. First. it was shown that the expression of the adhesion molecule el on activated HUVE cells can be modulated by IFN- $\gamma$. ELAM-1 is normally not expressed by HUVE cells, but its expression can rapidly be induced by TNF, IL-1, or LPS. Maximal expression is reached after 4 to $6 \mathrm{~h}$ of activation, and after $24 \mathrm{~h}$ the expression disappeared. whereas IFN- $\gamma$ per se did not induce expression of ELAM-1, it enhanced and prolonged the expression of ELAM-1. this enhancement occurred when IFN- $\gamma$ was added before or activation as well as when it was added simultaneously with activation. When IFN- $\gamma$ was added 6 to $9 \mathrm{~h}$ after the activation, the normally ongoing reduction of expression was not only retarded, but the expression increased for at least $3 \mathrm{~h}$. Moreover, IFN- $\gamma$ abrogated the refractery period for restimulation. Neither IFN- $\beta$ nor IL-6 had any effect on the expression of ELAM-1. The second effect of IFN- $\gamma$ on HUVE cells is the capacity to enhance the IL-6 production by these cells. Prestimulation as well as coincubation of IFN- $\gamma$ with TNF, IL-1 or LPS resulted in a strongly augmented production of IL-6. The effects of IFN- $\gamma$ may in vivo play a role in the regulation of an inflammatory reaction, because ELAM-1 is an adhesion molecule for neutrophils, and IL-6 has an enhancing effect on the cytotoxicity of neutrophils. 


\section{Introduction}

$\mathrm{I}$ nfiltration of neutrophils into vessel wall is thought to be a hallmark in the develThis process starts with adhesion of neutrophils to endothelial cells. In this process cytokines such as IL-6 and neutrophil activating factor (IL-8) may serve as activators of neutrophils $(1,2)$.

IL-6 is an inflammatory cytokine with multiple effects including the ability to stimulate or enhance 1) the differentiation and proliferation of $\mathrm{T}$ cells $(3), 2)$ the differentiation of B cells into plasma cells $(4), 3$ ) the production of acute phase proteins by hepatocytes (5), and 4) the toxicity of neutrophils (1).

Neutrophils as well as endothelial cells express surface molecules, that mediate adhesion. Inducible $\mathrm{Ag}$ on human endothelial cells have been described, which are normally not expressed on endothelial cells, such as ELAM-1 $(6,7)$, VCAM-1 (8), and the activation $\mathrm{Ag}$ described by Goerdt et al. (9). VCAM-1 is an adhesion molecule for lymphocytes (8), whereas ELAM-1 is involved in adhesion of neutrophils $(6,7)$.

Knowledge of the regulation of the expression of the Ag may lead to a better understanding of the development of the inflammatory reactions. The inducers of ELAM-1, i.e., TNF, IL-1, and LPS, also induce the production of other cytokines such as IFN- $\gamma$, IFN- $\beta$, IL-6, and IL-8 (10-13).

The cytokines IFN- $\beta$, IFN- $\gamma$, and IL-6 are known to interact with endothelial cells and to interact with TNF, IL-1 and LPS, either synergistically or antagonistically (14-17). The influence on the induction and the expression of ELAM-1 and on the produc- tion of IL-6 was investigated. Whereas neither IFN- $\beta$ nor IL- 6 affected the ELAM-1 expression, IFN- $\gamma$ enhanced the expression induced by TNF, IL-1 or LPS. Moreover, IFN- $\gamma$ enhanced IL- 6 production by activated endothelial cells.

\section{Materials and Methods \\ Cells}

HUVE cells cells were obtained by collagenase treatment of the human umbilical vein. The cells were cultured in fibronectin-coated (fibronectin kindly provided by Dr. van Mourik, CLB, Amsterdam, The Netherlands) tissue culture flasks (Costar, Cambridge, MA) in RPMI-1640 (Gibco Europe, Paisley, Scotland), supplemented with $10 \%$ pooled $0.2 \mu \mathrm{m}$ filtered heat inactivated human serum (HS) derived from the local blood bank, 10\% heat-inactivated bovine calf serum (BCS) (Hyclone, Logan, UT), $50 \mu \mathrm{g} / \mathrm{ml}$ heparin (Sigma), $30 \mu \mathrm{g} / \mathrm{ml}$ endothelial growth supplement (Collaborative Research Incorporated, Bedford, MA) and antibiotics. Endothelial cells were characterized by their pavement-like monolayer morphology, by positive staining with $\mathrm{mAb}$ hec7 directed against PECAM-1, generously provided by Dr. Muller (Rockefeller University. NY), and by positive staining with the anti-E-selectin mAb ENA1 after 4 hours of incubation with TNF.

\section{Reagents and $\mathbf{m A b}$}

rHuman TNF- $\alpha$ was kindly provided by BASF/Knoll AG. (Ludwigshaten, FRG). ril$1 \alpha$ was a kind gift of Dr. Gillis (Immunex. Seattle, WA). rIL-6 was a kind gift from Prof. Dr. W. Sebald (Wurzburg, FRG). rIFN$\beta$ was kindly provided by Prof. Bujard (Holfman-La Roche, Basel, Switserland). rIFN- $\gamma$ 
was gift from Dr. P. van der Meide (TNO, Rijswijk, The Netherlands). LPS (phenol extract, chromatographically purified from Escherichia Coli, serotype 055:LB5) was purchased from Sigma (St. Louis, MO). Preparations of TNF, IL-1 $\beta$ and PMA were tested for endotoxin contamination by the chromogenic limulus amoebocyte lysate assay (Coatest, Kabi Diagnostica, Nyköping, Sweden), and were found to contain less than $5 \mathrm{pg} / \mathrm{ml}$ LPS in final solutions.

mAb ENA1 (IgG1) was obtained by immunizing mice with HUVE cells, pretreated with IL- 1 and TNF during $5 \mathrm{~h}$ as described (18). mAb ENAI is specific for endothelial cells activated with TNF, IL-1, LPS or phorbol esthers and is not reactive with other cell types. Cross-blocking studies with the labeled mAb ENA1 and 1.2B6 (kindly provided by Dr. D. Haskard, Devision of Medicie, UMDS, Guy's Hospital, London, UK), which is known to react with ELAM-1 (19), showed that mAb ENA1 and 1.2B6 reacted with the same epitope on activated HHUVE cells, being the ELAM-1 structure (data not shown). $F\left(a b^{\prime}\right) 2$ fragments were prepared by pepsin digestion (Immobilized Pepsin, Pierce Chemical Co., Rockford, IL) as described (7). Complete digestion of the $\mathrm{F}\left(\mathrm{ab}^{\prime}\right) 2$ preparation was ascertained by SDSPAGE on Phast System separation unit (Pharmacia, Uppsala, Sweden).

\section{Induction of $\mathrm{Ag}$ and cytokine release}

HUVE cells cells of passage 3 were seeded at $10^{4}$ cells/well in fibronectin-coated 96 well flat-bottom tissue culture plates (Costar) in culture medium, one day prior to stimulation. HUVE cells were rinsed twice with RPMI- 1640 and the medium was replaced by the appropriate agents in 200 $\mu \mathrm{V} /$ well RPMI-1640 supplemented with antibiotics, without growth factor, and with $10 \%$ HS (not heat-inactivated), or $0.1 \% \mathrm{BSA}$ (endotoxin contamination $<0.1 \mathrm{ng} / \mathrm{g}$, Sigma) in experiments in which serum-free medium was employed. Media were tested for endotoxin contamination in the chromogenic limulus amoebocyte lysate assay, and were found to contain less than $5 \mathrm{pg} / \mathrm{ml}$ LPS. Supernatants were harvested and kept at $-20^{\circ} \mathrm{C}$ until use in the IL-6 ELISA. Endothelial cell monolayers were washed, fixed with $0.05 \%$ glutaraldehyde for 10 minutes at room temperature, and kept at $4^{\circ} \mathrm{C}$ until use in the ELAM-1 ELISA.

\section{IL-6 ELISA}

The IL- 6 concentration in the culture supernatant was determined using a sandwichELISA for IL-6. In short, 96-well immuno maxisorp plates (Nunc, Roskilde, Denmark) were coated with mAb CLB.IL6-8 (kindly provided by Dr. L. Aarden, CLB, Amsterdam, The Netherlands) directed against human IL-6 (20). rHuman IL-6 (a generous gift from Prof. Dr. Sebald, PhysiologischChemisches Institut der Universität, Würzberg, FRG) was used for standard titration curves. Test samples were added. Plates were incubated with polyclonal rabbit antihuman IL-6 antibodies, followed by peroxidase conjugated goat anti-rabbit IgG (Jackson, Westgrove, PA). O-phenylene-diamine (Sigma) was added as a substrate and photospectometry was performed at $492 \mathrm{~nm}$. Standard titration curves were not influenced by presence of serum in the sample buffer. The IL-6 ELISA had a lower detection limit of $10 \mathrm{pg} / \mathrm{ml}$ IL-6. 

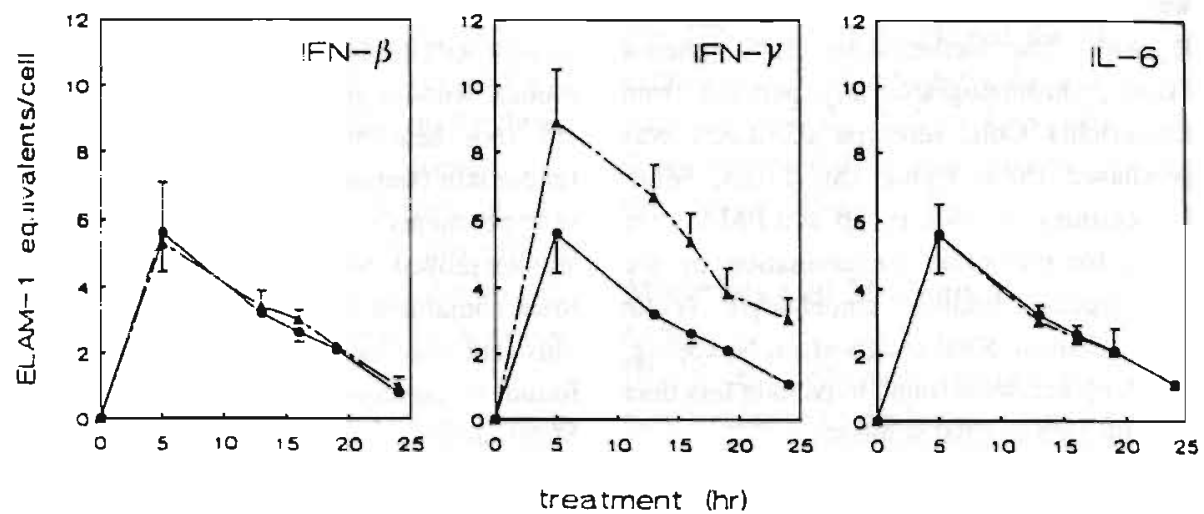

\section{Detection of ELAM-1 expression}

ELAM-1 expression was determined by ELISA using the ELAM-1 specific mAb ENA1, followed by peroxidase conjugated goat anti-mouse IgG. O-phenylene-diamine (Sigma) was added as a substrate and photospectometry was performed at $492 \mathrm{~nm}$.

To correct for differences in cell numbers between individual wells, we performed a standard crystal violet staining, after the ELISA in the same wells. OD values were adjusted for the amount of crystal violet staining after substraction of the background, and for the ELISA-specific OD curve, and referred to ELAM-1 equivalents per cell.

\section{Results}

Effect of rIFN- $\beta$, rIFN- $\gamma$, and $r I L-6$ on induction and expression of ELAM-I

To investigate whether the cytokines rIFN $\beta$, rIFN- $\gamma$, or IL-6 interfere with the expression of ELAM-1, we studied 1) the effect of simultaneous addition of inducer and rIFN$\beta$, rIFN- $\gamma$, or rIL- 6 , and 2 ) the effect of preincubation with IIFN- $\beta$, rIFN- $\gamma$, and rIL- 6 on EL.AM-1 expression.
Figure 1. Eiffects of rIFN- $\beta$, rIFN- $\gamma$, and rIL. 6 on the expression of ELAM-I on HUVE cells. HUVE cells were activated with $10 \mathrm{U} / \mathrm{ml} \mathrm{L}-\mathrm{L}$ in the absence (O) or pres-

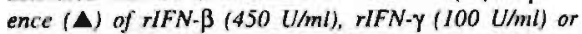
with $I L-6(20,000 \mathrm{U} / \mathrm{m})$ ). At the different intervals $E L A M$. I expression was determined in ELSSA, followed by crystal violet staining of cells. ELAM-I expression was given in mean $\pm S D$ of ELAM-I equivalents per cell as described in Materials and Methods.

First the effect of simultaneous incubation of rIFN- $\beta$, rIFN- $\gamma$, or rIL- 6 and an inducer of ELAM-1 was studied. In Figure 1 the results are shown of a representative experiment using rIL- 1 as an inducer of ELAM-1 expression at a concentration of $10 \mathrm{U} / \mathrm{ml}$. Neutrher rIFN- $\beta$ nor rIL- 6 affected the kinetics of ELAM- 1 expression. rIFN- $\gamma$ had a significant enhancing effect on ELAM-1 expression. The peak expression was enhanced, and it was shown that the expression decreased to a lesser degree. In Figure 2 the results are given of an expirement with different inducers of ELAM- 1 at a range of concentrations and with rIFN- $\gamma$ as a costimulator at a concentration of 30 and $100 \mathrm{t} / \mathrm{ml}$. At all concentrations of inducer, even when optimal concentrations of inducer were used, $10 \mathrm{ng} / \mathrm{ml} \mathrm{rTNF}$, an enhancing etfect of IFN- $\gamma$ 

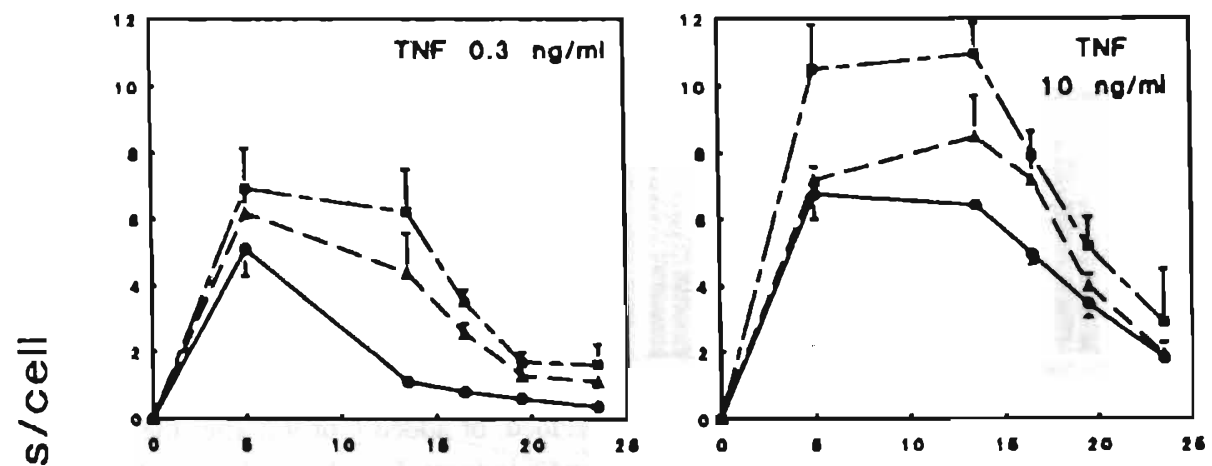

$\frac{5}{0}$
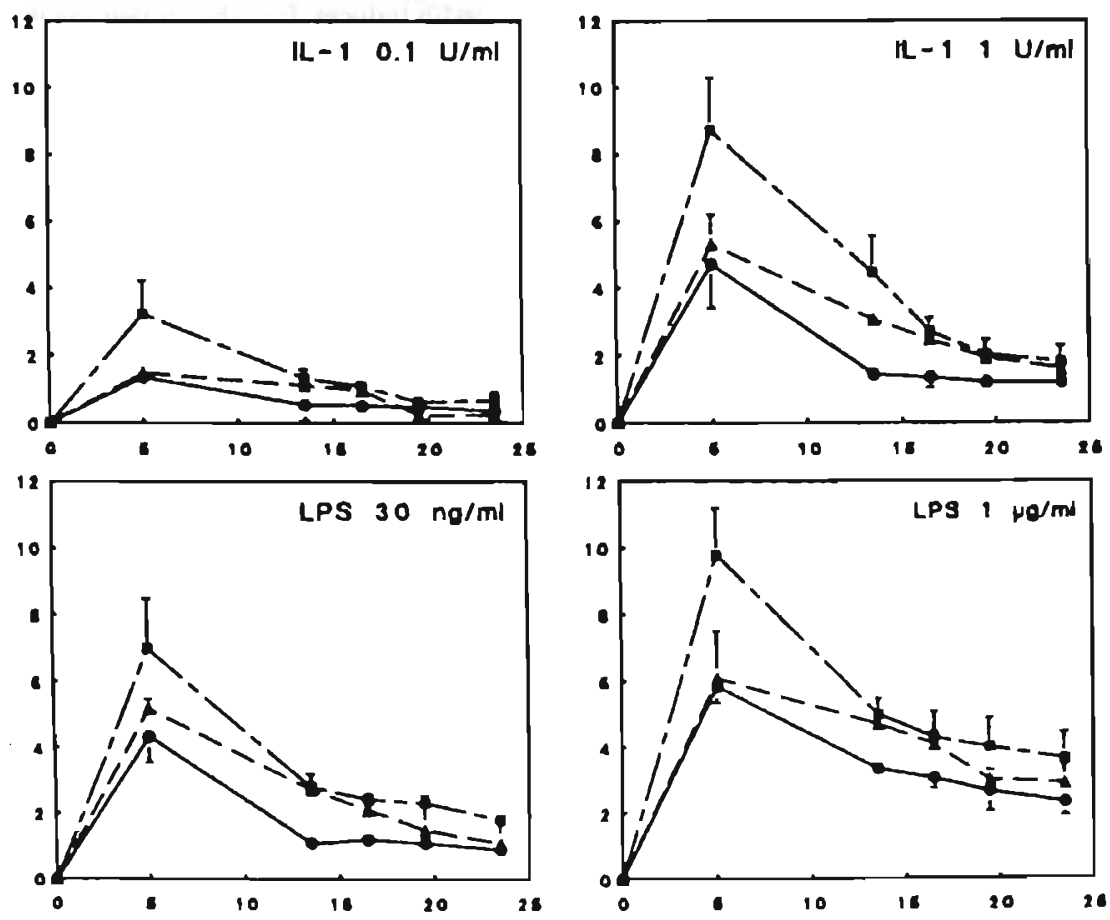

incubation time (hr)

Figure 2. Effects of rIFN- $\gamma$ (not added $0,30 \mathrm{U} / \mathrm{ml} \mathbf{\Delta}$, and $100 \mathrm{U} / \mathrm{ml} \mathbf{0}$ ) on the expression of ELAM-I by HUVE cells incubated wit rTNF, rIL-I, or LPS in the concentrations indicated. At the different intervals ELAM-I expression was determined in ELISA. ELAM-I expression was given in mean +-SD of ELAM-1 equivalents per cell as described in Materials and Methods. 


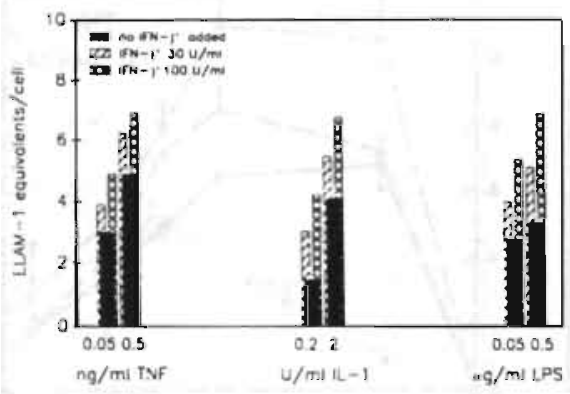

Figure 3. Effects of preincubation with rIFN- $\gamma$ an ELAM1 expression. $r I F N-\gamma(30$ and $100 \mathrm{U} / \mathrm{ml})$ was added $20 \mathrm{~h}$ before activation of the HUVE cells with rTNF, rIL-1, or L.PS. After a nexs 5 h ELAM-I expression was detennined in ELISA. ELAM-I expression was given in mean ELAM1 equivalents per cell as described in Materials and Methods. SD of quadruplicates were less than $10 \%$ of the mean (not shown).

on the ELAM-1 expression was observed. The heigt of the maximum expression was not only enhanced, but rIFN- $\gamma$ also broadened the peak of expression.

Next the effect of pretreatment with rIFN- $\beta$, rIFN- $\gamma$, rIL-6 on ELAM- 1 was studied. This was performed by preincubation of HUVE cells during $20 \mathrm{~h}$ with rIFN- $\beta$, rIFN- $\gamma$, or rIL-6. The cells were subsequently washed and incubated with different concentrations of ITNF, rIL-1, or LPS.

After $5 \mathrm{~h}$ the ELAM-1 expression was determined. Pretreatment of the HUVE cells with rIFN- $\beta$ (up to $450 \mathrm{U} / \mathrm{ml}$ ) or rlL-6 (up to $20,000 \mathrm{U} / \mathrm{ml}$ ) had no effect on the expression of ELAM-1 induced by the different concentrations of rTNF, rlL-1, or LPS (data not shown). Pretreatment of the cells with rIFN$\gamma$, however, caused an enhancement of the ELAM-1 expression as shown in Figure 3.

\section{Effect of rIFN-Y on ELAM-I expression} when added after activation

Next we investigated the effect of IIFN- $\gamma$ on HUVE cells already activated with ITNF or rIL-1. In Figure 4 the results are shown of two seperate experiments, in which HUVE cellswere activated with $2 \mathrm{ng} / \mathrm{ml} \mathrm{rTNF}$ or with $10 \mathrm{U} / \mathrm{ml} \mathrm{IL}-1$ as inducer of ELAM-1 expression.

rIFN- $\gamma$ was either omitted, or simultaneously added, or added 6 or $9 \mathrm{~h}$ after the activation with inducer. It is shown that the down-regulation of the expression is interrupted; rIFN$\gamma$ up-regulates the expression in contrast 10 the ongoing reduction in the control cultures.

\section{table I}

effect of IFN- $\gamma$ on refractory period

\begin{tabular}{lccc}
\multirow{2}{*}{$\begin{array}{l}\text { second } \\
\text { activation }\end{array}$} & \multicolumn{3}{c}{ prestimulation $^{\mathrm{a}}$} \\
\cline { 2 - 4 } & & LPS & LPS+IF \\
\hline & $0.052^{2}$ & 0.048 & 0.261 \\
& & & \\
TNF(ng/ml) & & & \\
0.01 & 0.213 & 0.165 & 0.491 \\
0.1 & 1.423 & 1.168 & 1.456
\end{tabular}

\section{$\mathrm{LPS}(\mathrm{ng} / \mathrm{ml})$}

$\begin{array}{llll}50 & 1.280 & 0.307 & 1.062 \\ 500 & 1.720 & 1.221 & 1.642\end{array}$

"HUVE cells were prestimulated or not with LPS $(1 \mu \mathrm{g} / \mathrm{ml})$, or with LPS $(1 \mu \mathrm{g} / \mathrm{ml})$ combined with $I F N-\gamma$ (100 U/ml) during $20 \mathrm{~h}$

"HUVE cells were reactivated with TNF or LPS dwing $5 \mathrm{~h}$ at the indicaledconcentrations.

'ELALM-1 expression was determined in EIJSA $5 \mathrm{~h}$ afer the second actrivion. The data were: reporled as the metan absorbance units from quadruplicate determinations after substraction of the backgrouml. SD of quadruplicates were less than $10 \%$ of she mean (not shown). 

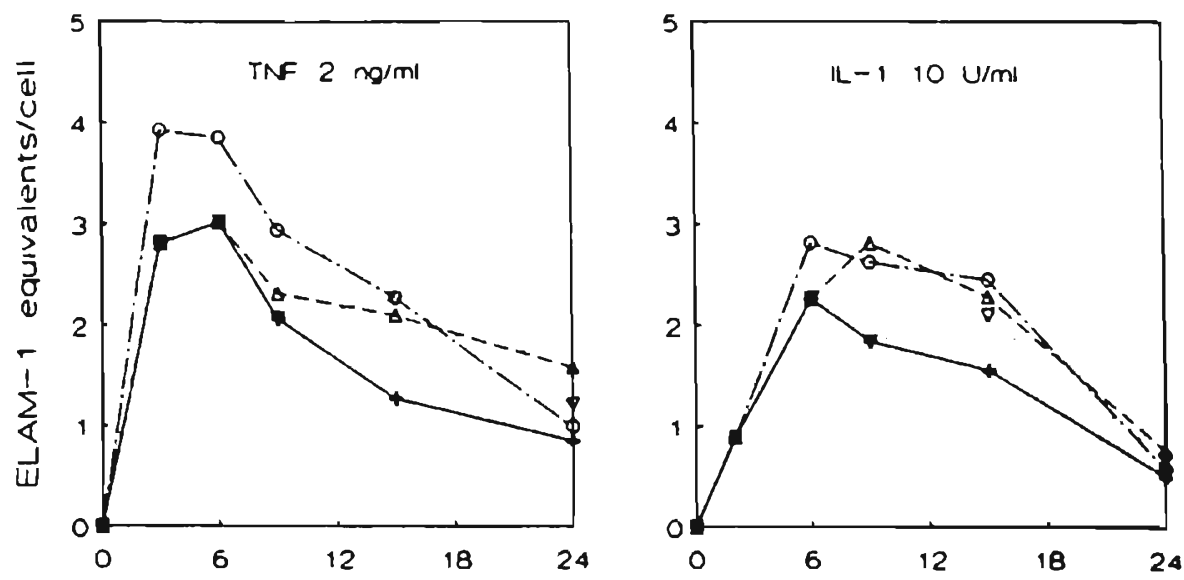

Figure 4. Effects of rlFN- $\gamma(100 \mathrm{U} / \mathrm{ml})$ on the expression of ELAM-I by HUVE cells incubated wit rTNF or by rIL-I (+), when added simultaneously $(\mathrm{O})$ with $r T N F$ or $r I L-1$, or added $6 h(\Delta)$, or added $9 h(\nabla)$ after activation with $r T N F$ or rIL-I. Al the different intervals ELAM-I expression was determined in ELISA. ELAM-I expression was given as mean ELAM-I equivalents per cell as described in Materials and Methods. SD of quadruplicates were less than IO\% of the mean (not shown).

\section{Effect of rIFN- $\gamma$ on refractory period of} ELAM-I induction.

A refractory period was described for the induction of ELAM-1, i.e., cells activated with inducer, e.g., TNF, become refractory to restimulation by the same inducer TNF, but to a lesser degree by another inducer, e.g., rIL-1 or LPS (21).

In Table $l$ the results are shown of an experiment in which the effect of rIFN- $\gamma$ on the refractoriness was investigated. HUVE cells were prestimulated with LPS, in the presence or absence of $100 \mathrm{U} / \mathrm{ml}$ rIFN- $\gamma$. After $18 \mathrm{~h}$ the cells were washed and restimulated with rTNF and LPS at two concentrations each. ELAM-1 expression was determinde $5 \mathrm{~h}$ after the restimulation.

Prestimulation with LPS did not completely abolish the signal, induced by the second stimulation. The effect of restimulation by
rTNF as well as by LPS was reduced and this effect was most pronounced usinf the lowest concentration of LPS. Prestimulation, however, in the presence of rIFN- $\gamma$ abrogated largely the refractoriness for restimulation as demonstrated by an enhanced ELAM-1 expression.

\section{Effect of rIFN- $\gamma$ on IL-6 production by HUVE cells.}

Having established a role of IFN- $\gamma$ on the expression of the adhesion molecule ELAM-1, we investigated the effect of rIFN- $\gamma$ on the production of the inflammatory cytokine IL-6. At the same intervals at which ELAM-1 expression was measured in the experiments mentioned above, samples of the HUVE cells cultures were taken to measure the IL- 6 content. Firs, we looked at the effect of rIFN- $\gamma$ in the above mentioned 
Regulation of ELAM-1 expression and IL-6 production by endothelial cells

table 2

IL-6 production of HUVE cells 13 and $20 \mathrm{~h}$ after incubation with a combination of ELAM-I inducer and IFN- $\gamma$

\begin{tabular}{|c|c|c|c|c|c|c|}
\hline \multirow{2}{*}{$\begin{array}{l}\text { ELAM-1 } \\
\text { inducer }\end{array}$} & \multicolumn{3}{|c|}{$13 \mathrm{~h}$} & \multicolumn{3}{|c|}{$20 \mathrm{~h}$} \\
\hline & & $30 U^{3}$ & $100 \mathrm{U}$ & & $30 \mathrm{U}$ & $100 \mathrm{U}$ \\
\hline & $40^{h}$ & 240 & 320 & 60 & 150 & 180 \\
\hline \multicolumn{7}{|c|}{ TNF (ng/ml) } \\
\hline 0.3 & 130 & 470 & 480 & 300 & 550 & 560 \\
\hline 10 & 480 & 750 & 760 & 550 & 1830 & 1950 \\
\hline \multicolumn{7}{|c|}{ IL-1(U/ml) } \\
\hline 1 & 300 & 410 & 620 & 1.110 & 1.880 & 2.040 \\
\hline 10 & 3.060 & 6.310 & 7.850 & 4.510 & 18.090 & 20.000 \\
\hline \multicolumn{7}{|c|}{ LPS $(\mu \mathrm{g} / \mathrm{ml})$} \\
\hline 0.03 & 560 & 730 & 750 & 690 & 990 & 1.160 \\
\hline 1 & 1.220 & 1.700 & 1.750 & 2.040 & 2.470 & 3.310 \\
\hline
\end{tabular}

costimulation experiment, in which IL-6 production was measured $5,14,17,20$ and $24 \mathrm{~h}$ after stimulation of the HUVE cells.

As shown in Figure 5, rTNF, rIL-1, and LPS induced IL- 6 production, and this production was strongly increased by the addition of riFN- $\gamma$. In Table 2, the results are shown of the IL-6 production after 13 and $20 \mathrm{~h}$ of simultaneous stimulation with different concentrations of rTNF, rIL-1, or LPS, and 30 or $100 \mathrm{U} / \mathrm{ml}$ of rIFN- $\gamma$. rIFN- $\gamma$ had an overall enhancing effect on the IL- 6 production.

This effect was most pronounced in the com-

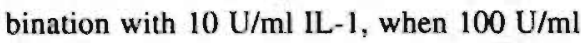
rIFN- $\gamma$ caused a six-fold increase of IL- 6 production. Although variability exists in the different experiments, the enhancing effect of IIFN- $\gamma$ on IL- 6 production was observed in four seperate experiments.

\section{Effect of preincubation of HUVE cells} with rIFN- $\gamma$ on IL-6 production.

The effects of prestimulation with rIFN- $\gamma$ on the IL- 6 production by HUVE cells are shown in Figure 6. HUVE cells were preincubated during $20 \mathrm{~h}$ with rIFN- $\gamma$, and subsequently washed before activation with rTNF, rIL-1, or LPS. Five $h$ after activation IL-67 production was measured in ELISA. In these excperiments, rIFN- $\gamma$, rTNF, rIL- 1, LPS and 

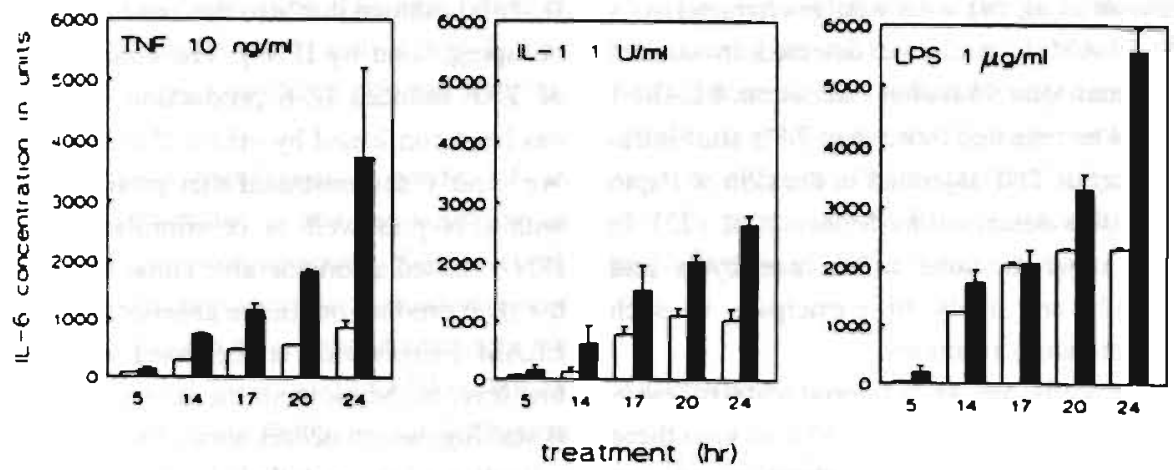

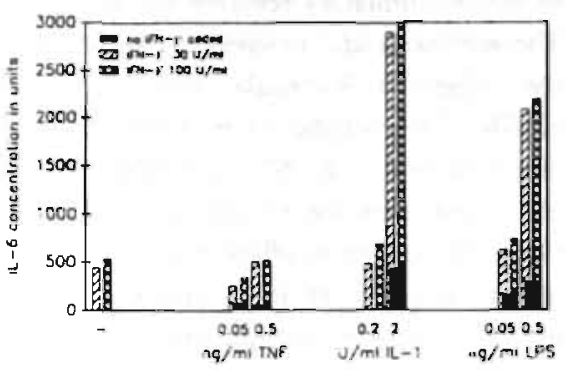

Figure 6. Effect of $r I F N-\gamma(100 \mathrm{U} / \mathrm{ml})$ on production of IL. 6 by HUVE cells, when added $20 \mathrm{~h}$ before stimulation with rTNF, rIL-l, or LPS.

Samples were taken after a next 5 h for $I L-6$ measurement. Means of quadruplicate wells are given: $S D$ of quadruplicate wells never exceeded $10 \%$ of the mean (not shown).

the combination of IFN- $\gamma$ and rTNF induced only a weakly IL-6 production $(<600 \mathrm{U} / \mathrm{ml})$. A strong potentiating effect, however, of IL-6 production was observed, when HUVE cells were preincubated with rIFN- $\gamma$ and subsequently activated with $2 \mathrm{U} / \mathrm{ml} \mathrm{rL}-1$ or with $0.5 \mu \mathrm{g} / \mathrm{ml}$ LPS leading to an IL-6 production of $3000 \mathrm{U} / \mathrm{ml}$ within $5 \mathrm{~h}$.
Figure 5. Production of $I L-6$ by HUVE cells, stimulated with rTNF ( $10 \mathrm{ng} / \mathrm{mi}), \mathrm{rlL}-1$ (I U/mnl), LAS (I $\mathrm{Ig} / \mathrm{ml})$ (open bars), or with a combination (closed bars) of ifFN. $\gamma(100 \mathrm{U} / \mathrm{ml})$ and forementioned activators.

Samples were taken at the different intervals indivcated to determine $I L-6$ production. Mean $\pm S D$ of quadruplicate wells are given.

\section{Discussion}

In this study the effect of the cytokines IFN- $\gamma$, IFN- $\beta \mathrm{m}$, and IL- 6 on IL-1, TNF, and LPS-activated human endothelial cells was explored. The activation of endothelial cells by the mediators IL-1, TNF, and LPS was shown by the rapid induction of an adhesion molecule ELAM-1, and by the production of IL-6.

The kinetics of the expression in vitro of ELAM-1 are well known; maximal expression of this $\mathrm{Ag}$ occurs after 4 to $6 \mathrm{~h}$ of stimulation with TNF, IL-1, LPS or phorbol esters, after which the expression decliones despite the contineous presence of activator $(18,21)$.

Several in vivo dat, however, showed an expression of activation $\mathrm{Ag}$ for a longer peri- 
od, e.g., the activation antigen described by Goerdt et al. (9) with similar characteristics as ELAM-1, could be detected in contact eczemas after $96 \mathrm{~h}$ after elicitation. ELAM-1 could be detected more than $24 \mathrm{~h}$ after intracutaneous TNF injection in the skin of Papio anubis as described by Munro et al. (22). In vivo other immune cells, monocytes and $\mathrm{T}$ cells are likely to participate in such inflammatory reactions,

These cells are known producers of cytokines and it is conceivable that in vivo these cytokines modulate the duration of the expression of this adhesion molecule. It was found, that IFN- $\gamma$, but not IFN- $\beta$ or IL-6 enhanced the ELAM-1 expression and retarded the decrease. Doukas and Pober (23) reported recently a similar effect using the combination of TNF and IFN- $\gamma$. Moreover, IFN- $\gamma$ abrogated the refractoryness to restimulation. The mechanism via which ELAM- $1 \mathrm{Ag}$ expression decreases, is not yet understood.

The decrease of the expression after 4 to $6 \mathrm{~h}$ could be provoked by an unknown soluble factor released by the endothelial cells in the culture medium. Supernatants, however, derived from endothelial cells activated with TNF, IL-1, or LPS have no decreasinf effect on ELAM-1 expression (J. F. M. Leeuwenberg. unpublished observation).

These findings suggest, that the down-regulation of ELAM-1 is an intracellular event. IFN- $\gamma$ is apparently able to interfere with this process and this effect may partly explain the in vivo data.

Further evidence for the activated state of endothelium is provided by the production of IL-6. Knowledge on the role, which IL-6 may play in a local inflammatory process is limited. Endothelial cells are known produc- ers of IL-6, when activated by TNF, LPS, and IL-1. It is shown that also this production can be upregulated by IFN- $\gamma$. The enhancement of TNF induced IL- 6 production by IFN- $\gamma$ has been confirmed by others (24).

We clearly demonstrated that preincubation with IFN- $\gamma$ as well as co-stimulation with IFN- $\gamma$ caused a conciderable enhancement of the IL- 6 production. In the absence of IFN- $\gamma$, ELAM-1 expression is decreased to reach a low level at the moment the IL- 6 production is starting, which occurs about 5 to $10 \mathrm{~h}$ after activation of the endothelial cells.

The regulatory role of IFN- $\gamma$ as coordinator of the inflammatory reaction seems evident. The enhanced and prolonged expression of the adhesion molecule for neutrophils ELAM-1, in conjunction with the accelerated production of IL-6, which stimulates the neutrophil merdiated cellular cytotoxicity (1), contribute to an efficient progress in the inflammatory reaction. Furthermore, IL-6 may accelerate the inflammatory reaction by stimulating $\mathrm{T}$ and $\mathrm{B}$ cells, leading to further IFN- $\gamma$ production.

A number of adhesion molecules are known, which expression is known to be regulated by cytokines. In addition to ELAM-1, an adhesion molecule VCAM-1, inducible by TNF and IL-1 on endothelial cells has recently been described (8). VCAM-1 is an adhesion molecule for lymphocytes and is thought to play a role in acute as well as in a chronic inflammation, whereas ELAM-1 is involved in the acute inflammatory reaction. Whether IFN- $\gamma$ also medulates the expression of VCAM-1 as shown for ELAM-1. remains to be investigated.

The expression of the adhesion molecule ICAM-1, but so far known not ICAM-2 (25), 
can be up-regulated by TNF, Il-1, and IFN- $\gamma$ on many cell types (26). The expression of the ligand of ICAM-1 and ICAM-2, i.e., LFA-1 is so far known not affected by cytokines (27).

An increased expression, however, of an adhesion molecule is not required for an enhanced adhesion, because Kooyk et al. (28) demonstrated recently, that activation of $T$ cells resulted in an enhanced adhesion, not by an increased expression of LFA-1, but by a modulation of the molecular conformation of LFA-1.

A number of other effects of IFN- $\gamma$ can be enhanced by a synergism with TNF and/or IL-1 or vice versa on endothelial cells, including the enhancement of MHC class I and induction of MHC class II Ag (14). All these effect may contribute to the amplification of an immunologic reaction. The role of IFN- $\gamma$ to implicate endothelium in an inflammatory process seems also relevant for the induction of the Shwartzman reaction. In the latter phenomenon, activation of endothelium and adhesion of neutrophils is known to play a role in pathophysiology (29).

Billiau et al. (30) clearly demonstrated a role of endogenous IFN- $\gamma$ in the elicitation of the Shwartzman reaction using antibodies to IFN- $\gamma(30)$.

In this sludy we demonstrated that the expression of the adhesion molecule ELAM- 1 and the IL- 6 production by endothelial cells can be modulated by the cytokine IFN- $\gamma$. The potentiating effect of IFN- $\gamma$ described, in the induction of ELAM-ion human endothelial cells, may explain at least in part the difference between in vivo and in vitro dataon kinetics of ELAM-1 expression.
However, other cytokines or a combination of cytokines, which undoubtedly circulate in vivo during an inflammatory reaction, may be also responsible for the prolonged expression of the adhesion molecule observed in vivo. Additionally, the enhancement by IFN$\gamma$ of the production of IL- 6 may result in an amplification of the immune reaction.

\section{References}

1. Borish, L., R. Rosenbaum, L. Alburny, and S. Clark. 1989. Activation of neutrophils by recombinant interleukin 6. Cell Immunol. 121:280.

2. Schroder, J. M., U. Mrowietz, E. Morita, and E. Christophers. 1987. Purification and partial biochemical characterization of a human monocytederived, neutrophil-activating peptide that lacks interleukin-1 activity. J. Immunol 139:3474.

3. Takai, Y., G. G. Wong, S. C. Clark, S. J. Burakoff, and S. H. Herrmann. 1988. B cell stimulatory factor2 is involved in the differentiation for cytotoxic $T$ lymphocytes. J. Immunol. 140:508.

4. Muraguchi, A., T. Hirano, B. Tang, T. Matsuda, Y. Horii, K. Nakajima, and T. Kishimoto. 1988. The essential role of B-cell stimulatory factor 2 (BSF2/IL -6) for the terminal differentiation of B-cells. J. Exp. Med. 167:332.

5. Gauldi, J., C. Richards, D. Harnish, P. Lansdorp, and H. Baumann. 1987. Interferon $\beta 2 / \mathrm{B}$-cell stimulatory factor 2 shares identity with monocyte-derived hepatocyte stimulating factor and regulates the major acute phase protein response in liver cells. Proc. Nath. Acad. Sci. USA 84:7251.

6. Bevilacqua, M. P., J. S. Pober, D. L. Mendrick, R. S. Cotran, and M. A. Gimbrone. 1987. Identification of an inducible endothelial-leukocyte adhesion molecule. Proc. Nall Acad. Sci USA 84:9238.

7. Leeuwenberg, J. F. M., G. M. A. A. Jeunhomme, and W. A. Buurman. 1990. Adhesion of polymorphoniclear cells to human endothelial cells. Adhesionmolecule-dependent and Fe-receptor-mediated adhesion-molecule-independent mechanisms. Clin. Exp. Immunol 81:496.

8. Osborn, L., C. Hession, R. Tizard, C. Vassalallo, S. Luhowskyj, G. Chi-Rosso, and R. Lobb. 1989. Direct expression cloning of vascular cell adhesion moleculc 1, a cytokine-induced endothelial protein that binds lymphocytes. Cell 59:1203.

9. Goerư, S., G. Zwadlo, R. Schregel, H. Hagemeier, and C. Sorg. 1987. Characterization and expression kinetics of an endothelial cell activation anigen present in vivo only in acule inflammatory tissues. Exp. Cell Biol 55:117.

10. Puri, J., B. Eglash, and P. Lonai. 1987. Induction of 


\section{Regulation of ELAM-I expression and IL-6 production by endothelial cells}

IFN- $\gamma$ production and la expression by interleukin-1 in bone marrow culture cells. Eur. J. Immunol. 17:223.

11. Leeuwenberg, J. F. M., J. Van Damme, T. M. A. A. Jeunhomme, and W. A. Buurman. 1987. Interferon B1, an intermediate in the tumor necrosis factorinduced increased MHC Class I expression and an autocriene regulator of the constitutive MHC Class I expression. J. Exp. Med. 166:1180.

12. Van Damme, J., G. Opdenakker, R. Simpson, M. Rubira, S. Cayphas, A. Vink, A. Billiau, and J. Van Snick. 1986. Identification of the human $26-\mathrm{kD}$ protein, interferon B2 (IFN-B2), as a B-cell hybrido$\mathrm{ma}$ plasmacytoma growth factor induced by interleukin 1 and tumor necrosis factor. J. Exp. Med. 165:914.

13. Schroder, J. M., and E. Christophers. 1989. Secretion of novel and homologous neutrophil-activating peptides by LPS-stimulated human endothelial cells. J. ImmunoL 142:244.

14. Lecuwenberg, J. F. M., J. Van Damme, T. Maeger, T. M. A. A. Jeunhomme, and W. A. Buurman. 1988. Effect of tumor necrosis factor on the inetrferonganma-induced major histocompatibility complex class II antigen expression by human endothelial cells. Eur. J. Immunol. 18:1469.

15. Lesczynski, D., 1990 . Interlekin-1 alpha inhibits the effects of gamma-interferon and tumor necrosis factor alpha on the expression of the major histocompatibility antigens by the rat endothelium. Am. J. Pathol 18:1469.

16. Mizutani, H., L. T. May, P. B. Seghal, and T. S. Kupper. 1989. Synergistic interactions of $\mathrm{LL}-1$ and $\mathrm{IL}-6$ in T cell activation. Mitogen but notantigen receptorindueed proliferation of a cloned $T$ helper cell line is enhanced by exogenous II.6. J. Immunol. 143:896.

17. Issekutz, T. B., and J. M. Stoltz. 1989. Stimulation of lymphocyte migration by endotoxin, tumor necrosis factor, and interferon. Cell. Immunol. 120:165.

18. Leeuwenberg, J. F. M., T. M. A. A. Jeunhomme, and W. A. Buurman. 1989. Induction of an activation antigen on human endothelial cells in virro. Eur. J. Immunol. 19:715.

19. Wellicome, S. M., M. H. Thornhill, C. Pitzalis, D. S. Thomas, J. S. S. Lanchbury, G. S. Panayi, and D. O. Haskard. 1990. A monoclonal antibody that detects a novel antigen on endothelial cells that is induced by tumor necrosis factor, IL-1, or lipopolysaccharide. J. Immunol. 144:2558

20. Brakenhoff, J. P. J., M. Hart, E. de Groot, F. Di Padova, and 1. Aarden. 1990. Structure-function analysis of human Il-6. Epitope mapping of neutralizing monoclonal antibodies with amino- and carboxylterminal deletion mutants. J. Immunol. 144:2558.

21. Pober, J. S., M. P. Bevilacqua, D. L. Mendrick, L. A. Lapierre, W. Fiers, and M. A. Gimbrone. 1986. Two distinct monkines interleukin 1 and tumor necrosis factor, each independently induce biosynthesis and transient expression of the same antigen on the surface of cultured human vascular endothelial cells. J, Immanol 145:561.

22. Munro, J. M., J. S. Pober, and R. S. Cotran. 1989.
Tumor necrosis factor and interferon-gamma induce distinct patterns of endothelial activation and associated leukocyte accumulation in the skin of Papio anubis. Am, J. Pathol. 135:121.

23. Doukas, J., and J. S. Pober. 1990. [FN- $\gamma$ cnhances endothelial activation induced by TNF but not $\mathbf{L}-1$, FASEB J. 4:A1713.

24. Shalaby, M. R. A. Waage, and T. Espevik. 1989. Cytokine regulation of interleukin 6 production by human endothelail cells. Cell. Immunol. 121:372.

25. Staunton, D. E., M. L. Dustin, and T. A. Springer. 1989. Functional cloning of ICAM-2, a cell adhesion ligand for LFA-1 homologous to ICAM-1. Nature 339:61.

26. Dustin, M. L., R. Rothlein, A. K. Bhan, C. A. Dinarello, and T. A. Springer. 1986. Induction by $\mathrm{L}, \mathrm{l}$ and interferon- $\gamma$. Lissue distribution, biochenistry, and function of a natural adherence molecule (ICAM-1). J. Immnnol. 137:245.

27. Jutila, M. A., L. Rott, E. L. Berg, and E. C. Butcher. 1989. Function and regulation of the neutrophil MEL-14 antigen in vivo: comparison with LFA-1 and MAC-1.J. Immunol, 143:3318.

28. Kooyk, Y. van, P. van de Wiel-van Kemenade, P. Weder, T. W. Kuijpers, and C. G. Figdor. 1989. Enhancement of LFA-1 mediated ecll adhesion by triggering through CD2 or CD3 on T-lymphocytes. Nafure 342:811.

29. Movat, H. Z., C. E. Burrowes, M. I. Cybulsky, and C A. Dinarcllo, 1987. Acute inflammation and a Shwartzman-like reaction induced by interleukin-1 and tumor necrosis factor. Synergistic action of the cytokines in the induction of inflammation and microvascular injury. Am. J. Pathol, 129:463.

30. Billiau, A., H. Heremans, F. VandeKerckhove, C. Dillen. 1987. Anti-inetrferon-garnma antiburly protects mice against the generalized Shwartzman reac tion. Eur. J. Immunol. 17;1851. 


\title{
LPS AND CYTOKINE-INDUCED ENDOTHE- LIAL CELL IL-6 RELEASE AND ELAM-1 EXPRESSION; INVOLVEMENT OF SERUM
}

\author{
E.J.U. VON ASMUTH, J.F.M. LEEUWENBERG, M. CESKA*, W.A.BUURMAN \\ *Sandoz Forschungsinstitut, Wien, Austria.
}

Eur. Cytokine Net., 1991, 2:291-297

\section{Summary}

I

$\mathrm{n}$ this in vitro study, the influence of serum-concentration. heat inactivation of the serum and the origin of the serum on the responsiveness of cultured human umbilical vein endothelial cells (HUVEC) to immunological challenges was investigated. Addition of human serum during stimulation with $1 \mu \mathrm{g} / \mathrm{ml}$ bacterial lipopolysaccharide (LPS) increased endothelial cell ELAM-1 expression and interleukin (IL)- 6 release five to ten-fold. Full endothelial cell responsiveness to LPS required 10 to $50 \%$ human serum and was largely abrogated after heating the serum for 30 minutes to $56^{\circ} \mathrm{C}$. Addition of newborn- or fetal bovine serum instead of human serum, induced even higher IL-6 release and ELAM- 1 expression in response to LPS, whilst heat-inactivation of these serum-batches only moderately decreased endothelial cell responses. Endothelial cell IL- 6 release and ELAM-1 expression after stimulation with IL- $1 \beta$ and tumor necrosis factor- $\alpha$ (TNF- $\alpha$ ) were less influenced by heat inactivation of the serum and by omission of serum, whilst responses to PMA remained completely unaffected by such modifications in assay media. Finally, we demonstrated that also endothelial cell IL- 8 ; release and ICAM-1 expression in response to LPS and cytokines were increased by addition of human serum, indicating that the use of serum-free assay media, or the use of media enriched by heat-inactivated (HI) human serum interferes with physiological endothelial cell responsiveness.

Although the origin of serum requirement for full endothelial cell responsiveness to LPS, IL- $1 \beta$ and TNF- $\alpha$ remains to be elucidated, these findings argue for the use of at least $10 \%$ not heat-inactivated serum as a medium-supplement during in vitro assays in which endothelial cells are used. 


\section{Introduction}

T The use of endothelial cell monolayers, grown on protein coated laboratory plastic has become a widely used model to study endothelial cell function in vitro. Little consensus exists on the choice of assay-media used in such studies.

Whilst some groups claim that $100 \% \mathrm{HI}$ autologous human plasma, being the most physiological vehiculum, should be used (1), others choose buffered salt solutions enriched by glucose and bovine serum albumin as the standard medium. In most cases, assay media are positioned somewhere in between these two extremes, and contain 5 to $10 \%$ serum, which is, for economic reasons, often of bovine origin. Additional variation has risen from the habit of heat-inactivation of the serum. Heating serum for 30 minutes to $56^{\circ} \mathrm{C}$ inactivates complement factors $\mathrm{C} 1, \mathrm{C} 2$, $\mathrm{C5}, \mathrm{C8}, \mathrm{C} 9$ and factor $\mathrm{B}$, thus preventing activation of the complement cascade.

Meanwhile, it has become clear that endothelial cell function depends on serum presence in culture medium. At less than 5\% serum, endothelial cell proliferation is strongly reduced (2), endothelial cell monolayer integrity is perturbed $(3,4)$, and permeability of the monolayer increases (5).

Immunological responses of endothelial cells are altered in absence of serum. For example. TNF causes lysis of rat pulmonary endothelial cells cultured in serum free medium, which is prevented by presence of $5 \%$ bovine calf serum (BCS) (6).

Likewise, a more than tenfold increased prostaglandin $E_{2}$ and prostacyclin release by bovine pulmonary endothelial cells after TNF- $\alpha$ stimulation was measured when fetal bovine serum was added to serum-free medium (7). Occasionally, serum constituents such as hypoxanthine (8) have been identified as a factor responsible for altered endothelial cell function in presence of serum, but often it is even unclear whether one particular factor, or a combination of influences of serum is involved.

In this study, we investigated the influence of serum on endothelial cell responsiveness to LPS, and the LPS inducible cytokines TNF- $\alpha$ and IL- $1 \beta$. LPS, TNF and $\Pi-1$ incite a number of pro-inflammatory events in endothelial cells (reviewed in 9). Increased and de novo expression of respectively ICAM-1 and ELAM-1, two endothelial cell adhesion molecules involved in leukocyte adherence, and the release of the inflammatory cytokines IL- 6 and IL- 8 were measured to define endothelial cell activation.

\section{Materials and Methods \\ Reagents}

Recombinant human (rh) TNF- $\alpha$ was kindly provided by BASF/Knoll Ag. (Ludwigshafen, FRG). rhIL-1 $\beta$ was a kind gift of Dr. S. Gillis (Immunex, Seattle, WA). LPS (E. Coli derived) and the phorbol ester PMA were purchased from Sigma (St. Louis, MO). Human serum was obtained from the local blood bank, pooled (unless mentioned otherwise), and either stored directly at $-20^{\circ} \mathrm{C}$, or heated to $56^{\circ} \mathrm{C}$ and maintained at that temperature for $30 \mathrm{~min}$ before storage (referred to as HI serum). Pooled human serum contained $<5 \mathrm{pg} / \mathrm{ml}$ endotoxin, as determined in the Limulus-assay (Kabi Coa-test, Kabi Diagnostica, Nykoping, Sweden). 


\section{Cells}

HUVEC were obtained by collagenase treatment of the human umbilical vein and cultured in fibronectin-coated (fibronectin kindly provided by Dr. J. van Mourik, CLB, Amsterdam, The Netherlands) tissue culture flasks (Costar, Cambridge, MA) in culture medium. Culture medium was composed of RPMI-1640 (Gibco Europe, Paisley, Scotland), supplemented with $10 \% \mathrm{HI}$ human serum, $10 \%$ HI bovine calf serum (BCS) (Hyclone, Logan, UT), 50 $\mathrm{g} / \mathrm{ml}$ heparin (Sigma), 30 $\mu \mathrm{g} / \mathrm{ml}$ endothelial growth supplement (Collaborative Research Incorporated, Bedford, MA) and antibiotics.

Endothelial cells were characterized by their pavement-like monolayer morphology, by positive staining with $\mathrm{mAb}$ hec7 directed against PECAM-1 (10), generously provided by Dr. W.A. Muller, Rockefeller University, $N Y$, and by positive staining with the anti ELAM-1 mAbs ENA1 and ENA2 (11) after 4 hour incubation with TNF- $\alpha$.

\section{Induction of ELAM-1 and ICAM-I expression, and cytokine release.}

HUVEC were seeded at $10^{4}$ cells/well in fibronectin-coated 96-well flat-bottom tissue culture plates (Costar) in culture medium, one day prior to stimulation. HUVEC were rinsed twice with RPMI-1640 and the medium was replaced by the appropriate agents in RPMI-1640 supplemented with antibiotics, without growth factor, and with serum as indicated (and $0.1 \%$ BSA (endotoxin contamination $<1 \mathrm{ng} / \mathrm{g}$, Sigma) in experiments in which serum-free medium was employed).

Supernatants were harvested and kept at $-20^{\circ} \mathrm{C}$ until use in the IL-6 and IL-8 ELISA's. Endothelial cell monolayers, were washed, fixed with $0.05 \%$ glutaraldehyde for $10 \mathrm{~min}$ - utes at room temperature (RT), and kept at $4^{\circ} \mathrm{C}$ to determine cell-surface antigen expression.

\section{IL-6 and IL-8 ELISA's}

The culture supernatant IL-6 and IL- 8 concentrations were determined using previously described sandwich-ELISA's for IL-6 (12) and IL-8 (13). In short, 96-well immuno maxisorp plates (Nunc, Roskilde, Denmark) were coated overnight at $4^{\circ} \mathrm{C}$ with murine mAb 8, specific for human IL-6 (14), kindly provided by Dr. L.A. Aarden (CLB, Amsterdam, The Netherlands), and polyclonal goatanti IL- 8 antiserum $(5 \mu \mathrm{g} / \mathrm{ml})$ for the IL- 6 and the IL-8 ELISA respectively, rhIL-6 (a generous gift from Prof. Dr. W. Sebald, Physiologisch-Chemisches Institut der Universität, Würzberg, FRG) and rhIL-8 were used for standard titration curves.

Test samples were added and incubated for 1.5 hours. Polyclonal rabbit anti-human IL-6 antiserum, followed by peroxidase conjugated goat anti-rabbit IgG (Jackson, Westgrove, PA), or biotin conjugated polyclonal goat anti-human IL-8 $(2.5 \mu \mathrm{g} / \mathrm{ml})$, followed by peroxidase conjugated avidin (Bio-Rad, Richmond, CA) were used for the IL, 6 and IL-8 ELISA respectively. O-Phenylenediamine (Sigma) was added as a substrate and photospectometry was performed at $492 \mathrm{~nm}$. Standard titration curves in the ELISA's were not influenced by presence of different amounts of untreated or HI serum in the sample buffer.

\section{Detection of cell-surface antigens.}

ELAM-1 and ICAM-1 expression were determined in ELISA's, using the ELAM-1 specific mAb ENA1 (11), and the ICAM-1 specific mAb RR1/1 (15), followed by per- 

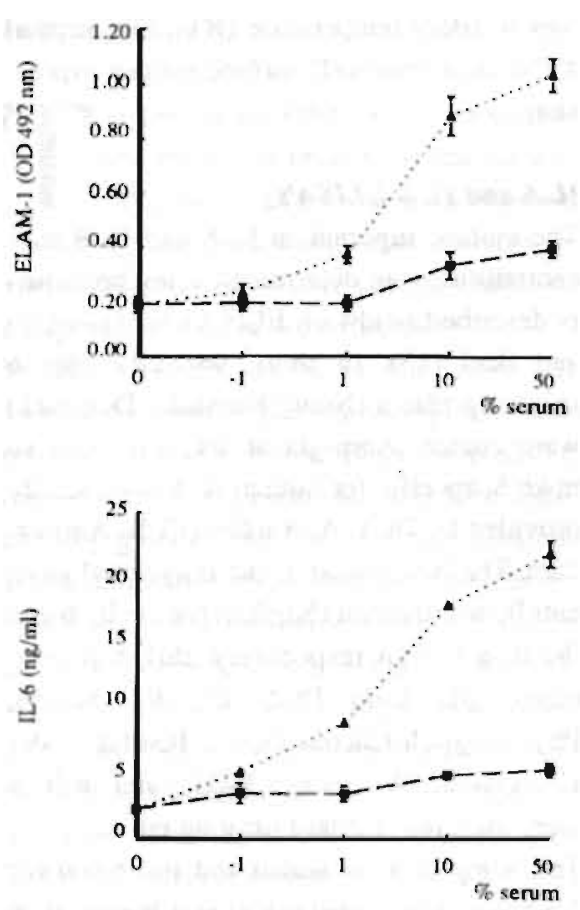

Figure 1: Effects of different amounts of untreated ( $\mathbf{\Delta}$ ) and $H I$ ( $\square$ human serum on ELAM-I expression and $I L-6$ release induced by $I \mu g / m I L P S$. HUVEC were incubated in presence of LPS for 18 hours in RPMI supplemented with $0.1 \%$ BSA and the indicated amount of serum. ELAM-I expression and $I L-6$ release were measured as indicated in Materials and Methods. Spontaneous IL-6 release reached $0.2 \mathrm{ng} / \mathrm{ml}$ in presence of both $H I$ and untreated serum, whilst ELAM-I expression remained below the detection limit of the assay. Data are expressed as mean and $S D$ of four measurements.

oxidase conjugated goat anti-rabbit IgG. O.Phenylene-diamine (Sigma) was added as a substrate and photospectometry was performed with a Microtiter ELISA reader. Results are expressed in optical density (OD) units at $492 \mathrm{~nm}$.

\section{Results}

Effect of serum on endothelial ELAM-I expression and $I L-6$ release induced by LPS

Addition of human serum to basal medium (RPMI-1640 supplemented with $0.1 \%$ BSA and antibiotics), induced increases in both ELAM-1 expression and IL-6 release by HUVEC stimulated for 18 hours with $1 \mu \mathrm{g} / \mathrm{ml}$ LPS in such medium (Fig. 1 ).

IL-6 release was significantly increased by as little as $0.1 \%$ human serum $(\mathrm{P}<0.01$, compared to $0 \%$ serum by the unpaired, twotailed Student's $t$-test), whilst higher ELAM-1 expression was apparent at $1 \%$ or more human serum.

Microscopic evaluation revealed no increase in the number of pyknotic cells and no severe monolayer disruption during the first 24 hours of serumfree culture. In the same experiments the influence of human serum, heat-inactivated for 30 minutes at $56^{\circ} \mathrm{C}$ (HI serum), was assessed. Addition of $50 \%$ HI serum to basal medium increased LPS induced ELAM-1 expression as measured in ELISA from 0.19 to 0.40 (OD units at $492 \mathrm{~nm}$ ), whilst an OD 1.04 was reached in presence of untreated serum. IL-6 release was influenced even more by serumpresence (without serum $2.2 \mathrm{ng} / \mathrm{ml}$, in presence of $50 \%$ HI serum $5.3 \mathrm{ng} / \mathrm{ml}$. in presence of untreated serum $22 \mathrm{ng} / \mathrm{ml}$ ) (Fig. 1).

To investigate whether heat-inactivation of the serum reduced the stimulating effect of serum on endothelial cell responsiveness, or whether an additional negative influence was induced by heat inactivation, $10 \% \mathrm{HI}$ serum was added to the assay-medium and subsequently replaced step-wise by untreated serum. Clear positive effects on LPS induced 


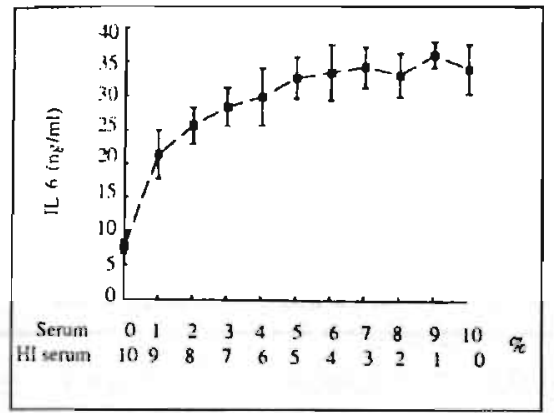

Figure 2: Effecs of replacement of HI human serum by unireated serum on $I L-6$ release induced by $/ \mu \mathrm{g} / \mathrm{ml} L P S$. HUVEC were incubaled in presence of LPS for 18 hours in RPMI supplemented with the indicated amounts of untreated and HI human serum. Spontaneous IL-6 release did not exceed $0.5 \mathrm{ng} / \mathrm{ml}$. Data are expressed as mean and $S D$ of four measurements.

ELAM-1 expression (data not shown) and IL-6 release (Fig. 2) were induced by replacing $1 / 10$ of the HI serum for untreated serum. In contrast, no significant effects were found after changing of 5/10 of untreated serum for $\mathrm{HI}$ scrum, indicating that HI serum has no negative effect on endothelial cell responsiveness in this model.

\section{Influence of $H I$ and untreated human} serum on ELAM-I expression and IL-6 release, induced by LPS, TNF- $\alpha, I L-1 \beta$ and PMA

To investigate whether the serum-effect interfered selectively with endothelial responses to LPS, we compared IL-1 $\beta$, TNF- $\alpha$ and PMA induced ELAM-1 and IL-6 time-response curves with LPS induced responses. The kinetics of ELAM-1 expression were not influenced by serum-presence; a decrease in expression started after 6 hours, independent whether incubations were per-
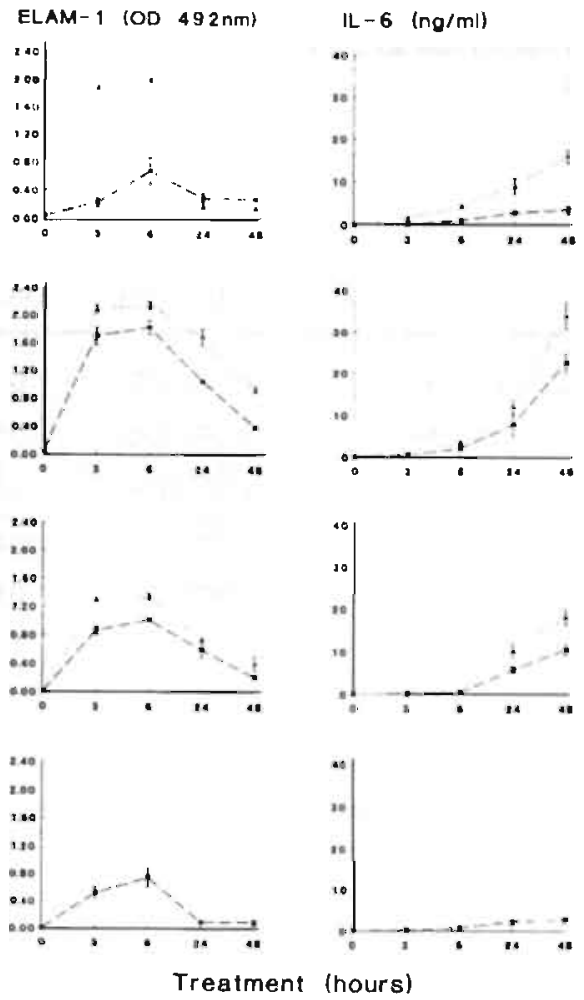

Figure 3: Kinevica of ELAM-I expression and $L-6$

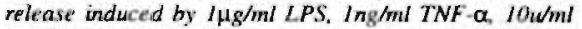
$I L-I \beta$ or Sng/ml PMA in presence of antreased $1 \mathbf{A}$ and $H I$ (G) hwian serum. HUVEC were incwhared for the time interval indicated in RPMI supplememed with $10 \%$ untreated or $H$ h human serum in prexence of the indicated agent. Spontaneous 48 hour $1 L-6$ release reached $2 \mathrm{ng} / \mathrm{ml}$ in presence of both $\mathrm{HI}$ and untreased senm. whitst 6 how ELAM-I expression remained below the detection limit. Datu are expressed as mean and SD of four nieasuremens.

formed in presence of $10 \% \mathrm{HI}$ human serum or untreated human serum (Fig. 3) or in absence of serum (data not shown).

Maximal differences of $\mathrm{HI}$ human serum and untreated human serum on ELAM-1 expression and IL-6 release were observed in response to LPS (Fig. 3 ). 
Table 1

Comparison of the effects of HI and untreated human serum on ICAM-1 expression and $I L-8$ release induced by $L P S, I L-1 \beta$ and $T N F-\alpha$

\begin{tabular}{|c|c|c|c|c|}
\hline & IOD & $\begin{array}{l}-1 \\
\mathrm{~nm})\end{array}$ & 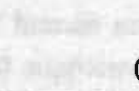 & \\
\hline & HI serum & untr. serum & HI serum & untr. serum \\
\hline unstimulated & $0.33 \pm 0.02$ & $0.43 \pm 0.02$ & $1.3 \pm 0.3$ & $4.7 \pm 0.3$ \\
\hline LPS $10 \mathrm{ng} / \mathrm{ml}$ & $0.39 \pm 0.02$ & $0.59 \pm 0.02$ & $3.6 \pm 0.4$ & $14 \pm 3$ \\
\hline LPS $1 \mathrm{ug} / \mathrm{ml}$ & $0.77 \pm 0.04$ & $0.87 \pm 0.01$ & $39 \pm 3$ & $73 \pm 7$ \\
\hline $\mathrm{IL}-1 \beta 10 \mathrm{U} / \mathrm{ml}$ & $0.75 \pm 0.02$ & $0.81 \pm 0.01$ & $65 \pm 6$ & $79 \pm 7$ \\
\hline $\mathrm{IL}-1 \beta 500 \mathrm{U} / \mathrm{ml}$ & $0.97 \pm 0.03$ & $0.94 \pm 0.01$ & $116 \pm 3$ & $134 \pm 5$ \\
\hline TNF- $\alpha \operatorname{lng} / \mathrm{ml}$ & $1.05 \pm 0.03$ & $1.10 \pm 0.02$ & $130 \pm 10$ & $150 \pm 6$ \\
\hline
\end{tabular}

HUVEC were incubated for 18 hours in RPMI supplemented with $10 \%$ untreated or HI human serum in presence of the indicated agent. Data are expressed as mean $\pm S D$ of four measurements

Endothelial cell responsiveness to TNF and IL-1 was, however, also increased by serumpresence. Addition of $10 \% \mathrm{HI}$ human serum to basal medium (data not shown), as well as replacing HI serum for untreated serum (Fig. 3) consistently increased both IL-1 $\beta$ and TNF- $\alpha$ induced endothelial cell ELAM- 1 expression and IL-6 release, although such increases were generally below $100 \%$. PMA induced ELAM-1 expression and IL-6 release remained unaffected by either addition of HI serum or untreated serum to basal medium.

Heat-inactivated $\left(100^{\circ} \mathrm{C}, 30\right.$ minutes $)$ preparations of IL-1, TNF and PMA did not induce IL- 6 release or ELAM-1 expression, indicating that the described influences of serum on TNF and IL.-1 provoked responses were not caused by endotoxin contamination (data not shown).

\section{Influence of $\mathrm{HI}$ and untreated human} serum on endothelial $I L-8$ release and ICAM-1 expression

To investigate whether serum-presence interfered selectively with endothelial IL-6 release and ELAM-1 expression, we investigated two other parameters of endothelial cell activation, IL- 8 release and ICAM-1 expression. Both IL-8 release and ICAM-1 expression, induced by stimulation with low amounts of LPS, were increased by addition of $10 \%$ HI human serum to basal medium (data not shown) as well as by replacing HI serum for untreated serum (Table 1 ). Lower but consistent differences between untreated and $\mathrm{HI}$ serum were also found 
Chapter 4.3

Table 2.

Comparison of human sera from different individuals and commercial bovine sera preparations on their influence on LPS induced HUVEC IL-6 release and ELAM-1 expression
IL-6
ELAM-1
$(\mathrm{ng} / \mathrm{ml})$
(OD 492nm)

\begin{tabular}{lccccccccc}
\hline & \multicolumn{2}{c}{ HI serum } & \multicolumn{2}{c}{ untr. serum } & \multicolumn{2}{c}{ HI serum } & \multicolumn{2}{c}{ untr. serum } \\
& exp. 1 & exp. 2 & exp. 1 & exp. 2 & exp. 1 & exp. 2 & exp. 1 & exp. 2 \\
\hline HS-I & $0.3 \pm 0.1$ & $2.0 \pm 0.1$ & $4.6 \pm 0.2$ & $18 \pm 4$ & $0.08 \pm 0.03$ & $0.16 \pm 0.01$ & $0.48 \pm 0.06$ & $0.51 \pm 0.02$ \\
HS-2 & $0.3 \pm 0.1$ & $2.6 \pm 0.7$ & $4.0 \pm 0.2$ & $22 \pm 4$ & $0.19 \pm 0.07$ & $0.13 \pm 0.01$ & $0.57 \pm 0.07$ & $0.50 \pm 0.02$ \\
HS-3 & $1.2 \pm 0.3$ & $8.3 \pm 0.4$ & $5.4 \pm 0.5$ & $47 \pm 3$ & $0.27 \pm 0.06$ & $0.30 \pm 0.01$ & $0.66 \pm 0.05$ & $0.48 \pm 0.02$ \\
HS-4 & $1.0 \pm 0.3$ & $6.1 \pm 0.1$ & $4.6 \pm 0.4$ & $38 \pm 4$ & $0.11 \pm 0.02$ & $0.14 \pm 0.02$ & $0.28 \pm 0.03$ & $0.26 \pm 0.01$ \\
HS-5 & $0.4 \pm 0.1$ & $4.2 \pm 0.4$ & $4.1 \pm 0.2$ & $18 \pm 3$ & $0.19 \pm 0.03$ & $0.21 \pm 0.02$ & $0.65 \pm 0.02$ & $0.57 \pm 0.11$ \\
HS-6 & $0.4 \pm 0.1$ & $4.6 \pm 0.3$ & $6.3 \pm 0.9$ & $34 \pm 2.6$ & $0.27 \pm 0.12$ & $0.27 \pm 0.03$ & $0.81 \pm 0.06$ & $0.58 \pm 0.10$ \\
BCS Hyclone-1 & $1.6 \pm 0.1$ & $8.1 \pm 0.5$ & $6.1 \pm 0.4$ & $19 \pm 2$ & $0.67 \pm 0.04$ & $0.50 \pm 0.01$ & $1.2 \pm 0.04$ & $0.71 \pm 0.01$ \\
BCS Hyclone-2 & $1.7 \pm 0.1$ & $15 \pm 1$ & $6.5 \pm 0.9$ & $39 \pm 3$ & $0.74 \pm 0.04$ & $0.54 \pm 0.02$ & $1.2 \pm 0.10$ & $0.76 \pm 0.03$ \\
NCS Gibco & $5 \pm 0.9$ & $65 \pm 7$ & $10 \pm 2.0$ & $57 \pm 3$ & $1.2 \pm 0.11$ & $0.72 \pm 0.02$ & $1.2 \pm 0.13$ & $0.62 \pm 0.04$ \\
FCS Hyclone-1 & $7.5 \pm 1.6$ & $56 \pm 4$ & $10 \pm 1.6$ & $50 \pm 4$ & $1.3 \pm 0.08$ & $0.81 \pm 0.02$ & $1.4 \pm 0.10$ & $0.69 \pm 0.02$ \\
FCS Gibco & $6.8 \pm 1.1$ & $56 \pm 8$ & $10 \pm 2.1$ & $52 \pm 6$ & $1.5 \pm 0.07$ & $0.87 \pm 0.01$ & $1.5 \pm 0.07$ & $0.79 \pm 0.03$ \\
FCS Hyclone-2 & $6.8 \pm 0.8$ & $57 \pm 8$ & $8.2 \pm 1.9$ & $43 \pm 4$ & $1.4 \pm 0.10$ & $0.79 \pm 0.03$ & $1.3 \pm 0.07$ & $0.67 \pm 0.03$ \\
\hline
\end{tabular}


using $1 \mu \mathrm{g} / \mathrm{ml}$ LPS, and IL- $1 \beta$ and TNF- $\alpha$ as stimuli, except for ICAM-1 expression after strong stimulation $(500 \mathrm{U} / \mathrm{ml} \quad \mathrm{IL}-1 \beta$ and $1 \mathrm{ng} / \mathrm{ml}$ TNF). Unstimulated HUVEC expresses low levels of ICAM-1 (16) and releases small amounts of IL- 8 . These basal levels of ICAM-1 expression and IL-8 release were also significantly increased by exchanging $\mathrm{HI}$ serum for untreated serum $(p<0.01$ as compared by the unpaired, twotailed Student's $t$-test).

\section{Comparison of sera from different indi- viduals, and commercial preparations of BCS, NCS (newborn calf serum) and FCS (fetal calf serum).}

Six human sera, obtained from healthy adult donors of the local blood bank, and standard commercial bovine sera preparations of BCS, NCS and FCS, obtained from Gibco and Hyclone, were compared on their influence on endothelial cell responsiveness. HUVEC IL-6 release and ELAM-1 expression after 18 hours of stimulation with $1 \mu \mathrm{g} / \mathrm{ml}$ LPS in presence of $10 \% \mathrm{HI}$ and untreated serum were measured. Consistent lower HUVEC responses were measured after HI of the human sera, although there was some inter-individual and inter-assay variation in absolute levels of IL- 6 release and ELAM-1 expression (Table 2).

Sera of bovine origin generally induced higher 1L-6 and ELAM-1 responsiveness than human serum. In contrast to human serum, heat inactivation of BCS only slightly reduced endothelial cell responsiveness, whilst consistent heat inactivation induced reductions were not observed with NCS or FCS. None of the sera-batches used, induced significant spontaneous IL-6 release or ELAM- 1 expression (data not shown).

\section{Discussion}

We demonstrate in this study that HUVEC ELAM-1 expression and IL-6 release, induced by stimulation with LPS, were increased by addition of $0.1 \%$ to $1 \%$ human serum, and showed five to ten times higher levels after addition of $50 \%$ human serum to BSA containing basal medium. Addition of human serum, heat-inactivated for $30 \mathrm{~min}$ utes at $56^{\circ} \mathrm{C}$, had less response enhancing effects. Since presence of HI human serum instead of untreated serum did not seriously interfere with other endothelial cell functions, such as responses on PMA, monolayer integrity (by microscopic evaluation) and endothelial cell proliferation (2), and since no evidence was found for a negative influence of HI serum on endothelial cell responsiveness, we conclude that one or more heat labile serum factors in human serum specifically enhance endothelial cell responses to LPS, and the cytokines TNF- $\alpha$ and IL- $\beta$. This effect of human serum appeared to involve a direct effect on the endothelial cell, since also in absence of a stimulus, ICAM- 1 expression and $\mathrm{IL}-8$ release were upregulated by presence of $10 \%$ untreated human serum. Furthermore, a serum induced increase in the biological activity of TNF- $\alpha$ and $I L-1 \beta$ is unlikely, since endothelial ELAM-1 expression and IL- 6 release induced by addition of anti TNF-receptor antibody htr-9, known to mimic TNFactivation by cross-linking TNF-receptors on endothelial cells (17), also were higher in presence of untreated human serum than in presence of HI serum (data not shown).

Protein kinase $\mathrm{C}$ activation by phorbol esters induces IL-6 release (18) and ELAM-1 
expression (11) by endothelial cells. Protein kinase $\mathrm{C}$ activation is, however, not involved in TNF induced ELAM-1 expression on endothelium (19). Cytokine induced IL-6 release by endothelial cells might also be induced independently from protein kinase C, since IL-6 gene activation in fibroblast can be induced independently from protein kinase C (20). Since we found no influences of human serum on endothelial cell responses to the protein kinase $C$ activating phorbol ester PMA, we conclude that serum-presence selectively enhances protein kinase $C$ independent endothelial cell activation.

Untreated human serum increased LPS induced endothelial cell responses stronger than responses to IL- $1 \beta$ and TNF- $\alpha$. The additional enhancing effect of serum presence on LPS-stimulation might depend on specific interactions between bacterial LPS and serum, changing the biological activity of LPS. Serum causes an alteration of the association state of LPS, by binding of LPS to the lipid-fraction in serum, and by an interaction with specific LPS binding proteins (2l). Several LPS binding proteins, some of which unstable at $56^{\circ} \mathrm{C}$, have been described in different animals (22-25).

Variation in the presence and the nature of such proteins might have contributed to the difference in influence of human serum and bovine sera batches, and the lack of reduction in serum effects after heat inactivation of bovine sera described in this study. Wright and co-workers recently showed that a $55 \mathrm{kD}$ human acute phase protein binds to LPS (26), and that the interaction of this complex with membrane CD14 is a crucial step in the activation of macrophages (27) and neutrophil granulocytes (28) by LPS.
Whether this LPS binding protein and CD 14 are involved in endothelial cell responses on LPS in presence of serum is currently being investigated. Identification of a serum protein involved in enhancing endothelial cell responses to LPS could offer new insights in the regulation of host responses to microbial challenge, and in the pathophysiology of related syndromes such as septic shock, multiple organ failure and the acute respiratory distress syndrome.

We demonstrated in this study that omittance. of serum from the medium, heat inactivation of human serum, and the use of bovine sera instead of human serum influenced endothelial cell responsiveness. These findings argument for the use of at least $10 \%$ untreated human serum as a medium-supplement during in vitro experiments in which human endothelial cells are used, to avoid interference with physiological endothelial cell responsiveness.

\section{References.}

1. Moser R, Schleiffenbauin B. Groscurth P. Fehr J. 1989. Interleukin 1 and tumor necrosis factor stimulate human vascular endothelial cells to promote transendothelial passage. J. Clin. Invest. 83: 444.

2. Gordon PA, Sussman II, Harcher VB. 1983, Longterm culture of human endotheliall cells. In Vitro 19: 661.

3. Cavender DE. Edelbaum D. 1988. Inhibition by R-1 of endothelial cell activation induced by tumor necrosis factor or Jymphoroxin. J. ImmunoL. 141: 3111 .

4. Gimbrone Jr MA. Cotran RS, Folkman J. 1974. Human vascular endothelial cells in culture. Growth. and DNA synthesis. J. Cell. BioL 60: 673.

5. Langeler EG. Hinsbergen VWM. 1990. Characterization of an in vitro model to study the permeability of human arterist cndothelial cell monolayers. Tromb. Haemost 60: 240.

6. Varani J, Bendelow MJ, Sealey DE, Kunkel SL, Johnson KJ, Ward PE. 1988. Tumoir necrosis factor enhances suscepuibility of vascular endothelial cells to neutrophil mediated killing. Lab. Invest. 59: 292.

7. Meyrick B, Christman B, Jesmok G. 1991. Effects of recombinant tumor necrosis factor-alpha on cultured pulmonary artery and lung microvascular endothelial monolayers. Am. J. Palhol. 138: 93. 


\section{Endothelial responses are serum dependent}

8. Hayashiti Y, Hirai S, Harayama H. Ichikawa A. 1989. Fibroblast growth factor-stimulated growth of porcinc aortic endothelial cells depends on

hypoxanthine in fetal bovine serum in culture media. Exp. Cell Res. 185: 217.

9. Mantovani A, Dejana E. 1989. Cytokines as commu. nication signals between leukocytes and endothelial cells. Immunol. Today 10: 370.

10. Muller WA, Ratti CM, McDonnell SL. Cohn ZA. 1989. A human endothelial cell-restricted, externally disposed plasmalemmal protein enriched in intercellular junctions. J. Exp. Med 170: 399.

11. Leeuwenberg JFM, Jeunhomme GMAA, Buurman WA. 1990. Characterization of two monoclonal antibodies directed against an adhesion molecule on endothelial cells. Transplant. Proc. 22: 1991.

12. Leeuwenberg JFM, VonAsmuth EJU, Jeunhomme TMAA, Buurman WA. 1990. IFN- $\gamma$ regulates the expression of the adhesion molecule ELAM-1 and IL-6 production by human endothelial cells in vitro. J. Immunol 145: 2110.

13. Ceska M, Effenberger F, Peichl P, Pursch E. 1989 Purification and characterization of monoclonal and polyclonal antibodies to neutrophil activating peptide (NAP-1). The development of a sensitive ELISA for the determination of NAP- 1 and anti-NAP-1 antibodies. Cytokine I: 136 (abstract).

14. Aarden LA, de Groot ER, Schaap OL, Lansdorp PM. 1987. Production of hybridoma growth factor by human monocytes, Eur. J. Immunol. I7: 1411.

15. Rothlein $\mathbf{R}$, Dustin ML, Marlin SD, Springer TA. 1986. A human intercellular adhesion molecule distinet from L.FA-1.J. ImmunoL 137: 1270.

16. Dustin ML, Springer TA. 1988. Lymphocyte function-associated antigen-1 (LFA-1) interaction with iniercellular adhesion molecule-1 (ICAM-1) is one of at least three mechanisms for lymphocyte adhesion to cultured endothelial cells. J. Cell BioL 107: 321 .

17. Espevik T, Brockhaus $M$, Loctscher $H$, Nonstad U, Shalaby R. 1990. Characterization of binding and biological effects of monoclonal antibodies against a human tumor necrosis receptor. J. Exp. Med. I7I: 415 .

18. Aarden L, Helle M, Bocije L, Pascaul-Salcedo D, de Groot E. 1991. Differential induction of interleukinproduction in monocytes, endothelial cells and smooth muscle cells. Ear. Cytokine Nerwork 2: IIS.

19. Ritchie AJ, Johnson DR, Ewenstein BM. Pober JS 1991. Tumor necrosis factor induction of endothelia cell surface antigens is independent of protein kinase C activation or inactivation. J. Immunol 146. 3056.

20. Zhan Y. Lin JX, Vilcek J. 1988. Synthesis of interleukin- 6 (interferon- $\beta / \beta$ cell stimulating factor 2 ) in human fibroblasts is triggered by an increase in intracellular cyclic AMP. J. Biol Chem. 263: 6177.

21. Ulevitch RJ, Johnston AR. 1978. The modification of biophysical and endotoxic properties of bacterial lipopolysaccharides by serum. J. Clin. Invest. 62: 1313.

22. Hacfiner-Cavaillon N, Cavaillon J, Etievant M, Lchbar S, Szabo L. 1985. Specific binding of endotoxin to monocytes and murine macrophages: serum requirement. Cell Immunol 91 : 119

23. Aida Y, Pabst MJ. 1990. Priming of neutrophils by lipopolysaccharide for enhanced release of superoxide. Requirement for plasma but not for tumor necrosis factor-alpha. J. Immunol. 145; 3017.

24. Tobias PS, Soldau K, Ulevitch RJ. 1986. Isolation of a lipopolysaccharide-binding acute phase reactant from rabbit serum. J. Exp. Med. 164: 777.

25. Brade L, Brade H. 1985. A 28,000-dalton protein of normal mouse-serum binds specifically to the inner core region of bacterial lipopolysaccharide. Infect Immun. 50: 687.

26. Schuman RR, Lcong SR, Flaggs GW, Gray PW, Wright SD, Mathison JC, Tobias PS, Ulevitch RJ. 1990. Structure and function of lipopolysaccharide binding protein. Science 249: 1429.

27. Wright SD, Ramos RA, Tobias PS, Ulevitch RJ, Mathison JC. 1990. CD14, a receptor for complexes of lipopolysaccharide (LPS) and LPS binding protein. Science 49: 1431.

28. Wright SD, Ramos RA, Hermanowski-Vosatka A, Rockwell P, Detmers PA. 1991. Activation of the adhesive capacity of $C R 3$ on neutrophils by endotoxin: dependence on lipopolysaccharide binding protein and CD14. J. Exp. Med. 173: 1281 . 


\section{ANTI-CD14 ANTIBODIES REDUCE RESPONSES OF CULTURED HUMAN ENDO- THELIAL CELLS TO ENDOTOXIN}

ECKHARDT J. U. VON ASMUTH, MIEKE A. DENTENER, VLADIMÍR BAZIL*, MAARTEN G. BOUMA, JET F. M. LEEUWENBERG AND WIM A. BUURMAN

'Harvard University, Dept. of Biochem. and Molecular Biol., Cambridge, U.S.A. Immunology 1990, 80: 78-83

\section{Summary}

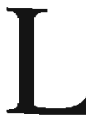

PS activates both myeloid cells and endothelial cells. Whereas CD14 has shown to be involved in LPS recognition by mycloid cells, the mechanism responsible for the strong response of endothelial cells to LPS remains to be elucidated. The role of CD14 in this process was studied using CD14 specific Ab. Anti-CD14 Ab inhibited LPS-induced IL-6 release and E-selectin expression by cultured human umbilical vein endothelial cells (HUVEC). mRNA encoding IL-6 and E-selectin was reduced in parallel. The inhibitory effect of anti-CDI4 Ab was epitope dependent, maximal at low LPS concentrations and dropped with increasing LPS dose. Anti-CD14 Ab did not affect endothelial cell activation induced by IL-1B, TNF- $\alpha$ and PMA. HUVEC IL-6 release and E-selectin expression were strongly reduced when LPS-activation was performed in absence of serum, indicating involvement of serum-components in LPS-activation of HUVEC. Nevertheless, anti-CD14 Ab blocked LPSinduced HUVEC activation also in absence of serum. Although the role of serum-components in LPS-activation remains to be elucidated, CD14 seems to be a key-mediator in LPS-induced activation of endothelial cells. 
aysis is aks? (3) $x+x^{2}=y^{2}$

$$
y^{2}
$$
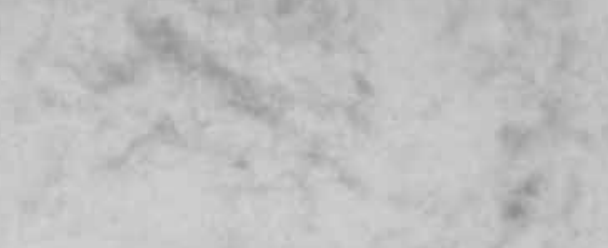

85

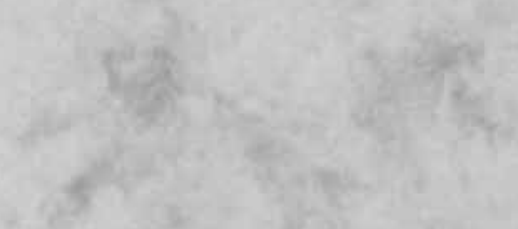

$y^{2}$

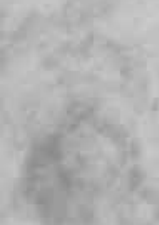

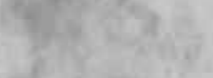

$y^{3}+x^{3}=$

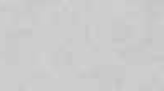

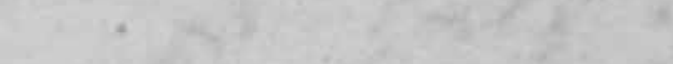

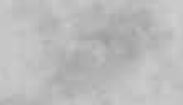

$6 y^{3}+4$

yon

tirt

$\ln ^{2} x^{2}$

(3) $5 x^{3}$

? + as

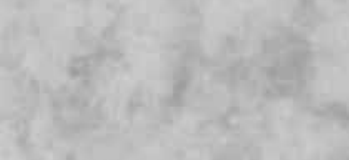

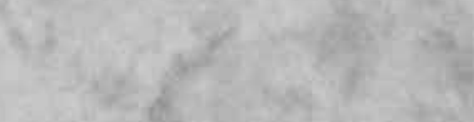

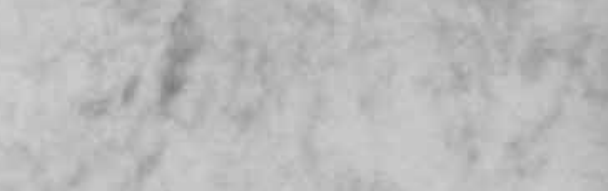

12: 20

$+4$

$+7$

y

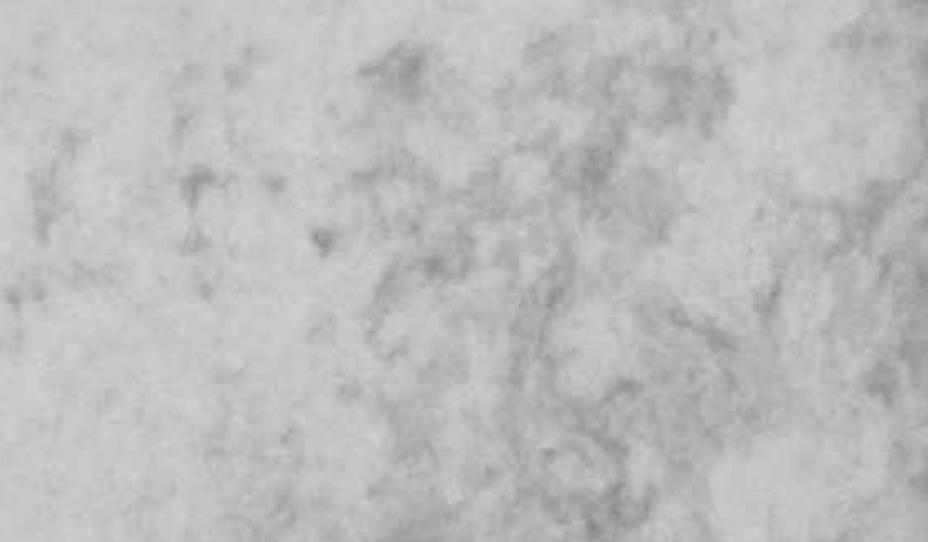

$y^{2}+2$

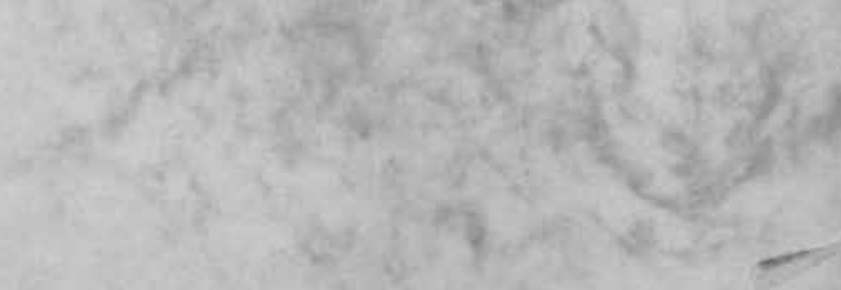

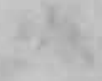


Anti-CDI4 Ab reduce responses of human endothelial cells to endotoxin

table I

Anti-CDI4 antibodies can inhibit LPS-induced responses of both HUVEC and human monocytes

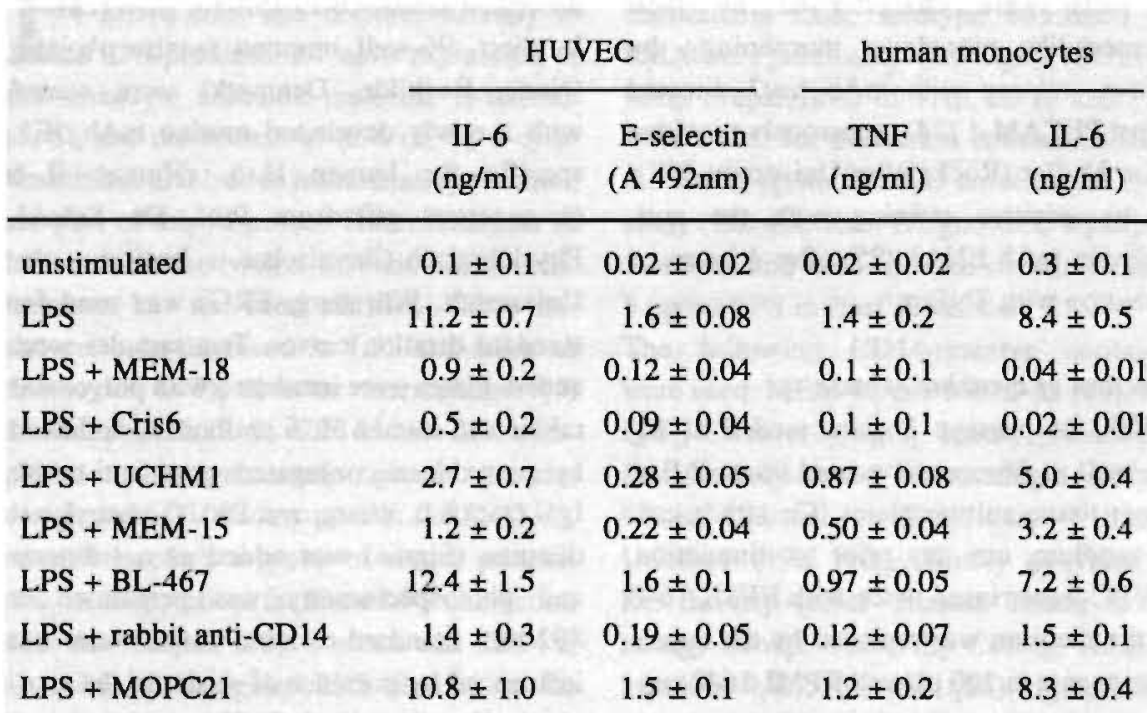

Influence of $10 \mu \mathrm{g} / \mathrm{ml} \mathrm{mAb}$ and rabbit polyclonal untibodies reactive with CDI4 on HUVEC $I L-6$ release and E-seles: in expression and monocyte TNF and $I L-6$ release induced by $L P S . M O P C 21$, a non-reacrive mAb of the $18 G$, subclass, was used as a control. Cells were incubated in presence of LPS (monocytes with $100 \mathrm{pg} / \mathrm{ml}$ and HUVEC with $I \mu \mathrm{g} / \mathrm{ml} L \mathrm{LPS}$ ) and antibodies for 5 hours (to determine maximal E-selectin expression) and 18 hours (10 delermine cyto. kine release). Data are expressed as mean $\pm S D$ of four measurements.

primer labeling kit of Boehringer Mannheim (Boehringer Mannheim, Mannheim, FRG) and hybridized to the blot $\left(10^{6} \mathrm{cpm} / \mathrm{ml}\right)$ as described (28). The IL-6 probe (1.3 kb HIIIEcoRI fragment) was kindly provided by Dr. Aarden (CLB, Amsterdam, Netherlands), the E-selectin probe $(1.0 \mathrm{~kb}$ EcoRI-BgIII fragment) was kindly provided by Celltech andthe actin probe (1.3 Pst fragment) was kindly provided by Dr. Berkvens (University of Leiden, Leiden, The Netherlands). Labeled bands were visualized by autoradiography.

\section{Results}

Anti-CD14 antibodies inhibit LPS-induced HUVEC responses

HUVEC-monolayers were incubated with $1 \mu \mathrm{g} / \mathrm{ml}$ LPS in RPMI-1640 enriched with $10 \%$ HS and antibiotics. The influence of coincubation with five murine anti-CD14 mAb, MEM-18, Cris6, UCHM1, MEM-15 and BL-467, and of serum of CD14 immunized rabbits ( $\mathrm{IgG}$ concentration $10 \mu \mathrm{g} / \mathrm{ml}$ ), on IL-6 release and on E-selectin expression by HUVEC was investigated.

MEM-18, Cris6, MEM-15 and rabbit polyclonal anti-CD14 antibodies prevented LPS 
induced IL-6 release and E-selectin expression for $80 \%$ or more. UCHM1 inhibited HUVEC responses less effectively, whilst $\mathrm{BL}-467$ as well as a nonreactive control mAb did not influence HUVEC responses. (Table I).

As a control, the same panel of antibodies was tested for their influence on $100 \mathrm{pg} / \mathrm{ml}$ LPS induced TNF and IL- 6 release by human monocytes. The LPS-induced release of both cytokines was completely prevented by coincubation with MEM-18 and Cris6, whilst MEM-15 and rabbit anti-CD14 antibodies reduced both TNF and IL-6 release for more than $60 \%$ (Table 1).

In parallel to the effect on LPS-induced HUVEC activation, mAb BL-467 hardly influenced LPS-induced monocyte TNF and IL-6 release (Tuble I). None of the antiCD14 antibodies induced HUVEC IL-6
A

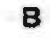

c

IL-6

\section{E-selectin}

actin

Figure I: MEM-18 inhibits LPS-induced $I L-6$ and E-selectin mRNA expression in HUNEC, $M R N A$ was isolated from wontreated HUVEC (A) and HUVEC stimulated for 2 hours with $/ \mu \mathrm{g} / \mathrm{ml}$ LPS in absence $(B)$ presence $(C)$ of $5 \mathrm{\mu g} / \mathrm{m} / \mathrm{MEM}-\mathrm{I8}$, in medium containing $10 \% \mathrm{HS}$.

Parallel blots were run and hybridized with actin probe to compare the amount of RNA of different samples.
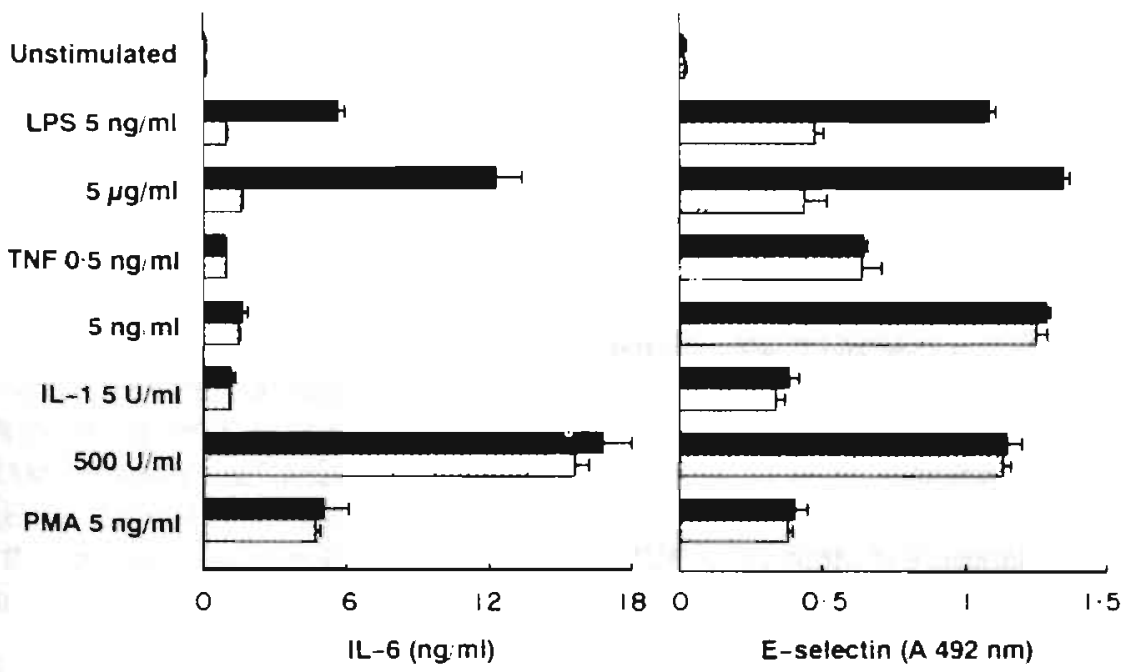

Figure 2: MEM-18 inhibits LPS-induced, but not TNF, IL-1/3 and PMA-induced $I L-6$ release and $E$-selectis expression. HUVEC were incubared with the indicated reagents in absence (D) and presence (JII) of $5 \mu \mathrm{g} / \mathrm{ml} \mathrm{MEM}-18$. E-selectin expression and $1 L-6$ release were measured after respectively 5 and 18 hours as indicared in Material and Methods. Dala are expressed as mean and SD of four measurements. 
Anti-CD14 Ab reduce responses of human endothelial cells to endotoxin
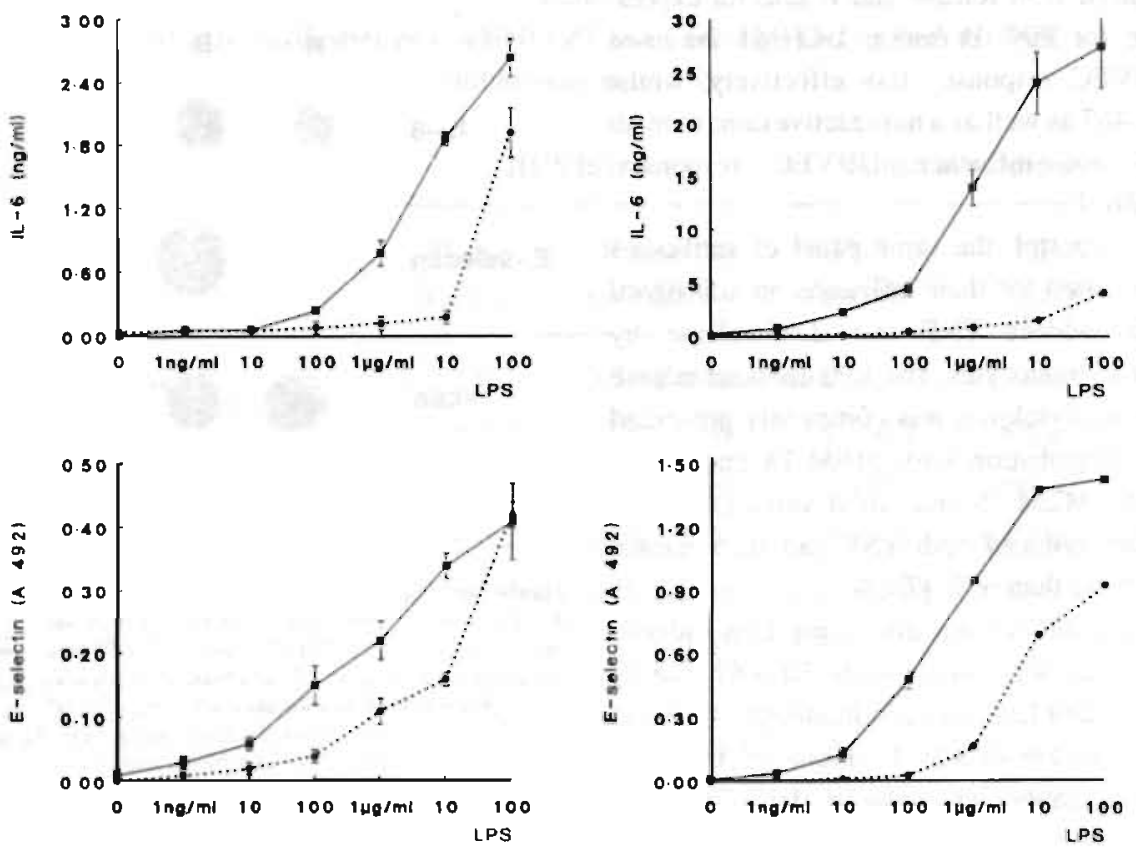

Figure 3: $M E M-18$ inhibits LPS-induced $L$ - 6 reledse and E-selectin expression both in absence (left graphs) and presence (right graphs) of $10 \%$ HS. HUVEC were incubated with different concentrations of LPS with (O) and without (D) of $5 \mathrm{\mu g} / \mathrm{m} M \mathrm{MEM}-18$ for 5 hours (to determine maximal E-selectin expression) and 18 hours (to determine $I L$-6 relews) in presence or absence of serum. Data are expressed as mean and SD of four measurements. If SD bars are not shown, they fall within the symbol.

release, HUVEC E-selectin expression and monocyte cytokine release in absence of L.PS (data not shown). MEM-18, which inhibited HUVEC IL-6 release and E-selectin expression at $0.2 \mu \mathrm{g} / \mathrm{ml}$, with a maximal inhibition at $2 \mu \mathrm{g} / \mathrm{ml}$ (data not shown) was selected for further experiments.

Next, the influence of MEM-18 on HUVEC IL-6 and E-Selectin mRNA expression induced by incubation with $1 \mu \mathrm{g} / \mathrm{ml}$ LPS for 2 hours, was determined. In presence of MEM-18, substantially reduced amounts of mRNA encoding $\mathrm{L}-6$ and E-selectinwere detected (Figure 1), indicating interference of MEM-18 with LPS induced IL-6 release and $E$-selectin expression on a pre-transcriptional level. To investigate whether antiCD14 antibodies specifically inhibited HUVEC responses to LPS, we compared HUVEC responses to LPS, IL-1B, TNF- $\alpha$ and PMA in presence and absence of MEM18. Whereas MEM-18 induced a major reduction E-selectin expression and $\mathrm{LL}-6$ release in response to $5 \mathrm{ng} / \mathrm{ml}$ LPS and $5 \mu \mathrm{g} /$ $\mathrm{ml}$ LPS, no clear influence on responses of HUVEC monolayers stimulated with IL-1B, TNF- $\alpha$ and PMA was found (Figure 2). 
Inhibition of LPS induced HUVEC IL-6 release and E-selectin expression is notabrogated in absence of serum

To investigate whether serum-presence is a prerequisite for CD14 mediated LPS-activation of HUVEC, HUVEC monolayers were rinsed intensively with serum-free medium before addition of LPS, to assure maximal removal of soluble serum-components. Monolayers were subsequently incubated in presence or absence of $10 \%$ HS with LPS concentrations ranging from $1 \mathrm{ng} / \mathrm{ml}$ to 100 $\mu \mathrm{g} / \mathrm{ml}$ in RPMI-1640 supplemented with $0.1 \%$ BSA. In presence of serum, MEM- 18 reduced IL-6 release and E-selectin expression in response to $1-100 \mathrm{ng} / \mathrm{ml}$ LPS for $90 \%$ or more. This reduction was partly overcome by stimulation with higher concentrations of LPS (Figure 3). As reported previously (29) HUVEC showed diminished responses to LPS in absence of serum (Figure 3). MEM-18, however, still effectively reduced both LPS induced IL-6 release and E-selectin expression in absence of serum in the incubationmedium (Figure 3). The use of special serum free endothelial cell culture medium (Endothelial-SFM, Gibco) instead of RPMI supplemented with BSA, and additional attempts to remove serum proteins, either by repeating the wash-procedure or by 24 hour culture in serum-free medium before washing and activation in new serum free medium, did not prevent the inhibitory effects of MEM-18 coincubation in the above described experiment (data not shown).

\section{Discussion}

We demonstrated that certain anti-CD $14 \mathrm{Ab}$ inhibited LPS-induced activation of cultured
HUVEC, measured by induction of (1) II -6 release; (2) E-selectin surface expression, and (3) IL-6 and E-sclectin mRNA expression. We also found that anti-CD $14 \mathrm{mAb}$ reduced LPS-induced IL- 8 release, and surface expression of ICAM-1 and VCAM-1 (data not shown). On the basis of these results, we conclude that CD14 participates in the response of endothelial cells to L.PS.

A recent study of Frey et al (30), also demonstrates CD14 involvement in endothelial cell activation by LPS.

This finding extends the immunological importance of CD14 in terms of its role in LPS-induced activation of not only hemopoictic, but also non-hemopoictic cells. We and others found clear differences in the capacities of anti-CDI4 Ab to block L.PS induced cellular activation $(5,30)$. Both differences in epitope-specificity and differences in aftinity of the individual anti-CD14 Ab could have contributed to this variation.

Capacities of anti-CD14 Ab to block LPSinduced HUVEC activation were, however, similar to the capacities of these Ab to block LPS-induced activation of monocytes, indicating that the same CD14 epitope is involved in the activation process. The finding that anti-CD $14 \mathrm{mAb}$ do not inhibit endothelial cell responses to cytokines and PMA demonstrates that CD14 is specifically involved in the LPS-induced activation.

There are still several questions to be answered. First, what is the role of CD14 in cellular activation by LPS? The fact that anti$\mathrm{CD} 14 \mathrm{mAb}$ are able to inhibit LPS-induced activation of HUVEC in the absence of serum supports the concept that CD14 is able to interact directly with LPS $(7,8,11,12$, 30 ). It can, however, not be excluded that 
some serum proteins like LBP may remain bound to the endothelial cell surface and mediate LPS-CD14 interactions, despite the efforts to wash theseproteins away. Another conclusion drawn from this observation is that $\mathrm{CD} 14$ must be associated with the endothelial cell membrane.

A next question regards the origin of CD14 present on endothelial cells. One possibility is that CD14 represents an endogenous membrane molecule. Since soluble CD14 is found in high amounts in normal plasma $(22,31)$, association of exogenous CD14 with a counter-receptor on the surface of endothelial cells would be another option, which has recently been claimed (30). Attempts to prevent association of exogenous $\mathrm{CD} 14$ with the endothelial cell surface by culturing HUVEC monolayers under serum-free conditions before LPS-activation did, however, not prevent the inhibitory effect of anti-CD14 mAb. Whatever the answer is, the quantity of cell surface-associated CD14 on HUVEC seems to be fairly low, since we were not able to detect surface $\mathrm{CD} 14$ using either flow cytometry analysis or precipitation from detergent lysate of surface iodinated HUVEC (data not shown).

In contrast, we obtained positive results using both these methods for detection of surface $\mathrm{CD} 14$ on monocytes (data not shown). However, in addition to the functional evidence for the presence of CD14 on endothelial cells, weak staining of endothelial cells by anti-CD $14 \mathrm{mAb}$ has been reported (19-21). Finally, it is not clear which serum proteins are involved in CD14-dependent activation of endothelial cells in the presence of serum. For monocytes, LBP and 'septin' have been identified as serum-components which enhance CD14 mediated LPS activation $(5,6,10)$. The fact that the LPS. induced response of endothelial cells in presence of serum is much stronger compared to in serum-free conditions, clearly indicates that serum factors such as LBP participate in this process. The experiments addressing the questions mentioned above are currently being addressed in our laboratory.

\section{References}

1 Schleimer R.P. \& Rutledge B.K. (1986) Cultured human vascular endothelialcells acquire adhesiveness for neutrophils after stimulation with interleukin 1 . endotoxin, and tumor-producing phorbol diesters. J. Immunol. 136, 649.

2 Bevilacqua M.P., Pober J.S., Mendrick D.L., Cotran R.S. \& Gimbrone M.A.(1987) Identification of an inducible endothelial-leukocytc adhesion molecule. Proc. natl Acad. Sci. USA, 84, 9238.

3 May L.T., Torcia G., Cozzolino F., Ray A., Tatter S.B. Santhanam U., Sehgal P.B. \& Stern D. (1989) Interleukin-6 gene expression in human endothelialcells; RNA stant sites, multiple IL-6 proteins and inhibition of proliferation. Biochem. Biophys. Res. Comm. 159, 991.

4 Loppnow H. \& Libby P. (1989) Human endothelial cells express the IL-6gene in response to interleukin 1 and bacterial LPS. Cefl Immunol. 122, 493.

5 Wright S.D., Ramos R.A., Tobias P.S., Ulevitch R.J. \& Matbison J.C. (1990)CD 14, a receptor for conplexes of lipopolysaccharide: (LPS) and LPS binding protein. Science, 249, 1431.

6 Heumann D., Gallay P., Barras C., Zaech P., Ulevitch R.J., Tohias P.S., Glauser M-P. \& Baumgartner J.D. (1991) Control of lipopolysaccharide (LPS)binding and LPS-induced tumor necrosis factor secretion in human peripheral blood monocytes. J. ImmunoL 148, 3505 .

7 Dentener M.A., Bazil V., von Asmuth E.J.U., Ceska M. \& Buurman W.A. (1993) Involvement of CD14 in lipopolysaccharide induced tumor necrosis factor- $\alpha$. interleukin- 6 and interleukin-8 release by human monocytes and alveolar macrophages. J. Immunol. 150, 2885 .

8 Lynn W.A., Raetz C.R.H., Qureshi N. \& Golenbock D.T. (1991) Lipopolysaccharide-induced stimulation of CD1 Ib/CD18 expression on ncutrophils. Evidence of specific receptor-based response and inhibition by lipid A-based antagonists. J. ImmunoL 147, 3072.

9 Wright S.D., Ramos R.A., Hermanowski-Yosalka A. Rockwell P. \& DetmersP.A. (1991) Activation of the adhesive capacity of $\mathrm{CR} 3$ on neutrophils by endotoxin: dependence on lipopolysaccharide binding protein and CD14.J. Exp.Med. 173, 1281

10 Wright S.D., Ramos R.A., Patel M. \& Miller D.S. (1992) Septin: a factor inplasma that opsonizes lipo- 
polysaccharide-bearing particles for recognition by CD14 on phagocytes. J. Exp. Med. I76, 719.

11 Lee J.-D., Kato K., Tobias P.S., Kirkland T.N. \& Ulevitch R.J. (1992)Transfection of CD14 into 70Z/3 cells dramatically enhances the sensitivity to complexes of lipopolysaccharide (LPS) and LPS binding protein. J. Exp. Med.175, 1697.

12 Kitchens R.L., Uleviteh R.J. \& Munford R.S. (1992) Lipopolysaccharide(LPS) partial structures inhibit responses to LPS in a human macrophage cell line without inhibiting LPS uptake by a CD14-mediated pathway. J. Exp. Med.176, 485.

13 Haziot A., Chan S., Ferrero E., Low M.G., Silber R. \& Goyert S.M. (1988) The monocyte differentiation antigen, CDI4, is anchored to the cell membrane by a phosphatidyl-inositol linkage. J. ImmunoL 14I, 547.

14 Simmons D.L., Tan S., Tenen D.G., Nicholson-Weller A. \& Seed B. (1989) Monocyte antigen CDI4 is a phospholipid anchored membrane protein. Blood, 73, 284.

15 VanVoorhis W.C., Steinman R.M., Hair L.S., Luban J., Witmer M.D., Koide S. \& Cohn Z.A. (1983) Specific antimononuclear phagocyte monoclonalantibodies. Application to the purification of dendritic cells and the tissue localization of macrophages. $J$. Exp. Med. 158, 126.

16 McMichael A. (1987) Leucocyle Typing III. White cell differentiation antigens, p. 572. Oxford University Press, Oxford.

17 Ziegler-Heitbrock W., Passlick B. \& Flieger D. (1988) The monoclonalantibody MY4 stains B lymphocytes and two distinct monocyte subsets in human peripheral blood. Hybridoma, 7, 521 .

18 Labeta M.O., Landmann R., Obrecht J.P. \& Obrist R (1991) Human B-cells express membrane-bound and soluble forms of CD14 myeloid antigen. Mol ImmunoL 289, III.

19 Hogg N., MacDonald S., Slusarenko M. \& Beverly P.C.L. (1984) Monoclonal antibodies specific for human monocytes, granulocytes and endothelium. Immunol 53, 753.

20 Medeiros L.J., Herrington R.D., Gonzules C.I., Jaffe E.S. \& Cossman J.(1991) My4 antibody staining of non-Hodgkin lymphomas. Am, J. Clin. Pathol95, 363.

21 Bogman MJJ.T., Dooper I.M.M., van de Winkel J.G.J., Tax W.J.M.,Hoitsma A.J., Assmann K.J.M., Ruiter D.J. \& Kocne R.A.P. (1989) Diagnosisof renal a)lograft rejection by macrophage immunostaining with a CD14 monxional antibody, WT14. Lancet, $\ddot{i}$, 235.

22 Bazil, V., Horejsi, V., Buudys, M., Kristofová, H., Strominger, J. L., Kostka, W. \& Hilger, I. (1986) Biochemical characterization of a soluble form of the $53-k D$ a monocyle surface antigen. Eur. J. ImmunoL 16, 1583.

23 Goyen S.M. Tesio L. et al. (1989) Leucocyte Typing IV. White cell differentiation antigens. p. 789. Oxford University Press, Oxford.

24 Muller W.A., Ratti C.M., McDonnall S.I. \& Cohn Z.A. (1989) A humanendothelial cell-restricted. extemally disposed plasmalemmal protein enriched in intercellular junctions. J. E.xp. Med. 170, 399.

25 Leeuwenberg J.F.M., Jeunhomme G.M.A.A. \& Buurman W.A. (1990) Characterization of two monoclonal antibodies directed against an adhesion molecule on endothelial cells. Transplant. Proc., 22, 1991.

26 Leeuwenberg J.F.M., von Asmuth E.J.U., Jeunhomme T.M.A.A \& Buurman W.A. (1990) IFN-y reg. ulates the expression of the adhesion molecule ELAM- 1 and II 6 production by human endochelial cells in vitro. J. Immunol, 145, 2110.

27 Sambroook J., Fritsch E.F. \& Maniatis T. (1989) Molecular Cloning. p 7.10. Cold Spring Harbor Laboratory Press. New York.

28 Sambroook J., Fritsch E.F. \& Maniatis T. (1989)) Molecular Cloning. p 7.52.Cold Spring Harbor Laboratory Press, New York.

29 von Asmuth E.J.U., Leeuwenberg J.F.M., Ceska M. \& Buurman W.A. (1991) LPS and cytokine-induced endothelial cell IL-6 release and ELAM-1 expression; involvement of serum. Eur. Cytokine NeL 2, 291.

30 Frey, E.A., Miller, D.S., Gullstein Jahr T., Sundan A. Bazil V., Espevik, T., Fulay B.B. \& Wright S.D. (1992) Soluble CD14 participates in the response ofcells to lipopolysaccharide. J. Exp. Med. 176, 1665.

31 Kriger C., Schütt C., Obertacke U., Joka T., Müller F.E., Knöller J., Köller M., König W. \& Schönfeld W. (1991) Serum CDi4 levels in polytraumatizedand severely burned patients. Clin. Exp. Immunol. 85, 297. 


\title{
TUMOUR NECROSIS FACTOR- $\alpha$ INDUCES NEUTROPHIL MEDIATED INJURY OF CULTURED HUMAN ENDOTHELIAL CELLS
}

\author{
E.J.U. VON ASMUTH, J.F.M. LEEUWENBERG, C.J. VAN DER LINDEN, \\ W.A. BUURMAN.
}

Scand. J. ImmunoL 1991, 34: 197-206

\section{Summary}

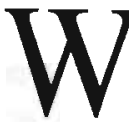

$\mathrm{e}$ investigated the ability of TNF- $\alpha$ to mediate damage of endothelial cells in presence of neutrophils, by measuring detachment of cultured human umbilical vein endothelial cells (HUVEC). Endothelial cell detachment was increased from 5\% to about $75 \%$ by presence of 1 to $10 \mathrm{ng} / \mathrm{ml}$ TNF- $\alpha$ during incubation with neutrophils, whereas negligible endothelial cell lysis was observed as measured by ${ }^{51} \mathrm{Cr}$ release. TNF- $\alpha$ was compared with the cytokines IL- $1 \alpha$ and IFN- $\gamma$ and with PMA and LPS. Both TNF- $\alpha$ and PMA appeared to be strong triggers for neutrophil induced endothelial cell detachment, whilst reduced injury was seen after addition of IL-1 $\alpha$ and LPS. IFN- $\gamma$ did not induce endothelial cell detachment, but potentiated the effect of both TNF- $\alpha$ and IL-1 $\alpha$. TNF- $\alpha$ induced endothelial cell detachment was neutrophil dependent, since preincubation of neutrophils, but not preincubation of endothelial cells with TNF- $\alpha$, caused endothelial cell detachment. Thus, TNF- $\alpha$ induced increase in neutrophil-adhesiveness of HUVEC was found not to be essential for endothelial damage. Preincubation of neutrophils in suspension with TNF- $\alpha$, induced rapid activation, followed by nearly complete deactivation of neutrophils, as measured by their capacity to induce detachment of endothelial cells after removal of TNFF- $\alpha$.

These results indicate, that local presence of TNF- $\alpha$ might be critical in tissue or organ damage during early, neutrophil mediated inflammatory processes, independent of enhanced adhesiveness of endothelium for neutrophils. 


\section{Introduction}

$\mathrm{N}$ eutrophil infiltration is a general pathophysiological finding in early inflammatory tissue or organ damage. Local release of TNF- $\alpha$, together with other cytokines such as IL- 1 and IFN- $\gamma$, can be incited by microbial products, as well as by nonspecific stress, resulting from short term ischaemia during organ transplantation procedures, vascular surgery, or severe circulatory shock $(1,2)$. These cytokines can induce several pro-inflammatory events in the interaction between neutrophils and endothelium (reviewed in 3 ).

Endothelial cells respond to TNF- $\alpha$ and IL-1 with increased and de novo expression of the adhesion molecules ICAM-1 and ELAM-1 (4-6) leading to increased neutrophil adherence and rapid neutrophil transmigration (7, 8). Simultaneously neutrophils can be activated directly by TNF- $\alpha$ and IL-1 (9-13), and indirectly via the release of IL-6 $(14,15)$, IL8 (16), GM-CSF $(11,17,18)$ and platelet activating factor (PAF) $(19,20)$ by endothelial cells upon TNF- $\alpha$ and IL- 1 stimulation. Whether neutrophil-endothelial interaction in presence of TNF- $\alpha$ or other cytokines induces direct damage to endothelial cells. still has to be revealed.

Prolonged exposure to TNF- $\alpha$ or $\Pi-1 \alpha$ is not directly cytotoxic for endothelial cells cultured in vitro $(21,22)$. However, local endothelial cell damage can be incited in experimental animals by local TNF- $\alpha$ plus IL- $1 \alpha$ administration during the Shwartzman reaction (23) and by systemic TNF- $\alpha$ addition after previous methylcholanthrene induced tumor growth (24). Prolonged continuous subcutaneous perfusion of high amounts of TNF- $\alpha$ in mice, can induce local necrosis (25). Tissue and endothelial cell damage, observed in these experiments, is accompanied by local accumulation of neutrophils. These cells are considered to play an important role in endothelial cell damage.

The aim of this study was to investigate the role of TNF- $\alpha$ in neutrophil induced endothelial cell damage in vitro. Capacities of TNF- $\alpha$, compared to IL- $1 \alpha$, IFN- $\gamma$, LPS, and PMA, in inducing neutrophil mediated injury of HUVEC, were determined. Furthermore, we demonstrated that preincubating of neutrophils, but not preincubation of endothelial cells with TNF- $\alpha$, increases endothelial cell damage.

\section{Materials and Methods}

\section{Reagents}

Recombinant ( $\mathrm{s}$ ) human (h) TNF- $\alpha$ was kindly provided by BASF/Knoll Ag. (Ludwigshafen FRG). rhIL- $1 \alpha$ was a kind gift of Dr. S. Gillis, Immunex, Seattle, WA. rhIFN$\gamma$ (E. Coli derived) was a gift from Dr. P. Van der Meide, TNO, Rijswijk, The Netherlands. LPS (E. Coli derived) and PMA were purchased from Sigma (St. Louis, MO).

\section{Cells}

HUVEC were obtained by collagenase treatment of the human umbilical vein. The cells were cultured in fibronectin-coated (fibronectin kindly provided by Dr. J. van Mourik. CLB, Amsterdam, The Netherlands) tissue culture flasks (Costar, Cambridge, MA) in RPMI1640 (Gibco Europe, Paisley, Scotland), supplemented with $10 \%$ heat-inactivated human serum, $10 \%$ heat-inactivated bovine calf serum (BCS) (Hyclone, Logan, $\mathrm{UT}$ ), $50 \mu \mathrm{g} / \mathrm{ml}$ heparin (Sigma), 30 $\mathrm{g} / \mathrm{ml}$ endothelial growth supplement (Collabora- 
tive Research Incorporated, Bedford, MA) and antibiotics. Endothelial cells were characterized by their pavement-like monolayer morphology, by positive staining with Mab hec7 directed against PECAM-1 (26), generously provided by Dr. W.A. Muller, Rockefeller University, NY, and by positive staining with the anti ELAM-1 Mab ENA2 (27) after $4 \mathrm{~h}$ incubation with TNF- $\alpha$.

Neutrophil leukocytes were prepared from bulfy coats of donor blood kindly provided by the local blood bank, using standard techniques of buoyant density centrifugation on Lymphoprep (Nycomed, Oslo, Norway). Neutrophils were separated from erythrocytes by density gradient centrifugation on percoll $(1.08 \mathrm{~g} / \mathrm{ml}$, Pharmacia, Uppsala, Sweden). Preparations of neutrophils were $>95 \%$ pure, as evaluated after May Grunwald Giemsa staining.

Preincubation of neutrophils with TNF- $\alpha$ was performed by incubating neutrophils in polypropylene tubes at $10^{7} \mathrm{cells} / \mathrm{ml}$ in RPMI 1640 10\%BCS with $10 \mathrm{ng} / \mathrm{ml}$ TNF- $\alpha$ for the time-interval indicated. Subsequently neutrophils were rinsed twice with ice-cold RPMI $16401 \% \mathrm{BCS}$, and added to the monolayers. Control cells were kept at $4^{\circ} \mathrm{C}$ during this period.

To determine cell-loss by the preincubationprocedure, tubes were incubated with EDTAcontaining lavage-medium for an additional 10 minutes at $37^{\circ} \mathrm{C}$, to detach remaining adherent neutrophils. Neutrophil-loss was determined separately for each tube, by measuring total cell-numbers in pooled wastc-media and lavage-medium, and never exceeded $10 \%$.

\section{Injury assays}

${ }^{51} \mathrm{Cr}$-release and detachment assays were performed essentially as described by Harlan et al. (28). HUVEC (passage 3 ) were grown to confluence during $24 \mathrm{~h}$ in fibronectin-coated 96-well, flat bottom, microtiter plates (Costar). Final plating density was $\pm 2 * 10^{4}$ cells/well (well-surface: $0.32 \mathrm{~cm}^{2}$ ) The last $16 \mathrm{~h}$ of this culture Chromium-5l as sodium $\left[{ }^{5 i} \mathrm{Cr}\right]$ chromate was added to the wells $(18 \mathrm{kBq} /$ well, specific activity $11 \mathrm{~GB} q / \mu \mathrm{g} \mathrm{Cr}$ ). At the beginning of the assay monolayers were carefully washed by five successive exchanges of $200 \mu 1 /$ well RPMI $16401 \%$ BCS.

Neutrophils and reagents in RPMI1640 supplemented with $10 \% \mathrm{BCS}$ were added to the monolayer as indicated, at a final volume of $200 \mu \mathrm{l} /$ well, and incubations were performed at $37^{\circ} \mathrm{C}$ for $3 \mathrm{~h}$, unless mentioned otherwise. Endothelial cell lysis was determined by measuring ${ }^{{ }^{5 i} \mathrm{Cr}}$ release in $100 \mu \mathrm{l}$ cell-free supernatant medium, removed from each well with care not to disturb the monolayer. Next, $100 \mu \mathrm{l}$ of fresh medium was added to the remaining $100 \mu \mathrm{l}$ in each well. Detached endothelial cells were suspended by repeated careful pipetting, and $100 \mu \mathrm{l}$ of this suspension was removed to determine detachment (these samples thus contained 50\% of the amount of ${ }^{51} \mathrm{Cr}$ in the lysis samples, plus the ${ }^{51} \mathrm{Cr}$ present in the detached cells).

Control monolayers remained visually confluent after performing this procedure. Maximal ${ }^{31} \mathrm{Cr}$ content was determined in wells receiving $100 \mu \mathrm{l}$ of $1 \mathrm{~N} \mathrm{NaOH}$, and reached about $10^{5} \mathrm{dpm}$. All samples were counted in a gamma-spectrophotometer.

Detachment values were calculated by subtracting half of the ${ }^{5 i} \mathrm{Cr}$ counts measured in the lysis samples drawn from the same wells, 
A

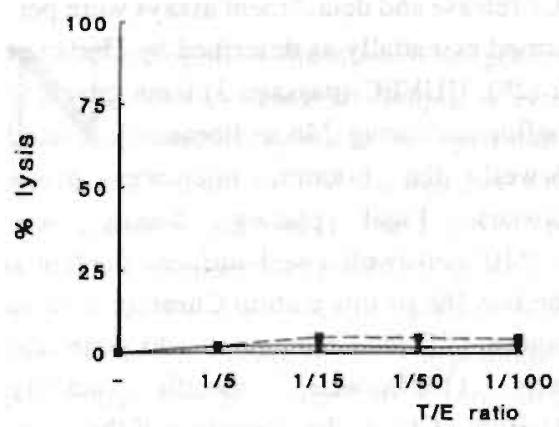

B

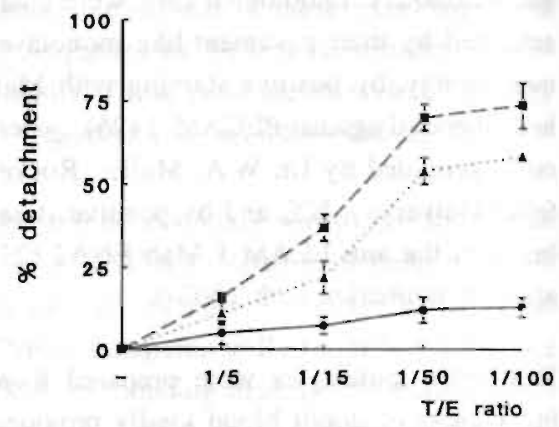

Fig. 1. Neutrophil mediated HUVEC lysis (A) and HUVEC detachment (B), induced by $10 \mathrm{ng} / \mathrm{ml} T \mathrm{TNF}-\alpha$ (D), 50ng/ml PMA (A), or without stimulation (-), at different T/E ratios. HUVEC injury was measured after $3 \mathrm{~h}$ of incubation in presence of effector-cells and agents. A representative experiment out of a series of 4 is shown. Data indicate mean $\pm S D$ of four measurements.

from the ${ }^{51} \mathrm{Cr}$ counts measured in the detachment samples. Furthermore, measurements of endothelial cell lysis and endothelial cell detachment were corrected for non-specific ${ }^{51} \mathrm{Cr}$ content, by subtracting ${ }^{51} \mathrm{Cr}$ counts measured in lysis/detachment samples from wells without effector cells (in these wells spontaneous ${ }^{51} \mathrm{Cr}$ release and endothelial cell detachment ranged from 5 to $10 \%$ of total ${ }^{51} \mathrm{Cr}$ content).

\section{Results}

Effect of TNF- $\alpha$ and PMA on neutrophil induced endothelial cell injury

Neutrophils were analyzed for their capacity to induce lytic injury or non-lytic detachment of HUVEC. Neither presence of TNF$\alpha$ nor presence of PMA during a $3 \mathrm{~h}$ assay at $37^{\circ} \mathrm{C}$ in medium containing $10 \% \mathrm{BCS}$, induced substantial endothelial cell lysis in presence of neutrophils, as measured by ${ }^{51} \mathrm{Cr}$ release from HUVEC (Fig. IA). In our hands, substantial short term endothelial cell lysis only occurred by using IL-2 cultured lymphocytes as effector cells, or by performing the assay in absence of serum (and presence of $0.5 \% \mathrm{BSA}$ ) (data not shown).

To determine the capacity of neutrophils to affect endothelial cell monolayer integrity, we measured detachment of endothelial cells from HUVEC monolayers, after applying mild shear stress by repeated pipette suction, as a parameter for early cell damage (18). Unstimulated neutrophils induced a minor increase in endothelial cell detachment. Both TNF- $\alpha$ and PMA induced a clear target effector (T/E) ratio dependent increase in endothelial cell detachment, which leveled off at a $T / E$ ratio of $1 / 50$, reaching $74 \%$ and $58 \%$ detachment in presence of respectively 10 ng/ml TNF- $\alpha$ and 50ng/ml PMA (Fig. IB). Next, detachment was measured after different time-intervals, at a T/E ratio of 1/50. TNF- $\alpha$ caused a rapid increase in endothelial cell detachment, which did not increase further after $2 \mathrm{~h}$ (Fig. 2). PMA, was maximal effective in triggering detachment at a con- 


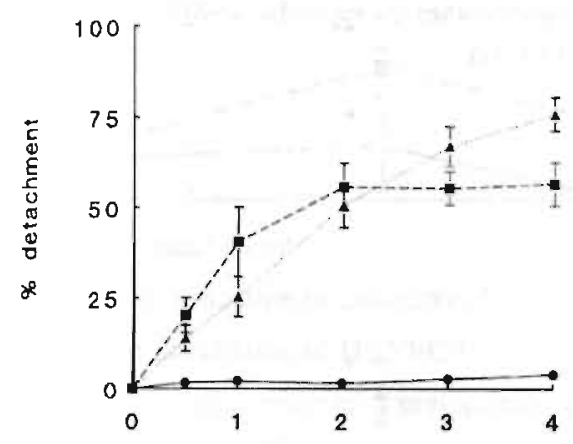

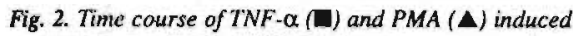
neutrophil mediated HUVEC-danage, compared to detachment induced by unstimulated neutrophils (O). Neutrophils were added to HUVEC-monolayers (T/E = (150), and incubated together with the stimulus for the time-interval mentioned.

A representarive experiment out of a series of 3 is shown. Data indicate mean $\pm S D$ of 4 measurements. centration between 5 and $50 \mathrm{ng} / \mathrm{ml}$ (data not shown), and induced a continuous increase in endothelial cell detachment over the first $4 \mathrm{~h}$ (Fig. 2).

Comparison of the cytokines TNF- $\alpha, I L-I \alpha$ and IFN- $\gamma$, and of LPS on neutrophil mediated endothelial cell damage

Several concentrations of known neutrophil activating agents were tested for their influence on neutrophil mediated endothelial cell detachment after 3 h of coincubation (Fig. 3). TNF- $\alpha$ induced maximal endothelial cell detachment at a concentration of $10 \mathrm{ng} / \mathrm{ml}$, but showed already a clear effect at $100 \mathrm{pg} / \mathrm{ml}$. IL- $\mathrm{L} \alpha$, in a range of $10-1000 \mathrm{u} / \mathrm{ml}$, induced endothelial cell detachment, although lower
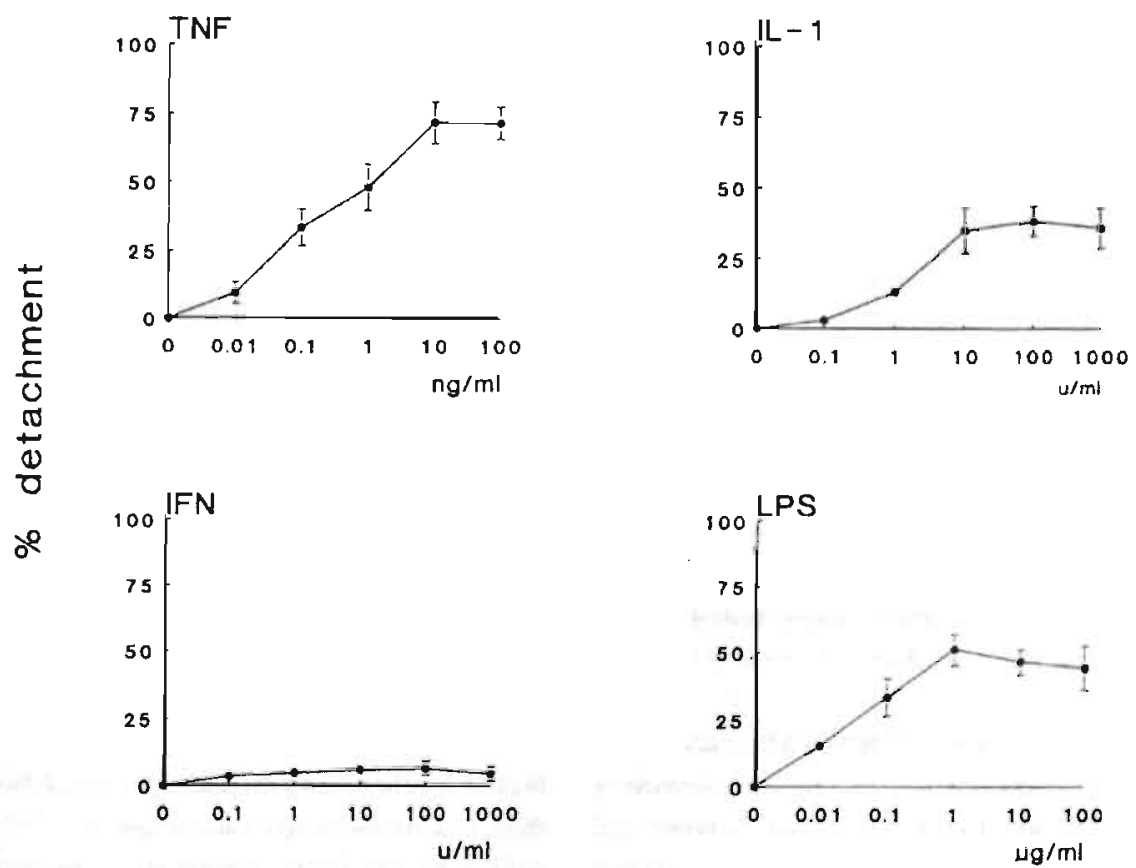

Fig. 3. Effects of TNF- $\alpha, L-l \alpha, I F N-\gamma$, and LPS on neurrophil mediated HUVEC-detachment. Neutrophils $(T / E=1 / 50)$ were added together with the agents to the assay. Cells were coincubated for $3 \mathrm{~h}$ at $37^{\circ} \mathrm{C}$. A representative experiment out of series of 3 is shown. Data indicate mean $\pm S D$ of 4 measurements. 


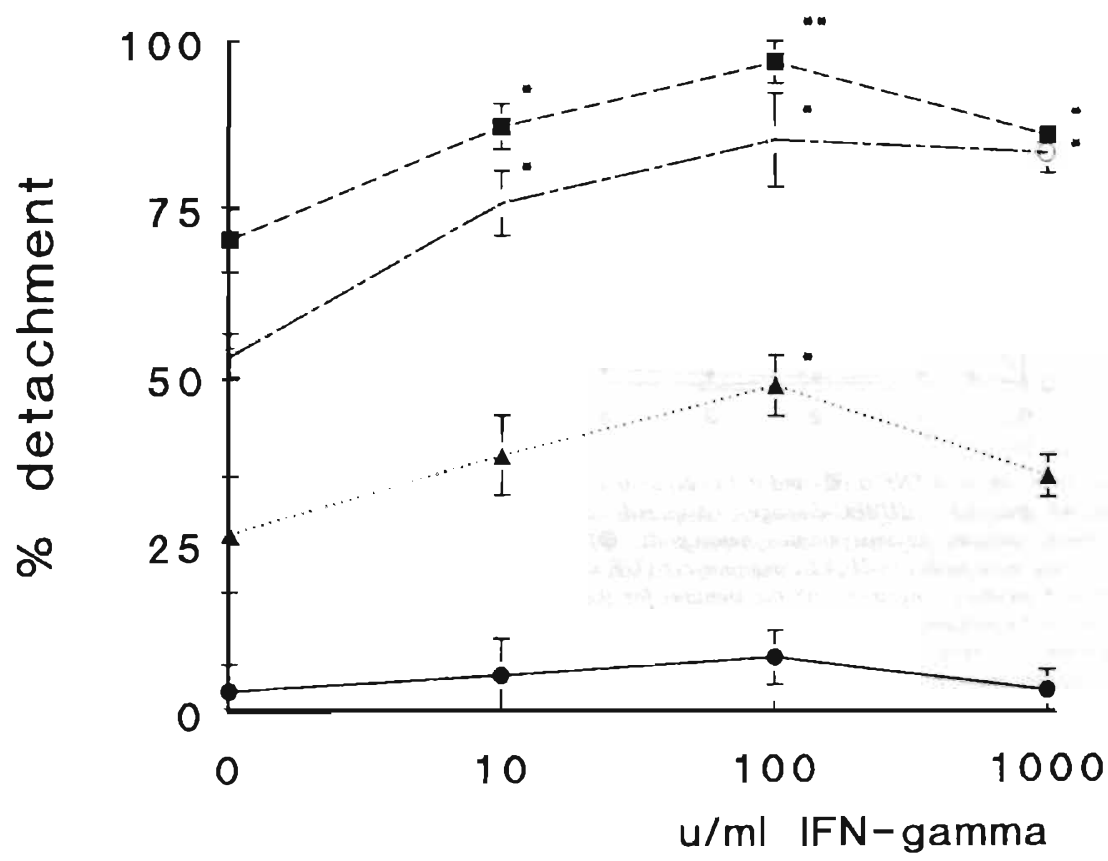

Fig. 4. Effects of combined addition of cytokines on neutrophil mediated HUVEC-detachment. Neutrophils (T/E $=I / S 0)$ were added together with cytokines and incubated for $3 \mathrm{~h}$ at $37^{\circ} \mathrm{C}$.

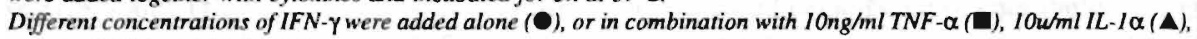
or both $T N F-\alpha$ and $I L-/ \alpha(O)$.

A representative experiment out of a series of 3 is shown. Data indicate mean $\pm S D$ of 4 measurements.

${ }^{*} p<0.05$ and ${ }^{* *} p<0.01$ when compared to endothelial cell detachment under identical conditions, in absence of IFN$\gamma$. as determined by the unpaired one-tailed Student's t-lest.

values were reached as with TNF- $\alpha$. IFN- $\gamma$ failed to cause a clear increase in endothelial cell damage. LPS induced about $50 \%$ endothelial cell detachment, when added at concentrations higher than $100 \mathrm{ng} / \mathrm{ml}$ (Fig. 3).

Since the cytokines IFN- $\gamma$, TNF- $\alpha$ and IL- $1 \alpha$ are expected to be produced simultaneously in vivo, we studied the effect of combined administration of these cytokines. IFN- $\gamma$ showed a moderate potentiating effect on IL- $\alpha$ and/or TNF- $\alpha$, when present in con- centrations of 10,100 or $1000 \mathrm{u} / \mathrm{ml}$ (Fig. 4). Combined addition of $10 \mathrm{ng} / \mathrm{ml}$ TNF- $\alpha$ and $100 \mathrm{u} / \mathrm{ml} \mathrm{IFN}-\gamma$ resulted in nearly complete disruption of the HUVEC monolayer. IL-1 $\alpha$ and TNF- $\alpha$ did not prove to have a synergistic effect on endothelial cell damage (Fig. 4). Combining TNF- $\alpha$ with LPS did not induce higher levels of endothelial cell detachment than TNF- $\alpha$ alone (data not shown).

Addition of heat-inactivated $(10 \mathrm{~min}$ at $\left.100^{\circ} \mathrm{C}\right)$ TNF- $\alpha, \mathrm{IL}-1 \alpha$ and IFN- $\gamma$, did not increase neutrophil mediated endothelial cell 
Table 1. Effects of separate incubations with $10 \mathrm{ng} / \mathrm{ml}$ TNF- $\alpha$ on neutrophil induced HUVEC detachment

\begin{tabular}{|c|c|c|c|c|}
\hline & Exp. 1 & Exp. 2 & Exp. 3 & Exp. 4 \\
\hline TNF- $\alpha$ coincubation ${ }^{\text {a) }}$ & $79 \pm 9$ & $63 \pm 5$ & $84 \pm 5$ & $81 \pm 4$ \\
\hline TNF- $\alpha$ preincubation of neutrophils ${ }^{b)}$ & $74 \pm 2$ & $66 \pm 6$ & $74 \pm 9$ & $75 \pm 8$ \\
\hline TNF- $\alpha$ preincubation of HUVEC ${ }^{c)}$ & $3 \pm 2$ & $-4 \pm 4$ & $9 \pm 4$ & $11 \pm 6$ \\
\hline "(e) plus neutrophil preincubation ${ }^{\text {b) }}$ & $53 \pm 4$ & $71 \pm 8$ & $75 \pm 12$ & $69 \pm 7$ \\
\hline$"{ }^{c}$ plus TNF- $\alpha$ coincubation ${ }^{a)}$ & $59 \pm 5$ & n.t. & n.t. & n.t. \\
\hline
\end{tabular}

HUVEC detachment was measured after 3 h incubation with neutrophils (T/E $=1 / 50$ ) at $37^{\circ} \mathrm{C}$. Data indicated mean \pm S.D. of the percentage detached endothelial cells, of 4 measurements.

a) $10 \mathrm{ng} / \mathrm{ml}$ TNF- $\alpha$ was presen during the assay. b) Neutrophils were incubated with $10 \mathrm{ng} / \mathrm{ml} \mathrm{TNF}$ - $\alpha$ for $30 \mathrm{~min}$ at $4^{\circ} \mathrm{C}$, rinsed twice and added to the HUVEC-monolayers. $\varepsilon$ ) TNF-a preincubation of HUVEC-monolayers was performed by adding TNF- $\alpha$ in a small volume to the HUVEC during the last 4 h of culture with " $\mathrm{Cr}$.

detachment (data not shown), indicating that the effects of the cytokine-preparations were not due to endotoxin contamination.

\section{Characterization of TNF- $\alpha$ induced endo- thelial cell detachment.}

To investigate whether TNF- $\alpha$ induces its effect mainly by a direct activation of neutrophils, or by modulating the endothelial cell monolayer, we stimulated either neutrophils or endothelial cells, before performing the endothelial cell damage assay under standard conditions ( $3 \mathrm{~h}$ incubation, $\mathrm{T} / \mathrm{E}=1 / 50$ ). The results of 4 independent experiments are shown in Table 1.

Addition of neutrophils, preincubated with $10 \mathrm{ng} / \mathrm{ml}$ TNF- $\alpha$ for $30 \mathrm{~min}$ at $4^{\circ} \mathrm{C}$, induced detachment levels similar to levels measured after coincubation of neutrophils and TNF- $\alpha$ during the assay. Next, the endothelial cells were incubated for $4 \mathrm{~h}$ with $10 \mathrm{ng} / \mathrm{ml}$ TNF- $\alpha$ to acquire maximal neutrophil-adhesiveness via the induction of ELAM-1 $(4,6)$.
Expression of ELAM-1 was confirmed in parallel-microtiter plates in an ELISA using ELAM-1 specific Mab as reported (27) (data not given). TNF- $\alpha$ preincubation of HUVEC increased neutrophil adhesion from 8-19\% to $51-71 \%$, as measured in a parallel adhesion assay, as described (29) (data not shown). Endothelial cell detachment, after incubation TNF-activated endothelium with unstimulated neutrophils for $3 \mathrm{~h}$, was not increased above background by this treatment (Table I). Moreover, TNF-activated endothelium did not appear to be more vulnerable to, or to trigger additional injury by TNF- $\alpha$-activated neutrophils (Table 1).

Since neutrophil mediated endothelial cell detachment in presence of TNF- $\alpha$ appeared to depend on direct activation of neutrophils by TNF- $\alpha$, we investigated kinetics and conditions of neutrophil activation by $\mathrm{TNF}^{-}-\alpha$. Preincubation of neutrophils with $10 \mathrm{ng} / \mathrm{ml}$ TNF- $\alpha$ at $37^{\circ} \mathrm{C}$ under non-adherent condi- 


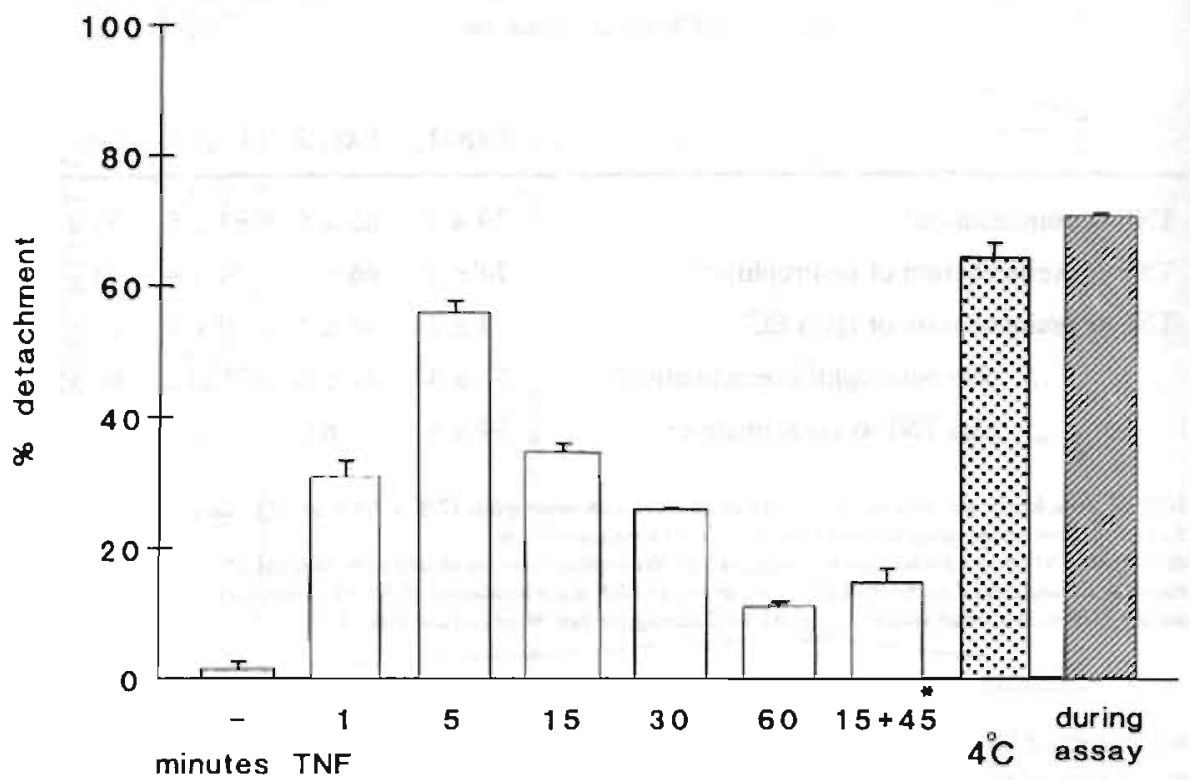

Fig. 5. Effect of neutrophil preincubation with TNF- $\alpha$ for different times at $37^{\circ} \mathrm{C}$ (open bars), compared to neutrophil preincubation for 60 min at $4^{\circ} C$ (doned bar), and to TNF- $\alpha$ presence during the assay (hatched bar), on HUVEC-detachment. TNF-cs was used at $10 \mathrm{ng} / \mathrm{ml}$. Neutrophil preincubation were performed as mentioned in Materials and methods. HUVEC-detachment was measured after 3 h incubation with neutrophils $(T / E=1 / 50)$ at $37^{\circ} \mathrm{C}$. A representative experiment out of a series of 4 is shown. Data indicate mean $\pm S D$ of 6 measurements.

* Neutrophils were incubated with TNF- $\alpha$ for $15 \mathrm{~min}$ at $37^{\circ} \mathrm{C}$, rinsed, and incubated in absence of stimulus for another 45 min ar $37^{\circ} \mathrm{C}$

tions, showed to induce a rapid activation, followed by a nearly complete deactivation of neutrophils, as measured by their capacity to induce subsequent endothelial cell detachment (Fig. 5).

Maximal activation of neutrophils was reached after $5 \mathrm{~min}$, and was similar to activation induced by $60 \mathrm{~min}$ of preincubation with TNF- $\alpha$ at $4^{\circ} \mathrm{C}$. or to activation of neutrophils by presence of TNF- $\alpha$ during the assay (Fig. 5). Preincubation of neutrophils in absence of stimulus for $60 \mathrm{~min}$ at $37^{\circ} \mathrm{C}$ did not diminish their response on TNF- $\alpha$ during the assay, as compared to neutrophils kept at $4^{\circ} \mathrm{C}$ for $60 \mathrm{~min}$ (data not given).

The decrease in neutrophil activation, measured after prolonged preincubation with TNF- $\alpha$ at $37^{\circ} \mathrm{C}$, did not depend on continuous presence of TNF- $\alpha$, since $60 \mathrm{~min}$ TNFactivated neutrophils showed a reduced capacity to detach endothelial cells, independent of whether they where continuously incubated with TNF- $\alpha$, or rinsed after $15 \mathrm{~min}$ and incubated further for $45 \mathrm{~min}$ at $37^{\circ} \mathrm{C}$ in absence of TNF- $\alpha$ (Fig. 5). 


\section{Discussion}

In this study we demonstrated that the cytokines TNF- $\alpha$ and IL- $1 \alpha$, and LPS can induce endothelial cell detachment in presence of neutrophils. It appeared that also PMA induced high levels of endothelial cell detachment, which is in concordance with previous reports $(30,31)$. The cytokine IFN- $\gamma$ did not induce significant endothelial cell detachment, but enhanced moderately TNF- $\alpha$ or IL- $1 \alpha$ induced activation.

This enhancing effect of IFN- $\gamma$ may explain the contribution of IFN- $\gamma$ in the elicitation of the Shwartzman reaction and the concomitantly occurring endothelial damage, as described by Billiau et al. (32).

Recent reports described a s similar enhancing effect of IFN- $\gamma$ on TNF- $\alpha$ and IL- 1 induced ELAM-1 expression by endothelial cells, as well as on IL- 6 release by endothelial cells $(15,33,34)$.

We investigated the effect of 4 hour preincubation of endothelial cells with TNF- $\alpha$ on subsequent neutrophil mediated endothelial cell injury. Endothelial cell detachment, mediated by either untreated or TNF-activated neutrophils was not increased by this treatment, although these monolayers showed highly increased adhesiveness for neutrophils. Other data support the hypothesis that the function of endothelial responses on treatment with TNF- $\alpha$, such as expression of adhesion molecules, is limited mainly to leukocyte-adhesion instead of triggering leukocytes to induce direct local damage.

A recent study by Mier et al. (35) showed that TNF- $\alpha$ preincubation of endothelium diminished LAK-cell induced endothelial cell lysis and endothelial cell monolayer permeability, although TNF- $\alpha$ preincubation of endothelial cells enhanced LAK-cell adhesion. Additionally, TNF- $\alpha$ preincubation of endothelium did not result in activation of neutrophils, placed on such endothelium, since no influence on elastase release or respiratory burst activity could be measured (36).

On the other hand, previous reports of Varani et al. (37) and Gibbs et al. (36) stated that respectively 4 to $18 \mathrm{~h}$ preincubation of endothelium with TNF- $\alpha$, increased their vulnerability to PMA or C5a activated neutrophils. The increase of neutrophil induced endothelial cell monolayer permeability induced by TNF- $\alpha$ pretreatment reported by Gibbs et al was, however, rather small, and only significant at higher TNF- $\alpha$ concentrations.

Results of Varani et al were obtained using rat pulmonary endothelial cells. In a later report of this group, they stated that such a TNF- $\alpha$ induced enhanced susceptibility for neutrophil-mediated damage was absent in endothelial cells derived from human umbilical veins (as we used here), and suggested that the two endothclial cell populations had a significant biological difference in their response to TNF- $\alpha$ (38).

We demonstrated in this study that the endothelial cell damage, induced by TNF- $\alpha$ in presence of neutrophils, depends on activation of neutrophils by TNF- $\alpha$. Neutrophils can produce two groups of products, reactive oxygen metabolites and proteases, which bothe damage endothelial cells $(28,30,39$. 41). TNF- $\alpha$ activation of neutrophils incites both production of large amounts of $\mathrm{H}_{2} \mathrm{O}_{2}$ and $\mathrm{O}_{2^{-}}$, and release of the content of primary and secondary granules of neutrophils (9-11), which thus seems in agreement with 
a role for TNF- $\alpha$ in triggering neutrophils to induce endothelial cell damage. Under the conditions described in this report, endothelial cell lysis remained negligible and damage was restricted to detachment of the cells from the substratum.

Compared to other cell-populations, such as fibroblasts $(37,42)$ and kidney-cells (43), endothelial cells are relatively vulnerable to oxidant-injury, making endothelial cell damage an early pathophysiological phenomenon in syndromes involving free radical generation (44). $\mathrm{H}_{2} \mathrm{O}_{2}$ exposure to endothelial cell in vitro, can cause a number of time and concentration dependent changes, ranging from changes in intra-cellular free $\mathrm{Ca}^{*+}$ and the release of PAF, to ATP breakdown, cell retraction, and lysis $(42,45,46)$.

In such in vitro assays in which reactive oxygen species involving endothelial cell lysis is measured, complete culture media are usually replaced by balanced salt solutions, lacking serum. Serum presence is a prerequisite for normal endothelial cell growth and function $(47,48)$, and can protects against endothelial cell lysis (38). Besides the presence of $10 \%$ bovine calf serum in our assay-medium, the source of the endothelial cells used here might also have contributed to the absence of endothelial cell lysis in our set of experiments. HUVEC show, in contrast with rat pulmonary endothelial cells (38) and cow pulmonary endothelial cells (45), increased resistance to neutrophil mediated killing. This resistance has been contributed to increased activity of glutathione-peroxidase linked mechanisms to detoxify $\mathrm{H}_{2} \mathrm{O}_{2}$ in HUVEC $(38,45)$.

We showed that prolonged incubation of suspended neutrophils with TNF- $\alpha$ at $37^{\circ} \mathrm{C}$, but not at $4^{\circ} \mathrm{C}$, led to a reduction of endothelial cell detachment induced subsequently by these neutrophils. These results are in concordance with a recent report of Schleiffenbaum et al. (12), who demonstrated that prolonged incubation with either TNF- $\alpha$, FMLP, $\mathrm{C} 5 \mathrm{a}$ and the Calcium ionophore A12357 decreases TNF- $\alpha$ binding capacity on neutrophils and abrogates the production of $\mathrm{H}_{2} \mathrm{O}_{2}$ upon subsequent TNF- $\alpha$ exposure.

Porteu et al. (49) demonstrated that such a decrease in TNF- $\alpha$ binding capacity is caused by shedding of the neutrophil TNF receptor, which occurs within $15 \mathrm{~min}$ after addition of a stimulus. No receptor-shedding was measured when neutrophil-stimulation was performed at $4^{\circ} \mathrm{C}$ and $16^{\circ} \mathrm{C}$. These in vitro findings may reflect a mechanism which prevents excessive activation of circulating neutrophils in situations of systemic cytokine challenge. Especially local presence of TNF- $\alpha$ therefore could play a crucial role in endothelial cell damage seen in acute inflammatory syndromes, like multiple organ failure during septic shock, and acute allograft rejection.

\section{References}

I. Ghezzi P, Bianchi M. Dinarello CA. et al. Hypoxia increases IL-1 and TNF production [Abstract]. Cytokines 1989;1:122.

2. Maury CPJ. Teppo AM. Rajed serum levels of cachectin/umor necrosis factor $\alpha$ in renal allograft rejection. J Exp Med 1987;166:1132.

3. Mantovani A, Dejana E. Cytokines as communication signals between leukocytes and endothelial cells. Immunol Today 1989;10:370.

4. Bevilacqua MP, Pober JS, Mendrick DL, Cotran RS, Gimeirone MA. Identification of an inducible endothelial-leukocyte adhesion molecule. Proc Nall Acad Sci USA 1987;84:9238.

5. Dustin MI. Springer TA. Lymphocyte function-associated antigen-1 (L.FA-1) interaction with intercelltlar adhesion molccule-1 (IC.AM-1) is one of at least three mechanisms for lymphocyte adhesion to cultured endothelial cells. $J$ Cel Biol 1988;107:321.

6. Leeuwenberg JFM, Jeunhomme GMAA, Buumin 
WA. Adhesion of polymorphonuclear cells to human endothelial cells. Adhesion-molecule-dependent and Fe-receptor-mediated adhesion-molecule-independent mechanisms. Clin Exp Immunol 1990;81:496.

7. Furie MB, MeHugh DD. Migration of neutrophils across endothelial monolayers is stimulated by treatment of the monolayers with interleukin-1 or tumor necrosis factor- $\alpha$. J Immunol 1989; 143:3309.

8. Moser R, Schleiffenbaum B, Groscurth P, Febr J. Interleukin 1 and tumor necrosis factor stimulate human vascular endothelial cells to promote transendothelial passage. J Clin Invest 1989;83:444.

9. Kownatzki E, Kapp A, Uhrich S. Modulation of human neutrophil granulocyte functions by recombinant tumor necrosis factor and recombinant human lymphotoxin. Promotion of adherence, inhibition of chemotactic migration and superoxide anion release from adherent cells. Clin Exp Immunol 1988; $74: 143$.

10. Nathan CF. Neutrophil activation on biological surfaces. J Clin Invesi 1987;80:1550.

11. Richter J, Andersson T, Olsson I. Effect of tumor necrosis factor and granulocyte/mactophage colonystimulating factor on neutrophil degranulation. J Immunol 1989; 142:3199.

12. Schleiffenbaum B, Fehr J. The tumor necrosis factor receptor and human neutrophil function. $J \mathbf{C l i n}$ Invest 1990;86:184,

13. Smith RJ, Speziale SJ, Bowman BJ. Properties of interleukin- 1 as a complete secretagogue for human neutrophils. Biochem Biophys Res Commun 1985; 130:1233.

14. Borish L, Rosenbaum R, Albury L, Clark S. Acrivation of neutrophils by interleukin 6. Cellular Immunol 1989;121:280.

15. Shalaby MR, Waage A, Espevik T. Cytokine regulation of interleukin 6 production by human endothelial cells. Cellular Immunol 1989;121:372.

16. Baggiolini M, Walz A. Kunkel SL. Neutrophil-activating peptide-1/interleukin 8 , a novel cytokine that activates neutrophils. J Clin Invest 1989;84:1045.

17. Broudy VC. Kaushansky K, Harlan JM, Adamson JW. Interleukin 1 stimulates endochelial cells to produce granulocyte-macrophage colony-stimulating factor and granulocyte colony stimulating factor. J Immunol 1987;139:464.

18. Weisbart RH, Kwan L, Golde DW, Gasson JC. Human GM-CSF primes neutrophils for enhanced oxidative metabolism in response to major physiological chemoattractents, Blood 1988;69:18.

19. Bussolini F, Camussi G, Baglioni C. Synthesis and release of platelet-activating factor by buman vascular endothelial cells treated with tumor necrosis factor or interlcukin 1 $\alpha$. J Biol Chem 1988; 142:11856.

20. Vercelloti GM, Yin HQ, Gustafson KS, Nelson RD, Jacob HS. Platelet-activating factor primes neutrophil responses to agonists: role in promoting neutrophil-mediated endothelial cell damage. Blood 1988; 4:1100.

21. Cavender DE, Edelbaum D, Ziff M. Endothelial cell activation induced by tumor necrosis factor and lymphotoxin. Am J Palhol 1989;134:551.
22. Stolpen AH, Guinan EC, Fiers W, Pober JS. Tumor necrosis factor and immune interferon act singly and in combination to reorganize human vascular endothelial cells. Am J Pathol 1986;123:16.

23. Movat HZ, Burrowes CE, Cybulsky MI, Dinarello CA. Acute inflammation and a Shwartzman-like reaction induced by interleukin-1 and tumor necrosis factor. Am J Pathol 1987;129:463.

24. Carswell EA, Old LJ, Kassel RL, Green S, Fiore N, Williamson B. An endotoxin-induced serum factor that causes necrosis of tumors. Proc Nall Acad Sci USA 1975;73:3666.

25. Piguet PF, Grau GE, Vassalli P. Subcutaneous perfusion with tumor necrosis factor induces local proliferation of fibroblasts, capillaries, and epidermal cells, or massive tissue necrosis. Am J Palhol 1990; 136:103.

26. Muller WA, Ratt CM, McDonnell SL, Cohn ZA. A human endothelial cell-restricted, externally disposed plasmalemmal protein enriched in intercellular junctions. J Exp Med 1989;170;399.

27. Leeuwenberg JFM, Jeunhomme GMAA, Buurman WA. Characterization of two monoclonal antibodies directed against an adhesion molecule on human endothelial cells. Transplant Proc 1990;22:1991.

28. Harlan IM, Killen PD, Harker LA, Striker GE. Neutrophil-mediated endothelial injury in vitro. $J \mathbf{C l i n}$ Invest 1981;68:1394.

29. Smith CW, Rothlein R. Hughes, BJ et al. Recognition of an endothelial determinant for CD18-dependent human neutrophil adherence and transendothelial migration. $J$ Clin Invest 1988;82:1746.

30. Breedveld FC, Heurkens AHM, Lafeber GJM, van Hinsbergh VWM, Cats A. Immune complexes in sera from patients with rheumatoid vasculitis induce polymorphonuclear cell-mediated injury to endothelial cells. Clin Immunol Immunopath 1989;48:202.

31. Diener AM, Beaty PG, Ochs HD, Harlan JM. The role of neutrophil membrane glycoprotein 150 (GP. 150 ) in neutrophil-mediated endothelial cell injury in vitro. J Immunol 1985; 135:537.

32. Billiau A, Heremans $H$, Vandekerckhove $F$, Dillen $C$. Anti-interferon- $\gamma$ antibody protects mice against the generalized Shwarzman reaction. Eur J Immunol 1987; 17:1851.

33. Doukas J, Pober J. IFN- $\gamma$ enhances endothelial activation induced by tumor necrosis factor bul not $\mathrm{L}-1$ J Immunol 1990;145:1727.

34. Lecuwenberg JFM. Von Asmuth EJU, Jeunhomme, TMAA. Butrman WA. IFN-Y regulates the expression of the adhesion molecule ELAM-1 and IL, 6 production by endothelial cells in vitro. $J$ Immunol 1990; 145:2110.

35. Mier JW, Brandon EP, Libby P, Janicka MW, Aronson FR. Activated endothelial cells resist lymphokine-activated killer cell-mediated injury. J Immunol $1989 ; 143: 2407$.

36. Gibbs LS, Lai L, Malik AB. Tumor necrosis factor enhances the neutrophil-dependent increase in endothelial permeability. J Cell Phys 1990;145:496.

37. Varani J, Bendelow MJ, Sealcy, et al. Tumor necrosis factor enhances susceptibility of vascular endothelial 
cells to neutrophil mediated killing. Lab Invest 1988;59:292.

38. Schuger L, Varani J, Marks RM, Kunkel SL, Johnson $\mathrm{KJ}$, Ward PA. Cytotoxicity of tumor necrosis factor- $\alpha$ for human umbilical vein endothelial cells. $L a b$ Invest 1989;61:62.

39. Weiss SJ. Tissue destruction by neutrophils. New Engl J Med 1989;320:365.

40. Varani J. Fligiel SEG, Till GO, Kunkel RG, Ryan US, Ward P. Pulmonary endothelial cell killing by human neutrophils. Lab Invest 1985;53:656.

41. Weiss SJ, Young J, LoBuglio AF, Slivka A, Nimeh NF. Role of hydrogen-peroxide in neutrophil mediated destruction of cultured endothelial cells. J Clin Invest 1981;68:714.

42. Michiels $C$, Toussaint $O$, Remacle J. Comparative study of oxygen toxicity in human fibroblasts and endothelial cells. J Cell Phys 1990;14:295.

43. Andreoli SP, McAteer JA. Reactive oxygen molecule-mediated injury in endothelial and renal tubular epithelial cells in vitro. Lab Invest 1990;38:785.

44. Webster NR, Toothill C, Cowen PN. Tissue responses to hyperoxia. Br J Anaesth 1987;59:760.

45. Vercelloti GM, Dobson M, Schorer AE. Moldow CF. Endothelial cell heterogeneity: Antioxidant profiles determine vulnerability to oxidant injury. Proc Soc Exp Biol Med 1988;187:181.

46. Varani J, Phan SH, Gibbs DF, Ryan US, Ward PA. $\mathrm{H}_{2} \mathrm{O}_{2}$-mediated cytotoxicity of rat pulmonary endothelial cells. Lab lnvest 1990;63:683.

47. Cavender DE, Edelbaum D. Inhibition by IL-1 of endothelial cell activation induced by tumor necrosis factor or lymphotoxin. J Immunol 1988; 141:3111.

48. Gimbrone Jr MA, Cotran RS, Folkman J. Human vascular endothelial cells in culture. Growth and DNA synthesis. J Cell Biol 1974;60:673.

49. Porteu $F$, Nathan $C$. Shedding of tumor necrosis factor receptors by activated human neutrophils. $J$ Exp Med 1990;172:59. 


\title{
FC $\gamma$ RECEPTOR-MEDIATED ACTIVATION OF NEUTROPHIL $\mathrm{H}_{2} \mathrm{O}_{2}$-RELEASE AND OF NEU- TROPHIL MEDIATED ENDOTHELIAL CELL DAMAGE BY A MONOCLONAL ANTIBODY AGAINST ELASTASE
}

\author{
ECKHARDT J.U. VON ASMUTH, JET F.M. LEEUWENBERG, P. LESAVRE \\ AND WIM A. BUURMAN \\ ${ }^{\prime}$ Department of Nephrology, Hopital Necker, Paris, France. \\ Submitted for publication
}

\section{Summary}

\begin{abstract}
$A$ mAb directed against human neutrophil elastase was tested for its ability to activate isolated human neutrophils. Neutrophils incubated with anti-elastase $\mathrm{mAb}$ released high amounts of $\mathrm{H}_{2} \mathrm{O}_{2}$, whilst isotype matched control mAb were ineffective. The amount of $\mathrm{H}_{2} \mathrm{O}_{2}$ release was similar to $\mathrm{H}_{2} \mathrm{O}_{2}$ release by TNF-activated neutrophils, and could not be increased by combining TNF and anti-elastase mAb. In parallel, neutrophil mediated injury of cultured human umbilical vein endothelial cell (HUVEC ${ }^{3}$ ) monolayers was measured. Anti-elastase mAb induced neutrophil mediated HUVEC detachment, although to a lesser extent than TNF. The mechanism of anti-elastase $\mathrm{mAb}$ induced neutrophil $\mathrm{H}_{2} \mathrm{O}_{2}$ release was investigated and was found to involve Fc $\gamma \mathrm{RII}$, as evidenced by inhibiting anti-elastase mAb induced neutrophil $\mathrm{H}_{2} \mathrm{O}_{2}$-release by mAb reactive with Fcy receptor II (FcyRII), and by showing that $F\left(a b^{\prime}\right)_{2}$ fragments of anti-elastase $m A b$ failed to induce neutrophil activation. Furthermore, neutrophil $\mathrm{H}_{2} \mathrm{O}_{2}$-release induced by anti-elastase mAb could be inhibited by addition of mAb reactive with CD18 and with $C D 11 \mathrm{~b}$, suggesting simultaneous involvement of the $\beta_{2}$ integrin member $C D 11 \mathrm{~b} / \mathrm{CD} 18$ in anti-elastase $\mathrm{mAb}$ induced neutrophil activation.
\end{abstract}

These data demonstrate that elastase specific antibodies can trigger neutrophil respiratory burst activity and neutrophil mediated endothelial cell damage, via $\mathrm{Fc} \gamma$ receptor and $\beta_{2}$ integrin dependent mechanisms. Anti-elastase antibodies might play a role in the pathogenesis of tissue damage in clinical auto-immune syndromes with circulating elastase reactive antibodies, such as Wegener's granulomatosis. 


\section{Introduction}

$\mathrm{P}$ resence of circulating autoantibodies against components of neutrophil to development of primary idiopathic systemic vasculitis syndromes including the granulomatosis (Wegener's granulomatosis and Churg-Strauss syndrome) and the polyarteritis group (classical polyarteritis nodosa, microscopic polyarteritis and its renallimited variant idiopathic rapidly progressive glomerulonephritis) (reviewed in 1).

Two groups of anti-neutrophil cytoplasm antibodies have been defined, based upon their characteristic staining pattern after standard indirect immunofluorescence technique on methanol-fixed neutrophils: classical or cytoplasmic ANCA (cANCA) and the perinuclear ANCA (pANCA). Elastase, a poly-cationic serine protease found in the primary granules of neutrophils, has been identified as one of the pANCA targets, together with lactoferrin and the most predominant pANCA antigen, myeloperoxidase $(2-6)$. Whether and how ANCA presence is related to the pathogenesis of systemic vasculitides, is unclear.

A number of recent data support the hypothesis that direct interaction of ANCA with neutrophils can trigger degranulation and activation of neutrophil respiratory burst activity, which might cause subsequent endothelial cell injury and trigger a cascade of pro-inflammatory and tissue-destructive events. In vitro activation of neutrophil respiratory burst activity and in some instances also degranulation has been demonstrated with isolated ANCA from patients with vasculitis (7), with $\mathrm{mAb}$ reactive with myeloperoxidase (7), and with a series of polyclonal antibody-preparations against ANCA antigens, including elastase (8). Furthermore, antibodies reactive with myeloperoxidase and proteinase 3 have been shown to increase neutrophil mediated endothelial cell damage $(9,10)$. The mechanism via which these autoantibodies trigger neutrophil activation is unclear.

In this in vitro study, we show that an antielastase $\mathrm{mAb}$ can induce the release of high amounts of $\mathrm{H}_{2} \mathrm{O}_{2}$ by isolated human neutrophils, and induce neutrophil mediated endothelial cell injury. Furthermore, we present evidence for involvement of FcrRII and of CD11b/CD18 in anti-elastase mAb induced neutrophil $\mathrm{H}_{2} \mathrm{O}_{2}$-release.

\section{Materials and Methods}

\section{Antibody preparations and reagents.}

Neutrophil reactive mAb were raised by standard hybridoma technique from spleens of mice immunized with human neutrophils. An anti-elastase $m A b$ of the $\mathrm{lgG}_{1}$ subclass, termed HM.4, was further characterized and used in this study.

Indirect immunofluorescence, performed using a modification of the method of van der Woude et al. (11), showed high and selective binding to ethanol-fixed human neutrophils with a characteristical pANCA immuno-fluorescence pattern. Selective reactivity of mAb HM.4 with human neutrophil elastase was confirmed by: 1) Binding to the elastase peak after chromatography of azurphilic granule extracts on an Orange

A Matrex column, as discribed previously (12). 2) Binding to commercial elastase, but not to lactoferrin or myeloperoxidase. 3) Fluid phase inhibition of the binding of $\mathrm{mAb}$ HM.4 to fixed neutrophils with purified elas- 
tase. HM.4 binding to commonly used human cells and cell-lines was investigated. No HM. 4 binding to HUVEC and low HM. 4 binding to lymphoid cells and monocytes was found.

For use in in vitro neutrophil activation assays, protein $\mathrm{G}$ purified antibody-preparations were used. $F\left(a b^{\prime}\right)_{2}$ fragments were prepared by pepsin (Immobilized Pepsin, Pierce, Rockford, IL) digestion according to the manufacturers instructions.

The following mAb were employed to identify receptor-involvement in anti-elastase $\mathrm{mAb}$ induced neutrophil activation: $\mathrm{mAb}$ IB4 $\left(\operatorname{IgG}_{23}\right)$, reactive with CD18 (13), a gift of Dr. M. Daha, University Hospital Leiden, The Netherlands; mAb $60.3\left(\mathrm{IgG}_{2 \mathrm{~d}}\right.$ ), reactive with CD18 (14), a gift of Dr. P.G. Beatty, Fred Hutchinson Cancer Research Center, Seattle, WA; mAb $904\left(\operatorname{IgG}_{1}\right)$ reactive with CD1lb (15), a gift of Dr. J.D. Griffin, Dana Farber Cancer Institute, Boston, MA; mAb PDV11.2 ( $\left.\operatorname{IgG}_{2 \mathrm{a}}\right)$, reactive with CD11b (16), a gift of Dr. F. Koning, University Hospital Leiden, The Netherlands, mAb $44\left(\operatorname{IgG}_{1}\right)$. reactive with CD11b (17), a gift of Dr. N. Hogg, ICRF, London, UK; mAb TB-3 $\left(\operatorname{lgG}_{24}\right)$, reactive with $\mathrm{Fc} \gamma \mathrm{RI}(18)$, a gift of Dr. R. A. W. van Lier, CLB, Amsterdam, The Netherlands; mAb CIKM5 (IgG) $)$, reactive with FcyRII (19), a gift of Dr. G. Pilkington, Australia; mAb $3 G 8\left(\operatorname{IgG}_{1}\right)$, reactive with FcyrIII (20), a gift of Medarex, West Lebanon, NH, and $\mathrm{mAb}$ CLB/Fcgranl ( $\operatorname{lgG}_{2 a}$ ), reactive with FcyRIII (21), a gift of Dr. T. Huizinga, CLB, Amsterdam, The Netherlands. mAb $3.9\left(\mathrm{IgG}_{1}\right)$, reactive with CD1lc (22), a gift of Dr. N. Hogg, ICRF, London, UK, and the non-specific mAb
MOPC21 $\left(\operatorname{IgG}_{1}\right)$, kindly provided by Celltech (Slough, UK), were used as a control. Recombinant human (rh) TNF- $\alpha$ was kindly provided by BASF/Knoll AG, Ludwigshafen, FRG. PMA was purchased from Sigma, St. Louis, MO.

\section{Cells}

Neutrophils were prepared from buffy coats of donor blood kindly provided by the local blood bank, using standard techniques of buoyant density centrifugation on Lymphoprep (Nycomed, Oslo, Norway), followed by separation of neutrophils from erythrocytes by density gradient centrifugation on percoll (1.08 g/ml, Pharmacia, Uppsala, Sweden). Neutrophil preparations contained $<5 \%$ contaminating cells, as evaluated by May Grunwald Giemsa staining.

HUVEC were obtained by collagenase treatment of the human umbilical vein and cultured in fibronectin-coated (fibronectin kindly provided by Dr. J. van Mourik, CLB, Amsterdam, The Netherlands) tissue culture flasks (Costar, Cambridge, MA) in culture medium.

Culture medium was composed of RPMl1640 (Gibco Europe, Paisley, Scotland), supplemented with $10 \%$ heat-inactivated human serum, $10 \%$ heat-inactivated bovine calf serum (BCS) (Hyclone, Logan. UT), 50 $\mu \mathrm{g} / \mathrm{ml}$ heparin (Sigma), $30 \mu \mathrm{g} / \mathrm{ml}$ endothelial growth supplement (Collaborative Research Incorporated, Bedford, MA) and antibiotics. Endothelial cells were characterized by their pavement-like monolayer morphology and by positive staining with the anti-E-selectin mAb ENAl (23) after $4 \mathrm{~h}$ incubation with TNF- $\alpha$. 


\section{Injury assay}

${ }^{51} \mathrm{Cr}$-release and detachment assays were performed as described before (24). In short, HUVEC (passage 3 ) were grown to confluence during $24 \mathrm{~h}$ in fibronectin-coated 96-well flat bottom microtiter plates (Costar). The last $16 \mathrm{~h}$ of this culture Chromium-51 as sodium $\left[{ }^{51} \mathrm{Cr}\right]$ chromate was added to the wells $(18 \mathrm{kBq} /$ well, specific activity $11 \mathrm{GBq} / \mu \mathrm{g} \mathrm{Cr}$ ). Monolayers were carefully washed, and neutrophils (targeteffector cell ratio 1:50) and reagents in RPMI-1640 supplemented with $10 \%$ BCS were added to the monolayer at a final volume of $200 \mu \mathrm{l} /$ well.

Incubations were performed at $37^{\circ} \mathrm{C}$ for $3 \mathrm{~h}$. Endothelial cell lysis was determined by measuring ${ }^{51} \mathrm{Cr}$ release in $100 \mu \mathrm{l}$ cell-free supernatant medium, removed from each well with care not to disturb the monolayer. Next, $100 \mu \mathrm{l}$ of fresh medium was added to the remaining $100 \mu \mathrm{l}$ in each well. Detached endothelial cells were suspended by repeated careful pipetting, and $100 \mu \mathrm{l}$ of this suspension was removed to determine detachment (these samples thus contained $50 \%$ of the amount of ${ }^{51} \mathrm{Cr}$ in the lysis samples, plus the ${ }^{51} \mathrm{Cr}$ present in the detached cells). Maximal ${ }^{51} \mathrm{Cr}$ content was determined in wells receiving $100 \mu \mathrm{l}$ of $1 \mathrm{~N} \mathrm{NaOH}$.

All samples were counted in a gamma-spectrophotometer. Detachment values were calculated by subtracting half of the ${ }^{51} \mathrm{Cr}$ counts measured in the lysis samples drawn from the same wells, from the ${ }^{51} \mathrm{Cr}$ counts measured in the detachment samples, and corrected for non-specific ${ }^{51} \mathrm{Cr}$ content, by subtracting ${ }^{51} \mathrm{Cr}$ counts measured in detachment samples from wells without effector cells.

\section{$\mathrm{H}_{2} \mathrm{O}_{2}$ measurement}

A previously described colorimetric method to determine $\mathrm{H}_{2} \mathrm{O}_{2}$ production was used (24). In short, neutrophils, reagents and $\mathrm{mAb}$ were suspended/dissolved in RPMI-1640 supplemented with $10 \%$ BCS, antibiotics, $200 \mu \mathrm{g} / \mathrm{ml}$ phenol red (Sigma) and $8.5 \mathrm{u} / \mathrm{ml}$ horse radish peroxidase (type VI, Sigma).

Neutrophils and reagents were placed in microtiter-plates coated with BCS at $2.5 \times 10^{5}$ cells/well to a final volume of $200 \mu \mathrm{V} /$ well, and incubated for $3 \mathrm{~h}$ at $37^{\circ} \mathrm{C}$. $50 \mu \mathrm{l} 2 \mathrm{M}$ $\mathrm{NaOH}$ was added and $\mathrm{OD}$ was determined at $620 \mathrm{~nm}$. The lower sensitivity of the assay was $1.6 \mu \mathrm{M} \mathrm{H}_{2} \mathrm{O}_{2}$.

\section{Results}

Anti-elastase mAb HM.4 induces neutrophil $\mathrm{H}_{2} \mathrm{O}_{2}$-release

Prolonged adhesion dependent neutrophil $\mathrm{H}_{2} \mathrm{O}_{2}$-release can be elicited by particles such as zymosan, and by cytokines such as TNF (24-26). Neutrophil binding murine mAb of the $\mathrm{IgG}_{1}, \mathrm{IgG}_{2 \mathrm{a}}$, or $\mathrm{IgG}_{2 \mathrm{~b}}$ subclass, used to interfere with the function of neutrophil surface structures such as CD11a, CD11b, CD11c, CD18 do not incite prolonged neutrophil $\mathrm{H}_{2} \mathrm{O}_{2}$-release (24-27).

Furthermore, no difference between complete $\mathrm{mAb}$, and $\mathrm{F}\left(\mathrm{ab} \mathrm{b}^{\prime}\right)_{2}$ fragments was evident in these inhibition studies (24). Additionally, we tested a panel of murine mAb reactive with the neutrophil surface struc-

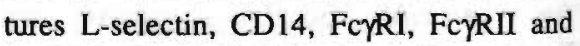
FcyRIII which all failed to influence prolonged neutrophil $\mathrm{H}_{2} \mathrm{O}_{2}$-release (data not shown). In contrast, incubation of isolated human neutrophils with mAb HM.4, an antielastase $\mathrm{mAb}$ of the $\mathrm{IgG}_{1}$ subclass, for $3 \mathrm{~h}$ at $37^{\circ} \mathrm{C}$ resulted in a concentration dependent increase of neutrophil $\mathrm{H}_{2} \mathrm{O}_{2}$-release (Fig. I), 


\section{Chapter 5.2}

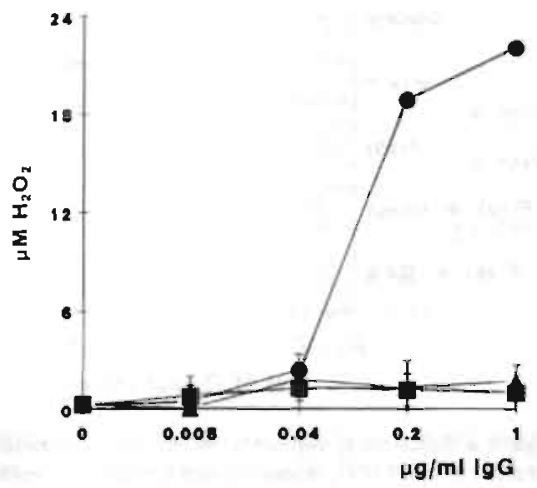

Figure 1. Influence of anti-elastase MAb HM.4(), anti$C D I l c$ mAb 3.9 (A) and the non-binding control mAb MOPC2I (ם) on $\mathrm{H}_{2} \mathrm{O}_{2}$ release by isolated human neutrophils. Antibodies and cells were added simultuneously to BCS coated microtiterplates, and $\mathrm{H}_{2} \mathrm{O}_{2}$ release was measured after $3 \mathrm{~h}$. Data indicate mean and $S D$ of 4 replicates. If SD bars are not shown, they fall within the symbol.

reaching maximal stimulation at $1 \mu \mathrm{g} / \mathrm{ml}$. Two isotype-matched control mAb were tested in parallel, a non-specific mAb without neutrophil binding capacity, and a neutrophil-reactive anti-CDI1c mAb. Both mAb's failed to induce neutrophil $\mathrm{H}_{2} \mathrm{O}_{2}$-release at identical Ig concentrations (Fig. I).

The anti-elastase mAb was found to be nearly equally potent in triggering neutrophil $\mathrm{H}_{2} \mathrm{O}_{2}$-release as the known neutrophil agonists TNF- $\alpha$ and PMA ( $1 \mu \mathrm{g} / \mathrm{ml}$ anti-elastase mAb HM.4: $22 \pm 0.3 \mu \mathrm{M} \mathrm{H}_{2} \mathrm{O}_{2}, 10 \mathrm{ng} / \mathrm{ml}$ TNF- $\alpha: 26 \pm 0.6 \mu \mathrm{M} \mathrm{H}_{2} \mathrm{O}_{2}, 50 \mathrm{ng} / \mathrm{ml}$ PMA: $28 \pm 1.0 \mu \mathrm{M} \mathrm{H} \mathrm{H}_{2} \mathrm{O}_{2}$, measured in the same experiment after $3 \mathrm{~h}$ of coincubation).

Combined addition of $10 \mathrm{ng} / \mathrm{ml}$ TNF- $\alpha$ and $1 \mu \mathrm{g} / \mathrm{ml}$ anti-elastase $\mathrm{mAb}$ did not further increase neutrophil $\mathrm{H}_{2} \mathrm{O}_{2}$ release (26 \pm 0.9 $\mu \mathrm{M} \mathrm{H}_{2} \mathrm{O}_{2}$ in the same experiment).

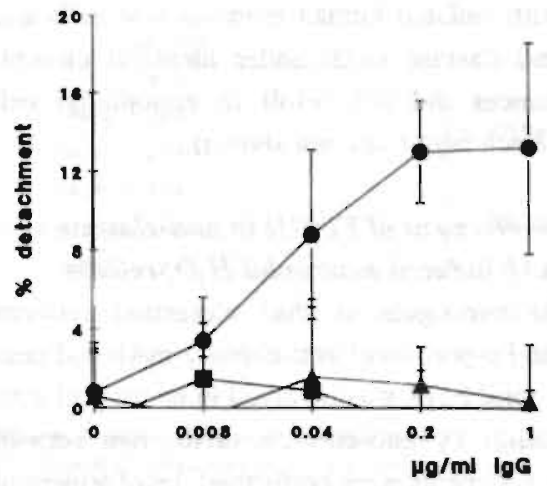

Figure 2. Influence of anti-elastase $M A b$ HM.4(O) anfi$C D 1 / c$ mAb 3.9 (A) and the non-binding control mAb MOPC2I (ㅁ) on neutrophil mediated endothetial cell detachment. Neutrophils were added together with the mAb to HUVEC monolayers. Endorhelial cell lysis and endorhelial cell detachment were measured after $3 h$ of incubation at $37^{\circ} \mathrm{C}$, as indicated in material and methorls. Endothelial cell lysis remained consistently below $5 \%$ of the total number of HUVEC. Data indicate mean and $S D$ of 4 measurements.

\section{Anti-elastase mAb HM.4 induces neu-} trophil mediated HUVEC detachment

${ }^{5} \mathrm{Cr}$-labeled HUVEC monolayers were incubated with neutrophils (target : effector-cell ratio $1: 50$ ) and antibodies for $3 \mathrm{~h}$ at $37^{\circ} \mathrm{C}$ to investigate whether neutrophils could be activated to induce endothelial cell injury. Neutrophil incubation with anti-elastase $\mathrm{mAb}$, but not with anti-CDIlc or non-reactive control $\mathrm{mAb}$, caused a concentration dependent increase of neutrophil mediated HUVEC detachment (Fig. 2), but no endothelial cell lysis (data not shown).

The influence of anti-elastase mAb on neutrophil mediated endothelial cell injury was relatively small in comparison to $10 \mathrm{ng} / \mathrm{ml}$ TNF- $\alpha$, which induced $86 \pm 6 \%$ HUVEC detachment, without HUVEC lysis, in the 
same experiment. Incubation of HUVEC with isolated human mononuclear cells and anti-elastase $\mathrm{mAb}$ under identical circumstances did not result in endothelial cell detachment (data not shown).

\section{Involvement of Fc $\gamma R I I$ in anti-elastase mAb induced neutrophil $\mathrm{H}_{2} \mathrm{O}_{2}$-release}

To investigate whether interaction between the Fc-portion of anti-elastase mAb and neutrophil FcyR was involved in neutrophil activation by anti-elastase mAb, two sets of experiments were performed. Involvement of the Fc-portion was investigated by testing $\mathrm{F}\left(\mathrm{ab}^{\prime}\right)_{2}$ fragments of anti-elastase $\mathrm{mAb}$ HM.4 for their capacity to induce neutrophil $\mathrm{H}_{2} \mathrm{O}_{2}$ release. Whilst $1 \mu \mathrm{g} / \mathrm{ml}$ intact anti-elastase mAb induced $40 \mu \mathrm{M} \mathrm{H}_{2} \mathrm{O}_{2}$ release after $3 \mathrm{~h}$ of incubation, equimolar concentrations of $F\left(a b^{\prime}\right)_{2}$ fragments of these anti-elastase mAb did not trigger neutrophil $\mathrm{H}_{2} \mathrm{O}_{2}$ release (Fig. 3).

The loss of the capacity to activate neutrophils after pepsin-digestion of anti-elastase $\mathrm{mAb}$ was not due to a decrease in the affinity of the $F\left(a b^{*}\right)_{2}$ fragments for neutrophils, as evidenced by positive pANCA staining using these $\mathrm{F}\left(\mathrm{ab} \mathrm{b}_{2}\right)_{2}$ fragments (data not shown). Moreover, addition of an excess of elastase reactive $F\left(a b^{\prime}\right)_{2}$ fragments inhibited neutrophil activation by $0.1 \mu \mathrm{g} / \mathrm{ml}$ of intact antielastase mAb (Fig. 3), confirming that the anti-elastase $F\left(a b^{\prime}\right)_{2}$ fragments do not have a decreased affinity to neutrophil bound elastase, and suggesting the involvement of saturatable antigen specific interactions between anti-elastase $\mathrm{mAb}$ and neutrophils in neutrophil activation by anti-elastase mAb.

To investigate whether cross-linking of neutrophil bound elastase to larger complexes

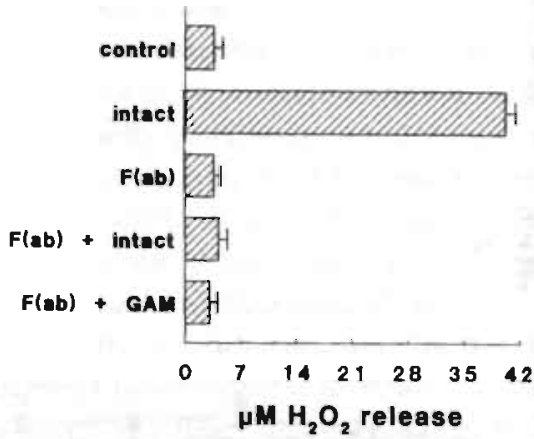

Figure 3. Influence of different combinations of antibod. ies on neutrophil $\mathrm{H}_{2} \mathrm{O}_{2}$ release: intact anti-elastase $\mathrm{mAh}$, $F(a b)_{2}$, fragments of anti-elastase $\mathrm{mAb}$, intact anti-elaslase $\mathrm{mAb}$ plus $\mathrm{F}\left(a b^{\prime}\right)_{2}$ fragments of anti-elastase $\mathrm{mAb}$, and $F\left(a b^{\prime}\right)_{2}$ fragments of polyclonal goat anti-mouse antibodies after preincubution with $F\left(a b^{\prime}\right)_{2}$ fragments of anti-elastase $\mathrm{mAb}$. Intact $\mathrm{mAb}$ were used at $1 \mu \mathrm{g} / \mathrm{ml}$, all $F\left(a b^{\prime}\right)_{2}$ fragment prepartions were used at a concentration equimolar to $1 \mu \mathrm{g} / \mathrm{ml}$ intact mAb. Data indicate mean and $S D$ of 4 replicates.

would be involved in anti-elastase $\mathrm{mAb}$ induced neutrophil activation, we tested whether Fc-fragment independent crosslinking of surface bound elastase by preincubation with anti-elastase $F\left(a b^{\prime}\right)_{2}$ fragments, and subsequent addition of goat-anti-mouse $\mathrm{F}\left(\mathrm{ab}^{\prime}\right)_{2}$ fragments would trigger neutrophil $\mathrm{H}_{2} \mathrm{O}_{2}$ release. No increase in neutrophil $\mathrm{H}_{2} \mathrm{O}_{2}$ release, however, was induced by these $\mathrm{mAb}$ fragments (Fig. 3), indicating that complexation of neutrophil membrane elastase itself is not sufficient to cause neutrophil activation.

To investigate the involvement of $\mathrm{Fc} \gamma \mathrm{RI}$ (CD64), FcyRII (CD32) and FcyRIII (CD16) in neutrophil activation by anti-elastase $\mathrm{mAb}$, a number of $\mathrm{FcyR}$ reactive $\mathrm{mAb}$ known to prevent $\mathrm{F} c \gamma \mathrm{R}$ antibody interaction, were tested on their influence on anti-elastase $\mathrm{mAb}$ induced neutrophil $\mathrm{H}_{2} \mathrm{O}_{2}$-release. mAb TB-3 reactive with FcyRI and mAb 


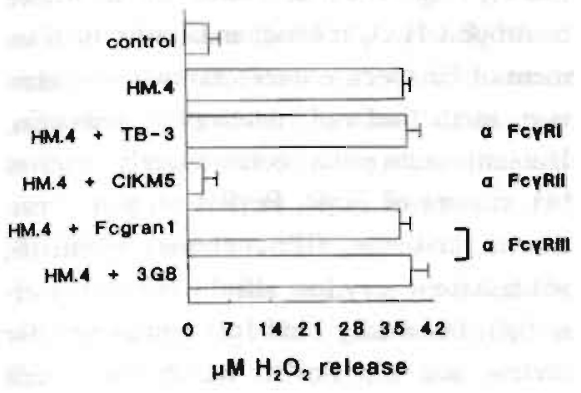

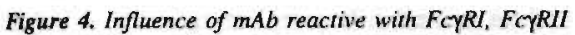
and $\mathrm{F}_{\mathrm{C}} \mathrm{HR}$ III on $\mathrm{H}_{2} \mathrm{O}_{2}$ release by neurrophils activated with anti-elastase mab. Neutrophils were incubated for 3 $h$ in presence of $0.1 \mu \mathrm{g} / \mathrm{ml}$ anti-elasiase $m A b$ and $5 \mu \mathrm{g} / \mathrm{ml}$ of the indicated ani-Fcy recepior $m A b$, after which the released amount of $\mathrm{H}_{2} \mathrm{O}_{2}$ was determined. Data indicate mean and $S D$ of 4 replicates.

CLB/Fcygran1 and 3G8, reactive with FcR $\gamma$ III failed to reduce anti-elastase mAb induced neutrophil $\mathrm{H}_{2} \mathrm{O}_{2}$ release, whilst mAb CIKM5 reactive with FcyRII completely prevented the mAb HM.4 induced increase in neutrophil $\mathrm{H}_{2} \mathrm{O}_{2}$ release (Fig. 4). None of the Fc $\gamma R$ reactive mAb induced $\mathrm{H}_{2} \mathrm{O}_{2}$ release by unstimulated neutrophils (data not shown).

\section{Involvement of the CDIIb/CDI8 integrin in anti-elastase antibody induced neu- trophil activation}

Substrate-contact mediated by the $\beta_{2}$ integrin dimer $\mathrm{CD} 1 \mathrm{lb} / \mathrm{CD} 18$ facilitates neutrophil $\mathrm{H}_{2} \mathrm{O}_{2}$-release induced by zymosan (25) and TNF $(24,26)$. To further characterize the mechanism of anti-elastase antibody induced neutrophil activation, we investigated involvement of the $\beta_{2}$ integrin dimer in antielastase mAb induced neutrophil $\mathrm{H}_{2} \mathrm{O}_{2}$ release. Coincubation with two different C.D18reactive $\mathrm{mAb}$, completely inhibited neutrophil $\mathrm{H}_{2} \mathrm{O}_{2}$ release induced by

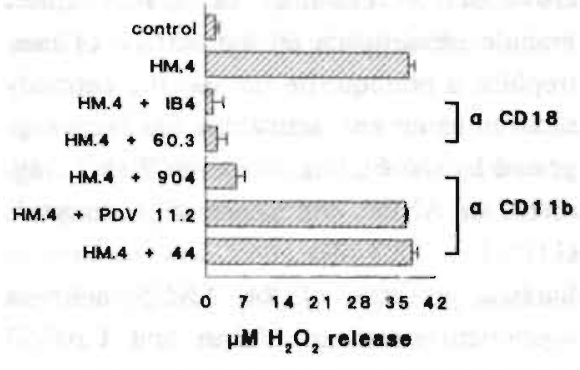

Figure 5. Influence of $m A b$ reactive with $C D I / b$ and $\mathrm{CDI} 8$ on $\mathrm{H}_{2} \mathrm{O}_{2}$ release by neutrophils activaled with antielastase $m A b$. Neutrophils were incubated for $3 \mathrm{~h}$ in presence of $0.1 \mu \mathrm{g} / \mathrm{ml}$ anti-elastase $m A b$ and $5 \mu \mathrm{g} / \mathrm{ml}$ of the indicated anti-CDIJb/CD $18 \mathrm{mAb}$, afier which the released amount of $\mathrm{H}_{2} \mathrm{O}_{2}$ was determined. Data indicate mean and $S D$ of 4 replicares.

$0.1 \mu \mathrm{g} / \mathrm{ml}$ anti-elastase $\mathrm{mAb}$. CD11b has two binding-sites, each engaged in the binding of distinct classes of ligands $(27,28)$. We observed a partial inhibition with $\mathrm{mAb} 904$, reactive with the so-called LPS-binding region of CDllb (28), whereas two other anti-CDIlb $\mathrm{mAb}$ (Fig. 5) and mAb reactive with CD1 la and CDI1c (data not shown) remained ineffective, suggesting involvement of specific substrate interactions via $\mathrm{CD} / \mathrm{lb} / \mathrm{CD} 18$ in anti-elastase mAb induced neutrophil $\mathrm{H}_{2} \mathrm{O}_{2}$ release.

\section{Discussion}

In the present study we demonstrated that an elastase reactive mAb can specifically trigger neutrophil activation, as monitored via in vitro measurements of neutrophil $\mathrm{H}_{2} \mathrm{O}_{2}$-release and neutrophil mediated endothelial ccll damage. Elastase is a serine protease which is present in abundant amounts in the primary granules of neutrophils, together with 
other inflammatory proteins such as myeloperoxidase. Accessibility of ANCA-related granule constituents on the surface of neutrophils, a prerequisite for specific antibody induced neutrophil activation, has been suggested by the finding that even $F\left(a b^{\prime}\right)$ fragments of ANCA can penetrate neutrophils (11).

Surface presence of the ANCA antigens myeloperoxidase, lactoferrin and CAP-57 has subsequently been demonstrated on activated neutrophils (8), thus facilitating FcyR independent binding of ANCA reactive with these proteins to activated neutrophils. We found strong binding of anti-elastase mAb HM. 4 bound to both untreated and pre-activated neutrophils, and low or absent binding to lymphocytes, monocytes and endothelial cells (data not shown). This finding suggests presence of elastase on the neutrophil-surface, probably involving neutrophil elastase receptors, as described by Dwenger et al. (29). Neutrophils used in this study were isolated from buffy coats of donor blood using standard techniques of buoyant density gradient centrifugation, which are known to induce changes in surface expression of several proteins $(30,31)$. Wether neutrophils constitutively express elastase, or whether neutrophils become activated to some degree during their procurement and isolation, allowing translocation of elastase from their intracellular stores to the cell-surface, remains to be elucidated. We therefore can not exclude that anti-elastase mAb induced neutrophil activation might, as suggested for neutrophil activation by other ANCA $(7,8)$, require previous priming of neutrophils.

Elastase reactive $F\left(a b^{\prime}\right)_{2}$ fragments were, even after cross-linking with anti-mouse IgG
$\left.\mathrm{F}(\mathrm{ab})_{2}\right)_{2}$ fragments, not sufficient to induce neutrophil $\mathrm{H}_{2} \mathrm{O}_{2}$ release, indicating involvement of Fc-specific interactions in anti-elastase $\mathrm{mAb}$ induced neutrophil activation. Human neutrophils constitutively express two classes of $\mathrm{Fcy}$, FcyRII ( $\mathrm{A}$ and $\mathrm{C}$ isoforms) and the GPI-anchored FcyRIIIB, witch have a very low affinity for monomeric IgG, but avidly bind IgG complexes (for review, see 32). FcyRI, which has a high affinity for monomeric IgG, can be expressed on neutrophils after activation (32). Multivalent ligation of either FcyRII or FcyRIIIB, by immune-complexes, IgG coated particles or heat aggregated IgG, or by crosslinking FcyR specific $\mathrm{mAb}$ with a secondary antibody, induces cellular activation (32). Divalent ligation of FcrRII, as performed in this study by incubating neutrophils with mAb CIKM5, does not activate neutrophils. $\mathrm{mFc} \gamma \mathrm{RII}$ is thought to be primarily responsible for IgG-mediated activation, while FcyRIIIB serves as a trap to hold IgG-coated particles in place on the neutrophil surface, thereby enhancing contact with FcyRII and facilitating cell activation in a cooperative manner $(33,34)$. We found that a mAb reactive with $\mathrm{Fc} \gamma \mathrm{RII}$ inhibited anti-elastase $\mathrm{mAb}$ induced neutrophil activation. Fc $\gamma$ RII thus seems to play a role in anti-elastase $\mathrm{mAb}$ induced neutrophil activation, probably by direct interaction with the Fc-portion of antielastase $\mathrm{mAb}$ captured on the neutrophil surface. Another option would be that FcyRII functions as a signal-rransducing molecule after association with FcyRIII molecules complexed with Ig $(30,34)$, but the absence of a reduction in neutrophil $\mathrm{H}_{2} \mathrm{O}_{2}$-release after addition of anti-Fc $\gamma$ III mAb makes critical involvement of this receptor unlikely. Neutrophil activation by $\mathrm{mAb}$ reactive with 
surface antigens is a rare finding. Myeloidrelated $\mathrm{mAb}$ submitted to the Fourth Workshop on human leucocyte differentiation antigens were tested by Sunder-Plassmann et al (35) on their influence on neutrophil respiratory burst activity. Only five out of 165 tested $\mathrm{mAb}$ were found to increase neutrophil respiratory burst activity induced by opsonized zymosan. Most studies to define the characteristics of antigens which allow antibody-binding induced $\mathrm{Fc} \gamma \mathrm{R}$ mediated activation have been performed using monocytes and platelets. In these studies, no relation was found between the number of cellbound $\mathrm{mAb}$ and the likelihood of activation; an activating mAb against a surface protein having about 1,000 copies per cell has been described $(36,37)$. Cellular activation appears to depend mainly on the nature of the ligand, although differences between mAb reactive with the same receptor have also been described (35-37). Surface-mobility of the antigenic structure is thought to be critical, since this would allow association with and cross-linking of $\mathrm{Fc} \gamma \mathrm{R}$, which would elicit cellular activation (36).

Otherwise, ligand dependent FcyR 'perturbation' instead of cross-linking has been hypothesized to be the eliciting event for cellular activation (37). The elastase receptor on neutrophils has been poorly defined. Whether anti-clastase $\mathrm{mAb}$ induced neutrophil activation involves specific characteristics of an elastase-binding site on neutrophils or whether membrane-elastase simply acts as a mobile surface-ligand for specific IgG, thus facilitating FcyRII cross-linking awaits further study. Other factors could also be relevant, such as the proteolytic activity of elastase itself, which might have a role in FcyR II activation, and the relative abundance of binding sites for anti-elastase antibodies in comparison to the anti-CDIlc which was used as a control $\mathrm{mAb}$ in this study.

Neutrophils can respond to stimulation with FMLP or PMA with rapid, adherence-independent $\mathrm{H}_{2} \mathrm{O}_{2}$-release $(38,39)$. Neutrophils stimulated with TNF, GM-CSF or LPS do not show rapid $\mathrm{H}_{2} \mathrm{O}_{2}$-release. In adequate substrate and medium-conditions, these neutrophils show progressive attachment and flattening, mediated by CD11b/CD18-substrate interactions and shedding of the negatively charged sialoprotein $\mathrm{CD} 43$, which enables subsequent massive $\mathrm{H}_{2} \mathrm{O}_{2}$-release $(24,26,39-43)$. We demonstrated in this study that anti-elastase mAb induced neutrophil $\mathrm{H}_{2} \mathrm{O}_{2}$-release can be inhibited by mAb reactive with $C D 11 b / C D 18$, suggesting that anti-elastase $\mathrm{mAb}$ induced neutrophil respiratory burst activation mimics the activation of neutrophil respiratory burst by TNF, GM-CSF and LPS concerning the need for substrate-interaction.

The absence of additive effects of TNF and anti-elastase mAb is congruent with this idea. TNF is, however, more potent than antielastase mAb in inducing neutrophil mediated endothelial cell detachment. Since direct effects of TNF on endothelial cells do not contribute to endothelial cell detachment in our model (44), TNF-induced and anti-elastase $\mathrm{mAb}$ induced neutrophil activation are partly discongruent.

In conclusion, we demonstrated that mAb directed against elastase can specifically induce neutrophil toxicity in vitro. On the basis of our data, we suggest that anti-elastase $\mathrm{mAb}$ bind to elastase on the neutrophil surface, enabling interaction between the 
IgG Fc-portion and neutrophil FcyRII, leading to cellular activation. This activation subsequently induces CD11b/CD18 dependent release of reactive oxygen species.

This mechanism might provide a link between the presence of anti-elastase antibodies and the inflammatory tissue destruction found in patients with Wegener's granulomatosis and other forms of systemic autoimmune vasculitis.

\section{References}

1. Hagen EC, Ballicux BEPB, Daha MR, van Es LA, van der Woude FJ: Fundamental and clinical aspects of anti neutrophil cytoplasmic antibodies. Autoimmunity 11:199, 1992

2. Falk RJ, Jennette J: Anti-neutrophil cytoplasmic antibodies with specificity for myeloperoxidase in patients with systemic vasculitis and idiopathic necrotizing and crescentic glomerulonepbritis. N. Engl. J. Med. 318:1651, 1988

3. Lesavre P: Antineutrophil cytoplasmic antibodies antigen specificity. Am. J. Kidney Dis. 18:159, 1991

4. Lesavre P, Noél LH, Gayno S, Nusbaum P, Reumaux D. Erlinger S, Grüfeld JP, Halbwachs-Mecarelli L: Atypical autoantigen targets ofperinuclear antineutrophil cytoplasm antibodies (P-ANCA): specificity and clinical associations. J. Autoimmun. 6:185, 1993

5. Savige JA, Gallicchio M, Georgiou T, Davies DJ: Diverse target antigens recognized by circulating antibodies in anti-neutrophil cytoplasm antibodyassociated renal vasculitides. Clin. Exp. Immunol. $82: 238,1990$

6. Gallicchio MC, Savige JA: Detection of anti-myeloperoxidase and anti-elastase antibodies in vasculitides and infections. Clin. Exp. Immunol. 84:232, 1991

7. Falk RJ. Terrel RS, Charles LA, Jennette JC: Antineutrophil cytoplasmic autoantibodies induce neutrophils to degranulate and produce oxygen radicals in vitro. Prac. Nath Acad. Sci USA 87:4115, 1990

8. Charles LA, Caldes ML.R. Falk RJ. Tertel RS, Jen. nette JC: Antibodies against granule proteins activate neutrophils in vitro. J. Leucocyle Biol. 50:539, 1991

9. Savage COS. Pottinger BE, Gaskin G. Puscy CD. Pearson JD: Autoantibodies developing to myeloperoxidase and proteinase 3 in systemic vasculitis stimulate neutrophil cytotoxicity toward cultured endothelial cells. Am. J. Pathol. 141:335, 1992

10. Ewert BH. Falk RJ, Jennette JC: Anti neutrophil cytoplasmic autoantibodies (ANCA) stimulate neutrophils to injure endothelial cells in vitro. Am. J. Kidney Dis. 18:203, 1991 (abstr)

11. Halbwachs-Mecarelli L, Nusbaum P, Noël LH, Reumaux D. Erlinger S, Grünfeld IP, Lesavre P: Antineutrophil cytoplasmic antibodies (ANCA) directed against Catchepsin $\mathbf{G}$ in ulcerative colitis. Crohn's disease and primary sclerosing cholangitis. Clin. Exp. Immunol. 90:79, 1992

12. Van der Woude FJ, Rasmussen N, Lobatto S, Wiik A, Permin H, van Es LA, van der Giessen M, van der Hem GK, The TH: Autoantibodies against neutrophils and monocytes: tool for diagnosis and marker for disease activity in Wegener's granulomatosis. Lancet i: 425,1985

13. Wright SD, Rao PE, van Voorhuis WC, Craigmyle IS, Iida K, Talle MA, Westberg EF, Goldstein G, Silverstein $\mathrm{SD}$ : Identification of the C3bi receptor on human monocytes and macrophages by using monoclonal antibodies. Proc. NatL Acad. Sci. USA 80:5699, 1983

14. Beatty PG, Ledbetter JA, Martin PJ, Price TH, Hansen JA: Definition of a common leukocyte cell-surface antigen (Lp95-150) associated with diverse cellmediated immune functions. J. ImmunoL 131:2913, 1983

15. Dana N, Styrt B, Griffin JD, Todd III RF, Klempner MS, Arnaout MA: Two functional domains in the phagocyte membrane glycoprotein Mol identified with monoclonal antibodies. J. Immunol. 137:3259, 1986

16. Koning $F$ : Identification and functional relevance of epitopes on human lymphocytes. Ph. D. thesis, University of Leiden, Leiden, The Netherlands, p.19, 1986

17. Dana V, Tod III RF, Pitt J, Springer TA, Amaout MA: Deficiency of a surface membrane glycoprotein (Mol) in man. J. Clin. Invest. 73:153, 1984

18. Van Lier RAW, Boot JHA, de Groot ER, Aarden LA: Induction of $T$ cell proliferation with anti-CD3 switch-variant monoclonal antibodies: effects of heavy chain isotype in monocyte-dependent systems. Eur. J. Immunol. 17:1599, 1987

19. Tetteroo PAT, van der Schoot CE, Visser FJ, Bos MJE, von dem Bome AEGK: Three different types of Fcy receptors on human leucocytes defined by workshop antibodies; FeyR, of neutrophils, FcyR of KNNK lymphocytes, and Feyll. In McMichael AJ (ed): Leukocyte Typing III. Oxford University Press, Oxford, England, 1987

20. Fleit HB, Wright SD, Unkeless JC: Human neutrophil Fo- $\gamma$ receptor distribution and structure. Proc. Nafl. Acad. Sci. USA 79:3275, 1982

21. Leeuwenberg JFM, van de Winkel JGJ. Jeunhomine TMAA, Buuman WA: Functional polymorphism of IgG FeRII(CD32) on human neutrophils. Immunolo. 8y 71:301, 1990

22. Canabas C, Sanches-Madrid F, Acevedo A, Bellon T. Fernandez JM, Larraga V. Bemabeu C: Characteriz! tion of a CDIlc-reactive monoclonal antibody (HC 1/1) obtained by immunizing mice with phorbol estcr differentiated U937 cells. Hybridoma 7:162, 1988

23. Leeuwenberg JFM, Jeunhomme GMAA, Buurnan WA: Characterization of two monoclonal antibodies directed against an adhesion molecule on endothelial cells. Transplant. Proc. 22:1991, 1990

24. Von Asmuth EJU, van der Linden CJ, Leeuwenberg JFM. Buurman WA: Involvement of the 
CD1 lb/CD18 integrin, but not of the endothelial cell adhesion molecule ELAM-1 and ICAM-I in tumor necrosis factor- $\alpha$-induced neutrophil cytotoxicity. J. Immunol. 147:3869, 199I

25. Ross GD, Cain JA, Lachmann PJ: Membrane complement receptor type three $\left(\mathrm{CR}_{3}\right)$ has lectin-like properties analogous to bovine conglutinin and functions as a receptor for zymosan and rabbit erythrocytes as well as a receptor for iC $3 b$. J. Immunol. 134:3307, 1985

26. Nathan C, Srimal S, Farber C, Sanchez E, Kabbash L, Asch A, Gailet J, Wright SD: Cytokine-induced respiratory burst of human neutrophils: dependence on extracellular matrix protcins and CD11/CD 18 integrins. J. Cell BioL 109:1341, 1989

27. Dana N, Styrt B. Griffin JD, Todd III RF, Klempner MS, Arnaout MA: Two functional domains in the phagocyte membrane glycoprotein Mol identified with monoclonal antibodies. J. Immunol 137:3259, 1986

28. Wright SD, Levin SM, Jong MTC, Chad Z, Kabbash LG: CR3 (CDI lb/CD18) expresses one binding site for Arg-Gly-Asp-containing peptides and a second site for bacterial lipopolysaccharide. J. Exp. Med. 169:175, 1989

29. Dwenger A, Tost P: Evaluation of elastase and $\alpha_{1}$. proteinase inhibitor-elastase uptake by polymorphonuclear leukocytes and evidence of an elastase-specific receptor. J. Clin. Chem. Clin. Biochem. 24:299, 1986

30. Kuijpers TW, Tool ATJ, van der Schoot CE, Ginsel LA, Onderwater JJM, Roos D, Verhoeven AJ: Membrane surface antigen expression on neutrophils: a reappraisal of the use of surface markers for neutrophil activation. Blood 78:1105, 1991

31. Watson F, Robinson JJ, Edwards SW: Neutrophil function in whole blood and after purification: changes in receptor expression, oxidase activity and responsiveness to cytokines. Biosci. Rep. 12:123, 1992

32. Kinct J-P: Antibody-cell interactions: FC receptors. Cell 57:351, 1989

33. Boros P, Odin JA, Muryoi T, Masur SK, Bona C, Unkless JC: IgM ant-FcyR autoantibodies trigger neutrophil degranulation. J. Exp. Med. I73:1473, 1991

34. Naziruddin B, Duffy BF, Tucker J, Mohanakumar T: Evidence for cross-regulation of FcyRIIB (CDI6) receptor-mediated signalling by FcyRII (CD32) expressed on polynorphonuclear neutruphils. J. Immunol I49.3702, 1992

35. Sunder-Plassmann G, Wagner L., Apperl A, Hruby K, Balcke P: Modulation of neutrophil respiratory burst and chemotaxis by the myeloid panel mAb. In Knapp W, Dörken B, Gilks WR, Rieber EP, Schmidt RE, Stcin H, von dem Bome AEGKr (eds): Leukacyre Typing IV. Oxford University Press, Oxford, Eng land, p. 896, 1989

36. Horsewood P. Hayward CPM, Warkentin TE, Kelton JG: Investigation of the mcchanism of monoclonal antibody-induced platelet activation. Blood 78:1019, [99]
37. Mucintire EA, Roberts PJ, Jones M, van der Schoch CE. Favalario EJ, Tidman N, Linch DC: Activation of human monocytes ocurs on cross-linking monocyte antigens to an Fc receptor. J. Immunol 142:2377, 1989

38. Shappell SB, Toman C, Anderson DC, Taylor AA, Entman ML. Smith CW: Mac-1 (CDIIb/CD18) mediates adherence-dependent hydrogen peroxide production by human and canine neutrophils. J. Immunol 144:2702, 1989

39. Dri P, Cramer R, Romano M, Spessotto P, Patriaca P: Effect of biological surfaces on neutrophil $\mathrm{O}^{2}$ production and its releationship to the CD $1 \mathrm{lb} / \mathrm{CD} 18$ integrin-dependent adherence. Int J. Tissue React. 13:193, 199I

40. Nathan C, Xie Q, Halbwachs-Mecarelli L, Jin WW: Albumin inhibits neutrophil spreading and hydrogen peroxide release by blocking the shedding of CD43 (sialophorin, leukosialin). J. Cell BioL 122:243, 1993

41. Dahinden C, Fehr J: Granulocyte activation by endotoxin. II. Role of granulocyte adherence, aggregation, and effect of cytochalacin B, and comparison with chemotactic peptide-induced stimulation. J. ImmunoL 130:863, 1983

42. Kapp A, Zeck-Kapp G, Danner M, Luger TA: Human granulocyte-macrophage colony stimulating factor: an effective direct activator of human polymorphonuclear neutrophilic granulocytes. J. Invest. Dermatol 91:49, 1988

43. Nathan C, Srimal S, Farber C, Sanchez E, Kabbash L. Asch A, Gailit J, Wright SD: Cytokine-induced respiratory burst of human neutrophils: dependence on extracellular matrix proteins and CD $1 / / C D 18$ integrins. J. Cell BioL 109:1341, 1989

44. Asmuth EJU von, Leeuwenberg JFM, van der Linden CJ, Buurman WA: Tumour necrosis factor $\alpha$ induces nestrophil mediated injury of cultured human endothelial cells. Scand. J. Immunol 34:197, 1991 


\title{
INVOLVEMENT OF THE CD11B/CD18 INTE- GRIN, BUT NOT OF THE ENDOTHELIAL CELL ADHESION MOLECULES ELAM-1 AND ICAM-1 IN TNF- $\alpha$ INDUCED NEUTROPHIL TOXICITY
}

\author{
ECKHARDT J.U. VON ASMUTH, CEES J. VAN DER LINDEN, \\ JET F.M. LEEUWENBERG AND WIM A.BUURMAN
}

J. ImmunoL 1991, 147: 3869-3875

\section{Abstract}

$7 N F-\alpha$ can incite neutrophil mediated endothelial cell damage, and neutrophil $\mathrm{H}_{2} \mathrm{O}_{2}$ release. Both effects require adherent neutrophils. Using specific $\mathrm{mAb}$, we showed in

1 this in vitro study that the CD18 $\beta_{2}$ chain and the CD11b $\alpha_{M}$ chain of the CD11/CD 18 integrin heterodimer have a major role in both TNF- $\alpha$ induced neutrophil mediated detachment of human umbilical vein endothelial cells (HUVEC) and $\mathrm{H}_{2} \mathrm{O}_{2}$ release by TNF- $\alpha$ activated human neutrophils. In contrast to anti CD18 mAb, which consistently prevented neutrophil activation, anti $\mathrm{CD} 1 \mathrm{la} \mathrm{mAb}$ and two out of three anti CD1 lb mAb did not reduce endothelial cell detachment and neutrophil $\mathrm{H}_{2} \mathrm{O}_{2}$ release, although they decreased neutrophil adhesion to HUVEC. mAb 904, directed against the bacterial lipopolysaccharide (LPS) binding region of CDIlb, reduced endothelial cell detachment for about $40 \%$ and neutrophil $\mathrm{H}_{2} \mathrm{O}_{2}$ release for more than $50 \%$, demonstrating that $\mathrm{CD} 11 \mathrm{~b} / \mathrm{CD} 18$ is engaged in TNF-induced neutrophil activation. Dependence on $\mathrm{CD} 11 \mathrm{~b} / \mathrm{CD} 18$ could not be overcome by $\mathrm{CD} 18$ independent anchoring of neutrophils via PHA. Additionally, neither induction of increased expression of the endothelial cell adhesion molecules ICAM-1 and ELAM-1, nor subsequent addition of specific mAb, influenced endothelial cell injury or $\mathrm{H}_{2} \mathrm{O}_{2}$ release by TNF-activated neutrophils. Interaction with ICAM-1 and ELAM-1 therefore appears not to induce additional activation of TNF-stimulated neutrophils.

These studies suggest that a specific, CD11b/CD18 mediated signal, instead of adherence only, triggers toxicity of TNF-activated neutrophils. 
Introduction

$\mathrm{N}$ eutrophil mediated inflammatory responses depend on adherence to endothelium, migration into an inflammatory site and on the release of toxic products by neutrophils. TNF- $\alpha$ influences these processes, by acting both on endothelium and on neutrophils. On endothelial cell monolayers TNF- $\alpha$ induces enhanced and de novo expression of adhesion molecules for neutrophils, such as ELAM-1 and ICAM-1 $(1-4)$.

Neutrophil transmigration occurs rapidly after adherence to TNF- $\alpha$ activated endothelium $(5,6)$. Neither increased monolayer permeability $(5,6)$, nor endothelial cell detachment (7) is provoked during this event. In contrast. TNF- $\alpha$ activated neutrophils show only a transient increase in adhesiveness, mediated by the CD11/CD18 complex, whilst subsequent migration through endothelial cell monolayers is not induced $(8,9)$. TNF- $\alpha$ triggers respiratory burst activity and the release of the content of primary and secondary granules by adherent neutrophils (10-12), which can lead to endothelial cell damage in vitro (7).

The effect of neutrophil-activation by TNF- $\alpha$ depends on adherence; TNF- $\alpha$ induces only minimal degranulation and respiratory burst activity of neutrophils in suspension, or neutrophils adherent to uncoated plastic surfaces, whereas neutrophils adherent to protein coated plastic or endothelial cell monolayers produce large amounts of reactive oxygen species upon TNF- $\alpha$ exposure (10-15).

Receptor mediated interaction with the substratum therefore might function as an important second trigger.
Several membrane structures contributing to the adherence of neutrophils to endothelium have been revealed during the last decennium. In unstimulated conditions, interaction between the integrin member $\mathrm{CD} 11 \mathrm{a} / \mathrm{CD} 18$ (LFA-1) on neutrophils and ICAM-1 on endothelial cells is the main adherence pathway. Neutrophil activation induces increased expression and adhesive capacities of CD11b/CD18 (Mac-1, complement receptor 3 ), which results in a $50 \%$ share of CD11b in adhesion $(9,16)$. Additionally, endothelial cell activation by stimuli such as LPS, IL-1, TNF- $\alpha$ and phorbol esthers results in a slow increase in ICAM-1 expression $(3,4)$ and in de novo expression of ELAM-1 $(1,2)$, a representative of the LECCAM family of adhesion molecules (17). ELAM-1 adhesion involves sialyl Lewis $X$ containing structures as a ligand (18-20), and results in highly increased, venous shear stress resistent adhesion of neutrophils (21). In spite of the detailed knowledge of the role of these membrane molecules in adhesion, little is known on their function in inter-cellular communication.

Previously we showed that considerable endothelial cell detachment, but no endothelial cell lysis, can be measured after addition of TNF- $\alpha$ activated neutrophils to cultured HUVEC $^{3}$ monolayers (7). In this study, we investigated the role of the neutrophil CD11/CD18 hetero-dimer and of ELAM-1 and ICAM-1, in TNF- $\alpha$ induced neutrophil toxicity. Using in vitro measurements of neutrophil induced HUVEC detachment, and neutrophil $\mathrm{H}_{2} \mathrm{O}_{2}$ release, evidence was obtained for a role of CD11b/CD18, other than mediating neutrophil adherence, in these processes. 


\section{Materials and Methods}

\section{Reagents}

Recombinant human TNF- $\alpha$ was kindly provided by $\mathrm{BASF} / \mathrm{Knoll} \mathrm{Ag}$. (Ludwigshafen, FRG). PMA was purchased from Sigma (St. Louis, MO), PHA (HA15) was purchased from Wellcome (Beckenham, Kent, UK).

\section{Monoclonal antibodies}

mAb ENA1 and ENA2 (both IgG1) were obtained by immunizing mice with L-1 \& TNF- $\alpha$ treated HUVEC, and react with different epitopes on $\operatorname{ELAM}-1$ (2, 22). RR1/1 (IgG1), reactive with ICAM-1 (23), was a kind gift of Dr. Rothlein (Boehringer Ingelheim, Ridgefield, CT). mAb MOPC 21 (IgG1), a non specific control antibody, was kindly provided by Celltech (Slough, UK). mAb 60.3 (IgG2a), reactive with CD18 (24) was a kind gift of Dr. P.G. Beatty (Fred Hutchinson Cancer Research Center, Seattle, WA). mAb IB4 (IgG2a), reactive with CD18 (25), was a generous gift of Dr. M. Daha, University Hospital Leiden, The Netherlands. mAb CLB-LFA $1 / 1$ (IgG1), reactive with CD18 (26) and CLB-LFA 1/2 (IgG2), reactive with CD11a (27) were kindly given by Dr. R.A.W. van Lier, CLB, Amsterdam, The Netherlands. mAb 25.31 (IgGI), reactive with CDIla (28), was generously provided by Dr. C. Mawas, INSERM, Marseille, France. $\mathrm{mAb} 44$ (IgGl), reactive with CD11b (29) and mAb 3.9 (30), reactive with CDIlc were kindly provided by Dr. N. Hogg, ICRF, London, UK. mAb PDV 11.2 (IgG2a) reactive with CD11b (31) was a gift of Dr. F. Koning, University Hospital Leiden, The Netherlands. mAb 904, (IgG1) reactive with CDI1b (32) was a generous gift of Dr. J.D. Griffin, Dana Farber Cancer Institute, Boston, MA. F(ab'), frag- ments were prepared by pepsin digestion (Immobilized Pepsin, Pierce, Rockford, IL) as described (2).

\section{Cells}

HUVEC were obtained by collagenase treatment of the human umbilical vein. The cells were cultured in fibronectin-coated (fibronectin kindly provided by Dr. J. van Mourik, CLB, Amsterdam, The Netherlands) tissue culture flasks (Costar, Cambridge, MA) in RPMI-1640 (Gibco Europe, Paisley, Scotland), supplemented with $10 \%$ heat-inactivated human serum, $10 \%$ heat-inactivated bovine calf serum (BCS) (Hyclone, Logan, UT), $50 \mu \mathrm{g} / \mathrm{ml}$ heparin (Sigma), $30 \mu \mathrm{g} / \mathrm{ml}$ endothelial growth supplement (Collaborative Research Incorporated, Bedford, MA) and antibiotics.

Endothelial cells were characterized by their pavement-like monolayer morphology and positive staining with $\mathrm{mAb}$ hec7 directed against PECAM-1 (33), generously provided by Dr. W.A. Muller, Rockefeller University, NY, and with the anti ELAM-1 mAb ENA1 and ENA2 after $4 \mathrm{~h}$ incubation with TNF- $\alpha$. Neutrophils were prepared from buffy coats of donor blood kindly provided by the local blood bank, using standard techniques of buoyant density centrifugation on Lymphoprep (Nycomed, Oslo, Norway), followed by separation of neutrophils from erythrocytes by density gradient centrifugation on percoll (1.08g/ml, Pharmacia, Uppsala, Sweden). Neutrophil preparations contained $<5 \%$ contaminating cells, as evaluated by May Grunwald Giemsa staining.

\section{Injury assay.}

${ }^{51} \mathrm{Cr}$-release and detachment assays were performed essentially as described by Diener et 
al. (34). HUVEC (passage 3) were grown to confluence during $24 \mathrm{~h}$ in fibronectin-coated 96-well, flat bottom, microtiter plates (Costar). Final plating density was $\pm 2 \times 10^{1}$ cells/well (well-surface: $0.32 \mathrm{~cm}^{2}$ ). The last $16 \mathrm{~h}$ of this culture Chromium-51 as sodium $\left[{ }^{s !} \mathrm{Cr}\right]$ chromate was added to the wells $(18 \mathrm{kBq} /$ well, specific activity $11 \mathrm{~GB} q / \mu \mathrm{g} \mathrm{Cr}$ ).

At the beginning of the assay monolayers were carefully washed by five successive exchanges of 200 $\mu \mathrm{l} /$ well RPMI-1640 $1 \%$ BCS. Neutrophils and reagents in RPMI1640 supplemented with $10 \%$ BCS were added to the monolayer as indicated, at a final volume of $200 \mu \mathrm{l} /$ well, and incubations were performed at $37^{\circ} \mathrm{C}$. for $3 \mathrm{~h}$, unless mentioned otherwise. Endothelial cell lysis was determincd by measuring ${ }^{51} \mathrm{Cr}$ release in 100 ul cell-free supematant medium, removed from each well with care not to disturb the monolayer. Next, $100 \mu \mathrm{l}$ of fresh medium was added to the remaining $100 \mu$ in each well.

Detached endothelial cells were suspended by repeated careful pipelting, and $100 \mu \mathrm{l}$ of this suspension was removed to determine detachment (these samples thus contained $50 \%$ of the amount of ${ }^{51} \mathrm{Cr}$ in the lysis samples, plus the "Cr present in the detached cells in the sample). Control monolayers remained visually confluent after performing this procedure. Maximal ${ }^{31} \mathrm{Cr}$ content was determined in wells receiving $100 \mu \mathrm{l}$ of $1 \mathrm{~N}$ $\mathrm{NaOH}$, and reached about $10^{5} \mathrm{dpm}$. All samples were counted in a gamma-spectrophotometer. Detachment values were calculated by subtracting half of the ${ }^{51} \mathrm{Cr}$ counts measured in the lysis samples drawn from the same wells, from the ${ }^{51} \mathrm{Cr}$ counts measured in the detachment samples. Furthermore, meas- urements of endothelial cell lysis and endothelial cell detachment were corrected for non-specific ${ }^{\text {s1 }} \mathrm{Cr}$ content, by subtracting ${ }^{51} \mathrm{Cr}$ counts measured in lysis/detachment samples from wells without effector cells (in these wells spontaneous ${ }^{51} \mathrm{Cr}$ release and endothelial cell detachment ranged from 5 to $10 \%$ of total ${ }^{51} \mathrm{Cr}$ content).

\section{Adherence assay}

A visual adherence assay, essentially as described by C.W. Smith et al. (35) was utilized. Sterile microscope-slides were gelatincoated by incubation with $0.75 \%$ gelatin (Difco, Detroit, MI) in PBS for $15 \mathrm{~min}$ at room temperature (RT), fixed with $0.5 \%$ glutaraldehyde (Merck, Darmstadt, FRG) in PBS for 10min at RT, dip-rinsed 3 times in PBS, and air-dried. Slides were seeded with HUVEC one day prior to the experiment. Slides with visually confluent HUVEC monolayers were placed in specially constructed adherence chambers.

The chambers consisted of two metal clamps holding an uncoated and a HUVEC coated microscope slide, separated by two rubber O-rings ( $\varnothing 25 \mathrm{~mm}$ ). Within these two closed compartments neutrophils could be observed, using an inverted microscope with phase contrast optics. Neutrophils were pre-

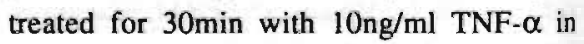
RPMI-1640 supplemented with $10 \%$ BCS and antibiotics at $4^{\circ} \mathrm{C}$ in polypropylene tubes, and washed twice with ice-cold medium, or handled identically without TNF- $\alpha$ addition.

Subsequently, neutrophils were suspended in RPMI-1640 supplemented with $10 \%$ BCS and antibiotics at $5 \times 10^{4} \mathrm{cells} / \mathrm{ml}$ and further incubated with $\mathrm{mAb}(5 \mu \mathrm{g} / \mathrm{ml})$ for $5 \mathrm{~min}$ at $37^{\circ} \mathrm{C}$. Thereafter, $800 \mu \mathrm{l}$ neutrophil suspen- 
sion was added to the chambers and allowed to settle onto the monolayer for a period of $10 \mathrm{~min}$ at $37^{\circ} \mathrm{C}$. The number of neutrophils present on the monolayer was determined by counting adherent neutrophils in 4 microscopic fields ( $x 40$ objective), and the chambers were inverted for another $10 \mathrm{~min}$ at $37^{\circ} \mathrm{C}$.

In the same fields, the percentage of cells remaining adherent on the monolayer was determined. In the results, the average of these 4 fields is expressed as percentage adherence.

\section{$\mathrm{H}_{2} \mathrm{O}_{2}$ measurements}

A colorimetric method was used to determine $\mathrm{H}_{2} \mathrm{O}_{2}$ production (36). HUVEC coated microtiter-plates, identical to the plates used in the injury assays, and microtiterplates coated with $50 \%$ BCS in RPMI-1640 for $60 \mathrm{~min}$ at RT, were used. Neutrophils and agents were suspended/dissolved in RPMI1640 supplemented with $10 \% \mathrm{BCS}$, antibiotics, $200 \mu \mathrm{g} / \mathrm{ml}$ phenol red (Sigma) and $8.5 \mathrm{u} / \mathrm{ml}$ Horse radish peroxidase (type VI, Sigma).

Ncutrophils were preincubated with $10 \mathrm{ng} / \mathrm{ml}$ TNF- $\alpha$ for $30 \mathrm{~min}$ at $4^{\circ} \mathrm{C}$, rinsed twice, and added to the wells at $2.5 \times 10^{5} \mathrm{cells} /$ well, together with mAb (at a final concentration of $5 \mu \mathrm{g} / \mathrm{ml}$ ), to a final volume of $200 \mu \mathrm{l} /$ well, and incubated for $3 \mathrm{~h}$ at $37^{\circ} \mathrm{C}$. A standard $\mathrm{H}_{2} \mathrm{O}_{2}$ dilution range (highest concentration $100 \mu \mathrm{M})$ was used.

Samples $(150 \mu \mathrm{L} /$ well) were carefully removed at the end of the incubation period and $O D$ was determined at $620 \mathrm{~nm}$ after addition of $50 \mu \mathrm{l} 2 \mathrm{M} \mathrm{NaOH}$. The lower sensitivity of the assay was $1.6 \mu \mathrm{M} \mathrm{H}_{2} \mathrm{O}_{2}$.

\section{Detection of endothelial cell-surface} antigens

HUVEC coated microtiter-plates, identical to the plates used in the injury assay, were washed and fixed with $0.05 \%$ glutaraldehyde for $10 \mathrm{~min}$ at RT. ELAM-1 and ICAM-1 expression were determined in ELISA's, using the ELAM-1 specific MAb ENAl, and the ICAM-1 specific mAb RR1/1, followed by peroxidase conjugated goat anti-rabbit IgG. O-Phenylene-diamine (Sigma) was added as a substrate and photospectometry was performed with a Microtiter ELISA reader at $492 \mathrm{~nm}$.

\section{Results}

\section{Effect of anti CDII and anti CDI8 mAb} on TNF- $\alpha$ induced neutrophil mediated

\section{endothelial cell detachment}

To assess the potential role of the $\alpha$ and $\beta$ chain of the $\beta_{2}$ integrin members CD1la/ $\mathrm{CD} 18, \mathrm{CD} 1 \mathrm{~b} / \mathrm{CD} 18$ and $\mathrm{CD} 11 \mathrm{c} / \mathrm{CD} 18$ in endothelial cell detachment induced by TNFpreincubated neutrophils, the influence of $\mathrm{mAb}$ directed against these molecules was tested. The effect of these mAb on adherence of TNF- $\alpha$ pretreated neutrophils to HUVEC was determined in parallel experiments. mAb IB4, mAb 60.3 and mAb CLB LFA 1/1, all reactive with $C D 18$ and added in concentrations adequate to reduce adherence of activated neutrophils to endothelium for more than $50 \%$ (Fig. 1), nearly completely prevented endothelial cell detachment induced by neutrophils preincubated with $10 \mathrm{ng} / \mathrm{ml}$ TNF- $\alpha$ for $30 \mathrm{~min}$ at $4^{\circ} \mathrm{C}$. mAb directed against CDIla, and two out of three $\mathrm{mAb}$ directed against CD1lb did not influence endothelial cell detachment, although significant inhibition of adherence (ranging from 30 to $50 \%$ ) was demonstrated in parallel 


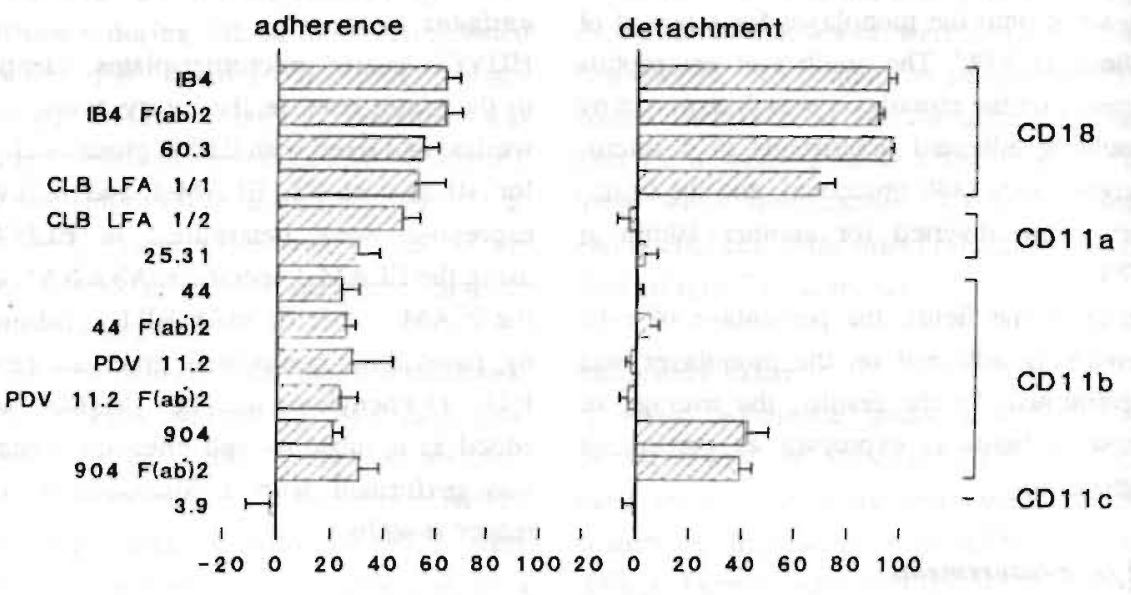

\section{$\%$ inhibition}

Figure I. Influence of anti CDII/CDI8 mAb on adherence of TNF- $\alpha$ stimulated neutrophils to endothelium (leff graph), and detachment of endothelium by TNF- $\alpha$ stimulated neutrophils (right graph). Newrophils were preincubated with $10 \mathrm{ng} / \mathrm{ml} \mathrm{TNF}$ - $x$ for $30 \mathrm{~min}$ at $\mathcal{H}^{\circ} \mathrm{C}$, and used in both the adherence and injury assays as mentioned in Materials and Methods, resulting in $19 \%$ neutrophil adherence and $62 \%$ HUVEC detachment. Data represent means and SE of the mA $b$ induced inhibition in adherence and detachment, compared to adherence and detachment by TNF- $\alpha$ activated neutrophils in absence of mAb, from 4 separate experinens.

experiments ( $p<0.05$ for each mAb, as compared with adherence in absence of mAb by the unpaired, two tailed Student's $t$-test). mAb 904, reactive with the LPS-binding region of $C D 11 b(32,37)$ induced a significant, $40 \%$ reduction in endothelial cell detachment $(p<0.01$ as compared with detachment in absence of $\mathrm{mAb}$ by the unpaired, two tailed Student's $t$-test).

$\mathrm{F}\left(\mathrm{ab}^{\circ}\right)_{2}$ fragments of al $\mathrm{CD} 11 \mathrm{~b}$ reactive $\mathrm{mAb}$ and of $\mathrm{mAb}$ IB4 directed against CD 18 were also tested, and found to have similar influences on TNF- $\alpha$ induced neutrophil mediated endothelial cell detachment (Fig. 1). Finally, the role of CD11c in endothelial cell detachment was investigated by using $\mathrm{mAb}$ 3.9 directed against $C D 11 \mathrm{c}$. Neither a reduction in detachment nor a reduction in adhe- sion, induced by this $\mathrm{MAb}$, was found.

MOPC 21 was used as a control mAb, and did affect neither detachment nor adhesion of neutrophils to endothelium (data not shown). The influence of anti CD18 and anti CD11a $\mathrm{mAb}$ on endothelial cell detachment was not specific for endothelium cultured on fibronectin-coated plastic, since culture of endothelium on gelatin-coated plastic instead of fibronectin-coated plastic did not markedly affect detachment values (data not shown).

\section{Effect of PHA induced neutrophil-} adherence on endothelial cell detachment by anti CDI8 treated neutrophils

To answer whether the above described inhibition of neutrophil detachment by anti $\mathrm{CD} 18 \mathrm{mAb}$ depended on the decrease in 

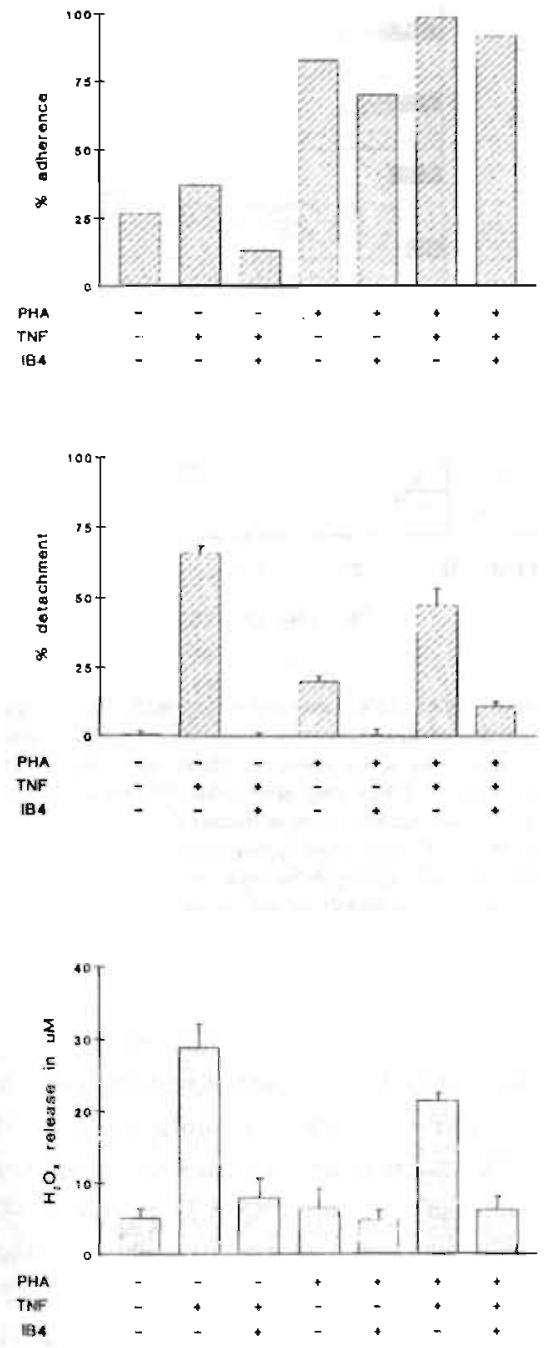

adhesion caused by these mAb, we investigated whether CD18 independent adherence could restore endothelial cell detachment by TNF- $\alpha$ activated and anti CD1 8 treated neutrophils. Addition of the multivalent lectin PHA was employed to induce CD 18 independent anchoring of neutrophils to the endothelium. PHA induced high levels of adherence of both TNF- $\alpha$ pretreated and untreated neutrophils, without increasing CD18 dependent neutrophil adhesiveness (Fig. 2A). A minor but reproducible increase in detachment of endothelial cells in presence of non-activated neutrophils was induced by PHA. IB4 preincubation of neutrophils inhibited endothelial cell detachment in presence of PHA by unstimulated as well as TNF- $\alpha$ stimulated neutrophils (Fig. 2B).

\section{The influence of ELAM-I and ICAM-I} on neutrophil-activation

Expression of ELAM-1 and ICAM-1 after TNF-stimulation of HUVEC, in conditions identically to HUVEC used for the detachment and $\mathrm{H}_{2} \mathrm{O}_{2}$-release assays, was assessed by ELISA as mentioned in Materials and Methods. ELAM-1 expression was found (o) be below the detection level of the assay in unstimulated wells, and was 1.84 ( $\mathrm{A}$ at $492 \mathrm{~nm}$ ) after $4 \mathrm{~h}, 1.87$ after $6 \mathrm{~h}$, and 1.54 after $8 \mathrm{~h}$ of activation.

The time-interval between 4 and 7 hours after beginning of TNF-activation was therefore considered to be the most appropriate time to study the influence of ELAM-1 expression on neutrophil activation. ICAM-1

Figure 2. Influence of PHA on adherence (A), $\mathrm{HUVEC}$ detachment (B) and $\mathrm{H}_{2} \mathrm{O}_{2}$-release (C). Neutrophils were subjected to none, one, or both of the following: preincubation with $10 \mathrm{ng} / \mathrm{ml}$ TNF-a for $30 \mathrm{~min}$ at $4^{\circ} \mathrm{C}$, and preincubation with $5 \mu \mathrm{g} / \mathrm{ml}$ IB4 for $30 \mathrm{~min}$ af $4^{\circ} \mathrm{C}$. Subsequently, neutrophils were added together with PHA (final concentration 1 so) to both assays. Measurements were performed as described in Maserials and Methods. Values are mean and SD of 4 measuremenis. A representative experiment oul of a series of 3 is shown. 

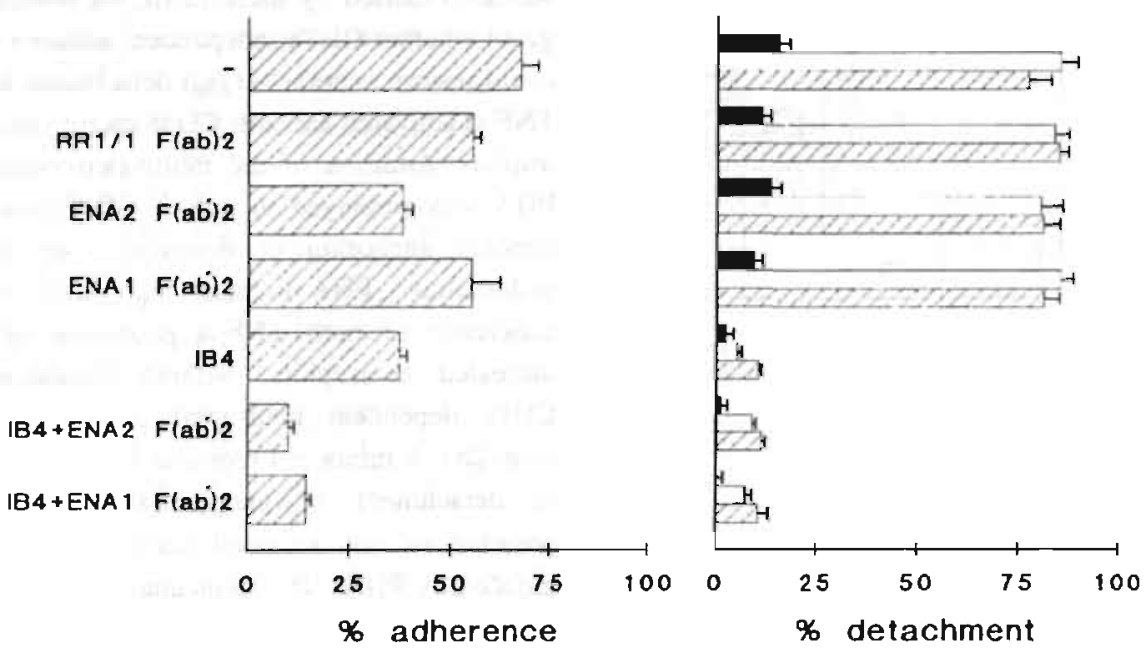

Figure 3. Influence of anti ICAM-I mAb (RRI/I), anti ELAM-I MAb (ENA1, ENA2) and anti CDI8 mAb (IBA) on neutrophil adherence to endothelium (left graph), and neutrophil mediated detachment of endothelium (right graph). Desachment was measured after HUVEC activation (filled bars), neutrophil activation (open bars) and both HUVEC and neutrophil activation (hatched bars). Adherence was measured after HUVEC and neutrophil activation. HUVEC were activated by incubation with $10 \mathrm{mg} / \mathrm{ml} T N F-\alpha$ for $4 \mathrm{~h}$ at $37^{\circ} \mathrm{C}$. Neutrophils were activated by incubation with $10 \mathrm{mg} / \mathrm{ml} \mathrm{TNF}-\alpha$ for $30 \mathrm{~min}$ at $4^{\prime \prime} \mathrm{C}$. Monolayers were incubated for $5 \mathrm{~min}$ at $R T$ with $\left.F(a)^{\prime}\right)_{2}$, fragments of the ant ELAM1 and ICAM-1 mAb directly before adding neutrophils plus the intact anti CDI8 mAb. Adherence and detachment assays were performed as described in Materials and Methods. Unstimulated neutrophils added to unstimulated HUVEC showed $18 \pm 4 \%$ adherence and induced $4 \pm 4 \%$ HUVEC detachment in absence of $m A b$. Data given are mean and $S E$ of 8 measurements from two independent experiments.

expression was increased from 0.18 at $\mathrm{t}=0$ to 0.92 after $4 \mathrm{~h}$ and 1.14 after $18 \mathrm{~h}$ of TNF- $\alpha$ stimulation. Neutrophil adhesion was increased from $18 \%$ to $62 \%$ by 4 h TNF- $\alpha$ stimulation of HUVEC.

Up to $43 \%$ of this adherence was inhibited by anti ELAM-1 mAb, whilst a smaller but significant reduction was induced by $F\left(a^{\prime}\right)_{2}$ fragments of RR $1 / 1$ directed against ICAM 1 (Fig. 3 lefi graph, $<<0.05$ as compared with adherence in absence of mAb by the unpaired, two tailed Student's $t$-test).

Substantial neutrophil mediated detachment of TNF- $\alpha$ activated endothelial cells was only seen after neutrophil activation by TNF$\alpha$, and was not further increased by previous activation of the endothelial cells (Fig. 3 right graph). Detachment of endothelial cells from TNF- $\alpha$ activated monolayers induced by TNF- $\alpha$-pretreated neutrophils could only be inhibited by the anti CD18 mAb IB4. $F\left(a b^{\prime}\right)_{2}$ fragments of the ELAM-1 specific mAb ENA1 and ENA2, and $F\left(a^{\prime}\right)_{2}$ fragments of the ICAM-1 specific mAb RR $1 / 1$ failed to induce a significant reduction in endothelial cell detachment (Fig. 3 right graph).

These experiments were repeated using neutrophils which were activated by coincubation with TNF during the detachment assay. Again we found no influence on endothelial cell detachment by $4 \mathrm{~h}$ TNF activation of 
A

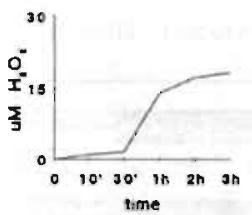

B

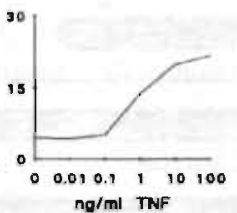

C

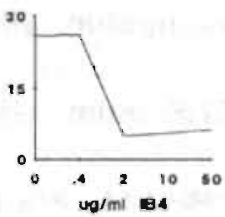

HUVEG

IB4

IB4 $F(a b) 2$

60.3

CLB LFA $1 / 1$

CLB LFA $1 / 2$

25.31

44

$44 \mathrm{~F}(\mathrm{ab}) 2$

PDV 11.2

PDV $11.2 \quad F(a b) 2$

904

$904 F(a b) 2$

3.9

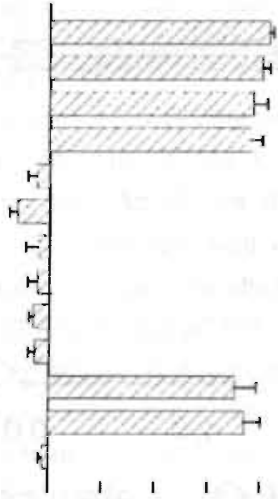

$-20$

204

- $6080100-20$
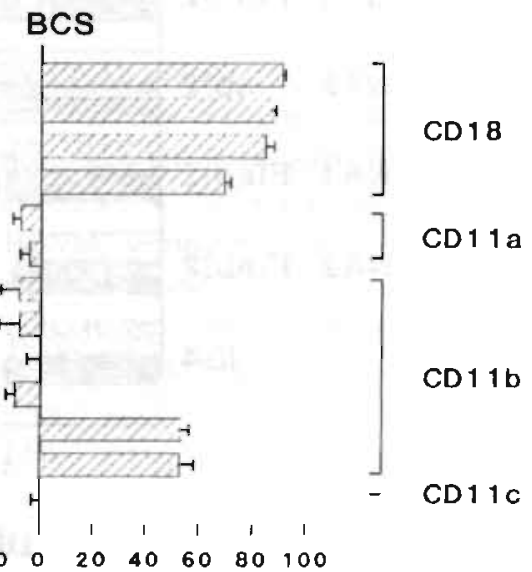

\% inhibition

Figure 4. Influence of anti $\mathrm{CD} / \mathrm{I} / \mathrm{CD} / 8 \mathrm{mAb}$ on $\mathrm{H}_{2} \mathrm{O}_{2}$ release by $\mathrm{TNF}$-a stimulated netutriphits placed on either endo. thelium (lefi graph) or BCS coated plasric (right graph). Insels: (A) $\mathrm{H}_{2} \mathrm{O}_{2}$ release in time by $10 \mathrm{ng} / \mathrm{ml} \mathrm{TNF}$ - $\mathrm{Q}$ stimulated neutrophils on endoshelium. (B) $\mathrm{H}_{2} \mathrm{O}_{2}$ release by neutrophils, preincubated with differemi cancentrations of $7 \mathrm{NF}-\alpha_{\text {, }}$ on endothelium, after $3 \mathrm{~h}$ of culture. (C) Effect of different concentrations of mAb IB4, directed against $\mathrm{CD} / \overline{8}$ an $\mathrm{H}_{2} \mathrm{O}_{2}$ release by $10 \mathrm{ng} / \mathrm{ml}$ TNF- $\alpha$ stimulated neutrophils on endothelium. Main Figure: Neutrophils were preinculiated wish $10 \mathrm{gg} / \mathrm{ml}$ TNF- $\alpha$ for $30 \mathrm{~min}$ at $4^{\circ} \mathrm{C}$, and added $1096-$ well microtiter plates which had been seeded with HUVEC ar coat. ed with BCS mAb were added together with the neutrophils to a final concentration of $5 \mu \mathrm{g} / \mathrm{an}$ each. $\mathrm{H}_{2} \mathrm{O}_{2}$ release was measured affer 3 h at $37^{\circ} \mathrm{C}$, and reached $37 \mu \mathrm{M}$ on HUVEC and $58 \mu \mathrm{M}$ on BCS caated plastic in absence of mAb Datal represent means and SD of the mAb induced inhibition in $\mathrm{H}_{2} \mathrm{O}_{2}$-release, compared to $\mathrm{H}_{5} \mathrm{O}_{2}$-release by TNF-x acrivated neutrophils in absence of mAb, from 4 measurements. A representave experinent out of a series of 3 is shown.

HUVEC, nor by subsequent addition of anti ELAM-1 and anti ICAM-1 antibody-fragments (data not shown). Also, prolonged TNF-activation of HUVEC to further increase ICAM-1 expression did not result in HUVEC activation dependent alterations in the amount of neutrophil mediated endothelial cell detachment.

\section{Receptor involvement in TNF- $\alpha$ induced} $\mathrm{H}_{2} \mathrm{O}_{2}$ release

To further asses whether CDI1/CD18, ELAM-1 and ICAM-1 receptors were involved in the activation of TNF-primed ncutrophils, we studied the influence of specific mAb on TNF- $\alpha$ induced $\mathrm{H}_{2} \mathrm{O}_{2}$ release by neutrophils placed on HUVEC and BCS 


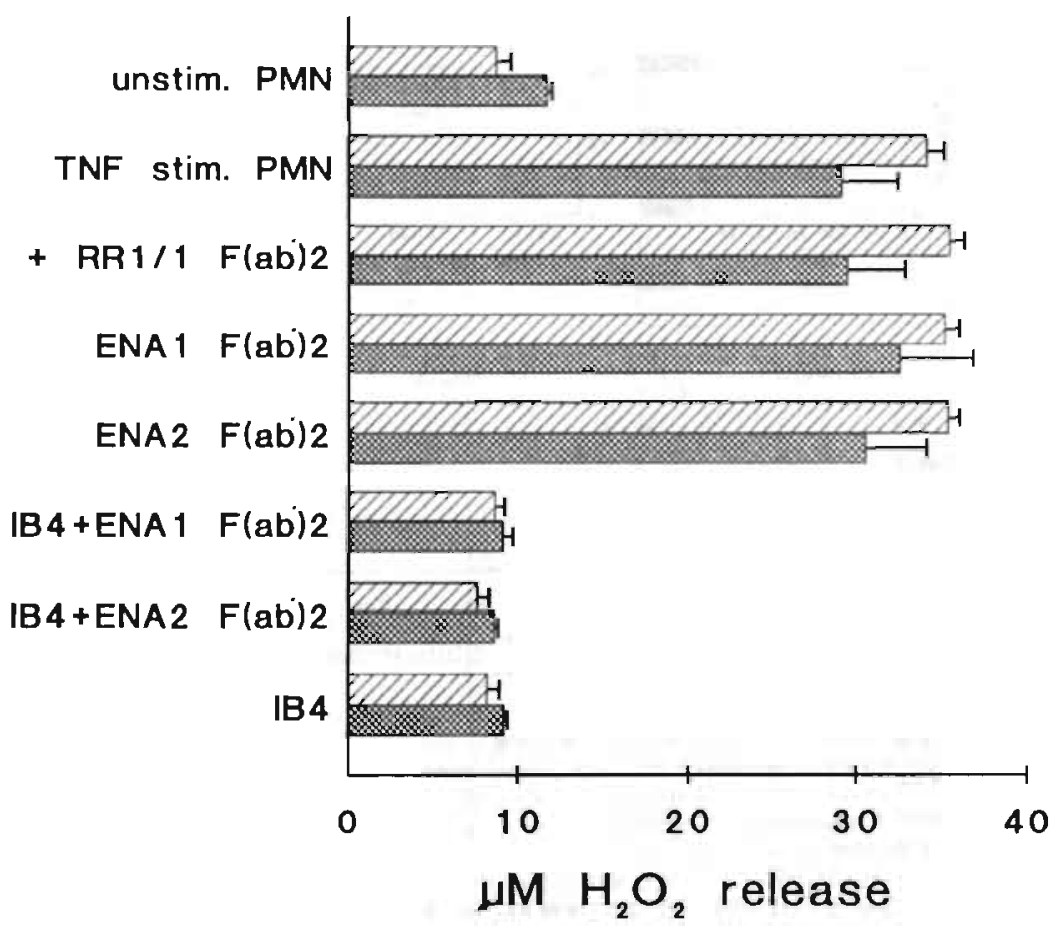

Figure 5. Influence of anti ELAM-I mAb (ENAI, ENA2), anti ICAM-I mAb (RRI/I), and anti CDI8 mAb(IB4) on $\mathrm{H}_{2} \mathrm{O}_{2}$ release by TNF- $\alpha$ stimulated neutrophils. Neutrophils were pretreated for $30 \mathrm{~min}$ with $10 \mathrm{mg} / \mathrm{ml}$ TNF- $\alpha$ at $4^{\circ} \mathrm{C}$ (TNF stim. PMN), or handled identically without TNF $\alpha$ addition (unstim. PMN), and added to unstimulated HUVEC (hatched bars) or HUVEC activated with $10 \mathrm{ng} / \mathrm{ml}$ TNF- $\alpha$ for $4 \mathrm{~h}$ (cross hatched bars). Expression of ELAM-1 and ICAM-1 was confirmed by ELISA in parallel microtiter plates. Monolayers were incubated for 5 min at $R T$ with $F\left(a b^{\prime}\right)_{2}$ fragments of the anti ELAM-I mAb or anti ICAM-I mAb, directly before adding neutrophils with or without the intact ant CDI8 $m A h . H_{2} \mathrm{O}_{2}$ release was measured afier $3 h$ ar $37^{\circ} \mathrm{C}$. Data indicate mean and $S D$ of 4 replicates. A representative experiment out of a series of 4 is shown.

coated plastic. TNF- $\alpha$ pretreatment augmented neutrophil $\mathrm{H}_{2} \mathrm{O}_{2}$ release on endothelial cell monolayers (Fig. 4 insets $A$ and $B$ ). and on BCS coated plastic (data not shown) in a clear time and concentration dependent manner . Intact as well as $F\left(a b^{\prime}\right)_{2}$ fragments of mAb directed against CD18 and of mAb 904 directed against the LPS binding region of CD11b, were found to prevent the TNF- $\alpha$ induced increase in $\mathrm{H}_{2} \mathrm{O}_{2}$ release on HUVEC (Fig. 4 main figure and inset $C$ ).
Again, presence of mAb directed against CD1 la, CD1 lc and presence of the other two anti CD11b mAb during the assay did not decrease $\mathrm{H}_{2} \mathrm{O}_{2}$ release. mAb inhibition-levels, using either BCS coated plastic or HUVEC grown on fibronectin coated plastic as a substrate for neutrophil adherence, were mainly identical, indicating that $\mathrm{CD} / \mathrm{lb} /$ CD18 mediated contact-activation of TNFprimed neutrophils did not engage a ligand restricted to HUVEC. 
Furthermore, we determined whether TNF- $\alpha$ stimulated neutrophils released $\mathrm{H}_{2} \mathrm{O}$, in presence of anti CD $18 \mathrm{mAb}$, after increasing CD18 independent adhesion by addition of PHA or by $4 \mathrm{~h}$ TNF activation of HUVEC. Neither presence of PHA nor 4h TNF activation of HUVEC induced a clear increase in neutrophil $\mathrm{H}_{2} \mathrm{O}_{2}$ release.

Also, the increase in $\mathrm{H}_{2} \mathrm{O}_{2}$ release induced by TNF- $\alpha$ pretreatment could, in both situations, still be reduced to basal levels by anti CDI8 mAb (Fig. 2C and 5). Blocking interaction between ELAM-1 or ICAM-1 and neutrophils using specific $m A b$ did not affect the release of $\mathrm{H}_{2} \mathrm{O}_{2}$ by TNF-activated neutrophils (Fig. 5), demonstrating the absence of engagement of ELAM-I and ICAM- 1 in $\mathrm{H}_{2} \mathrm{O}_{2}$-release by TNF-activated neutrophils. Identical $\mathrm{H}_{2} \mathrm{O}_{2}$-release levels were obtained using neutrophils which were activated by coincubation with TNF during the assay. No influence in neutrophil $\mathrm{H}_{2} \mathrm{O}_{2}$-release was found by placing neutrophils on $4 \mathrm{~h}$ TNF activation of HUVEC, or by subsequent addition of anti ELAM- 1 and of anti ICAM-1 antibody-fragments (data not shown).

\section{Discussion}

The cytokine TNF- $\alpha$ is reported to be a powerful stimulus for neutrophil mediated endothelial cell damage (7) and neutrophil $\mathrm{H}_{2} \mathrm{O}_{2}$ release $(10,11,14,15)$. Both endothelial cell damage and neutrophil $\mathrm{H}_{2} \mathrm{O}_{2}$ release require neutrophil-substratum interaction $(10,11,14,15,34)$, a process which might involve known adhesion mediating structures, like the CD11/CD 18 complex and the inducible endothelial cell adhesion molecules ELAM-1 and ICAM-1.
The role of these inolecules in TNF- $\alpha$ indueed neutrophil mediated endothelial cell detachment and $\mathrm{H}_{2} \mathrm{O}_{2}$ release, as facets of neutrophil toxicity, was investigated here by assessing the influence of $\mathrm{mAb}$ on the adhesion to endothelium, on endothelial cell detachment by neutrophils and on $\mathrm{H}_{2} \mathrm{O}_{2}$ release by neutrophils.

Two mAb reactive with CDIla were tested and found not to interfere with TNF-induced neutrophil activation, although they reduced adherence of TNF-stimulated neutrophils to HUVEC. Furthermore, mAb RRl/1 reactive with the ligand for CDIla on endothelial cells. ICAM-1, did not decrease neutrophil mediated endothelial cell detachment or neutrophil $\mathrm{H}_{2} \mathrm{O}_{2}$-release. The CDIla/CD18 or LFA-1 dimer therefore appeared not to be involved in activation of TNF-primed neutrophils. This finding is in concordance with previous literature on zymosan and FMI.P induced neutrophils activation, in which anti CDlla mAb did not reduce activation (38-40).

For neutrophils, the function of CDIlat CD1 8 dimer and of ICAM-1 therefore seems to be limited to adherence and monolayertransmigration (21), although $\mathrm{CD} 11 \mathrm{a} / \mathrm{CD} 18$ is capable of triggering cellular activation of lymphocytes $(27,41)$ and monocytes (42).

Up to $95 \%$ inhibition of endothelial cell detachment induced by TNF-activated neutrophils, and of $\mathrm{H}_{2} \mathrm{O}_{2}$-release by TNF- $\alpha$ activated neutrophils on either endothelium or BCS coated plastic was achieved by several mAb directed against the common $\beta$-chain of the $\mathrm{CD} 11 / \mathrm{CD} 18$ hetero-dimer. Intact antibodies or $F\left(a b^{*}\right)_{2}$ fragments of $m A b 904$, 
directed against the LPS binding region of CD11b $(32,37)$, reduced these neutrophil activities for 40 to $75 \%$. The CD11b/CD18 integrin, also known as complement receptor 3 or Mac-1, therefore appeared to have a major role in mediating endothelial cell detachment and $\mathrm{H}_{2} \mathrm{O}_{2}$-release by TNF-activated neutrophils. Involvement of $\mathrm{CD} 18$ in adherence dependent $\mathrm{H}_{2} \mathrm{O}_{2}$ release by TNFactivated neutrophils has been worked out by Nathan et al. $(14,43)$, and confirms our observations. In contrast with our results, Nathan et al. found no influence of addition of intact mAb 904 on $\mathrm{H}_{2} \mathrm{O}_{2}$-release by TNFactivated neutrophils (14). Although we have no explanation for this discrepancy, CD11b involvement in TNF-induced neutrophil activation appears to be presumable, since $\mathrm{CD} 1 \mathrm{lb} / \mathrm{CD} 18$ was found to be crucial in activation of neutrophil $\mathrm{H}_{2} \mathrm{O}_{2}$-release by other stimuli such as FMLP (38) and zymo$\operatorname{san}(39,40)$, and activation via $\mathrm{CD} 18$ is generally considered to depend on the ligandinteraction via one of its $\alpha$-chains.

CD1 lb has two binding sites, each engaged in the binding of distinct classes of ligands $(32,37)$. One site is capable of recognizing Arg-Gly-Asp containing proteins, such as C3bi, fibrinogen, Leishmania gp 63 and an unidentified ligand on endothelial cells (44). Interactions between these ligands and CD1lb do not induce neutrophil respiratory burst activity $(40,45)$. The other domain recognizes bacterial LPS, lipid A, zymosan and protein coated plastic, and is engaged in chemotaxis and respiratory burst activation $(32,37,40)$.

We observed an inhibition of TNF-induced neutrophil toxicity by mAb 904 , reactive with the latter domain, whilst two other anti CD11b mAb remained uneffective. Specific involvement of the LPS-binding region in a crucial, adherence induced, activation signal, passed to the neutrophil via $\mathrm{CD} 18$, thus appears to be the most logical explanation for this finding. The observed absence of inhibition of neutrophil mediated activation together with significant reductions in adherence by the anti CD11b mAb 44 and PDV11.2 might depend on an inhibition of ligand-interactions with the Arg-Gly-Asp binding region in absence of inhibition of the function of the LPS-binding region of CD11b. Further evidence that signal transduction instead of passive adherence is the specific function of CD11b/CD18 in TNFinduced neutrophil activation, was obtained by showing that CD18 independent adherence via addition of PHA, or by induction of ELAM-1 expression, could not overcome the inhibition of TNF- $\alpha$ induced neutrophil toxicity by anti CD $18 \mathrm{mAb}$.

One to five hour TNF- $\alpha$ or IL-1 preincubation of endothelium has been described to induce an increase in neutrophil mediated endothelial injury $(46,47)$, whilst others found no influence on endothelial cell injury and neutrophil activation $(6,48)$. We therefore investigated whether 4 hour TNF-preincubation of endothelium, and more specifically, whether de novo ELAM-1 expression, and increased ICAM-1 expression by 4 hour TNF-preincubated endothelium could trigger neutrophil mediated endothelial cell detachment and neutrophil $\mathrm{H}_{2} \mathrm{O}_{2}$-release.

We report here that neutrophil interaction with neither ELAM-1 nor ICAM-1 contributes to neutrophil toxicity, since $\mathrm{mAb}$ 
against these molecules did not reduce endothelial cell injury or $\mathrm{H}_{2} \mathrm{O}_{2}$-release by either unstimulated or TNF-preincubated neutrophils. Furthermore we showed that 4 hour TNF-preincubation of HUVEC did not increase $\mathrm{H}_{2} \mathrm{O}_{2}$-release by neutrophils placed un such endothelium, and thus extended our previous observation that TNF-activation of endothelial cells did not increase there vulnerability to, or trigger additional injury by TNF- $\alpha$ stimulated neutrophils (7).

The importance of the CD11/CD18 integrin for tissue injury in vivo has been demonstrated in a number of animal models. Addition of anti CD18 mAb showed to reduce tissue injury as well as mortality in ischaemia reperfusion induced shock in rabbits and monkeys $(49,50)$, and in bacterial meningitis in rabbits (51). In one study, the anti CD1lb mAb OKM1 was shown to reduce the myocardial infarct-size in dogs (52).

Specific engagement of CD11b/CDI8, via a pathway in which interactions with the lectin-like site of CD11b result in an CD18 transduced activation of previously primed neutrophils might thus be a major mechanism responsible for ischaemia or endotoxin induced tissue injury. In contrast, induction of local entrapment and transendothelial migration of leukocytes, without triggering local injury, might be the main function of increased ELAM-1 and ICAM-1 expression by activated endothelial cells.

A more detailed understanding of the function of the CD11/CD18 heterodimer en of endothelial cell adhesion molecules could add to the therapeutic potential for the management of syndromes with a neutrophil injury involving pathogenesis, like multiple organ failure, or acute allograft rejection.

\section{References}

1. Bevilacqua, M. P. J. S. Pober, D. L. Mendrick, R. S. Cotran, and M. A. Gimbrone. 1987. Identification of an inducible endothelial-leukocyte adhesion moleculc. Proc. Natl. Acad. Sci. USA. 84;9238.

2. Leeuwenberg. J. F. M., G. M. A. A. Jeunhonume, and W. A. Buurman. 1990. Adhesion of polymorphonuclear cells to human endothelial cells. Adhesionmolecule-dependent and Fe-receptor-mediated adhesion-molecule-independent mechanisms. Clin. Exp. ImmunoL 81:496.

3. Dustin, M. L., and T. A. Springer. 1988. Lymphocyte function-asscciated antigen-1 (LFA-1) interaction with intercellular adhesion molecule-1 (ICAM-1) is one of at least three mechanisms for lymphocyte adhesion to cultured endothelial cells. J. Cell. Biol. 107:321.

4. Pober, J. S., M. A. Gimbrone Jr., L. A. Lapierre, D. L. Mendrick. W. Fiers, R. Rothlein, and T. A. Springer. 1986. Overlapping patterns of activation of human endotheliul cells by interleukin 1 , tumor necrosis factor, and immune interferon. J. ImmunoL 137:1893.

5. Furie. M. B., and D. D. Melugh. 1989. Migration of neutrophils across endothelial monolayers is stimulated by treatment of the monolayers with interleukin-1 or tumor necrosis factor- $\alpha$. J. Immunol 143:3309.

6. Moser, R. B. Schleiffenbaum, P. Groscurth, and J, Fehr. 1989. Interleukin $I$ and tumor necrosis factor stumulate hurnan vascular endothelial cells to promote transendothelial passage, J. Clin. Invest. 83:44.

7. von Asmuth, E. J. U., J. F. M. Leeuwenterg. C. J. van der Linden, and W. A. Buurnan. 1991. Tumour necrosis factor- $\alpha$ induces neutrophil mediated injury of human endothelial cells, an in vitro study. Scand. J. Immunol. 34:197.

8. Lo, S. K., P. A. Detmers, S. M. Levin, and S. D. Wright. 1989. Transient adhesion of neutrophils to endothelium. J. Exp. Med. 169:1779.

9. Lo, S. K., G. A. van Seventer, S. M. Levin, and S. D. Wright. 1989. Two letukocyte receptors (CD1 la/CD18 and CD1 lb/CD18) mediate transient adhesion to endothelium by binding to different ligands. J. Immunol 143:3325.

10. Nathan, C. F. 1987. Neutrophil activation on biological surfaces. J. Clin. Invest. 80:1550.

11. Schleiffenbaun, B., and J. Fetr. 1990. The tumor necrosis factor receptor and human neutiophil func. tion. J. Clin. Invest. 86:184.

12. Richter, J., T. Andersson, and I. Olsson. 1989. Effect of tumor necrosis factor and granulocyte/macrophage: colcny-stimulating factor on neutrophil degranulation. J. ImmunoL 142:3199.

13. Kownatzlej, E., A. Kapp, and S. Uhrich. 1988. Modulaton of buman neutrophilic granulocytes by recombinant buman turnor necrosis factor and recombinant human lymphotoxin. Promotion of adherence, inhibition of chemotactic migration and superoxide anion 
release from adherent cells. Clin. Erp. ImmunoL 74:143.

14. Nathan, C., S. Srimal, C. Farber, E. Sanchez, L. Kabbash, A. Asch, J. Gailit, and S. D. Wright. 1989. Cytokine-induced respiratory burst of human neutrophils: dependence on exrracellular matrix proteins and CD11/CD18 integrins. J. Cell BioL 109:134I.

15. Neumann, M., and E. Kownatzki. 1989. The effect of adherence on the generation of reactive oxygen species by human neutrophilic granulocytes. Agents and Actions 26:183.

16. Smith, C. W. S. D. Marlin, R. Rothlein, C. Toman, and D. C. Anderson. 1989. Cooperative interactions of LFA-1 and Mac-1 with intercellular adhesion molecule-1 in facilitating adherence and transendothelial migration of human neutrophils in vitro. J. Clin. Invest 83:2008.

17. Stoolman, L.M. 1989. Adhesion molecules controlling lymphocyte migration. Cell 56:907.

18. Lowe, J. B., L. M. Stoolman, R. P. Nair, R. D. Larsen, T. L. Bernhend, and R. M. Marks. 1990. ELAM-1dependent cell adhesion to vascular endothelium determined by a transfected human fucosyltransferase cDNA. Cell 63:475.

19. Phillips, M. L., E. Nudelman, A. Gaeta, M. Perez, A. Singhal, S. I. Hakomori, and J. C. Paulson. 1990. ELAM-1 mediates cell adhesion by recognition of a carbohydrate ligand, sialyl-Lex. Science 250:1130.

20. Walz, G., A. Aruffo, W. Kolanus, M. Bevilacqua, and B. Seed. 1990. Recognition by ELAM-1 of the sialylLex determinant on myeloid and tumor cells. Science 250: 1132.

21. Lawrence, M. B., C. W. Smith, S. G. Eskin, and L. V. McIntire. 1990. Effect of venous shear stress on CD18-mediated neutrophil adhesion to cultured endothelium. Blood 75:227.

22. Leeuwenberg, J. F. M. G. M. A. A. Jeunhomme, and W. A. Buurman. 1990. Characterization of two monoclonal antibodies directed against an adhesion molecule on endothelial cells. Transplant. Proc. 22:1991.

23. Rothlein, R., M. L. Dustin, S. D. Marlin, and T. A. Springer. 1986. A human intercellular adhesion molecule distinct from LFA-1. J. Immunol 137:1270.

24. Beatty, P. G., J. A. Ledbetter, P. J. Martin, T. H. Price, and J. A. Hansen. 1983. Definition of a common leukocyte cell-surface antigen (Lp95-150) associated with diverse cell-mediated immune functions. $J$. Immunol 131:2913.

25. Wright, S. D., P. E. Rao, W. C. van Voorhuis, L. S. Craigmyle, K. lida, M. A. Talle, E. F. Westberg, G. Goldstein, and S. D. Silverstein. 1983. Identification of the C3bi receptor on human monocytes and mac. rophages by using monoclonal antibodies. Proc. Nafl Acad. Sci. USA 80:5699.

26. Miedema, F., P. A. T. Tetteroo, W. G. Hesselink, G. Werner, H. Spits, and C. J. M. Melief. 1984. Both Fc receptors and lymphocyte-function-associated antigen-1 on human T-lymphocytes are required for antibody-dependent cellular cytotoxicity (killer cell activity). Eur. J. Immunol 14:518.

27. Noesel, C. F. Miedema, M. Brouwer, M. A. de Rie, L. A. Aarden, and R. A. W. van Lier. 1988. Regulatory properties of LFA-1 alpha and beta chains in human T-lymphocyte activation. Nature 333:850.

28. Olive, D., D. Charnot, P. Dubreuil, A. Tounkara, M. Ragueneau, C. Mawas, and P. Manoni. 1985. T cel activation antigens. Kinetics, tissue distribution, molecular weight and function induction on non $T$ lines by lymphokines. In Immune Regulation M Feluman, and N.A. Mitchison, eds. The Human Press, Clifton, NJ, p. 39.

29. Dana, V., R. F. Todd IIl, J. Pitt, T. A. Springer, and M A. Amaout. 1984. Deficiency of a surface membrane glycoprotein (Mol) in man. J. Clin. Invest. 73:153.

30. Cabanas, C., F. Sanchez-Madrid, A. Acevedo, T. Bellon, J. M. Fernandez, V. Larraga, and C. Bemabeu. 1988. Characterization of a CD I lc-reactive monoclonal antibody (HC L/1) obtained by immunizing mice with phorbol ester differentiated U937 cells. Hybrid. oma 7:162.

31. Koning, F. 1986. Identification and functional relevance of epitopes on human lymphocytes. Ph.D. thesis, University of Leiden, Leiden, The Netherlands, p. 19.

32. Dana, N., B. Styrt, J. D. Griffin, R. F. Todd III, M. S. Klempner, and M. A. Amaout. 1986. Two functional domains in the phagocyte membrane glycoprotein Mol identified with monoclonal antibodies. J. Immunol 137:3259.

33. Muller, W. A., C. M. Ratti, S. L. McDonnell, and Z. A. Cohn. 1989. A human endothelial cell-restricted, externally disposed plasmalemmal protein enriched in intercellular junctions. J. Exp. Med. I70:399.

34. Diener, A. M., P. G. Beatty, H. D. Ochs, and J. M. Harlan. 1985. The role of neutrophil membrane glycoprotein 150 (GP-150) in neutrophil-mediated endothelial cell injury in vitro. J. Immunol 135:537.

35. Smith, C. W., R. Rothlein, B. J. Hughes, M. M. Mariscalco, H. E. Rudloff, F. C. Schmalstieg, and D. C. Anderson. 1988. Recognition of an endothelial determinant for CD18-dependent human neutrophil adherence and transendothelia! migration. J. Clin. Invest. 82:1746.

36. Pick, E., and Y. Keisari. 1980. A simple colorimetric method for the measurement of hydrogen peroxide produced by cells in culture. J. ImmunoL Methods. 38:161.

37. Wright, S. D., S. M. Levin, M. T. C. Jong. Z. Chad, and L. G. Kabbash. 1989. CR3 (CD11b/CD18) expresses one binding site for Arg-Gly-Asp-containing peptides and a second site for bacterial lipopolysaccharide. J. Exp. Med. 169:175.

38. Shappel, S. B., C. Toman, D. C. Anderson, A. A. Taylor, M. L. Entman, and C. W. Smith. 1990. Mac-1 (CDI1b/CD18) mediates adherence-dependent hydrogen peroxide production by human and canine neutrophils. J. Immunol. 144:2702.

39. Pham Huu, T., S. Chollet-Martin, A. Perianin, C. Marquetty, P. Sourbier, C. Babin-Chevaye, D. Olive, M. A. Gougerot-Pocidalo, P. Debre, and J. Hakim. 1987. Comparison of blocking effects of monoclonal antibodies anti-MOl- $\alpha$ and anti-LFA $1-\alpha$ on human neutrophil functions. Immunology 62:61.

40. Ross, G. D., J. A. Cain, and P. J. Lachman. 1985 
Membrane receptor type three (CR3) has lectin-like properties homologous to bovine conglutinin and functions as a receptor for zymosan and rabbit erythrocytes as well as for iC 3b. J. Immunol. 134:3307.

41. Pardi, R., J. R. Bender, C. Dettori, E. Giannazza, and E. G. Engleman. 1989. Heterogenous distribution and transmembrane signalling properties of lymphocyte function-associated antigen (LFA-1) in human lymphocyte subsets. J. Immunol 143:3157.

42. Peri, G., F. Chiaffarino, S. Bernasconi, I. M. Padura, and A. Mantovani. 1990. Cytotoxicity of activated monocytes to endothelial cells. J. ImunoL 144:1444.

43. Nathan, C., and E. Sanchez. 1990. Tumor necrosis factor and CD11/CD18 ( $\beta 2$ ) integrins act synergistically to lower cAMP in human neutrophils. J. Cell Biol $111: 2171$.

44. Lo, S. K.. and S. D. Wright. 1988. CR3 mediates binding of PMN to endothelial cells (EC) via its RGD binding, not the LPS binding site. Fed. Am. Soc. Exp. Biol. J. 2:A991.

45. Wright, S. D., and S. C. Silverstein. 1983. Receptors for $\mathrm{C} 3 \mathrm{~b}$ and $\mathrm{C} 3$ bi promote phagocytosis but not release of toxic oxygen from human phagocytes. J. Exp. Med. 158:2016.

46. Varani, J., M. J. Bendelow, D. E. Sealey, S. L. Kunkel, D. E. Gannon, U. S. Ryan, and P. E. Ward. 1988. Tumor necrosis factor enhances susceptibility of vascular endothelial cells to neutrophil mediated killing. Lab. Invest. 59:292.

47. Gibbs, L. S., L. Lai, and A. B. Malik. 1990. Tumor necrosis factor enhances the neutrophil-dependent increase in endothelial permeability. $J$. Cell Phys. 145:496.

48. Schuger, L., J. Varani, R. M. Marks, S. L. Kunkel, K. J. Johnson, and P. E. Ward. 1989. Cytotoxicity of tumor necrosis factor- $\alpha$ for human umbilical vein endothelial cells. Lab. Invest. 61:62.

49. Vedder, N. B., R. K. Winn, C. L. Rice, E. Y. Chi, K. E. Arfors, and J. M. Harlan. 1988. A monoclonal antibody to the adherence-promoting leukocyte glycoprotein, CD18, reduces organ injury and improves survival from hemorrhagic shock and resuscitation in rabbits. J. Clin. Invest. 81:939.

50. Mileski, W. J., R. K. Winn, N. B. Vedder, T. H. Pohlman, J. M. Harlan, and S. L. Rice. 1990. Inhibition of CD18-dependent neutrophil adherence reduces organ injury after hemorrhagic shock in primates. Surgery 108:206.

51. Tuomancn, E. I., K. Saukkonen, S. Sande, C. Ciolfe, and S. D. Wright. 1989. Reduction of inflammation, tissue damage, and mortality in bacterial meningitis in rabbits treated with monoclonal antibodies against adhesion-promoting receptors of leukocytes. J. Exp. Med. 170:959.

52. Simpson, P. J., R. F. Todd, III, J. C. Fantone, J. K. Mickelson, J. D. Griffin, and B. R. Lucchesi. 1988. Reduction of experimental canine myocardial reperfusion injury by a monoclonal antibody (anti-MOl, anti CDI lb) that inhibits leukocyte adhesion. J. Clin. Invest 81:624. 


\title{
ENDOTHELIAL CELL ASSOCIATED PLATELET- ACTIVATING FACTOR (PAF), A CO-STIMULA- TORY INTERMEDIATE IN TUMOR NECROSIS FACTOR- $\alpha$ (TNF) INDUCED $\mathrm{H}_{2} \mathrm{O}_{2}$ RELEASE BY ADHERENT NEUTROPHIL LEUKOCYTES
}

\author{
E.J.U. VON ASMUTH AND W.A. BUURMAN
}

\section{J. Immunol. in press}

\section{Summary}

7 NF is a strong secretagogue for surface-contacting neutrophils. During inflammation, endothelium offers the first substrate for neutrophil adherence and for modulation of

1 the toxic response of neutrophils to soluble agonists such as TNF. In this in vitro study. evidence is presented that endothelium participates actively in TNF-induced neutrophil respiratory burst activity, by expressing PAF in response to initial neutrophil $\mathrm{H}_{2} \mathrm{O}_{2}$ release. Threc findings are shown, which favor such a mechanism. Firstly, PAF receptor antagonists reduced $\mathrm{H}_{2} \mathrm{O}_{2}$ release by TNF-activated neutrophils placed on endothelium for about $50 \%$, whilst $\mathrm{H}_{2} \mathrm{O}_{2}$ responses by neutrophils placed on serum-coated polystyrene remained intact. Secondly, preincubation of HUVEC with known PAF-inducing agents PMA, $\mathrm{H}_{2} \mathrm{O}_{2}$ and thrombin, followed by fixation,enhanced neutrophil $\mathrm{H}_{2} \mathrm{O}_{2}$ release in response to TNF. $\mathrm{H}_{2} \mathrm{O}_{2}$-releaseby these neutrophils was sensitive for presence of PAF-receptor antagonists, whilst $\mathrm{H}_{2} \mathrm{O}_{2}$-release from neutrophils placed on fixed non-activated endothelial cells was not. Finally, replacing endothelium by monolayers of human renal cortical epithelial cells and human fibroblasts, cells which are known to produce less PAF than endothelial cells, reduced the effect of PAF receptor antagonists. P-selectin expression and IL-8 release, two other ways by which endothelial cells might interfere with $\mathrm{H}_{2} \mathrm{O}_{2}$-release by TNF-preincubated neutrophils, were examined in parallel, and were found not to influence TNF-induced neutrophil $\mathrm{H}_{2} \mathrm{O}_{2}$-release.

We conclude that during neutrophil-endothelial interaction in inflammation, endothelium modulates the toxic response of neutrophils to TNF. Endothelial cell associated PAF, but not endothelial cell IL-8 release and P-selectin expression, is likcly to participate in TNF-induced neutrophil respiratory burst activity. 


\section{Introduction}

$\mathrm{T}$ NF-induced neutrophil respiratory burst activity is associated with highly flattened substrate-adherent neutrophils (1-4). It is not understood how this highly-adhesive status of neutrophils cooperates with signals from TNF-receptors in triggering respiratory burst activity. The following steps all appear essential in facilitating TNF induced neutrophil respiratory burst activity: a sustained fall in cAMP (2), reorganization of the cytoskcletal protein actin into focal subcortical $\mathrm{F}$-actin at adhesive sites (2), and specific CD1 lb/CD18 mediated substrate interaction $(1,5)$.

This specific substrate interaction by the $B_{2}$ integrin member $\mathrm{CD} 1 \mathrm{lb} / \mathrm{CD} 18$ requires a certain substrate-composition (not just ligand-presence) $(1,6)$ and requires shedding of the neutrophil sialoprotein CD43, which, in its normal expression, antagonizes neutrophil spreading (3).

TNF-induced neutrophil respiratory burst activity has been mainly investigated using protein coated polystyrene as an in vitro model. CD11b/CD18 has a binding site which can directly bind polystyrene (7), and neutrophil interaction with polystyrene could alter respiratory burst responses.

Endothelium has anti-adhesive properties in comparison to protein coated plastic (8), and endothelium does not offer a ligand for the binding site of $\mathrm{CD} 11 \mathrm{~b} / \mathrm{CD} 18$ which has affinity for plastic and microbial products (7). Whether neutrophils in contact with more physiological surfaces, such as a monolayer of endothelial cells, respond differently to TNF, is unknown. Previously we showed that HUVEC-adherent neutrophils show a $\mathrm{CD} 11 \mathrm{~b} / \mathrm{CD} 18$ mediated $\mathrm{H}_{2} \mathrm{O}_{2}$ response to TNF which is similar to the response of neutrophils placed on coated polystyrene (5).

In this study the contribution of HUVEC tothis response is analyzed. Evidence is shown suggesting that HUVEC have a costimulatory role in TNF-induced neutrophil $\mathrm{H}_{2} \mathrm{O}_{2}$-release, by expressing membrane associated PAF.

\section{Materials and Methods}

Reagents and antibodies

rhTNF- $\alpha$ was kindly provided by BASF/Knoll Ag. (Ludwigshafen, FRG). PMA was purchased from Sigma (St. Louis, MO). Thrombin was kind gift of Dr. V. van Hinsbergen (Gabius Institute, Leiden, The Netherlands). rhIL-8 was a kind gift of Dr. J. Lindley (Sandoz Forschungsinstitut, Wien, Austria). WEB2086 was a kind gift of Dr. H. Heuer (Boeringer Mannheim GmbH, Mannheim, FRG). CV6209 and CV3988 were gifts from Takeda Chemical Industries (Osaka, Japan). Stock solutions of PAF receptor antagonists were prepared fresh for each experiment, by dissolving these agents in $0.9 \% \mathrm{NaCl}$ at $10^{-4} \mathrm{M}$ at $\mathrm{RT}$ (suspensions of CV3988 was heated to $50^{\circ} \mathrm{C}$ for $30 \mathrm{~min}$ todissolve). The following antibodies were employed: Polyclonal goat anti IL-8, a gift of Dr. J. van Damme (Rega Institute, University of Leuven, Leuven, Belgium); mAb CLB$\mathrm{C} 2, \mathrm{IgG}_{1}$, reactive with $\mathrm{P}$-selectin $(\hat{9})$, a gift of Dr. D. Roos (CLB, Amsterdam, The Netherlands); $m A b G 1, \operatorname{IgG}_{1}$, reactive with P-selectin (10), a giftof Dr. R. P. McEver (University of Oklahoma, Oklahoma, USA): mAb IB4 $\left(\mathrm{IgG}_{2 \mathrm{a}}\right)$, reactive with CD18 (11), a gift of Dr. M. Daha (University Hospital Leiden, The Netherlands); mAb 904 ( $\left(\mathrm{gG}_{1}\right)$ 
reaclive with CD11b (12), a gift of Dr. J.D. Griftin (Dana Farber Cancer Institute, Boston, MA). F(ab') ${ }_{2}$ fragments were prepared by pepsin digestion (Immobilized Pepsin, Pierce, Rockford, IL).

\section{Cells}

HUVEC were obtained by collagenase treatment of the human umbilical vein. The cells were cultured in fibronectin-coated (fibronectin kindly provided by Dr. J. van Mourik, CLB, Amsterdam, The Netherlands) tissue culture flasks (Costar, Cambridge, MA) inRPMI1640 (Gibco Europe, Paisley, Scotland), supplemented with $10 \%$ heat-inactivated human serum, $10 \%$ heat-inactivated bovine calf serum (BCS) (Hyclone, Logan, UT), $50 \mu \mathrm{g} / \mathrm{ml}$ heparin (Sigma), 30 $\mu \mathrm{g} / \mathrm{m}$ ] endothelial growth supplement (Collaboralive Research Incorporated, Bedford, MA) and antibiotics. Endothelial cells were characterized by their pavement-like monolayer morphology and by positive staining with an anti E-selectin $\mathrm{mAb}$ after $4 \mathrm{~h}$ incubation with TNF. Cells of passage 3 to 4 were used for the experiments.

Human renal cortical epithelial cell explant cultures were obtained using previously described techniques (13). Briefly, small biopsies from the human renal cortex were obtained from kidneys not suitable for transplantation for technical reasons. The capsula was removed and the cortex-tissue was cut into small pieces, which were incubated in $0.25 \%$ trypsin for 25 minutes at $37^{\circ} \mathrm{C}$.

The mixture was then filtered through one layer of sterilegauze, the filtrate was centrifuged, and the pellet was resuspended in RPMI-1640 supplemented with $10 \%$ heatinactivated BCS and antibiotics. The mixture was placed in fibronectin coated tissue culture flasks. After culturing, a cell population characterized by a pavement-like monolayer morphology and by positive staining with anti-cytokeratin $\mathrm{mAb}$ was obtained. Endothelial cell contamination was absent as concluded from negative staining with an anti $\mathrm{E}$ selectin mAb after $4 \mathrm{~h}$ incubation with TNF. Cells of passage 3 to 4 were used for the experiments.

Human fibroblasts (kindly provided by the department of Human Genetics, University of Limburg. The Netherlands) were propagated in RPMI-1640 supplemented with $10 \%$ $\mathrm{BCS}$ and antibiotics in fibronectin coated tissue culture flasks and characterized bytheir spindle-like morphology. Endothelial cell contamination was absent, as concluded from negative staining with an anti E-selectin $\mathrm{mAb}$ after $4 \mathrm{~h}$ incubation with TNF.

Cells of passage 6 to 10 were used for the experiments.

Neutrophils were prepared from buffy coats of donor blood kindly provided by the local blood bank, using standard techniques of buoyant density centrifugation on Lymphoprep (Nycomed, Oslo, Norway). Neutrophils were separated from erythrocytes by density gradient centrifugation on percoll $(1.08 \mathrm{~g} / \mathrm{ml}$, Pharmacia, Uppsala, Sweden). Preparations of neutrophils contained $<5 \%$ contaminating cells, as evaluated after May Grunwald Giemsa staining.

\section{$\mathrm{H}_{2} \mathrm{O}_{2}$ measurement}

A previously described colorimetric method to determine $\mathrm{H}_{2} \mathrm{O}_{2}$ production was used (5). In short, neutrophils, reagents and $\mathrm{mAb}$ were suspended/dissolved in RPMI-1640 supple- 
mented with $10 \%$ BCS. antibiotics, $200 \mu \mathrm{g} / \mathrm{ml}$ phenol red (Sigma) and $8.5 \mathrm{u} / \mathrm{ml}$ Horse radish peroxidase (type VI, Sigma). Neutrophils and reagents were added to microtiter-plates coated with BCS at $2.5 \mathrm{x}$ $10^{5}$ cells/well to a final volume of $200 \mu \mathrm{l} /$ well, and incubated for $3 \mathrm{~h}$ at $37^{\circ} \mathrm{C}$. $50 \mu \mathrm{l} 2 \mathrm{MNaOH}$ was added and $\mathrm{OD}$ was determined at $620 \mathrm{~nm}$. The lower sensitivity of the assay was $1.6 \mu \mathrm{M} \mathrm{H}_{2} \mathrm{O}_{2}$.

\section{Results}

$P A F$-receptor antagonists reduce $\mathrm{H}_{2} \mathrm{O}_{2}$ release by TNF stimulated neutrophils in contact with HUVEC

As demonstrated previously $(5,14)$, neutrophil preincubation with 1 to $10 \mathrm{ng} / \mathrm{ml}$ TNF- $\alpha$ resulted, after a lag phase of about

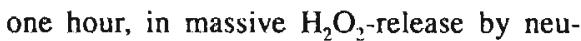
trophils placed on a HUVECmonolayer. To investigate whether PAF is involved in this process, three PAF-receptor antagonists were employed in concentrations which interfere with exogenous PAF induced neutrophil activation (15-17). Neutrophils were pre-incubated with $10 \mathrm{ng} / \mathrm{ml}$ TNF- $\alpha$ for 30 minutes at $4^{\circ} \mathrm{C}$ in polypropylene-tubes, washed, and placed inmicrotiter-plates on either BCScoated plastic or on a confluent HUVECmonolayer for 3 hours at $37^{\circ} \mathrm{C}$ in the presence or absence of different concentrations of PAF-receptor antagonists.

When neutrophils were placed on endothelium, $10^{-6} \mathrm{M}$ of PAF receptorantagonist CV6209 reduced TNF induced $\mathrm{H}_{2} \mathrm{O}_{2}$-release from about $17 \mu \mathrm{M}$ to $5 \mu \mathrm{M}$ (Fig. I).

Addition of similar amounts of PAF receptor antagonist WEB2086 reduced $\mathrm{H}_{2} \mathrm{O}_{2}$-release from $18 \mu \mathrm{M}$ to $9 \mu \mathrm{M}$ (Fig. 1 ). $10^{-6} \mathrm{M}$ of PAF receptor antagonist CV3988 also induced up
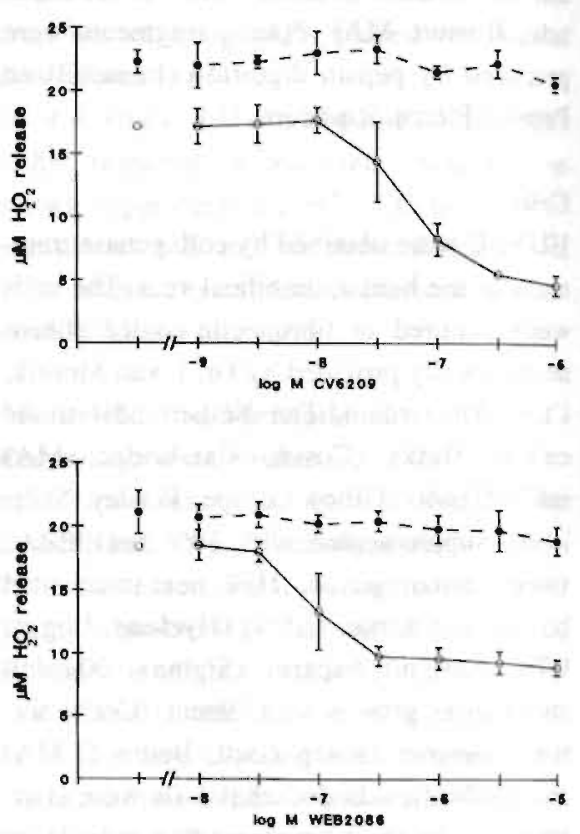

Figure 1: PAF receptor antagonist CV6209 and WEB2086 inhibit $\mathrm{H}_{2} \mathrm{O}_{2}$-production by $10 \mathrm{ng} / \mathrm{ml}$ TNF preincubated neutrophils placed on HUVEC coated wells (O) but not on BCS coated wells (O). $\mathrm{H}_{2} \mathrm{O}_{2}$-concentrations were measured affer 3 hours of incubation.

Data indicate mean and $S D$ of quadruplicate measurements. If $S D$ bars are not shown, they fall within the symbol.

to 50\%inhibition of TNF-induced neutrophil $\mathrm{H}_{2} \mathrm{O}_{2}$-release, whilst similar amounts of WEB 1090, an analog of WEB2086 without affinity for the PAF-receptor, did not influence TNF-induced neutrophil $\mathrm{H}_{2} \mathrm{O}_{2}$-release (data not shown).

The effect of PAF-receptor antagonists was relatively stronger after sub-maximal stimulation of neutrophil $\mathrm{H}_{2} \mathrm{O}_{2}$-release; addition of CV6209 nearly completelyinhibited neutrophil $\mathrm{H}_{2} \mathrm{O}_{2}$-release after preincubation of 

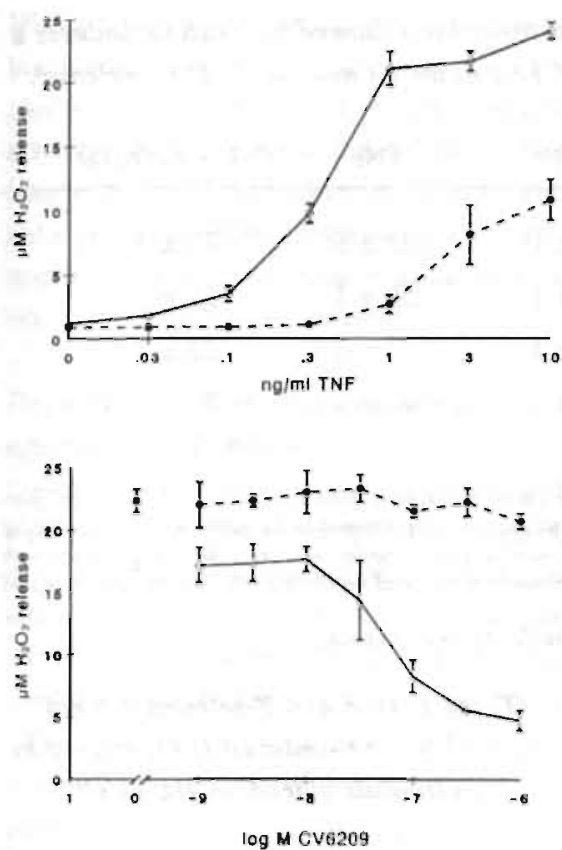

Figure 2: PAF receptor antagonist CV6209 reduces $\mathrm{H}_{2} \mathrm{O}_{2}$-production by neutrophils activated with different concentrations of TNF. Neutrophils were preincubated in polypropylene-tubes with the indicated concentrations of TNF for 30 minutes at $4^{\circ} \mathrm{C}$, washed, and added alone $(O)$ or in combination with $10^{6} \mathrm{M} \mathrm{CV6209}$ (1) to HUVEC. coated wells. $\mathrm{H}_{2} \mathrm{O}_{3}$-concentrations were measured after 3 hours of incubarion.

Data indicase mean and SD of quadruplicate measurements. If $S D$ bars are not shown, they fall within the nymbol.

neutrophils with 30 to $300 \mathrm{pg} / \mathrm{ml}$ TNF (Fig. 2). When BCS-coated plastic was used instead of endothelium as a substrate for neutrophil adherence, no inhibitory effect of CV6209, WEB 2086 (Fig. l) and CV3988 (data not shown) was found, suggesting involvement of PAF in endothelial cell-neutrophil rather than in neutrophil-neutrophil interaction.

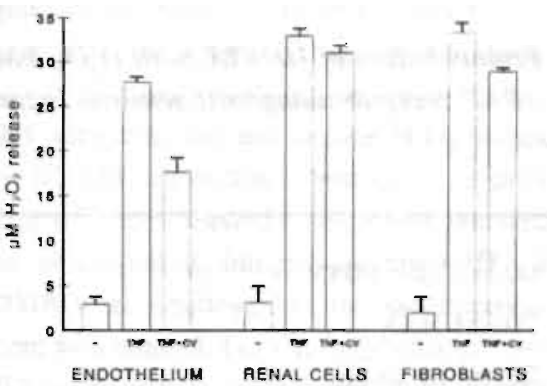

Figure 3: Comparison of the inhibitory effects of CV6209 on $\mathrm{H}_{2} \mathrm{O}_{2}$-production by neutrophils placed on monolayers of HUVEC, renal epithelial cells and fibroblasts. Neutrophils were preincubated with TNF and $\mathrm{H}_{2} \mathrm{O}_{2}$-concentrations were measured after 3 hours of incubation with or without $10^{\circ} \mathrm{M} \mathrm{CV6209.} \mathrm{Data} \mathrm{indicate} \mathrm{mean} \mathrm{and} \mathrm{SD} \mathrm{of}$ quadruplicate measurements.

* $\mathrm{P}<0.01$, when compared to $\mathrm{H}_{2} \mathrm{O}_{2}$-release in absence of CV6209, as determined by the unpaired one-tailed Student'st-test.

\section{Comparison of different cell-types as a substrate for neutrophil-adherence}

Endothelial cells are potent PAF-producers, in comparison to other non hemopoietic cells (18). To gain further evidence for a specific role of endothelial cells in PAF-receptor antagonist sensitive TNF-induced neutrophil $\mathrm{H}_{2} \mathrm{O}_{2}$-release, we comparedendothelium with monolayers of human renal epithelial cells and human fibroblasts. TNF preincubated neutrophils were added to monolayers of these three cell-types, and $\mathrm{H}_{2} \mathrm{O}_{2}$-release wasmeasured in presence and absence of $10^{6} \mathrm{M}$ CV6209.

Significant reductions in the amount of $\mathrm{H}_{2} \mathrm{O}_{2}$ produced after 3 hours of incubation at $37^{\circ} \mathrm{C}$ were found selectively when HUVEC were used asa substrate for neutrophil adherence (Fig. 3), although on both renal cells and fibroblasts, addition of CV6209 resulted consequently in slightly reduced $\mathrm{H}_{2} \mathrm{O}_{2}$ amounts as experiments were repeated. 
Table 1:

Preincubation of $\mathrm{HUVEC}$ with $\mathrm{H}_{2} \mathrm{O}_{3}, \mathrm{PMA}$ and thrombin, followed by fixation, induces a $P A F$ receptor antagonist-sensitive increase of TNF-induced neutrophil $\mathrm{H}_{2} \mathrm{O}_{2}$-release ${ }^{A}$.

no TNF TNF TNF + CV6209

no HUVEC preinc.

$20 \mathrm{mM} \mathrm{H}_{2} \mathrm{O}_{2}$

$2 \mathrm{U} / \mathrm{ml}$ thrombin

10ng/ml PMA

$\begin{array}{lll}1 \pm 1^{b} & 23 \pm 3 & 23 \pm 3 \\ 2 \pm 1 & 50 \pm 1 & 21 \pm 2 \\ 1 \pm 1 & 42 \pm 2 & 22 \pm 3 \\ 1 \pm 1 & 37 \pm 2 & 19 \pm 2\end{array}$

${ }^{4} \mathrm{H}_{2} \mathrm{O}_{2}$ thrombin, PMA and control medium (no HUVEC preinc.) were added in a small volume ro HUVEC coated, prewarmed wells containing $200 \mu \mathrm{l}$ culture-medium, to the final concentrations mentioned in the table. After 30 minutes of incubation at $37^{\circ} \mathrm{C}$, the 96 -well microtiter-plates were placed on melting ice, rinsed with ice-cold PBS enriched with $\mathrm{Ca}^{*+}$ and $\mathrm{Mg}^{+*}$, incubated with $0.1 \%$ glutaraldehyde for 10 minutes, rinsed, and incubated with neutrophils, $0.5 n g / m ?$ TNF, and $10^{\circ} \mathrm{M}$ CV6209 for 3 hours at $37^{\circ} \mathrm{C}$.

"Data are expressed in $\mu M$ and indicate mean and SD ofquadruplicate measurements.

Table 2: IL-8 and P-selectin are not

HUVEC-activation with $\mathrm{PMA}, \mathrm{H}_{2} \mathrm{O}_{2}$ and thrombin, followed by fixation induces a $P A F$-receptor antagonist sensitive increase in $\mathrm{TNF}$-induced neutrophil $\mathrm{H}_{2} \mathrm{O}_{2}$-release

Since PMA, $\mathrm{H}_{2} \mathrm{O}_{2}$ and thrombin are known inducers of endothelialcell PAF-production (19-21), and membrane-associated PAF remains functionally intact after fixation (22), we tested whether preincubation of HUVEC with these agents, followed by rapid cooling of the monolayers and fixation with $0.1 \%$ glutaraldehyde, would prime neutrophil $\mathrm{H}_{2} \mathrm{O}_{2}$ release in response to TNF. On fixedunstimulated HUVEC TNF-induced neutrophil $\mathrm{H}_{2} \mathrm{O}_{2}$-release was low, and no influence of CV6209 was measured.

Preincubation of HUVEC for 30 minutes at $37^{\circ} \mathrm{C}$ with either $20 \mathrm{mM} \mathrm{H}_{2} \mathrm{O}_{2}, 2 \mathrm{U} / \mathrm{ml}$ thrombin, or $10 \mathrm{ng} / \mathrm{ml}$ PMA enhanced neutrophil $\mathrm{H}_{2} \mathrm{O}_{2}$-release in response to $1 \mathrm{ng} / \mathrm{mlTNF}$, whilst preincubation was not sufficient to trigger $\mathrm{H}_{2} \mathrm{O}_{2}$-release by unstimulated neutrophils (Table 1). $\mathrm{H}_{2} \mathrm{O}_{2}$-release by TNFengaged in $\mathrm{TNF}$-induced $\mathrm{H}_{2} \mathrm{O}_{2}$-release by neutrophils placed on HUVEC ${ }^{a}$.

no TNF TNF

\begin{tabular}{|c|c|}
\hline No agent & $3 \pm 1^{b} 52 \pm 1$ \\
\hline $100 \mathrm{ng} / \mathrm{ml} \mathrm{IL-8}$ & $3 \pm 1 \quad 50 \pm 2$ \\
\hline anti IL-8 ab & $3 \pm 1 \quad 53 \pm 1$ \\
\hline anti P-selectin mAb C2 & $3 \pm 1 \quad 54 \pm 1$ \\
\hline anti P-selectin mAb Gl & $3 \pm 1 \quad 54 \pm 1$ \\
\hline anti P-selectin $F\left(a b^{\prime}\right)_{2} G \mathbf{I}$ & $3 \pm 1 \quad 54 \pm 1$ \\
\hline anti $\mathrm{CD} 18 \mathrm{~F}\left(\mathrm{ab}^{\prime}\right)_{2}$ IB4 & $4 \pm 1$ \\
\hline anti CD1 lb $\mathrm{F}(\mathrm{ab})_{2} 904$ & $3 \pm 1 \quad 39 \pm 7$ \\
\hline $10^{-6} \mathrm{M}$ WEB 2086 & $4 \pm 1 \quad 37 \pm$ \\
\hline
\end{tabular}

'HUVEC were incuhated with antibodies (final concen(ration $5 \mu \mathrm{g} / \mathrm{ml}$ ) and WEB 2086 for 5 minutes at $R T$, and neutrophils and TNF (final concentration $0.5 \mathrm{ng} / \mathrm{ml}$ ) were added as indicated in the table $\mathrm{H}_{2} \mathrm{O}_{2}$-concentrations were measured afier 3 hours of incubation at $37^{\circ} \mathrm{C}$ and are expressed in $\mu M$.

'Dita indicate' mean and $S D$ of quadruplicate measure. ments. 
stimulated neutrophils placed on fixed HUVEC activated with either $\mathrm{H}_{2} \mathrm{O}_{2}$, thrombin or PMA, was again sensitive for CV6209 (Table 1). In presence of $10^{\circ} \mathrm{M} \mathrm{CV} 6209$, priming effects ofendothelial cell preincubation with $\mathrm{H}_{2} \mathrm{O}_{2}$, thrombin and PMA were nolonger detectable, suggesting that neutrophil priming by activated endothelial cells was completely PAF-mediated.

\section{$P$-selectin and IL-8 do not influence neutrophil $\mathrm{H}_{2} \mathrm{O}_{2}$-release}

Endothelial cells respond to stimulation with $\mathrm{H}_{2} \mathrm{O}_{2}$, PMA andthrombin with rapid and de novo membrane expression of the neutrophil adhesion molecule P-selectin, which parallels PAF expression (20, 23-26). Another candidate for endothelial cell interference with neutrophil activation is IL-8, which is released in high amounts by endothelial cells activated with TNF, IL-1 and microbial products (27-29), and is thought to mediate neutrophil emigration from the vasculature by forming a chemotactic gradient from the luminal side to the basal side of the endothelium $(30,31)$. To investigate whether P-selectin and IL-8 might influence $\mathrm{H}_{2} \mathrm{O}$, release by neutrophils in contact with HUVEC, we investigated the influence of rhL-8, of goat polyclonal antibodies which inhibit the biological activity of IL-8, and of two monoclonal antibodies reactive with $\mathrm{P}$ selectin in our model. Addition of $10(\mathrm{ng} / \mathrm{ml}$ rhIL-8 neither induced neutrophil $\mathrm{H}_{2} \mathrm{O}_{2}$ release, nor enhanced TNF induced neutrophil $\mathrm{H}_{2} \mathrm{O}_{2}$-release (Table 2). In agreement with the absence of a role for IL- 8 on TNF. induced neutrophil $\mathrm{H}_{2} \mathrm{O}_{2}$-release, we found that IL-8 reactive antibodies were unable to reduce $\mathrm{H}_{2} \mathrm{O}_{2}$ release by HUVEC-contacting neutrophilsin presence of TNF (Table 2).
Addition of $\mathrm{mAb} \mathrm{C} 2, \mathrm{mAb} \mathrm{Gl}$ and $\mathrm{F}\left(\mathrm{ab}^{\prime}\right)_{2}$ fragments of $\mathrm{mAb} \mathrm{Gl}$, in concentrations which inhibited P-selectin-mediated neutrophil adhesion, did not reduce $\mathrm{H}_{2} \mathrm{O}_{2}$-release by HUVEC-contacting neutrophils in presence of TNF (Table 2 ). mAb reactive with the neutrophil $B_{2}$ integrin member $C D 1 \mathrm{lb} /$ CD18 were employed in the same experiment as a control. $F\left(a b^{\prime}\right)_{2}$ fragments of $\mathrm{mAb}$ IB4 reactive with CD18 nearly completely reduced neutrophil $\mathrm{H}_{2} \mathrm{O}_{2}$-release, whilst $\mathrm{F}\left(\mathrm{ab}^{\prime}\right)_{2}$ fragments of mAb 904 partially reduced neutrophil respiratory burst activity (Table 2), which is in line with previous observations (5).

Addition of isotype-matched control antibodies did not influence $\mathrm{H}_{2} \mathrm{O}_{2}$-release (data not shown).

\section{Discussion}

In this study, we demonstrated that endothelial cells can regulate TNF-induced respiratory burst activity by contacting neutrophils, by a PAF-receptor antagonist sensitive mechanism. In our in vitro model at least $50 \%$ of the $\mathrm{H}_{2} \mathrm{O}_{2}$ production by TNFactivated neutrophils was dependent on endothelial cell activity. This endothelial cell contribution could by blocked by preventing activation of endothelial cells by fixation of the monolayer.

It was restored if, before fixation, endothelial cells were incubated with PAF-inducing agents, and blocked again by subsequent addition of PAF-receptor antagonists, which suggests that endothelial cell associated PAF mediates the increase in TNF-induced neutrophil $\mathrm{H}_{2} \mathrm{O}_{2}$-release. In line with these results, we showed thatneutrophil $\mathrm{H}_{2} \mathrm{O}_{2}$ release was not PAF-receptor antagonist 
sensitive in absence of bystander-cells, and probably moderately PAF-receptor antagonist sensitive using fibroblasts or RCEC as bystander cells.

Endothelial cells are well known producers of PAF. In response to thrombin, reactive oxygen species, histamine, leukotrienes and PMA, endothelial cells produce PAF within minutes (19-21). TNF, IL-1 and LPS also trigger endothelial cell PAF production, although to a lesser extend and at later timepoints than the first group of agents (31-35). Endothelial PAF remains mainly cell-associated, and can be recognized by contacting neutrophils (36). $\mathrm{H}_{2} \mathrm{O}_{2}$-concentrations between $100 \mu \mathrm{M}$ and $10 \mathrm{mM}$, which can be reached easily in the micro-environment of the contact-area between $\mathrm{H}_{2} \mathrm{O}_{2}$-producing neutrophils and endothelium, incite expression of membrane PAF within 10 to $30 \mathrm{~min}$ utes $(19,20)$.

Initial respiratory burst activity by TNFactivatedneutrophils thus might initiate an auto-amplification cycle, which is regulated by neighboring endothelial cells by expressing surface-associated PAF. Experiments using selective inhibitors ofthe NADPH-oxidase pathway are currently being conducted at our lab, to investigate whether respiratory burst products are indeed responsible endothelial cell PAF production.

Endothelial cell associated PAF is known to participate in regulating neutrophil attachment to activated endothelium. In parallel to rapid PAF production, endothelial cells respond to thrombin, reactive oxygen species, histamine, leukotrienes and PMA by de novo expression of P-selectin (20, 23-26). In parallel to late PAF production, endothe- lial cells respond to TNF, IL- 1 and LPS by de novo expression of E-selectin $(34,37,38)$. PAF cooperates with P-selectin (23) and with E-selectin (39) in mediating increased neutrophil endothelial cell adherence, by triggering an increase in affinity of CD11b/CD18. During neutrophil interaction with E-selectin expressing endothelium, the role of PAF is, however, less essential since $\mathrm{CD} 1 \mathrm{lb} / \mathrm{CD} 18$ 'activation' can also be triggered by E-selectin alone $(39,40)$, or by IL-8, a neutrophil chemotaxin produced by endothelium activated with E-selectin inducing agents, but not by endothelium activated with the P-selectin inducing agents thrombin, reactiveoxygen species, histamine and leukotrienes (27-29). Other influences of endothelial cell associated PAF on neutrophil function are less clear. Neutrophil diapedesis through the endothelium is triggered clearly by E-selectin expressing endothelium (4144) but hardly by $P$-selectin expressing endothelium $(42,45,46)$. Presence of PAF, without simultaneous presence of IL-8, might be insufficient in triggering neutrophil transmigration $(30,31)$.

Besides its role in neutrophil endothelial cell adherence and transmigration, endothelial cell associated PAF might influence neutrophil respiratory burst and protease release. Like neutrophil chemotaxins such as IL-8. C5a and FMLP, nM concentrations of PAF can be chemotactically active, can induce CD11b/CD18 activation and upregulation. and can prime neutrophils for increased responses to other chemotaxins (47-50).

Also like other chemotaxins, $\mu \mathrm{M}$ concentrations of PAF can trigger a short and low respiratory burst in non adherent neutrophils, which can be increased by previous incuba- 
tion of neutrophils with cytochalacins (4951). This in contrast to neutrophil secretagogues such as TNF, which at $\mathrm{nM}$ concentrations lack chemotactic activity (52-54), but induce a highly adhesive status, associated with prolonged massive oxygen radical release, which is inhibited in stead of increased by cytochalacin-presence $(2,55)$.

TNF-induced adhesion dependent neutrophil respiratory burst activity has, until now, not been described to be increased by presence of chemotaxins. Endothelial cell released or added IL-8 (this study), C5a (own unpublished observation), FMLP (52), P-selectin binding (this study) or E-selectin binding (5), known to function as a 'tethered chemotaxin' (40), all fail to increase TNF-induced adherence dependent neutrophil respiratory burst activity.

Moreover, previous activation by such agonists decreases the sensitivity of neutrophils for TNF, by inducing rapid shedding of the TNF-receptor $(57,58)$. Our finding, that endothelial cell associated PAF can increase prolonged adhesion dependent TNF induced neutrophil- $\mathrm{H}_{2} \mathrm{O}_{2}$ release thus defines a functional effect of PAF on neutrophils which distinguishes PAF from other neutrophilchemotaxins.

So far, two physiological mechanisms have been suggested which regulate neutrophil respiratory burst activity after TNF-activation. The first involves human serum albumin, which can antagonize TNF-induced neutrophil respiratory burst activity by binding to surface CD43. Albumin binding to CD43 prevents shedding of this negatively charged sialophorin, and thus prevents extensive neutrophil spreading and the subsequent TNF-induced respiratory burst (3).
Additionally, the composition of the substrate to which the neutrophil attaches, determines the duration of the lag phase before TNF-induced oxygen radical production starts, and influences its size $(1,6)$. The mechanism and physiological relevance of the influence of substrate-proteins such as collagen, fibronectin and vitronectin remains unclear.

A thirth co-regulatory mechanism is suggested in this study. Neutrophil-contacting endothelial cells, and probably to a lesser extend also other cells, can enhance ongoing TNF-induced neutrophil respiratory burst activity by expressing membrane-associated PAF. TNF-induced neutrophil toxicity thus is highly dependent on the environmental context, and is closely connected to PAF-mediated toxicity.

Both TNF (59-61) and PAF (62-64) have been claimed to mediate tissue and organ damage in clinical syndromes such as ischemia reperfusion injury and ARDS.

The costimulatory effect of PAF on TNFinduced neutrophil toxicity demonstrated in this study might be one of the levels at which PAF and TNF cooperate in these syndromes.

\section{References.}

1. Nathan, C., S. Srimal, C. Farber, E. Sanchez. L. Kabbash, A. Asch, J. Gailit, and S. D. Wright. 1989. Cytokine-induced respiratery burst of human neutrophils: dependence on extracellular matrix proteins and CDI 1/CD18 integrins. J. Cell Biol. 109:1341.

2. Nathan, C, and E. Sanchez. 1990. Tumor Necrosis Factor and $\mathrm{CD} 1 / / \mathrm{CD} 18\left(\mathrm{~B}_{2}\right)$ integrins act synergistcally to tower eAMP inhuman neutrophils. J. Cell Biol. 111:2171.

3. Nathan, C., Q. Xie, L. Halbwachs-Mecarelli, and W. W. Jin. 1993. Albumin inhibits neutrophil spreading and hydrogen peroxide release by blocking the shedding of CD 43 (sialophorin, leukosialin). J. Cell BioL 122:243.

4. Kapp, A., G. Zeck-Kapp, and D. Blohm. 1989. Human tumor necrosis factor is a potent activator of the oxidative metabolism in human polymonphonu- 
clear neutrophilic granulocytes: comparison with human lymphotoxin. J. Invest. Dermatol. 92:348.

5. von Asmuth, E. J. U., C. J. van der Linden, J. F. M. Leeuwenberg and W. A. Buuman. 1991. Involvement of the CDIIb/CDI8 integrin, but not of the endothelial cell adhesion molecules ELAM-1 and ICAM- 1 in tumor necrosis factor- $\alpha$ induced neutrophit toxicity. J. Immunol. 147:3869.

6. Dri, P., R. Cramer, M. Romano, P. Spessotto, and P. Patriaca. 1991. Effect of biological surfaces on neutrophil $O^{2}$ productionand its releationship to the CDIlb/CDI8 integrin-dependent adherence. Int. J. Tissue React. 13:193.

7. Wright, S. D., S. M. Levin, M. T. C. Jong, Z. Chad, and L. G. Kabbash. 1989. CR3 (CDIlb/CD18) expresses, one binding site for Arg-Gly-Asp-containing peptides and a second site for bacterial lipopolysaccharides. J. Exp. Med. 169:175.

8. Fehr, J., R. Moser. D. Leppert, and P. Groscurth. 1985. Antiadhesive properties of biological surfaces are protective against stimulated granulocytes. J. Clin. Invess. 76:535.

9. Von dem Borne, A. E. G. Kr., P. W. Modderman. L.G. Admiraal, and H. K. Nieuwenhuis. 1989. Joint report of the platelet section. In Leukocyte typing IV. W. Kniapp et al., eds. Oxford University press, Oxford, England, p. 951.

10. McEver, R. P., and M. N. Martin. 1984. A moneclonal antibody to a membrane glycoprotein binds only to activated platelets. J. BioL Chem. 259:9799.

11. Wright, S. D., P. E. Rao, W. C. van Voorhuis, L. S. Craigmyle, K. lida, M. A. Talle, E. F. Westberg, G. Goldstein, and S. D. Silverstein. 1983. Identification of the C3bi receptor on human monocytes and macrophages by using monoclonal antibodies. Proc. Nall. Acad. Sci. USA 80:5699.

12. Dana, N., B. Styr. J. D. Griffin, R. F. Todd III, M. S. Klempner, and M. A. Amaout. 1986. Two functional domains in the phagocyte membrane glycoprotein $\mathrm{Mol}$ identified with monoclonal antibodies. J. Immunol 137:3259.

13. Kempson, S. A., J. A. McAteer, H. A. Al-Mahroug, T. P. Dousa, G. S. Dougherty, and A. P. Evan. 1989. Proximal tubule characteristics of cultured human renal cortex epithelium. J. Lab. Clin. Med. 113:285.

14. Asmuth, E. J. U. von, J. F. M. Leetwenberg. C. J. van der Linden, and W. A. Buuman. 1991. Tumour neerosis factor $\alpha$ induces neutrophil mediated injury of cultured human endothelial cells. Seand. J. Immunol. 34:197.

15. Marquis, O., C. Robaut, and 1. Cavero. 1989. Evidence for the existence and ionic moxlulation of platelet-activating factor receptors mediating degranulato$r y$ responses in human polymorphonuclear leukocytes. J. Pharmacol Exp. Ther. 250:293.

16. Bates, E. J. D. P. Harvey, and A. Ferrante. 1992. Inhibition of neutrophil respiratory burst and degranulation responses to platelet-activating fuctor by antagonists WEB 2086, CV6209 and CV3988. Int. Arch. Allergy Immunol. 97:50.

17. Steward, A. G., P. N. Dubbin, T. Harris, G. J. Dusting. 1990. Platelet-activating factor may act as a second messenger in the release of icosanoids and superoxide anions from leukocytes and endothelial cells. Proc. Nall. Acad. Sci. USA 87:3215.

18. Koltai, M., D. Hosford, P. Guinot, A. Esanu, and P. Braquet. 1991. PAF, a review of its effects, antagonists and possible future clinical implications. Drugs 42:9.

19. Lewis, M. S., R. E. Whatley, P. C. Cain, T. M. Mclntyre, S. M. Prescoll, and G. A. Zimmerman. 1988 Hydrogen peroxide stimulates synthesis of plateletactivating factor by endothelium and induces endo. thelial eell dependent neutrophil adhesion. J. Clin. Invest. 82:2045.

20. Patel, K. D., G. A. Zimmerman, S. M. Prescott, R. P. McEver, and T. M. Mclntyre. 1991. Oxygen radicals induce human endothelial cells to express GMP-140 and bind neutrophits. J. Cell. BioL I12:749.

21. Heller, R., F. Bussolino, D. Ghigo, G. Garbarino, G. Pescarmona, U. Till, and A. Bosia. 1991. Stimulation of platelet-activating factor synthesis in human endothelial cells byactivation of the de nowo pathway. J. Biol Chem. 266:21358.

22. Zimmerman, G. A., T. M. McIntyre, M. Mehra, and S. M. Prescoth 1990. Endothelial cell-associated platelet-activating factor: a novel mechanisin for sig naling intercellular adhesion. J. Cell BioL H10:529.

23. Lorant, D. E., K. D. Patel, T. M. Melntyrc, R. P. McEver, S. M. Prescott, and G. A. Zimmerman. 1991. Coexpression of GMP-140 and PAF by endothelium stimulated by histamine or thrombin: a juxtacrine system for adhesion and activation of neutrophils. J. Cell Biol 115:223.

24. Bonfanti, R., B. C. Furie, B. Furie, and D. D. Wagner 1989. PADGEM (GMP-140) is a component of Weibel-Palade bodies of human endothelial cells. Blond 73:1109.

25. MeEver, R. P., J. H. Beckstead, K. L. Moore, L. Marshall-Carlson, and D. F. Bainton. 1989. GMP-140, a platelet $\alpha$-granule membrane protein, is also synthesized by vascular endothclial cells and is localized in Weibel-Palade bodies. J. C.Lin. Invest. 84:92.

26. Zimmerman, G. A., T. M. Melntyre, M. Mehra, and S. M. Prescotr. 1990. Endothelial cell-associated platelet-activating factor: a novel mechanism for signalling intercellular adhesion. J. Cell BioL 110:529.

27. Carveth, H. J., J. F. Bohnsack, T. M. Melntyre, M. Baggiolini. S. M. Prescont and G. A. Zimmernan. 1989. Neutrophil activating factor (NAF) indices polymorphonuclear leukocytc adherenee to endothlial cells and to subendothelial matrix proteins. Biochem. Biophys. Res. Comm. 162:387.

28. Baggiolini, M., A. Walz, and S. L. Kunkel. 1989. Neutrophil-activating peptide-1firterleukin 8, a novel cytokine thatactivates neutrophils. J. Clin. Imesl. 84:1045.

29. Detmers, P. A., S. K. L.o, E. Olsen-Egbert, A. Walz, M. Baggiolini, and Z. A. Cohn. 1990 . Neutrophilactivating protein $1 /$ interleukin 8 stimulates the binding activity of the leukocyte adhesion receptor CD 11 b/CD 18 on human neutrophils. J. Exp. Med. 171:1155.

30. Huber, A. R., S. L. Kunkel, R. F. Todd III, and S. J. 
Weiss. 1991. Regulation of transendothelial migration by endogenous interleukin-8. Science 254:99.

31. Kuijpers, T. W. B. C. Hakker, M. H. L. Hart, and D. Roos. 1992. Neutrophil migration across monolayers of cytokine-prestimulated endothelial cells: a role for platelet-activating factor and IL-8,J. Cell BioL 117:565.

32. Bussolino, F., G. Camussi, and C. Baglioni. 1988. Synthesis and release of platelet-activating factor by human vascular endothelial cells treated with tumor necrosis factor of interleukin $1 \alpha$. J. BioL Chem. 263:11856.

33. Bussolino, F., G. Camussi, C. Tetta, G. Garbarino, A. Bosia, and C. Baglioni. 1990. Selected cytokines promote the synthesis of platelet-activating factor in vascular endothelial cells: comparison between tumor necrosis factor alpha and beta and interleukin-1. J. Lipid. Mediat. 2Suppl:SIS.

34. Bussolino, F. F. Brevario, C. Tetta, M. Anglictta, M. Mantovani, and E. Dejana. 1986. Interleukin 1 stimulates platelet activating factor production in cultured human endothelial cells. J. Clin. Invest. 77:2027.

35. Breviario, F. F. Bertocchi, E. Dejana, and F. Bussolino. 1988. IL-1-induced adhesion of polymorphonuclear leukocytes to cultured human endothelial cells. Role of platelet-activatingfactor. J. Immunol. I41:3391.

36. Prescon, S. M., G. A. Zimmerman, and T. M. Mclntyre. 1984. Human endothelial cells in culture produce platelet-activating factor (1-alkyl-2-acetyl-snglycero-3-phosphocholine) when stimulated with thrombin. Proc. Nall. Acad. Sci. USA 81:3534.

37. Pober, J. S., M. A. Gimbrone Jr, L. A. Lapierre, D. L. Mendrick, W. Fier, R. Rothlein, and T. A. Springer. 1986. Ovcrlapping patterns of activation of human endothelial cells by interleukin 1 , tumor necrosis factor, and immune interferon. J. ImmunoL 137:1893.

38. Leeuwenberg. J. F. M., G. M. A. A. Jeunhomme, and W. A. Buurman. 1990. Adhesion of polymorphonuclear cells to human endothelial cells. Adhesionmolecule-dependent and Fc-receptor-mediated adhesion-molecule-jndependent mechanisms. Clin. Exp. ImmunoL 81:496.

39. Kuijpers, T. W., B. C. Hakkert, M. Hoogerwerf, J. F. M. Leeuwenberg, and D. Roos. 1991. Role of endothelial leukocyte adhesion molecule-1 and platelet activating factor in neutrophil adherence to IL-1 prestimulated endothelial cells. J. ImmunoL 147:1369.

40. Lo, S. K., S. Lee, R. A. Ramos. R. Lobb, M. Rosa, G Chi-Rosso, and S. D. Wright. 1991. Endothelial-leukocyte adhesion molecule 1 stimulates the adhesive activity of leukocyte integrin CR3. (CD) lb/CDI8, Mac-1, $\alpha_{2} B_{2}$ ) on human neutrophils. J. Exp. Med. 173:1493.

41. Smith, C. W., R. Rothlein, B. J. Hughes, M. M. Mariscalco, H. E. Rudloff, F. C. Schmalstieg, and D. C. Anderson. 1988. Recognition of an endothelial cell determinan for CD18-dependent human neutrophil adherence and transendothelial migration. J. Clin. Invest 82:1746.

42. Moser, R., B. Scbleiffenbaum, P. Groscurh, and J. Fehr. 1989. Interleukin 1 and tumor necrosis factor stimulate human vascular endothclial cells to promote transendothelial neutrophil passage. J. Clin. Invest. 83:444.

43. Furic, M. B., and D. D. McHugb. 1989. Migration of neutrophils across endothelial monolayers is stimulated by treatment of the monoayers with inerieukinI or tumor necrosis factor. J. ImmunoL 143:3309.

44. Lawrence, M. B., C. W. Smith, S. G. Eslisin, and L. V. McIntire. 1990. Effect of venous shear stress on CD18-mediated neutrophil adhesion to exlmed endothelium. Blood 75:227.

45. Drake, W. T., N. N. Lopes, J. W. Fenton II, and A. C. 1ssckutz. 1992. Thrombin enhancement of interienkin-1 and tumor necrosis facter- $\alpha$ induced polymorphonuclear leukocyle migrution. Lah. Invest. 67:617.

46. Moser, R., P. Groscurt, and J. Fehr. 1990. Promotion of transendothelial neutrophil passuge by thrombin. J. Cell Sci. 96:737.

47. Shaw, J. O., R. N. Pinckard, K. S. Ferrigni, L. M. McManus, and D. J. Hanahan. 1981. Activation of human neutrophils with 1-O-hexadecyl/octadecyl-2acetyl-sn-glyceryl-3-phosphorylcholine (platelet actvating factor). J. ImmunoL 127:I250.

48. Tonnesen, M. G., D. C. Anderson, T. A. Springer, A. Knedler, N. Avdi, and P. M. Henson. 1989. Adherence of neutrophils to cultured human microvascular endothelial cells. Stimulation by chemotactic peptides and lipid mediators and dependence upon the Mac-1, LFA-1, gp150,95 glycoprotein family. J. Clin. Imvest. 83:637.

49. Vereelloti, G. M. H. Q. Yin, K. S. Gustavson, R. D. Nelson, and H. S. Jacob. 1988. Platelet-activating factor primes neutrophil response; to agonists: role in promoting neutrophil-mediated endothelial, cell darnage. Blood 71:1100.

50. Ingraharn, L. M., T. D. Coates, J. M. Allen, C. P. Higgins, R. L. Bachner, and L. A. Boxer. 1982. Metabolic, membrane, and functional responses of human polymorphomuclear leukoxytes to platelet-activating fictor. Blood 59:1259.

51. Shaw, J. O., R. N. Pinckard, K. S. Ferrigri, L. M. McManus, and D. J. Hanahan. 1981. Activation of human neutrophils with 1-O-hexadecyloctadecyl-2acetyl-sn-glyceryl-3-phosphorylcholine (plateles activating factor). J. Immunol 127:1250.

52. Kownatzki, E., A. Kapp, and S. Uhrich. 1988. Modulation of humari neutrophilic granulocyte functions by recombinant human rumor necrosis factor and recombinant human lymphotoxin. Promotion of adherence, inhibition of chemotactic migration and superoxide anion release from adherein cells. Clin. Exp. ImmunoL 74:143.

53. Salyer, J. L., J. F. Bohnsack, W. A. Knape, A. O. Shigeoka, E. R. Ashwood, and H. R. Hill. 1990. Mechanims of tumor necrosis factor- $\alpha$ alseration of PMN adhcsion and migration. Am. J. Pathol 136:831.

54. Schell-Frederick, E.. I. Tepass, G. Lorscheidt, M. Pfreundschuh, M. Schasudt, and V. Dichl. 1989. Effect of recombinant tumor necrosis factor (rHuTNFa) on human neutrophils and monocytes: in vitro, $\mathrm{cx}$ vivo 
and in vivo. Eur. J. HaematoL 43:286.

55. Nathan, C. F. 1987. Neutrophil activation on biological surfaces. J. Clin. Invest. 80:1550.

56. Laudanna, C., S. Miron, G. Berton, and F. Rossi. 1990. Tumor necrosis factor- $\alpha /$ cachectin activates the

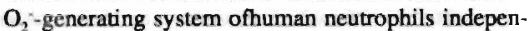
dently of the hydrolysis of phosphoinositides and the release of arachidonic acid. Biochem. Biophys. Res. Commun. 166:308.

57. Schleiffenbaum, B., and J. Fehr. 1990. The tumor necrosis factor receptor and neutrophil function. J. Clin. Invest. 86:184.

58. Porteu, F, and C. Nathan. 1990. Shedding of tumor necrosis factor receptors by activated human neutrophils. J. Exp. Med. 172:599.

59. Stephens, K. E., A. Ishizaka, J, W, Larrick, and T. A. Raffin. 1988. Tumor necrosis factor causes increased pulmonary permeability and edema. Comparison to septic acute lung injury. Am. Rev. Resp. Dis. 137:1364.

60. Maessen, J. G., J. W. Greve, and W. A. Buurman. 1991. Increased sensitivity to endotoxemia by tissue necrosis. Surgery 109:154.

61. Millar, A. B., M. Singer, A. Meager, N. M. Foley, N. McI. Johnson, and G. A. W. Rook. 1989. Tumour necrosis factor in bronchopulmonary secretions of patients with adult respiratory distress syndrome. Lancer ii:712.

62. Braquet, P., M. Paubert-Braquet, M. Koltai, R. Bourgain, F. Bussolino and D. Hosford. 1989. Is there a case for PAF antagonists in the treatment of ischemic states? MPS 10:23.

63. Doebber, T. W., M. S. Wu, J. C. Robbins, B. M. Choy, M. N. Chang, and T. Y. Shen. 1985. Platelet activating factor (PAF) involvement in endotoxin-induced hypotension in rats. Studies with $\mathrm{PAF}$-receptor antagonist kadsurenone. Biochem. Biophys. Res. Commun. 127:799.

64. Casals-Stenzel, J. 1987. Protective effect of WEB 2086, anovel antagonist of platelet activating factor, in endotoxin shock. Eur. J. Pharm. 135:117. 


\title{
INTERMEZZO
}

\author{
Uit "Gödel, Escher, Bach: \\ een eeuwige gouden band"
}

\section{(oorspronkelijke titel “Gödel, Escher, Bach: an eternal golden braid”) van Douglas R. Hofstadter}

\footnotetext{
A chilles: Ik weet dat jullie dit niet zullen geloven, maar het antwoord op de vraag staat pal voor onze neus, verborgen in de tekening. Het is maar cén woord - maar wat een belangrijk woord: 'MU'!
}

Kreeft: Ik weet dat jullie dit niet zullen geloven, maar het antwoord op de vraag staat pal voor onze neus, verborgen in de tekening. Het is maar één woord - maar wat een belangrijk woord: 'HOLISME'!

Achilles: Zeg, wacht eens even. Je ziet ze vliegen. Het is zo klaar als een klontje dat de boodschap van deze tekening 'MU' is, en niet 'HOLISME!

Kreefi: Neem me niet kwalijk, maar mijn ogen zijn uitzonderlijk goed. Wil je nog eens kijken en zeg me dan of de tekening zegt wat ik zei dat ze zegt!

Miereneter: Ik weet dat jullie dit niet zullen geloven, maar het antwoord op de vraag staat pal voor onze neus, verborgen in de tekening. Het is maar écn woord - maar wat een belangrijk woord: 'REDUCTIONISME'!

Kreef: Zeg, wacht eens even. Je ziet ze vliegen. Het is zo klaar als een klontje dat de boodschap van deze tekening 'HOLISME' is, en niet 'REDUCTIONISME!

Achilles: Nog iemand die erin vliegt! niet 'HOLISME', niet 'REDUCTIONISME', maar ' $M U$ ' is de boodschap van deze tekening, dat staat vast.

Miereneter: Neem mij niet kwalijk, maar mijn ogen zijn uitzonderlijk scherp. Wil je nog eens kijken en zeg me dan of de tekening zegt wat ik zei dat ze zegl!

Achilles: Zie je dan niet dat de tekening is samengesteld uit twee delen, die beide een letter vormen?

Kreeft: Je hebt gelijk als je zegt dat er twee delen zijn, maar je interpretatie klopt niet. Het linkerdeel is geheel opgebouwd uit drie kopieèn van één woord: 'HOLISME'; en het rechterdeel is opgebouwd uit vele kopieën, in kleine letters, van hetzelfde woord. Waarom de letters in de twee delen van verschillende grootte zijn weet ik niet, maar ik weet wel wat ik zie, en wat ik zie is 'HOLISME', zo klaar als een klontje. Het gaat me boven mijn pet hoe jullie iets anders kunnen zien.

Miereneter: Je hebt gelijk als je zegt dat er twee delen zijn, maar je interpretatie klopt niet. Het linkerdeel is opgebouwd uit vele kopieën van één woord: 'REDUCTIONISME'; en het rechterdeel opgebouwd uit één kopie, in grote letters, van hetzelfde woord. Waar- 


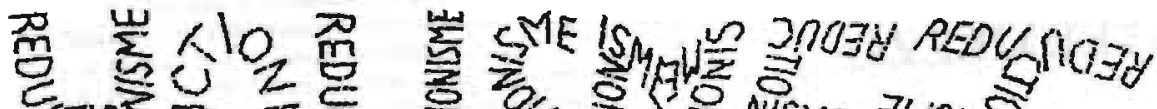

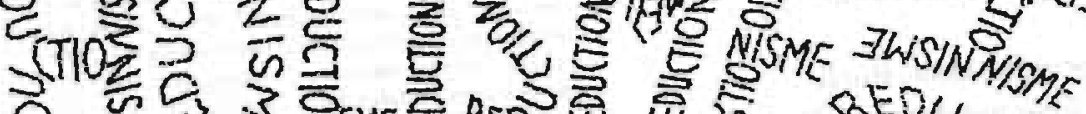

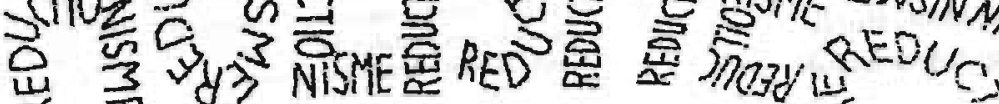

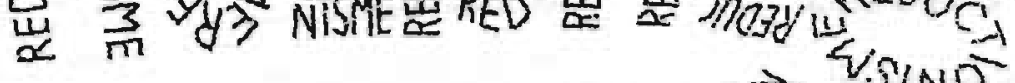

$$
\begin{aligned}
& \text { AEDUCTONISME } \\
& \gg \text { Nogy }
\end{aligned}
$$

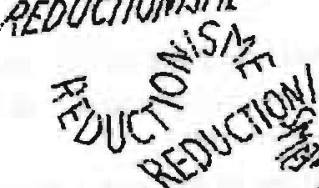

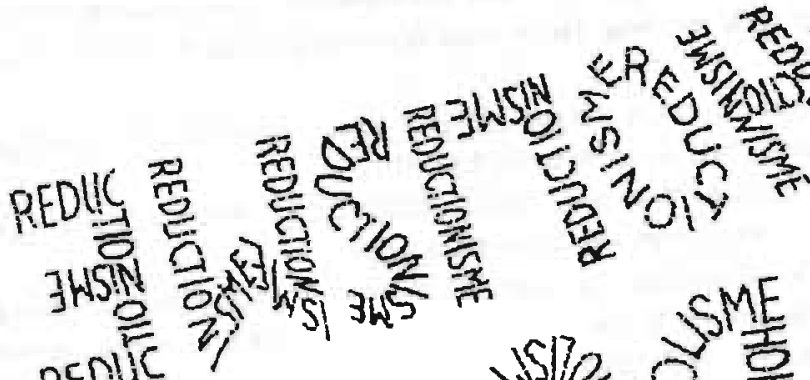

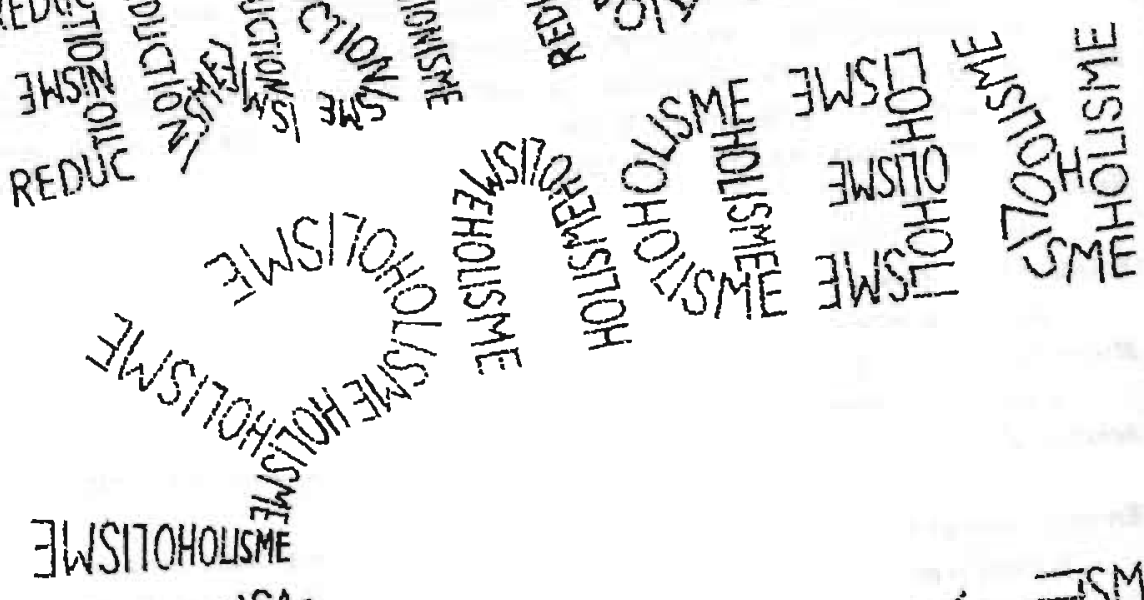

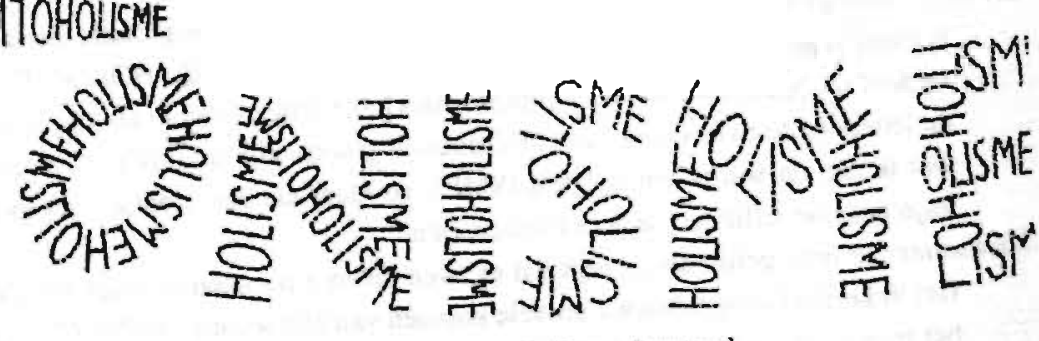

[Tekening Marjan Gerritse naar voorbeeld van de auteur.] 
om de letters in de twee delen van verschillende grootte zijn weet ik niet, maar ik weet wel wat ik zie, en wat ik zie is 'REDUCTIONISME', zo klaar als een klontje. Het gaat me boven mijn pet hoe jullie iets anders kunnen zien.

Achilles: Ik weet wat er hier aan de hand is. Jullie hebben alle twee letters gezien die andere letters vormen, of die zelf zijn gevormd uit andere letters. In het linkerdeel staan inderdaad drie 'HOLISME'S', maar die zijn elk weer gevormd uit kleinere kopieën van het woord 'REDUCTIONISME'. En op complementaire wijze zit er in het rechterdeel inderdaad een 'REDUCTIONISME', maar het is gevormd uit kleine kopieën van het woord 'HOLISME'. Dit is allemaal goed en wel, maar door jullie onnozele gekrakeel zagen jullie door de bomen het bos niet meer. Want wat heeft het voor zin om te kibbelen over 'HOLISME' of 'REDUCTIONISME' terwijl de enige manier om deze kwestie te begrijpen het trancenderen van de vraag is door te antwoorden: 'MU'?

Kreefi: Ik zie de tekening nu zoals jij hem hebt beschreven, Achilles, maar ik heb er geen flauw idee van wat je bedoelt met die vreemde uitdrukking: 'MU'.

Achilles: Ik wil jullie graag vertellen wat ik bedoel, als jullie mij eerst vertellen wat die vreemde uitdrukkingen 'HOLISME' en 'REDUCTIONISME' betekenen.

Kreeft: Het begrijpen van HOLISME is de natuurlijkste zaak van de wereld. Het is de opvatting dat 'het geheel groter is dan de som der delen'. Geen mens met een gezonde rechterhersenhelft kan holisme verwerpen.

Miereneter: Het begrijpen van REDUCTIONISME is de natuurlijkste zaak van de wereld. Het is de opvatting dat 'je een geheel volledig kan begrijpen als je de delen en de aard van hun "som" begrijpt'. Geen vrouw die niet twee linkerhersens heeft, kan reductionisme verwerpen.

Kreeft: $\mathrm{lk}$ verwerp reductionisme. $\mathrm{lk}$ daag je uit om mij te vertellen hoe je bij voorbeeld een stel hersenen reductionistisch moet verklaren. Iedere reductionistische verklaring van de hersenen zal onvermijdelijk te kort schieten als het gaat om de vraag waar het bewustzijn dat de hersenen ondervinden vandaan komt.

Miereneter: Ik verwerp holisme. Ik daag je uit om mij te vertellen hoe bijvoorbeeld een holistische beschrijving van een mierenkolonie meer verklaart dan een beschrijving van de mieren zelf, hun taken en hun onderlinge betrekkingen. Iedere holistische verklaring van een mierenkolonie zal onvermijdelijk tekort schieten als het gaat om de vraag waar het bewustzijn van een mierenkolonie vandaan komt.

Achilles: O nee! Nog een ruzie ontketenen was wel het laatste wat ik wilde. Maar nu ik de controverse begrijp, denk ik dat mijn verklaring van 'MU' uitkomst kan bieden. 'MU' is een oud Zen-antwoord dat, als antwoord op de vraag, de vraag ONVRAAGT. De vraag luidt hier volgens mij: 'Moet de wereld holistisch, of reductionistisch worden verklaard?' En het antwoord 'MU' verwerpt hier de premisse van de vragen, namelijk dat het een of het andere moet worden gekozen. Door de vraag te ontvragen openbaart zich een grotere waarheid: die van een ruimere context waarin zowel holistische als reductionistische verklaringen passen.

Miereneter: Absurd! Jouw 'MU' is even stom als het moe van een koe. Ik moet niks hebben 
van die Zen-rimram.

Kreef: Bespottelijk! Jouw 'MU' is zo onnozel als het mioe van een poes. Ik moet niets hebben van die Zen-ramrim.

Achilles: Lieve deugd! Zo komen we nergens. Waarom ben je zo eigenaardig stil, meneer Schildpad? Ik wordt er nogal zenuwachtig van. Jij bent toch zeker wel in staat om orde te scheppen in deze chaos?

Schildpad: Jullie zullen me niet geloven, maar het antwoord op de vraag staat pal voor onze neus, verborgen in de tekening. Het is maar één woord - maar wat een belangrijk woord: 'MU'!

Achilles: O meneer S., voor de eerste keer laat jij me in de steek. Ik dacht dat jij, die de dingen altijd zo goed ziet, in staat was dit dilemma op te lossen - maar kennelijk heb jij niet verder gekeken dan ik. Nou ja, ik denk dat ik al blij mag zijn dat ik voor een keertje even ver gekeken heb als meneer schildpad.

Schildpad: Neem me niet kwalijk, maar mijn ogen zijn opperbest. Wil je nog eens kijken en zeg me dan of de tekening zegt wat ik zei dat ze zegt!

Achilles: Natuurlijk wel! Je hebt alleen mijn eigen oorspronkelijke waarneming herhaald.

Schildpad: Misschien staat er 'MU' in deze tekening, maar op een dieper niveau dan jij je voorstelt, Achilles - een octaaf lager (figuurlijk gesproken). Maar op dit moment twijfel ik eraan of we onze onenigheid op zo'n abstract niveau kunnen bijleggen. Ik zou graag zien dat zowel het holistische als het reductionistische standpunt expliciet werden gemaakt; dan hebben we misschien een betere basis voor een beslissing. Ik zou bij voorbeeld bijzonder graag een reductionistische beschrijving van een mierenkolonie horen.

Kreeft: Misschien dat dr. Miereneter je iets wil vertellen over zijn ervaringen daarmee. Per slot van rekening is hij beroepshalve een soort expert op dat gebied.

Schildpad: Ik ben ervan overtuigd dat we veel van je kunnen leren, dr. Miereneter. Zou je ons meer kunnen vertellen over mierenkolonies uit reductionistisch perspectief.

Miereneter: Met alle genoegen. Zoals meneer Kreeft reeds vertelde, heb ik beroepsmatig de mierenkolonies diepgaand onderzocht.

Achilles: Dat kan ik me voorstellen! Het beroep miereneter mag wel haast synoniem met expert op het gebied van mierenkolonies worden genoemd.

Miereneter: Pardon. 'Miereneter' is niet mijn beroep; het is mijn soort. Ik ben koloniechirurg van beroep. Mijn specialisme is het corrigeren van nerveuze spanningen in de kolonie door middel van de chirurgische ingreep.

Achilles: $\mathrm{O}$, ik snap het. Maar wat versta jij onder 'nerveuze spanningen' bij een mierenkolonie?

Miereneter: De meeste van mijn cliënten lijden aan een vorm van spraakstoornis. Je weet wel, een kolonie die in alledaagse situaties steeds naar woorden moet zoeken. Dat kan heel tragisch zijn. Ik probeer de situatie te verbeteren door, eh, het aangetaste deel van de kolonie te verwijderen. Deze operaties zijn soms heel ingrijpend en het vergt een jarenlange studie voor je ze kunt uitvoeren. 
Achilles: Maar - om te kunnen lijden aan spraakstoornissen moet je toch eerst een spraakvermogen hebben?

Miereneter: Dat klopt.

Achilles: Aangezien mierenkolonies niet over dat vermogen beschikken, sta ik een beetje verstomd.

Kreefi: Jammer, Achilles, dat je er vorige week niet bij was toen dr. Miereneter en tante Myra Hoop bij mij op bezoek waren. Had ik jullie toen maar uitgenodigd.

Achilles: Is tante Myra Hoop een echte tante van je, meneer Kreeft?

Kreef: O nee, ze is eigenlijk niemands tante.

Miereneter: Maar de lieve schat staat erop dat iedereen haar zo noemt, ook vreemden. Het is een van haar vele vertederende trekjes.

Kreeft; Ja, tante Myra Hoop is heel excentriek, maar het is zo'n aardige troel. Toch jammer dat jullie er vorige week niet bij waren.

Miereneter: Ze is beslist cen van de meest ontwikkelde micrenkolonies dic ik ooit heb leren kennen. Wij hebben samen vele avonden lang zitten praten over de meest uiteenlopende onderwerpen.

Achilles: Ik dacht dat miereneters mierenverslinders waren in platats van beschermheren van het micrenintellect!

Miereneter: Ach, dat hoeft elkaar niet uit te sluiten. Ik sta op goede voet met mierenkolonies. Ik eet alleen MIEREN, geen kolonies - en dat komt beide partijen ten goede: mij en de kolonie.

Als ik, een miereneter, een bezoekje aan tante Myra Hoop kom brengen, raken al die dwaze mieren in paniek zodra ze mijn geur opsnuiven - en dat belekent dat $\propto$ totaal anders beginnen rond te rennen dan ze deden voor ik er was.

Achilles: Maar dat is begrijpelijk, want je bent een gevreesde vijand van de kolonie.

Miereneter: Ik moet toegeven dat iedere mier afzonderlijk bang voor me is; maar dat is een andere kwestie. Je ziet in ieder geval dat als reactie op mijn komst de interne verdeling van de mieren volkomen verandert.

Achilles: Dat is duidelijk.

Miereneter: En dat aanpassen aan de actuele situatie, weerspiegelt mijn aanwezigheid. Je kunt de verandering van oude toestand naar nieuwe beschrijven door te zeggen dat er een 'stuk kennis' aan de kolonic is toegevoegd.

Achilles: Hoe kun je de verdeling van verschillende types mieren over een kolonie nu een 'stuk kennis' noemen.

Miereneter: Daar raak je de kern van de zaak. Maar dat vergt enige nadere uitleg. Als je blijft denken in termen van de lagere niveaus - individuele mieren - zie je door de bomen het bos niet meer. Dat niveau is gewoon veel te microscopisch en als je microscopisch denkt, zal je onvermijdelijk sommige grootschalige kenmerken missen. Er zijn verschillende typen mieren, die 'kasten' genoemd worden, binnen iedere kolonie. Voor de beschrijving van de kasteverdeling zal je het juiste kader op hoog niveau moeten vin- 
den. Alleen dan wordt duidelijk hoe de kasteverdeling vele stukken kennis kan coderen. Achilles: Maar hoe vind je dan de juiste eenheden om de huidige toestand van de kolonie te beschrijven?

Miereneter: Goed, dan beginnen we van onder af aan. Als er bij mieren iets gedaan moet worden, vormen ze kleine 'ploegen', die samenwerken om een karwei te klaren. Zoals ik al eerder zei, vormen en ontbinden zich de hele tijd kleine groepen mieren. Groepen die een poosje bestaan zijn de ploegen, en ze vallen niet uiteen omdat er inderdaad iets voor ze te doen is. Als er ergens een onbeduidende hoeveelheid voedsel is, die wordt ontdekt door een rondtrekkende mier, die vervolgens haar enthousiasme probeert over te brengen op andere mieren, zal het aantal mieren dat reageert evenredig zijn met de hoeveelheid voedsel - en een onbeduidende hoeveelheid zal niet voldoende mieren aantrekken om de drempel te overschrijden.

Achilles: Ik snap het. Ik veronderstel dat deze 'ploegen' een van de structurele niveaus vormen die ergens tussen het niveau van de afzonderlijke mier en het niveau van de kolonie vallen.

Miereneter: Precies. Er bestaat een bijzondere ploeg die ik een 'signaal' noem - en alle hogere structurele niveaus berusten op signalen. In feite zijn alle hogere entiteiten verzamelingen van samenwerkende signalen. Er zijn ploegen op hogere niveaus waarvan de afzonderlijke leden geen mieren zijn, maar ploegen op lagere niveaus. Uiteindelijk kom je bij de ploegen op het laagste niveau - d.w.z. signalen - en daaronder vallen de mieren. Achilles: Vanwaar die suggestieve naam 'signalen'?

Miereneter: Dat komt door hun functie. Signalen zorgen ervoor dat mieren met verschillende specialismen in de juiste afdeling van de kolonie terechtkomen. Het klassieke verhaal van een signaal luidt als volgt: het komt tot leven doordat de drempel die nodig is om te overleven wordt overschreden, dan verplaatst het zich over enige afstand door de kolonie en op een gegeven moment valt het min of meer uiteen in de individuele leden die aan hun lot worden overgelaten.

Achilles: Dat lijkt op een golf, die van verre zeesterren en wier meevoert en ze dan, hoog en droog, her en der op het strand achterlaat.

Miereneter: In zekere zin is dat hetzelfde. want de ploeg laat inderdaad iets achter dat hij over een bepaalde afstand met zich heeft meegevoerd, maar terwijl het water van de golf terugspoelt naar zee, is er in het geval van een signaal geen sprake van een dragende substantie, aangezien de mieren dat zelf zijn.

Schildpad: En ik veronderstel dat juist op de plek in de kolonie waar mieren van dat type nodig waren een signaal zijn samenhang verliest.

Miereneter: Natuurlijk.

Achilles: Natuurlijk? IK vind het niet zo natuurlijk dat een signaal altijd daarheen gaat waar er behoefte aan is. En ook al gaat het in de goede richting, hoe weet het dan waar het uiteen moet vallen? hoe weet het dat het is aangekomen?

Miereneter: Dat zijn uiterst belangrijke kwesties, want dan moet je een verklaring vinden voor het feit dat signalen doelmatig gedrag - of iets wat op doelmatig gedrag lijkt - ver- 
tonen. Aan de hand van de beschrijving zou je geneigd zijn het gedrag van signalen te bestempelen als gedrag dat zich richt op het vervullen van een behoefte en het dan ook 'doelmatig' te noemen. Maar je kunt het ook op een andere manier bekijken.

Achilles: Wacht eens even. Het gedrag IS doelmatig, of het is het NIET. Het wil er bij mij niet in dat het beide kan zijn.

Miereneter: Laat me uitleggen hoe ik het zie, en daarna kunnen we kijken of we het eens zijn. Als een signaal eenmaal gevormd is, beseft het niet dat het in een bepaalde richting moet gaan. Maar hierbij is de verfijnde kasteverdeling cruciaal. Die bepaald juist de beweging van signalen door de kolonie en ook hoe lang een signaal stabiel blijft en waar het zal 'oplossen'.

Achilles: Alles berust dus op kasteverdeling.

Miereneter: Juist. Stel dat een signaal zich voortbeweegt. Terwijl het zich voortbeweegt ontstaat er een interactie tussen de mieren waar het uit bestaat, en de mieren van de lokale gebieden waar het doorheentrekt, hetzij door direct contact, hetzij door uitwisseling van geuren. Het contact en de geuren verschaften informatie over urgente plaatselijke aangelegenheden, zoals het bouwen van een nest, broedzorg, of wat dan ook. Het signaal blijft hecht bijeen zolang de plaatselijke behoeften afwijken van wat het kan bieden; maar ALS het cen bijdrage kan leveren, valt het uiteen en loost het ter plekke een frisse ploeg van beschikbare mieren. Zie je nu hoe de kasteverdeling fungeert als een overkoepelende instantie voor de ploegen binnen een kolonie?

Achilles: $\mathrm{Ja}$, nu is het me duidelijk.

Miereneter: En zie je ook dat het bij deze interpretatie niet nodig is om doclmatigheid toe te schrijven aan het signaal?

Achilles: lk geloof van wel. Ik begin de dingen nu ook van twee kanten te zien. In miere-ogen heeft een signaal GEEN doel. De typische signaalmier slentert een beetje door de kolonie, naar nicts speciaals op zoek, totdat ze het gevoel krijgt dat ze moet stoppen. Haar plocgmaten zijn het daar gewoonlijk mee eens en op dat moment lost de ploeg zich op door uiteen te vallen, waarbij wel de leden overblijven maar de samenhang verdwijnt. Er is geen planning en voorbereiding nodig; er hoeft evenmin gezocht te worden naar de juiste richting. Maar voor de KOLONIE reageerde de ploeg louter op een boodschap, geschreven in de taal van de kasteverdeling. Zo gezien heeft het erg veel weg van doelmatige activiteit.

Kreef: Wat zou er gebeuren als de kasteverdeling volkomen willekeurig was'? Zouden signalen dan nog altijd binden en ontbinden?

Miereneter: Zeker wel. Maar de kolonie zou door de zinloosheid van de kasteverdeling geen lang leven beschoren zijn.

Kreeft: Dat is nou wat ik bedoelde. Kolonies houden stand omdat hun kasteverdeling zinvol is, en dat zinvolle is iets holistisch, dat op lager niveau niet zichtbaar is. Je verklaring verliest aan kracht als je geen rekening houdt met dat lagere niveau.

Miereneter: Ik begrijp wat je bedoelt, maar ik geloof dat je de dingen te beperkt ziet.

Kreefi: Hoezo? 
Miereneter: Mierenkolonies zijn al miljarden jaren onderworpen aan de strenge wetten van de evolutie. Een paar mechanismen werden geselecteerd, maar de meeste werden weggeselecteerd. Het eindresultaat was een stel mechanismen die ervoor zorgen dat een mierenkolonie functioneert zoals we hebben beschreven. Als je het hele proces als een film zou kunnen zien - uiteraard een film die miljarden malen sneller loopt dan de werkelijkheid - zou je zien hoe het ontstaan van de diverse mechanismen een natuurlijke reactie is op druk van buitenaf, net zoals de belletjes in kokend water een natuurlijke reactie zijn op een warmtebron buiten. Ik denk niet dat je 'betekenis' en 'doel' ziet in de belletjes van kokend water - of wel soms?

Kreeft: Nee, maar -

Miereneter: Dat is nu wat IK bedoel. Hoe groot de luchtbel ook is , zij dankt haar bestaansrecht aan processen op moleculair niveau, en 'wetten op hoger niveau' kun je rustig uit je hoofd zetten. Hetzelfde geld voor mierenkolonies en hun ploegen. Als je de dingen beschouwt vanuit het weidse perspectief van de evolutie, ontneem je misschien de hele kolonie betekenis en doel. Dat worden dan overbodige begrippen.

Achilles: Maar dr. Miereneter, waarom vertel je me nu dan dat je met tante Myra Hoop sprak? Het lijkt nu wel of je ontkent dat ze zou kunnen spreken en denken.

Miereneter: Ik ben niet inconsequent, Achilles. Net als ieder ander heb ik er moeite mee om de dingen over een dergelijke immense tijdspanne te zien, en daarom vind ik het veel handiger om van gezichtspunt te veranderen. Als ik dat doe, en de evolutie even vergeet en de dingen in het hier en nu bekijk, komt het teleologische woordgebruik weer boven: de ZIN van de kasteverdeling en de DOELMATIGHEID van de signalen. Dit gebeurt niet alleen wanneer ik spreek over mierenkolonies, maar ook wanneer ik nadenk over mijn eigen hersenen en de hersenen van anderen. Maar als dat nodig is kan ik me, zij het met enige moeite, altijd wel het andere standpunt indenken en ook al deze standpunten hun betekenis ontnemen.

Schildpad: Kun je het volgende beantwoorden, dr. Miereneter? Bestaat een signaal, vanaf zijn ontstaan tot aan zijn ontbinding, altijd uit dezelfde verzameling mieren?

Miereneter: Inderdaad haken de individuen in een signaal soms af en als er enkele in het gebied zijn worden ze vervangen door andere van dezelfde kaste. Meestal bereiken signalen de plaats waar ze uiteenvallen met andere mieren dan bij het begin.

Kreefr: lk begrijp dat de signalen constant de kasteverdeling in de kolonie beïnvloeden, al naar gelang de interne behoeften van de kolonie - die op hun beurt weer de externe situatie weerspiegelen waarmee de kolonie wordt geconfronteerd. Zodoende past de kasteverdeling. om met jouw woorden te spreken, dr. Miereneter, zich voortdurend aan de actuele stand van zaken aan, op een manier die uiteindelijk de buitenwereld weerspiegeld.

Achilles: Maar hoe zit het dan met die tussenliggende structurele niveaus? Je beweerde dat de kasteverdeling beter niet kon worden afgeschilderd in mieren of signalen, maar in termen van ploegen waarvan de leden weer andere ploegen vormen, enzovoort, tot je op miere-niveau komt. En je zei dat dat de sleutel was tot de vraag hoe de kasteverdeling 
te beschrijven als gecodeerde stukjes informatie over de wereld.

Miereneter: Ja, daar komen we nog op terug. Ik geef er de voorkeur aan ploegen van voldoende hoog niveau 'symbolen' te noemen. Maar bedenk wel, deze betekenis van het woord verschilt aanzienlijk van de normale betekenis. Mijn 'symbolen' zijn ACTIEVE SUBSYSTEMEN en ze zijn samengesteld uit actieve subsystemen van een lager niveau ... Ze verschillen daarom ook sterk van PASSIEVE symbolen buiten het systeem, zoals de letters van het alfabet of muzieknoten, die onbeweeglijk op hun plaats blijven in afwachting van het moment waarop een actief systeem ze verwerkt.

Achilles: $\mathrm{O}$, dit is wel erg ingewikkeld hè? Ik had er geen idee van dat een mierenhoop zo'n abstracte structuur had.

Miereneter: Ja, dat is heel bijzonder. Maar al deze structurele lagen zijn nodig om het soort kennis op te slaan dat een organisme in staat stelt 'intelligent' te zijn in iedere - redelijke - zin van het woord. Ieder systeem dat een taal vormt, bezit in wezen dezelfde onderliggende verzameling van niveaus.

Achilles: Hola! Wil je daarmee suggereren dat mijn hersenen in wezen bestaan uit een zootje rondrennende mieren?

Miereneter: Nee, dat niet direct. Je moet het niet zo letterlijk opvatten. Het laagste niveau kan geheel verschillend zijn. De hersenen van miereneters zijn ook niet samengesteld uit mieren. Maar als je een niveau of twee omhoog gaat in de hersenen, bereik je een niveau met elementen die hun volmaakte tegenhangers hebben in andere systemen van gelijk intellectueel niveau -zoals mierenkolonies.

Schildpad: Daarom is het ook redelijk, Achilles, om jouw hersenen af te beelden op een mierenkolonie en niet op de hersenen van zomaar een mier.

Achilles: Bedankt voor het compliment. Maar hoe moet je je zo'n afbeelding voorstellen? Wat correspondeert in mijn hersenen bijvoorbeeld met de ploegen op een lager niveau die jij signalen noemt?

Miereneter: $\mathrm{O}$, op hersengebied ben ik maar een amateur en daarom zou ik de afbeelding niet tot in details kunnen uitdenken. Maar - en waarschuw me als ik het mis heb, meneer Kreeft - ik heb zo'n vermoeden dat bij de hersenen de tegenhanger van het signaal in de mierenkolonie, het afvuren van een neuron is; of misschien is het een grootschaliger gebeurtenis, zoals een patroon van neuraal afvuren.

Kreefi: Daar kan ik wel in meegaan. Maar bij onze discussie gaat het er toch niet in de eerste plaats om de exacte tegenhanger aan te geven, hoe wenselijk dat ook moge zijn? Volgens mij is het het belangrijkste dat er zo'n overeenkomst bestaat, ook al weten we op dit moment nog niet precies hoe we hem moeten definiëren. Ik zou alleen een vraagteken willen zetten bij één punt van jou, dr. Miereneter; het heeft te maken met het niveau waarop je kunt verwachten dat de overeenkomst begint. Jj denkt geloof ik dat een SIGNAAL een directe tegenhanger kan hebben in de hersenen; terwijl ik van mening ben dat het pas vanaf jouw ACTIEVE SYMBOLEN en hoger waarschijnlijk is dat er een overeenkomst bestaat.

Miereneter: Jouw interpretatie kan best veel nauwkeuriger zijn dan de mijne, meneer Kreeft. 


\section{Bedankt voor dit subtiele argument.}

Achilles: Wat doet een symbool dat een signaal niet doet?

Miereneter: Dat lijkt op het verschil tussen woorden en letters. Woorden zijn, als betekenis dragende entiteiten, samengesteld uit letters, die op zich geen betekenis dragen. Dat . geeft een goed idee van het verschil tussen symbolen en signalen. Het is in feite een bruikbare analogie, zolang je maar niet uit het oog verliest dat woorden en letters PASSIEF zijn, en symbolen en signalen ACTIEF.

Achilles: Daar zal ik aan denken, maar ik geloof niet dat ik begrijp waarom het verschil tussen actieve en passieve entiteiten zo ontzettend belangrijk is.

Miereneter: De reden daarvoor is dat de betekenis die je toekent aan een passief symbool, zoals een woord op een bladzij, eigenlijk afkomstig is van de betekenis van corresponderende actieve symbolen in je hersenen. Zodat de betekenis van passieve symbolen alleen goed geïnterpreteerd kan worden als deze in verband wordt gebracht met de betekenis van actieve symbolen.

Achilles: Oké. Maar waaraan ontleent een SYMBOOL - een actief symbool, voor alle duidelijkheid - zijn betekenis, als je stelt dat een SIGNAAL - zelf toch ook een volmaakte entiteit - geen betekenis heeft?

Miereneter: Dat heeft allemaal te maken met de manier waarop symbolen ervoor kunnen zorgen dat andere symbolen worden geactiveerd. Als een symbool actief wordt, geschiedt dit niet in isolement. Het zweeft rond in een medium dat wordt gekarakteriseerd door de kasteverdeling.

Kreeft: Natuurlijk is er in de hersenen niet zoiets als een kasteverdeling, maar de tegenhanger daarvan is de 'staat van de hersenen'. Dan beschrijf je de staat van alle neuronen en alle onderlinge verbindingen en de drempel voor het afvuren van elk neuron.

Miereneter: Goed dan: laten we 'kasteverdeling' en 'staat van de hersenen' onder een gezamenlijke noemer brengen en gewoon spreken over de 'staat'. Nu kan de staat op een laag niveau, of op een hoog niveau worden beschreven. Een beschrijving op laag niveau van de mierenkolonie vraagt om een nauwkeurige specificatie van de positie van iedere mier, naar leeftijd, kaste en meer van dergelijke zaken. Een zeer gedetailleerde beschrijving die weinig opheldering verschaft over de vraag WAAROM zij in die staat verkeert. Anderzijds zou bij een beschrijving op hoog niveau gespecificeerd moeten worden welke symbolen door welke combinatie van andere symbolen kunnen worden geactiveerd, onder welke condities, enzovoort.

Achilles: Wat dacht je van een beschrijving op het niveau van signalen, of ploegen.

Miereneter: Een beschrijving op dat niveau zou het midden houden tussen een beschrijving op laag niveau en de beschrijving op symbool niveau. Deze beschrijving zou een grote hoeveelheid informatie bevatten over wat er feitelijk gaande is op bepaalde plaatsen verspreid over de hele kolonie, maar minder dan een mier-voor-mierbeschrijving, want ploegen bestaan uit groepjes mieren. Een ploeg-voor-ploegbeschrijving is net zoiets als een samenvatting van een mier-voor-mierbeschrijving, maar je moet extra gegevens die niet aanwezig waren in de mier voor mier beschrijving toevoegen - zoals de betrekkin- 
gen tussen ploegen en de verspreiding van verschillende kasten over diverse plekken. Deze extra complicatie is de tol die je moet betalen voor het recht van samenvatten. Achilles: Ik vind het interessant om de voordelen van de beschrijvingen op verschillende niveaus met elkaar te vergelijken. Een beschrijving op het hoogste niveau lijkt het meest te kunnen verklaren, omdat deze je het meest intuitieve beeld van de mierenkolonie geeft, maar vreemd genoeg laat ze het kennelijk belangrijkste kenmerk buiten beschouwing: de mieren.

Miereneter: Het mag er dan anders uitzien, maar de mieren zijn niet het belangrijkste kenmerk.

Toegegeven, zonder hen zou de kolonie niet bestaan; maar iets dergelijks, de hersenen, kunnen wel mierloos bestaan. Dus je kunt, op hoger niveau, best buiten de mieren.

Achilles: Ik denk niet dat de mieren jouw theorie in dank zullen afnemen.

Miereneter: Ik ben nog nooit een mier van hoog niveau tegengekomen.

Kreeft: Je schets wel een contra-intuittief beeld, dr. Miereneter. Als wat je zegt waar is, moet je om de hele structuur te kunnen bevatten in je beschrijving ervan kennelijk iedere verwijzing naar zijn fundamentele bouwstenen weglaten.

Miereneter: Misschien dat ik het je kan verduidelijken met een analogie. Stel je hebt een roman van Charles Dickens voor je.

Achilles: The Pickwick papers - is dat goed?

Miereneter: Voortreffelijk! En stel je nu het volgende spelletje voor: je moet een manier vinden om letters af te beelden op ideëen, zodat de hele Pickwick Papers ook iets zinnigs voorstelt als je hem letter voor letter leest.

Achilles: Hmm... Je bedoelt dat ik iedere keer wanneer ik bijvoorbeeld op het woordje "het' stuit, aan drie vaststaande begrippen moet denken, het een na het ander, zonder enige ruimte voor variatie?

Miereneter: Precies. Het ' $h$ '-begrip, het ' $e$ '-begrip en het ' $t$ '-begrip - en steeds weer zijn deze begrippen hetzelfde als de keer ervoor.

Achilles: Zo te horen wordt het 'lezen' van The Pickwick papers een onbeschrijflijk vervelende nachtmerrie. Het zou een oefening in zinloosheid worden, ongeacht de begrippen die ik met de letters associeerde.

Miereneter: Precies. Er is geen natuurlijke afbeelding van de individuele letters op de werkelijke wereld. De natuurlijke afbeelding vindt plaats op een hoger niveau: tussen woor= den en delen van de werkelijke wereld. Als je het boek wilt beschrijven hoef je het letterniveau dan ook niet te vermelden.

Achilles: Natuurlijk niet! Ik zou de plot en de figuren die erin voorkomen beschrijven, enzovoort.

Miereneler: Aha. Je zou dus alle bouwstenen weglaten in je beschrijving, ook al dankt het boek zijn bestaan aan die letters. Ze zijn het medium, niet de boodschap.

Achilles: Akkoord - maar hoe zit het dan met mierenkolonies?

Miereneter: Daarbij heb je actieve signalen in plaats van passieve letters en actieve symbolen in plaats van passieve woorden - maar het idee blijft hetzelfde.

Achilles: Bedoel je dat ik geen afbeelding tussen signalen en dingen in de werkelijke wereld 


\section{kan vormen?}

Miereneter: Dan zal je ontdekken dat het je niet lukt nieuwe signalen zo te activeren dat ze enige zin hebben. En ook op een lager niveau - bijvoorbeeld op het mierniveau - zal je dat niet lukken. Alleen op symboolniveau hebben de activeringspatronen betekenis. Stel je voor dat je op een dag Myra Hoop observeerde en ik kwam op bezoek. Hoe zorgvuldig je ook observeerde, toch zou je vermoedelijk niets meer waarnemen dan een herschikking van mieren.

Achilles: Dat zal wel.

Miereneter: Toch zou ik, kijkend naar het hogere niveau in plaats van het lagere, zien hoe verschillende slapende symbolen gewekt werden; symbolen die zich laten vertalen in: 'Ach, daar heb je die charmante dr. Miereneter weer - wat aardig! - of woorden van gelijke strekking.

Achilles: Dat lijkt op wat er gebeurde toen we allevier verschillende niveaus vonden om de MU-tekening te lezen - of althans DRIE van ons ...

Schildpad: Wat een ongelooflijk toeval dat er een dergelijke overeenkomst bestaat tussen de vreemde tekening die ik tegenkwam in Wohl Temperierte Clavier en de loop van ons gesprek.

Achilles: Denk je dat het alleen maar toeval is?

Schildpad: Natuurlijk.

Miereneter: Wel, ik hoop dat je nu begrijpt hoe de gedachten in tante Myra Hoop voortkomen uit de symbolen die samengesteld zijn uit signalen die samengesteld zijn uit ploegen die samengesteld zijn uit ploegen op een lager niveau, en steeds verder omlaag, tot aan de mieren.

Achilles: Waarom noem je dat 'symboolmanipulatie'? Wie voert de manipulatie dan uit, de symbolen zijn immers zelf actief. Wie is het agens?

Miereneter: Dat voert ons terug tot de vraag over het doel, die je eerder stelde. Je hebt gelijk als je zegt dat de symbolen zelf actief zijn, maar toch zijn de activiteiten die zij ontplooien niet per definitie vrij. De activiteiten van alle symbolen zijn strikt bepaald door de staat van het complete systeem waarin zij voorkomen. Daarom is het complete systeem verantwoordelijk voor de manier waarop zijn symbolen elkaar activeren en daarom is het alleszins redelijk om het complete systeem te beschouwen als het agens. Je kunt het complete systeem een naam geven. Zo is tante Myra Hoop de 'wie' van wie gezegd kan worden dat ze haar symbolen manipuleert; en voor jou geld hetzelfde, Achilles.

Achilles: Dat is een nogal vreemde karakterisering van de notie wie ik ben. Ik kan het misschien niet helemaal begrijpen, maar ik zal er eens over denken.

Schildpad: Het zou interessant zijn om de symbolen in jou hersenen te volgen terwijl jij nadenkt over de symbolen in jou hersenen.

Achilles: Dat wordt mij te ingewikkeld. Ik heb al moeite genoeg on te bedenken hoe het mogelijk is naar een mierenkolonie te kijken en haar te lezen op symboolniveau. Ik kan me wel voorstellen dat ik haar waarneem op mierniveau; en met een beetje inspanning 
kan ik me voorstellen hoe het moet zijn om haar waar te nemen op signaalniveau; maar in hemelsnaam, wat is het om een mierenkolonie waar te nemen op symboolniveau?

Miereneter: Dat leer je alleen door langdurige oefening. Maar als je eenmaal zover bent als $\mathrm{ik}$, lees je het bovenste niveau van een mierenkolonie even makkelijk als je het ' $\mathrm{M} U$ ' leest in de MU-tekening.

Achilles: Is dat heus? Dat moet wel een verbijsterende ervaring zijn.

Miereneter: In zekere zin wel - maar toch is het ook iets wat jij heel goed kent, Achilles.

Achilles: Goed kennen? Wat bedoel je? Ik heb nog nooit anders naar een mierenkolonie gekeken dan op mierniveau.

Miereneter: Misschien niet, maar in veel opzichten verschillen mierenkolonies niet van hersenen.

Achilles: Maar ik heb nog nooit hersenen gezien of gelezen.

Miereneter: En je eigen hersenen dan? Ben je je dan niet bewust van je eigen gedachten? Is dat niet de essentie van bewustzijn? Wat doe je anders dan je eigen hersenen direct aflezen op symboolniveau?

Achilles: Zo heb ik het nog nooit beschouwd. Bedoel je dat ik voorbijga aan alle lagere niveaus en alleen het bovenste niveau zie?

Miereneter: Zo gaat dat althans bij bewuste systemen. Ze nemen zichzelf alleen waar op symboolniveau en ze zijn zich niet bewust van de lagere niveaus, zoals de signaalniveaus.

Achilles: Betekent dit dat er in de hersenen actieve symbolen zijn die zichzelf constant actualiseren, zodat ze de totale staat van de hersenen zelf weerspiegelen, natuurlijk op symboolniveau?

Miereneter: Jazeker. In ieder bewust systeem zijn er symbolen die de staat van de hersenen vertegenwoordigen en die zelf deel uitmaken van de staat van de hersenen die zij symboliseren. Bewustzijn vergt immers een grote mate van zelfbewustzijn.

Achilles: Dat is een krankzinnig idee. Dus, hoewel er in mijn hersenen de hele tijd een razende activiteit plaatsvindt, kan ik de activiteit slechts op één manier registreren - op symboolniveau; en ik ben volmaakt ongevoelig voor de lagere niveaus. Het is zoiets als het lezen van een roman van Dickens door middel van directe visuele waarneming, zonder ooit de letters van het alfabet geleerd te hebben. Ik kan me niet voorstellen dat zoiets krankzinnigs werkelijk gebeurt.

Kreefi: Maar iets dergelijks gebeurde toen jij 'MU' las, zonder de lagere niveaus 'HOLISME' en 'REDUCTIONISME' waar te nemen.

Achilles: Je hebt gelijk - ik ging voorbij aan de lagere niveaus en zag alleen de bovenlaag. Wellicht mis ik door alleen het symboolniveau te lezen ook allerlei betekenissen op lagere niveaus van mijn hersenen. Jammer dat het bovenste niveau niet alle informatie bevat over het laagste, zodat je door de top te lezen ook ervaart wat het onderste te zeggen heeft. Maar het zal wel naïf zijn om te denken dat in het bovenste niveau iets van het onderste is gecodeerd - het zou vermoedelijk niet naar boven doordringen. De MU: tekening is daarvan het meest frappante voorbeeld dat ik me kan voorstellen: het bovenste niveau luidt daar alleen ' $\mathrm{MU}$ ', wat in geen enkele relatie staat tot de lagere niveaus: 
Kreeft: Dat is volkomen waar. (pakt de MU-tekening op om hem nog eens te bekijken.) Hmm... Er is iets aan de hand met de kleinste lettertjes van deze tekening; ze zijn zeer priegelig...

Miereneter: Laat mij eens kijken. (Tuurt van heel dichtbij naar de MU-tekening.) Ik geloof dat er nog een niveau is dat we allemaal gemist hebben!

Schildpad: Spreek voor jezelf, dr. Miereneter.

Achilles: 't Is niet waar! Laat eens kijken. (Kijkt heel aandachtig.) Ik weet dat jullie dit niet zullen geloven, maar de boodschap van deze tekening staat pal voor onze neus, diep verborgen. Het is maar één woord, dat telkens herhaald wordt, als een mantra - maar wat een belangrijk woord: 'M U'! Wel heb ik ooit! Het is hetzelfde als het bovenste niveau! En niemand van ons had het in de gaten.

Kreeft: Als we jou niet hadden, Achilles zou het ons nooit zijn opgevallen.

Miereneter: lk vraag me af of het toeval is dat het hoogste en het laagste niveau samenvallen. Of is het doelbewust gedaan door één of andere schepper?

Kreeft: Hoe kom je daar ooit achter?

Schildpad: $\mathrm{lk}$ zou het niet weten, we weten immers ook niet waarom uitgerekend die tekening voorkomt in de uitgave van het Wohl Temperierte Clavier van de Kreeft. 


\section{SUMMARY}

7 he central theme of this thesis is the inflammatory interaction between neutrophils and endothelial cells. This inflammatory interaction is regu-

1 lated by a number of soluble inflammatory mediators, which control the make-up of adhesion molecules on both cell types, and influence their behavior. The investigations presented in this thesis are part of the vast amount of novel information on adhesion molecules and cytokines published during the last decennium. On the basis of this new data, a picture arises in which the molecular basis of the different aspects of neutrophil behavior during inflammation can be defined:

- Selectins, adhesion molecules on both endothelium and neutrophils, mediate neutro-phil rolling by providing rapidly arising and rapidly disappearing highly avid binding sites.

- $\quad \beta_{2}$ integrins on neutrophils guide chemotactic migration by providingdelicately tuned affinity to a broth array of substrata, which increases at the side of the neutrophil where an agonist concentration is sensed exceeding the previous concentration.

- $\quad \beta_{2}$ integrins can, in certain agonist and substrata-conditions, and incollaboration with $\mathrm{CD} 43$ on neutrophils, mediate a switch from 'migrating polar phenotype' to the 'immobilized spread phenotype' which is associated with neutrophil toxicity.

- Neutrophil agonists can be divided in 'chemotaxins' and 'secretagogues'. Chemotaxins, such as IL-8, can form gradients, thus supporting transendothelial migration and neutrophil accumulation at inflammatory sites. Secretagogues, such as TNF, support the aforementioned switch from 'migrating polar phenotype' to the 'immobilized spread phenotype' and initiate neutrophil toxicity.

The identification of these mediators, and the definition of their functions, which is depicted in detail in chapter $l$ of this thesis, has been of great benefit in understanding neutrophil behavior. The findings leave us with the challenge of translating this knowledge into clinical benefit for patients. 
The experimental work presented in this thesis focusses on TNF, E-selectin, and the role of these molecules in neutrophil endothelial cell interaction. Investigations on these specific subjects are presented respectively in chapter 3 , chapter 4 and chapter 5 .

In chapter 2, a short and more specific introduction to, and discussion of the experimental work is given.

In chapter 3 the conditions which lead to the release of TNF and related cytokines (IL-6 and IL-8) were investigated. Mononuclear phagocytes, activated by lipopolysaccharides from the outer leaflet of gram negative bacteria are the "classical' origin of soluble TNF during inflammation. TNF is, however, also released in response to other microbial surface components and serum-factors such as complement (chapter 3.1). Furthermore, TNF-release is shown not to be restricted to leukocytes, but to occur also by cytokine-activated renal epithelial cells (chapter 3.2). TNF thus can be associated with a wide array of inflammatory processes, which argues for a more basic role of TNF in inflammation. TNF-release by mononuclear phagocytes in response to lipopolysaccharides, is influenced by two homologous proteins, LPS binding protein, released during inflammation by the liver, and bactericidal/permeability-increasing protein, released by activated neutrophils. These two proteins can respectively increase and inhibit the detection of lipopolysaccharides by mononuclear phagocytes (chapter 3.3). Thus, TNF-release during gram-negative infection seems to be a host regulated event, rather than an overshoot-reaction to a bacterial 'toxin'.

Chapter 4 focusses on E-selectin, an inducible endothelial cell adhesion molecule which facilitates neutrophil 'rolling', the first step in neutrophil endothelial cell interaction during inflammation. Interference with E-selectin expression or E-selectin function thus might be effective in preventing neutrophil mediated inflammatory processes. E-selectin expression by endothelium is induced by the inflammatory mediators TNF and IL-1 and by bacterial lipopolysaccharides. Other factors can enhance E-selectin expression, such as IFN- $\gamma($ chapter 4.2) and yet unidentified serum factor(s) (chapter 4.3).

Furthermore, recognition of bacterial lipopolysaccharides by endothelial cells was shown to require $\mathrm{CD} 14$ (chapter 4.4). Future experiments will be necessary to determine the relevance of interference with E-selectin expression via these pathways. Besides mediating neutrophil rolling. E-selectin might have other functions. E-selectin is not stably expressed, but was found to be internalized rapidly after arriving on the cell-surface (chapter 4.1 ). The function of E-selectin internalization is unknown. By co-internalization of immune-complexes and soluble adhesion inhibiting factors, which are known to have affinity for 
E-selectin, E-selectin might play an important role in decontaminating the circulation in situations of severe immunological challenge.

In chapter 5, the involvement of TNF and E-selectin in neutrophil-mediated endothelial cell damage was investigated. In comparison to other physiological neutrophil agonists, TNF showed to be the strongest trigger for neutrophil-mediated endothelial cell injury (chapter 5.1 and 5.2). TNF induced neutrophil mediated endothelial cell injury depended completely on TNF-activation of neutrophils (chapter 5.1 and 5.3), which identifies TNF as a representative of a novel group of neutrophil agonists. Endothelial cells did, however, participate in neutrophil activation by $\mathrm{TNF}$, probably by expressing surface bound PAF in response to initial neutrophil $\mathrm{H}_{2} \mathrm{O}_{2}$-release (chapter 5.4). TNF was not unique in its capacity to activate neutrophils. FcyRII mediated neutrophil activation, induced by a neutrophil binding anti-elastase monoclonal antibody was able to mimic TNF in its capacity to induce neutrophil respiratory burst activity (chapter 5.2). This mechanism might play a role in the pathogenesis of tissue damage in clinical auto-immune syndromes with circulating elastase-reactive antibodies, such as Wegener's granulomatosis.

TNF-induced neutrophil activation required specific adhesive interactions. The contributions of different adhesion-molecules, and of adhesion-molecule independent neutrophil adherence in TNF-induced neutrophil activation were evaluated. $\beta_{2}$ integrin member CD11b/CD18 mediated substrate-interaction appeared to be essential in neutrophil toxicity incited by TNF (chapter 5.3). Neutrophil $\mathrm{CD} 11 \mathrm{~b} / \mathrm{CD} 18$ thus appears to be more than just an adhesion molecule. It controls the switch to a highly flattened phenotype which adapts the neutrophil to releasing its array of protein degradating enzymes and starting an ongoing burst of reactive oxygen species. 


\section{SAMENVATTING}

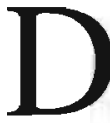

e interactie tussen neutrofiele granulocyten en endotheelcellen tijdens ontstekings-processen staat centraal in dit proefschrift. Deze interactie wordt gestuurd door een aantal ontstekings-mediatoren, die de aanwezigheid van adhesie-moleculen op beide cel-typen reguleren, en het gedrag van deze cellen beïnvloeden.

De onderzoeken in dit proefschrift zijn ingebed in de grote hoeveelheid nieuwe informatie over cytokinen en adhesie-moleculen die de laatste 10 jaar verschenen is. Op basis van deze informatie kan een indeling gemaakt worden van de moleculaire basis van de verschillende fasen van neutrofiel-gedrag tijdens ontstekingen:

- Selectines, adhesie-moleculen die zowel op endotheelcellen als op neutrofielen voorkomen, zijn betrokken in neutrofiel 'rolling' doordat ze neutrofielen kortdurend krachtig aan de vaatwand kunnen verankeren.

- De op neutrofielen aanwezige $\beta_{2}$ integrins zijn van belang bij chemotactische bewegingen, doordat ze, aan die kant van de neutrofiel waar deze een verhoging in de concentratie van een chemotactische stof waarneemt, een gedoseerde affiniteits-toename kunnen teweegbrengen.

- $\quad \beta_{2}$ integrins kunnen samen met CD43 op neutrofielen, wanneer de juiste substraat- en stimulus-condities aanwezig zijn, de neutrofiel laten veranderen van een 'polair migrerend fenotype' naar een 'geïmmobiliseerd uitgespreid fenotype', een vormverandering die in verband staat met neutrofieltoxiciteit.

- Neutrofiel agonisten kunnen worden ingedeeld in 'chemotaxinen' en 'secretagogen'. Chemotaxinen, zoals IL-8, kunnen gradiënten vormen, die het uit de bloedbaan treden en het migreren naar ontstekings-centra van neutrofielen bewerkstelligen. Secretagogen, zoals TNF, bewerkstelligen de bovengenoemde vormverandering van neutrofielen, en induceren neutrofiel toxiciteit.

De identificatie van deze mediatoren, en het ontrafelen van hun funclie, hetgeen in hoofdstuk I van dit proefschrift in detail uitgewerkt is, heeft een grote vooruitgang in het begrijpen van neutrofiel gedrag tijdens ontstekingen gegeven. Daarmee is een nieuwe uitdaging geschapen om dit begrip om te zetten in concrete vooruitgang in therapeutische mogelijkheden bij ontstekings-ziekten. 
In het in dit proefschrift beschreven experimentele werk staan TNF, E-selectin en neutrofiel endotheelcel interactie centraal. De onderzoeken over deze specifieke onderwerpen zijn respectievelijk in hoofdstuk 3, 4 en 5 weergegeven.

Een korte, meer specifieke introductie in, en discussie van het experimentele werk in deze hoofdstukken wordt in hoofdstuk 2 gegeven.

In hoofdstuk 3 werden de condities onderzocht, die afgifte van TNF en andere cytokinen zoals IL- 6 en IL-8 tot gevolg hebben. Door lipopolysacchariden uit de buitenwand van gram negatieve bacteriën (endotoxinen) gestimuleerde mononucleaire phagocyten, vormen de 'klassieke' bron van TNF tijdens ontstekingsprocessen. De afgifte van TNF en andere cytokinen kan echter ook veroorzaakt worden door andere microbiële oppervlakte-componenten en door serum-factoren zoals complement (hoofdstuk 3.1), terwijl ook andere cellen dan leukocyten, zoals uit de nier afkomstige epitheelcellen, een belangrijke cytokinen-bron bleken te kunnen zijn (hoofdstuk 3.2).

Gezien de veelheid van ontstekings-processen welke met TNF-afgifte gepaard gaan, lijkt een fundamentele rol voor TNF bij ontstekingen waarschijnlijk. TNF-afgifte door mononucleaire phagocyten in aanwezigheid van endotoxinen wordt beïnvloed door twee homologe eiwitten, 'LPS binding protein' afgegeven door de lever tijdens systemische ontstekingen, en 'bactericidal/permeability increasing protein' afgegeven door geactiveerde neutrofielen. Deze eiwitten kunnen de detectie van endotoxinen door mononucleaire phagocyten stimuleren respectievelijk blokkeren (hoofdstuk 3.3). Dit impliceert dat TNF-afgifte gedurende gram-negatieve infecties ecrder een door de gastheer gereguleerd fenomeen is, dan een uit de hand gelopen reactie op een bacterieel toxine.

In hoofdstuk 4 staat E-selectin centraal, een induceerbaar endotheelcel adhesiemolecuul dat neutroliel 'rolling', de eerste stap in neutrofiel endotheelcel interactie tijdens ontstekingen, mogelijk maakt. Het blokkeren van de expressie of de functie van E-selectin zou zodoende neutrofiel gemediëerde onstekings-schade kunnen voorkomen. E-selectin expressie wordt veroorzaakt door ontstekingsmediatoren zoals TNF en IL-1 en door endotoxine. Andere factoren kunnen E-selectin expressie verhogen, zoals IFN- $\gamma$ (hoofdstuk 4.2) en bepaalde nog ongeïdentificeerde serum bestanddelen (hoofdstuk 4.3). In door endotoxine veroorzaakte E-selectin expressie spelen CD14 receptoren een essentiële rol (hoofdstuk 4.4).

Toekomstig onderzoek zal moeten uitmaken of interventie met E-selectin expressie via één van deze routes zinvol is.

E-selectin zou, naast een rol bij neutrofiel 'rolling', nog andere functies kunnen hebben. E-selectin-moleculen worden niet stabiel tot expressie gebracht, maar bleken na een kort verblijf aan het cel-oppervlak weer geïnternaliseerd te wor- 
den. De functie van E-selectin internalizatie is onbekend. Via co-internalizatie van immuun-complexen en adherentie remmende factoren, stoffen waarvan bekend is dat deze affiniteit voor E-selectin hebben, zou E-selectin een belangrijke rol kunnen spelen in het 'schoon houden' van de circulatie tijdens ernstige ontstekingsprocessen (hoofdstuk 4.I).

In hoofdstuk 5 werd de betrokkenheid van TNF en E-selectin in neutrofiel gemediëerde endotheelcel-schade onderzocht. Aanwezigheid van TNF bleek uitgebreide neutrofiel-gemediëerde endotheelcel-schade te kunnen veroorzaken (hoofdstuk 5.1). TNF bleek krachtiger dan andere fysiologische neutrofiel agonisten in het induceren van $\mathrm{H}_{2} \mathrm{O}_{2}$ produktie door neutrofielen en van endotheelcel-schade (hoofdstuk 5.1), hetgeen TNF identificeert als een vertegenwoordiger van een nieuwe groep neutrofiel agonisten. Hoewel TNF-activatie van endotheelcellen geen rol bleek te spelen bij TNF-geïnduceerde endotheelcel schade (hoofdstuk 5.1 en 5.3), bleken endotheelcellen wel een actief aandeel te hebben in neutrofiel-activatie door TNF, waarvoor membraangebonden PAF, geïnduceerd op de endotheelcel door blootstelling aan $\mathrm{H}_{2} \mathrm{O}_{2}$ van de geactiveerde neutrofiel,verantwoordelijk lijkt (hoofdstuk 5.4). Het vermogen van TNF om $\mathrm{H}_{2} \mathrm{O}_{2}$ produktie door neutrofielen te veroorzaken bleek niet uniek te zijn. Sterke en langdurige zuurstof-radicaal produktie door neutrofielen werd ook veroorzaakt door een neutrofiel bindend anti-elastase monoclonaal antilichaam (hoofdstuk 5.2). Dit mechanisme kan een rol spelen in de pathogenese van weefselschade in klinische auto-immuun syndromen met circulerende elastase-bindende anti-lichamen, zoals in de ziekte van Wegener.

TNF-geïnduceerde neutrofiel activatie bleek afhankelijk te zijn van specifiek oppervlakte-contact. De rol van verschillende adhesie-moleculen, en van adhesie-molecuul onafhankelijke neutrofiel adherentie, in TNF-geïnduceerde neutrofiel activatie werd onderzocht. Substraat-contact via de $\beta_{2}$ integrin vertegenwoordiger CD11b/CD18 bleek onmisbaar te zijn voor neutrofiel toxiciteit geïnduceerd door TNF (hoofdstuk 5.3). Neutrofiel CD1 lb/CD18 blijkt zodoende meer te zijn dan een adhesie-molecuul. Het controleert de verandering van de neutrofiel van een polaire naar een plat uitgestrekte cel die de neutrofiel lijkt aan te passen aan het vrijmaken van zijn toxische areaal van eiwitsplitsende en zuurstof radicaal producerende enzymen. 


\section{DANKWOORD}

$\mathrm{H}$

et zoeken naar een plaats met ideale condities om je te ontplooien, is wellicht het meest elementaire streven van ieder levend organisme.

Het scheppen van plaatsen met ideale condities om je te begeven op de grenzen van kennis en begrip, is wellicht het meest elementaire streven van de hedendaagse westerse cultuur.

De condities op de plek waar ik drie-en-een-half jaar mocht werken (rweede stoel van links, aan de houten laboratorium-tafel aan het raam op lab 4.1 met uitzicht op de schapen van het BMC, en de 'nieuwe vleugel' van Annadal), en de bijdragen daaraan van Wim Buurman, Trudy Jeunhomme, Jet Leeuwenberg, Gaby Francot, Ingeborg Engelberts, Mark Bemelmans en Mieke Dentener binnen het laboratorium algemene heelkunde, en van Gauke Kootstra en Cees van der Linden daarbuiten, die weerspiegeld zijn in dit proefschrift, heb ik niet alleen ervaren als prettig, maar ook als bijzonder. 
206 


\section{PUBLICATIONS}

During the course of the experimental studies, which are partially presented in this thesis, the following publications were realized:

1. Von Asmuth, E. J. U., J. G. Maessen, C. J. van der Linden, and W. A. Buurman. 1990. Tumour necrosis factor alpha (TNF- $\alpha$ ) and interleukin 6 in a zymosan-induced shock model. Scand. J. ImmunoL 32:313.

2. Leeuwenberg, J. F. M., E. J. U. von Asmuth, T. M. A. A. Jeunhomme, and W. A. Buurman. 1990. IFN- $\gamma$ regulates the expression of the adhesion molecule ELAM-1 and IL6 production by human endothelial cells in vitro. J. Immunol. 145:2110.

3. Von Asmuth, E. J. U., J. F. M. Leeuwenberg, C. J. van der Linden, and W. A. Buurman. 1991. Tumour necrosis factor- $\alpha$ induces neutrophil mediated injury of cultured human endothelial cells. Scand. J. Immunol. 34:197.

4. Von Asmuth, E. J. U., C. J. van der Linden, J. F. M. Leeuwenberg and W. A. Buurman. 1991. Involvement of the CD11b/CD 18 integrin, but not of the endothelial cell adhesion molecules ELAM- 1 and ICAM- 1 in tumor nccrosis tactor- $\alpha$ induccd neutrophil toxicity. J. Immunol. 147:3869.

5. Smeets, E. F., E. J. U. von Asmuth, C. J. van der Linden, J. F. M. Leeuwenberg, and W. A. Buurman. 1992. A comparison of different substrates for culture of human umbilical vein endothelial cells. Biotech. Histochem. 67:24I.

6. Von Asmuth, E. J. U., J. F. M. Leeuwenberg, M. Ceska, W. A. Buurman. 1991. L.PS and cytokine-induced endothelial cell IL-6 release and ELAM- I expression; involvement of serum. Eur. Cytokine Net. 2:29I.

7. Engelberts, I., E. J. U. von Asmuth, C. J. van der Linden, and W. A. Buurman. 1991. The interrelationship between TNF, IL-6, and PAF secretion induced by LPS in an in vitro and in vivo murine model. Lymphokine Cytokine Res. 10:127. 


\section{Publications}

8. Von Asmuth, E. J. U., E. F. Smeets, L. A. Ginsel, J. J. M. Onderwater, J. F. M. Leeuwenberg, and W. A. Buurman. 1992. Evidence for endocytosis of E-selectin in human endothelial cells. Eur. J. Immunol 22:2519.

9. Dentener, M. A., V. Bazil, E. J. U. von Asmuth, M. Ceska M., and W. A.Buurman. 1993. Involvement of CD 14 in lipopolysaccharide induced tumor necrosis factor- $\alpha$, interleukin- 6 and interleukin- 8 release by human monocytes and alveolar macrophages. J. Immunol. 150:2885.

10. Von Asmuth, E. J. U., M. A. Dentener, V. Bazil, M. G. Bouma, J. F. M.Leeuwenberg, and W. A. Buurman. 1993. Anti-CD14 antibodies reduce responses of cultured human endothelial cells to endotoxin. Immunol. 80:78.

11. Dentener, M. A., E. J. U. von Asmuth, G. J. M. Francot, M. N. Marra, and W. A. Buurman. 1993. Antagonistic effects of lipopolysaccharide binding protein and bacterici$\mathrm{dal} /$ permeability-increasing protein on lipopolysaccharide-induced cytokine release by mononuclear phagocytes. Competition for binding to lipopolysaccharide. J. Immunol. $151: 4258$.

12. Von Asmuth, E. J. U., M. A. Dentener, M. Ceska, and W. A. Buurman. 1994. IL-6, IL-8 and TNF production by cytokine and lipopolysaccharide-stimulated human renal cortical epithelial cells in vitro. Eur. Cyt. Network 5:301.

13. Von Asmuth, E. J. U., J. F. M. Leeuwenberg, and W. A. Buurman. Fc $\gamma$ receptor-mediated activation of neutrophil $\mathrm{H}_{2} \mathrm{O}_{2}$-release and of neutrophil mediated endothelial cell damage by a monoclonal antibody against elastase. Submitted for publication.

14. Von Asmuth, E. J. U. and W. A. Buurman. Endothelial cell associated platelet-activating factor (PAF), a co-stimulatory intermediate in tumor necrosis factor- $\alpha$ (TNF- $\alpha$ ) induced $\mathrm{H}_{2} \mathrm{O}_{2}$ release by adherent neutrophil leukocytes. J. Immunol. in press. 


\section{CURRICULUM VITAE}

Eckhardt von Asmuth werd geboren op 11 september 1962 in Haarlem, als tweede zoon van uit de voormalige DDR gevluchte ouders. Zijn vader werkte als offset-drukker.

In Eindhoven groeide hij op binnen het vijf kinderen tellende gezin, en haalde hij in 1980 het atheneum-B diploma.

Van 1981 tot 1987 studeerde hij geneeskunde aan de Rijksuniversiteit Limburg te Maastricht. Tijdens zijn studie verdiepte hij zich in de psychiatrie, de antroposofische geneeskunde on in het studenten-leven. Na zijn artsexamen werkte hij tot einde 1991 aan een door de Nederlandse Nierstichting gesubsidieerd onderzoek naar de rol van cytokinen bij de transplantaatrejectie. Dit onderzoek, dat uitmondde in de totstandkoming van dit proefschrift, werd verricht op het laboratorium algemene heelkunde in het Biomedisch Centrum van de Rijksuniversiteit Limburg, onder leiding van Dr. W.A. Buurman, en supervisic van Prof. Dr. C.J. van der Linden en Prof. Dr. G. Kootstra.

In 1992 en 1993 volgde hij de Maastrichtse opleiding tot huisarts. Momenteel woont hij samen met zijn vader, zijn vrouw en hun vier zoons in Den Haag, waar hij sinds november j.l. samen met José Korte een antroposofische huisartsenpraktijk vorert. 
